THE ENABLING ENVIRONMENT CONFERENCE

Effective Private Sector Contribution to Development in Afghanistan

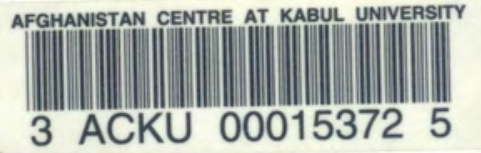

\title{
Background Material
}

Kabul, Afghanistan

June 2007 
THE ENABLING ENVIRONMENT CONFERENCE

Effective Private Sector Contribution to Development in Afghanistan

\section{CONTENTS}

\section{Background Papers}

Lack of Access to Energy - The World Bank Group

1

The Operating Environment for Small and Medium Enterprises in Rural

Afghanistan: Enabling or Disabling? - Saeed Parto, Anna Paterson and Asif Karimi,

Afghanistan Research and Evaluation Unit

Unleashing Entrepreneurship: Nurturing an Enabling Environment for

SME Development in Afghanistan - UNDP Afghanistan

Challenges of Access to Financial Services - The World Bank with Asian Development Bank

Lack of Human Capacity in the Public and Private Sectors - Dr. Sarah Lister

Challenges Presented by the Legal and Regulatory Framework Governing

Private For-Profit Activity - Altai Consulting

Challenges Presented by the Legal, Regulatory, Administrative and Fiscal Framework

Governing Civil Society - Dr. Leon E. Irish and Professor Karla W. Simon,

International Center for Civil Society Law

Potential for Public Private Partnerships in Afghanistan - Michael Barrow and

Martin Tornberg, Private Sector Operations Department, Asian Development Bank

Corporate Social Responsibility: Business and Civil Society Working Together -

Pakistan Centre for Philanthropy

\section{Case Studies}

Government and the Private Sector Working Together to Create the Afghan

Telecommunications Industry

The Afghanistan Beverage Industries Limited: "Cristal"

Essential Oils and Natural Perfumes: A Rural Development Opportunity in

Afghanistan: Gulestan Ariana Company

Socially Responsible Economic Development: The Shamali Model Farms

Public-Private Partnerships in Economic Development:

The New Baghlan Sugar Company

Helping Afghanistan's Street Working Children: Aschiana

The Rapid Expansion of Dried Fruit and Nuts Exports:

The Kabul Dried Fruit and Nuts Consortium and Angaza Limited

Expanding the Outreach of Financial Services: The Experience of Financial Institutions

Summary of Round Table Consultations with the Private Sector (Business and Civil Society) 


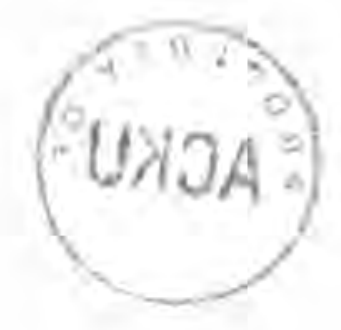

\section{ACKNOWLEDGEMENTS}

All authors are gratefully acknowledged for their contributions.

Financial support for preparing the background material was provided by UNDP Afghanistan, through the Trade and Private Sector Development Programme and Umbrella Programme for Post-Crisis Recovery \& Reconstruction through South-South Cooperation.

Copyright 2007 by the Aga Khan Foundation, 1-3 Avenue de la Paix, 1202 Geneva, Switzerland.

All rights reserved. No part of this document may be utilised or reproduced in any form or by any means, electronic or mechanical, without the prior written permission of the Aga Khan Foundation.

The views expressed in the background material are those of the respective authors. 


\title{
THE ENABLING ENVIRONMENT CONFERENCE
}

Effective Private Sector Contribution to Development in Afghanistan

\section{LACK OF ACCESS TO ENERGY}

Background paper prepared for the Enabling Environment Conference by:

\author{
The World Bank Group
}

\section{INTRODUCTION}

This background paper aims to address issues related to increasing reliable access to power in Afghanistan's urban and rural contexts. It focuses both on necessary public reforms and investments, and on exploring opportunities for leveraging private sector know-how and investments.

The electricity sector in Afghanistan is generally recognised as one of the primary constraints to the development of the country's economy. In the initial period of reconstruction, the efforts of the Government and its international development partners have focused on both the rehabilitation of damaged physical assets and the creation of new ones. The role of the private sector in this period has been limited, for the most part, to supplying goods and consulting services under contract. While the need for public investments in the power sector's physical infrastructure will continue for years to come, it will also be necessary to tap the financial resources and managerial "know-how" of the private sector, so that the power sector becomes an engine of economic growth and not an obstacle to development. As physical assets are completed and become operational, there is growing recognition for the need to reform the sector's institutional and policy framework so that the value of significant investments in the sector, and their long-term sustainability, are maximised and ensured. This process of policy reform entails, in part, supporting the growth of private initiative in the economy and exploiting opportunities for public-private partnership.

\section{ACCESS TO POWER: CURRENT STATISTICS AND TRENDS}

In all likelihood, the data on access to electricity in Afghanistan most commonly cited by the Government and others - namely, that only six percent of the population has access to electricity - significantly understate the actual level of access of electricity in Afghanistan today. Data from two recent household surveys indicate a much higher access to electricity.

The National Risk and Vulnerability Assessment (NRVA), a large, country-wide survey that was carried out in 2005, showed overall access to electricity at about 25 percent. This result is equivalent to 73 percent of urban respondents and 14 percent of rural respondents reporting access to electricity from any source. In the World Bankcommissioned Kabul Household Energy and Water Survey (KHEWS) carried out in August 2006, 89 percent of respondents reported access to electricity from any generating source. When batteries were included, this figure rose to 93 percent. Table 1 shows comparative data for these two surveys. 
Table 1: NRVA and KHEWS Comparative Data

Households Reporting Connection to (i) Public Supply of Power and (ii) From Any Source

\begin{tabular}{lccc} 
& $N=\begin{array}{c}\text { Public } \\
\text { access } \\
\%\end{array}$ & $\begin{array}{c}\text { From any } \\
\text { source } \\
\%\end{array}$ \\
\hline $\begin{array}{l}\text { NRVA national data } \\
\text { (incl. kuchi) (2005) }\end{array}$ & 30,020 & 15.6 & 24.8 \\
\hline NRVA Rural & 22,601 & 4.3 & 14.1 \\
\hline $\begin{array}{l}\text { NRVA Urban } \\
\text { (incl. Kabul) }\end{array}$ & 5,755 & 64.2 & 73.0 \\
\hline $\begin{array}{l}\text { NRVA Urban } \\
\text { (excl. Kabul) }\end{array}$ & 3,480 & 67.7 & 72.5 \\
\hline NRVA Kabul & 2,275 & 58.7 & 73.6 \\
\hline $\begin{array}{l}\text { KHEWS Kabul } \\
\text { (Aug 2006) }\end{array}$ & 2,000 & 68.2 & 88.6 \\
\hline
\end{tabular}

* For NRVA "any source" includes public supply, government generator, personal generator (engine), personal generator (microhydro), community generator (engine), community generator (microhydro) and solar.

For KHEWS "any source" includes Breshna (own house), Breshna (through neighbour's connection), personal generator (own), generator (neighbour's). generator (locally privately owned, not neighbour's) and community generalor.

A few factors account for the large discrepancy between the oft-cited low figure of six percent access and the survey results that show considerably higher levels of access. First, the estimate of six percent nation-wide access was probably inaccurate even when it was calculated some years ago - the result of an extrapolation of poor-quality data from registered utility customers on average household size and the overall population that were available after the fall of the Taliban. Second, the years of reconstruction efforts by the Government (or the utility acting on its behalf), have yielded results in urban areas and modestly increased access in rural areas (primarily thanks to the National Solidarity Program). Finally, the private efforts of individuals and domestic entrepreneurs have contributed to the increased access to electricity and other energy services.

\section{The important points to note are that:}

- Access to electricity has been increasing steadily in recent years.

- Improvements in this area will likely be the result of continued Government action (policy reform and public investments), along with the private actions of individuals and entrepreneurs.

\section{- Strong evidence that Afghans highly value} electricity and demonstrate a "willingness to pay" should send a positive signal to the private sector and to policymakers.
At the same time, it must be stressed that, notwithstanding these higher levels of access to electricity, the electricity sector continues to be a severe constraint to the economic and human development of Afghanistan. The power supplied is generally of poor quality, meaning that voltage levels fluctuate (which damages machines and appliances) and power surges and blackouts are common. There are still extreme supply-side constraints for existing consumers (power from the public grid is available only a few hours daily in most places), to say nothing of the supply that would be required to fuel economic growth; industrial load is virtually non-existent. The high cost of private generation is prohibitive for most of the population, allowing for only very limited generation when the public supply is not available.

The basic challenges in developing the power sector are:

- For consumers on the public grid (primarily urban-based consumers), increasing the quantum and quality of supply of affordable electricity, taking particular care to ensure high quality of supply to the fledgling industry of Afghanistan to "jump start" economic growth.

For the majority of rural consumers who will not be connected to a public grid in the foreseeable future, increasing their access to reliable supplies of electricity needed for basic services (such as lighting) and developing income-generating opportunities through improved power supply

\section{POLICY RESPONSES}

While policy innovation and reform will help to expedite the process of expanding access to power, the constraints to rapidly increasing access to electricity lie not so much in the arena of sector policy, but have more to do with the nature of the physical investments that are required, the objectively large scale of the problem, and in broad country issues such as the deteriorating security conditions. Given the fundamental economics of network-supplied services, areas with greater population concentrations and higher disposable incomes - that is, urban areas - will tend to show the most rapid and sustainable growth in response to investments in the sector (although there are other reasons why it will be important to continue to develop infrastructure in rural Afghanistan).

Afghanistan's various options for increasing generation capacity and supply were analysed in the course of the preparation of the Power Sector Master Plan (2003). 


\section{The Plan identified the country's least-cost generation expansion options as being:}

- The importation of low-cost electricity from Central Asia, which requires the construction of transmission lines (ongoing)

- The development of domestic generation capacity using the natural gas at Sheberghan (which has been delayed but has financing from USAID).

- The rehabilitation and expansion of existing hydropower plants as an important part of the supply story for Kabul and some other locations (taking place).

- In the medium- to longer-term, construction of new hydropower capacity and development of coalbased generation could conceivably be economic options for Afghanistan, but it would likely be several years before such projects would begin to produce electricity.

- While the Power Sector Master Plan identified the Baghdara Hydropower Project as worthy of immediate investigation (and a feasibility study is underway), projects of this type require some years of site investigation and new projects should not be considered an immediate investment priority (as they are apparently by some within the Government).

\section{The Government should renew its focus on implementing the Power Sector Master Plan to ensure that the economy has an adequate supply of generation at its disposal.}

Beyond that, much more attention should be given to the rehabilitation and expansion of distribution systems throughout Afghanistan. The present conditions of limited supply mask the problem of limited distribution capacity, but as sources of supply become more secure, local distribution networks will emerge as a constraint to delivering power to the end-consumers, In fact, this has already happened in Mazar-e Sharif and Herat, where adequate supply is available through interconnection to neighbouring countries but the local distribution networks cannot carry the available supply.

The solution to this problem will be found partly in continued public investments (with support from donor countries) and partly in unleashing the potential of the domestic (and, potentially, foreign) private sector to generate and distribute power (see Box 1 on Private Power Distribution in Ghazni). The policy actions called for here are not complex, generally falling under the heading of creating the enabling environment and "doing no harm".
While there are no known legal obstacles to the private provision of power, there are potentially practical obstacles such as interference from local officials and the utility, and issues of safety regulation and technical standards.

As the example of OEC in Ghazni suggests, there is potential for small- and medium-scale providers in smaller cities and towns (including in particular those that are not located close to transmission lines) to contribute to efforts to rapidly expand access to and improve the quality of supply of electricity. Government policy should be directed at encouraging this form of private sector activity.

The key investments that are required to ameliorate the power deficit are:

- The transmission lines from Uzbekistan to Mazare-Sharif and Pul-e-Khumri; Pul-e-Khumri to Kabul; Tajikistan to Pul-e-Khumri; and eventually Turkmenistan to Mazar.

- The rehabilitation and expansion of existing hydroelectric plants.

- A gas-to-power plant at Sheberghan (subject to satisfactory findings from additional investigations to be conducted).

- Potentially, other high-voltage transmission lines that could pass through Afghanistan in the broader context of regional energy trade.

Distribution

The concept of "conditions of confidence", or what is often called the "investment climate", embodies a range of attributes in any economy that go beyond any individual sector. Clearly, in Afghanistan, a primary concern for both foreign and domestic investors would be the fundamental security, both of personnel and physical assets (which are often located in remote, vulnerable areas), Other aspects of investment climate (such as repatriation of profits) also obviously need to be addressed but are not specific to the power sector.'

Sector-specific attributes in the power sector include regulation and perceptions of regulatory risk, such as whether an investor can be confident that the tariff allowed for the sale of electricity will make it possible for the business to cover costs, at a minimum. Given the low level of capacity in the sector and the existence of more pressing priorities, creation of independent regulatory capacity may not be appropriate in Afghanistan for the foreseeable future. Alternatives to consider are "regulation by contract", which could give greater comfort to investors than the existence of a 


\section{Box 1: Private Power Distribution in Ghazni}

Omary Electric Company (OEC) is a private power company that started business more than eight years ago when the Taliban were in power. The company runs eight diesel generators with a total capacity of about $1 \mathrm{MW}$ and distributes power throughout the city through its own decentralised low-voltage networks. The generator sets are self-made from truck engines. OEC began using two engines from junk Russian trucks and has now expanded by acquiring junk Mercedes truck engines. OEC serves 8,500 customers with a total staff of 42 employees and offers 24 -hour supply with decentralised generators. In contrast, the local division of the national utility, DABM, runs a centralised system serving I,460 customers with 29 employees and offers only five hours of supply daily. (Thus, the customer to employee ratio of OEC is four times greater than that of the local DABM branch.)

\section{OEC offers the four following tariff groups:}

- 24-hour supply

- load dependent

- evening lighting

- flat rate (100 Afs) for one $18 \mathrm{~W}$ bulb, 14 hours in winter, 10 hours in summer for shop lighting at night for security

- holy places, such as mosques, are served free of charge

The tariff is tied to the price of diesel. In July 2006 , the tariff was $35 \mathrm{Afs} / \mathrm{kWh}$; it is noteworthy that even though this was slightly higher than the tariff offered by the local DABM, OEC was clearly more competitive and was gaining customers thanks to the quality of supply offered.

\section{OEC categorises its customer in three classes:}

- customers who must pay within a month or face being cut-off from the power supply

- good customers who may pay with delay

- government offices which often face cash flow problems due to delayed budget disbursements and receive a credit of up to four months

Previously, OEC offered automatic switches which cut off customers in case they drew more load than agreed, and customers paid on the basis of flat rates. Nowadays, all 8,500 customers are metered. New customers pay a non-refundable connection fee of between 1,500 Afs and 3,000 Afs, depending on the connection distance.

Of note is the contention of the local DABM branch in Ghazni that when DABM customers fall far behind in their payments to DABM, they shift to OEC, leading to large outstanding accounts receivable for the utility. It is not possible to confirm or refute this contention, but obviously in encouraging the development of private provision of power, the Government will need to ensure that the financial position of the local utility is not undermined by widespread migration away from utility and refusal to pay bills. Discrete definition of service territories and measures to strengthen collection capacity could help address this potential problem.

fledgling regulatory agency, and light-handed economic regulation that would allow small, selfcontained systems (whether rural or urban in location) to be "self-regulating" i.e. to charge what the market would bear (as described in Box 1).

Domestic and foreign investors alike would benefit from a "one-stop window" in the Ministry of Energy and Water, or some other appropriately designated agency, that would allow them to handle all required transactions with the Government (licenses, fees) in one location, thereby facilitating the investors' work with the Government and reducing the potential for corruption.

For large-scale projects involving foreign investors, the Government could help build investor confidence by offering Government guarantees, potentially backstopped by a World Bank Partial Risk Guarantee (PRG) or similar instruments provided by other development agencies. PRGs cover private lenders against the risk of a government-owned entity failing to perform its obligations with respect to a private project, and can cover a range of risks relating to government performance including:

- changes in law

- failure to meet contractual payment obligations

- obstruction of an arbitration process

- expropriation and nationalisation

- foreign currency availability and convertibility

- non-payment of a termination amount or an arbitration award following a covered default

- failure to issue licenses, approvals and consents in a timely manner 


\section{ADDRESSING THE CHALLENGE OF PROVIDING POWER TO RURAL AFGHANISTAN}

The challenge of rural electrification will remain for many years and there are no easy fixes. Past years' achievements in increasing access to electricity in rural Afghanistan (primarily through the National Solidarity Program) have been made possible by heavy subsidisation, which may not be within the possibilities of the budget in years to come. Moreover, the rural electrification that is taking place provides only minimal levels of supply to cover basic demand for lighting, and in some cases, communal hot water heaters. The challenge of advancing to the next level of development supplying electricity for income-generation - is not merely a matter of increasing the supply of electricity. Larger systems with more complex load structures (residential, industrial, different types of motors, etc.) have different physical properties that require much more sophisticated load management than demanded by a simple $20 \mathrm{~kW}$ village system which provides only a few hours of lighting daily.

Thus, part of the challenge of developing rural Afghanistan is ensuring that there is adequate technical capacity to run larger-scale electrical systems in remote locations (adequate capacity does not exist today even in urban areas). The rural electrification that is taking place in Afghanistan today is taking place in a policy vacuum, without a clear institutional framework within Government for oversight of policy and programmes. There is a de facto split of responsibility for rural electrification over different ministries, and coordination between ministries and donor-funded programmes could be improved. As a first step to creating a more robust enabling environment for rural electrification, the Government should articulate a Rural Electrification Policy that defines the goals and objectives of such a policy; clarifies the role and expected scope of subsidies in supporting rural electrification programmes; and emphasises the role of the private sector and rural cooperatives in advancing rural electrification. (Of note in this regard is the ongoing effort by $\mathrm{ADB}$ to prepare a draft Policy for Renewable Energy Rural Electrification.) The policy should recognise the limitations of the Government's ability to intervene meaningfully in this area in view of the size and remoteness of much of the rural population. The need for small-scale, site-specific solutions means that significant technical and financial resources would be required to bring modern energy services to the bulk of the population in rural Afghanistan, and these resources may not be available to the Government given other claims on the budget.
In order to advance the economic development of rural Afghanistan - which has strategic relevance in the struggle against the opium economy and the Taliban insurgency - the Government should seek to promote rural electrification with an emphasis on income-generating activities (e.g, support for village-level light industry). Given the paucity of financial and technical resources, the Government could adopt a policy of concentrating resources on larger villages or small towns, with villages in the vicinity serving as growth points. Such an approach would help avoid the dispersion of resources and increase the likelihood of sustainable development that could be monitored.

For the overwhelming majority of villages, connection to the grid will not be a viable option, and the focus should be on (eventually) identifying the most appropriate supply solution for each particular location (which might be a renewable or non-renewable supply option).

Given the scope of the problem of rural energy and the limitations of Government resources, it is particularly important to prioritise the specific measures that are to be pursued in order to improve rural energy access and to ensure the consistency of these measures with the developmental goals as defined by Governmental policy. From a practical planning perspective, a good starting point would be the development of a differentiated typology of rural areas identifying, among other variables, the proximity to the regional power grid; the suitability of establishing a rural "growth point" in the area; the size and density of population; the structure of the local rural economy; and the availability of hydro, wind, solar and biomass resources.

In order to stimulate small-scale private entrepreneurial activity and/or rural cooperatives (for which numerous positive developing country examples exist, including Bangladesh and Sri Lanka in the region), the Government could announce an explicit policy of "laissez faire" in rural electrification, recognising that most rural communities will remain outside the public grid for years to come and that such systems are most successful when they are self-supporting, whether developed as cooperatives or as private enterprises. Economic regulation need not be required in a small village-based system. USAID is piloting a cooperative approach in the smaller cities of Aybak and Qalat in which the initial support consists of provision of a diesel generator and technical assistance in the areas of distribution, billing and collections. The community is responsible for the operation and maintenance of the system. 


\section{Box 2. Rural Electrification Fund and Supporting Technical Assistance in Bangladesh}

Introduction

The Bangladesh off-grid electrification fund, supported by the World Bank Rural Electrification and Renewable Energy Development Project (RERED), provides solar home systems to rural households at an unprecedented rate of more than 3,000 households per month. With the assistance of Participating Organisations (POs), which include municipalities, NGOs or the private sector, the programme has resulted in the installation of nearly 90,000 solar home systems to date-a figure much higher than the expected project target of 50,000 by 2008 . With additional funding from the World Bank, GTZ and $\mathrm{KfW}$, the target has now been raised to 200,000 units by 2010 . The programme has also expanded its scope of funding to other rural energy services such as biogas and community electricity systems.

\section{Fund Configuration}

The fund is administered by the Infrastructure Development Company Limited (IDCOL), a non-bank financial institution, and provides both credit and Global Environment Facility (GEF) subsidies to 14 POs for the purchase of photovoltaic (PV) household systems. In addition to its function as a source of finance, the fund also supports the development of energy projects that are appropriate in rural Bangladesh.

Participating Organisations purchase PV panels, batteries and other components from a list of vendors approved by a Technical Standards Committee (TSC). Vendors wishing to participate in the programme must submit documentation, test certificates and guarantees to the TSC. Once approved, vendors may then sell their products directly to POs with their own contractual terms. Vendors are generally eager to cooperate with POs, often times offering delayed payment terms. POs must also work with vendors to arrange regular and expedient after-sales service should any complaints arise.

\section{Fund Activities}

\section{The project includes the following types of activities:}

- providing loans to POs, who pass these funds on to their customers (up to 80 percent)

- providing the GEF-financed grant (starting at US\$90 per system and gradually declining to US\$50)

- developing consumer awareness of solar home systems or other rural energy interventions

- providing technical assistance to POs in developing proposals for financing

- selection of POs based on their performance and financial track record

- supervising the activities of POs and coordinating activities between POs, suppliers and customers

- assisting the TSC on programme-eligible equipment specifications

\section{Success Factors}

The main reason for the success of the programme has been the ability to mobilise non-governmental organisations (NGOs) and microfinance operators in rural Bangladesh to operate as solar home system intermediaries. The project was built upon the premise that NGOs, with an existing level of confidence among the rural population as well as established lines of credit stemming from strong collection histories, were well suited to function as solar home system delivery intermediaries. The utilities, in contrast, are not organised for social mobilisation, have limited access at the village level, and are not generally interested in off-grid options. With careful planning and adequate support in the initial stages, the project overcame the biggest challenge of ensuring adequate proficiency in selecting solar power systems from equipment suppliers and post-sales servicing among the NGOs, which has been one of the pitfalls of other rural electrification programmes.

Govemment could also give support to the development of domestic manufacture of energyrelated equipment that could be deployed in nural Afghanistan (e.g. turbines for microhydro plants) through provision of microfinance.

Bangladesh's successful rural electrification programme, described in Box 2, is based on an innovative collaboration with existing NGOs and other groups active in rural Bangladesh and has provided for the installation of nearly 90,000 solar home systems. Given its high potential for solar power and nascent microfinance programmes, Afghanistan could benefit from a rural electrification scheme of this sort.

\section{LEVERAGING THE PRIVATE SECTOR}

The demonstrated high demand for electricity and good growth potential suggest that there are many opportunities in the power sector for private sector involvement such as foreign and domestic capital; private equity projects as well as other forms of private sector participation; and largescale, multi-country projects as well as small-scale projects. At the same time, it should be recognised that the private sector's enthusiasm for the power sector will be tempered by perceptions of country risk (security, political instability, otc.) and sector risk. Govermment should seek to address these risks through appropriate policies to improve the investment climate, as Afghanistan's future will hinge on the ability of the Government and its 
international partners to defeat the ongoing insurgency's threat to the country's security.

\section{Some specific opportunities for private sector} participation in the power sector include;

- supplying the ongoing reconstruction effort

- owning/operating small stand-alone grids

- being management contractor for DABM and the North East Power System

- EPC ("turnkey") contract/O\&M for gas-to-power plant at Sheberghan

small-scale manufacturing, e.g. turbines, solar installations, networks

Different policies are required to attract the different types of private sector entities for the different types of projects. Large-scale, multicountry infrastructure projects (such as highvoltage transmission lines from Central Asia to and through Afghanistan) require a sophisticated legal and regulatory framework to give investors the assurances they demand before making investments worth hundreds of millions of dollars. Even relatively straightforward long-term power purchase transactions require complex legal instruments that do not yet exist in Afghanistan but that are being developed with donor assistance. As a general rule, foreign private sector entities will be more sensitive to perceptions of country and other types of risk, and adequate attention to these concerns by the Government will be a prerequisite to meaningful foreign private sector involvement in the power sector. Domestic private sector players, on the other hand, will generally be more capable of absorbing certain kinds of risks.

The Government should more explicitly take advantage of the potential of the domestic private sector in developing the power sector.

\section{INTERNATIONAL EXPERIENCES: LESSONS FOR AFGHANISTAN}

Given the concerns about the security situation in the country and the illiquid or "lumpy" nature of large infrastructure investments, it would be most prudent to assume that large-scale foreign equity investment in the power sector is unlikely in the near to medium term. At the same time, experience from other transition and post-conflict countries suggests that there are possibilities for other forms of private sector participation in the provision of electricity, including notably management contracts to manage and operate segments of the public power sector. From the perspective of the government in any country that has suffered from prolonged conflict, the private sector represents a vital source of finance and "know-how" which augments the government's own limited resources.

Management contracts have been successfully leveraged in past instances in reforming poorly performing sectors, particularly in post-conflict countries, where capacity is often limited. Box 3 highlights the Government of Georgia's sectorwide approach with management contracts, which were used to help turn around the power sector. The experience of Georgia demonstrates that financial discipline in the sector cannot be obtained by management contracts at the upstream end of the sector alone; the sector's problems need to be tackled holistically and improving performance of distribution is critical.

The experience of Cambodia in rapidly increasing access to electricity in rural areas through private provision of electricity could be relevant to Afghanistan. Like Afghanistan, Cambodia is a poor country with a large rural population that emerged from a long period of devastating conflict which destroyed part of the country's already underdeveloped physical infrastructure. According to the best-available data, at the beginning of the postconflict period, access to electricity was among the lowest in the world. By 2002, there were an estimated 600 private providers in rural Cambodia ranging from the largest who served up to 750 customers, with battery recharging reaching another 2,000 , to the smallest who had fewer than 20 customers. ${ }^{3}$ Prices charged by the providers were high, ranging from $25 \mathrm{USc} / \mathrm{kWh}$ to $90 \mathrm{USc} / \mathrm{kWh}$, which again underscores the high value accorded to electricity even by rural consumers with extremely limited means.

The capital costs of this expansion of electricity services in rural Cambodia were initially financed through the small-scale entrepreneurs' own funds. This limited source of capital is increasingly becoming a constraint on the continued growth of the rural electrical systems, and microfinancing and output-based aid schemes are being developed to remove this critical bottleneck. Such schemes would clearly be relevant in Afghanistan today.

In the area of licensing, there was recognition of the need not to impose onerous restrictions on rural private providers of electricity. Registration is required but is a formal process that does not involve any inspection of facilities (and is, in the event, not observed by many small-scale providers in rural Cambodia). There is no explicit regulation of tariffs for rural suppliers. 
Box 3. Management Contracts: The Power Sector in Georgia

Until recently, much of Georgia outside its capital, Tbilisi, suffered from shortages caused by sector-wide financial and technical mismanagement. To remedy the situation, the Government entered into three management contracts for power transmission, power distribution and a quasi-single wholesale buyer entity. This holistic approach has been critical in the successful development of the Georgian power sector, focusing not only on the upstream end, but also on the management and performance at the distribution level.

\section{Power Distribution}

United Energy Distribution Company (UEDC) of Georgia distributes power to the majority of Georgian consumers, excepl for Thilisi. The management contractors, PA Government Services (PA), addressed symptoms of utility mismanagement (as: manifested by the low consumer collection rate of 15 percent), in the following areas:

- Company Restructuring: The UEDC management team reformed the company's human resources, implementing updated salaries, transparent employment policies, hiring procedures, job descriptions and appraisal processes. They also decentralised management, placing management in each of the company's six regional branches to ensure proper adherence to Headquarter directives.

- Loss Prevention: PA formed a 30-person team to curb the theft of both electricity and of money through embezzlement. This eventually led to the prosecution of many former UEDC employees.

- Enabling Political Environment: The government of Georgia demonstrated commitment through its actions monetarily through subsidies, politically through public statements of support and legally by encouraging a close relationship between the management team and criminal justice authorities - which, in effect, created a change-fostering environment.

\section{Power Transmission}

ESBI, the Irish management contractor selected in December 2002, addressed four primary areas at the national power transmission company. Georgian State Electrosystem (GSE):

- Company Restructuring: Stressing the importance of labor relations, management immediately started paying salaries, including accumulated unpaid salaries (on average 11 months) with support from the government. In response to massive overstaffing, figures were gradually decreased from a starting point of 4,000 to 1,192 in October 2006. To retain quality staff, salaries were raised on the basis of responsibilities and performance.

- Commercial losses: Reducing loss of electricity due to theft took on heightened priority. Within the first 18 months, overall losses (technical and commercial) were reduced from 16 percent to less than 8 percent.

- Financial development: GSE faced a cash flow problem caused by the prohibition of switching off power supplies to non- or low-paying customers (i.e. distribution companies). Because of this, GSE lacked sufficient funds for preventative maintenance costs. This issue was ultimately solved by the distribution companies' success in collecting payments from end-users and through a large increase in end-user tariffs in 2006.

- Asset Control and Asset Transfers: GSE faced transmission and dispatch difficulties when dispateh orders were disobeyed while hydropower stations continued to illegally service non-paying power markets. ESBI initially grasped adequate control of the situation by rotating substation management, but eventually decided to transfer the assets over to the UEDC for better end-user management reasons.

\section{Wholesale Market}

GWEM was an association of sector entities that had aspects of a "single buyer" although not all electricity supplies were routed through GWEM. GWEM managed the payments to upstream service providers (transmission, dispatch and domestic power generation) which had been an area of corrupt practices. The Spanish management contractor, Iberdrola, initially succeeded in increasing transparency in the wholesale energy and financial transactions of the GWEM from 2001 to 2006. Though GWEM was replaced by direct contracts in 2006, the management contractor nonetheless played an important role in executing the first steps toward financial discipline.

Box 4 describes the Pamir Private Power Project, an innovative, multi-donor project that helped restore reliable and affordable electricity supply to a poor nural region of Tajikistan. Although the region benefited from the Soviet legacy of universal access to power (distinguishing it from most rural parts of the world), in the post-Soviet years household incomes had contracted severely and the quality of electricity supply had deteriorated sharply.

The project demonstrates an innovative publicprivate approach in overcoming a number of challenges, including the limited ability of customers to pay for electricity services. The project has pioneered a new way of collaborating between investors, development agencies, bilateral donors, governments and the project sponsor. 


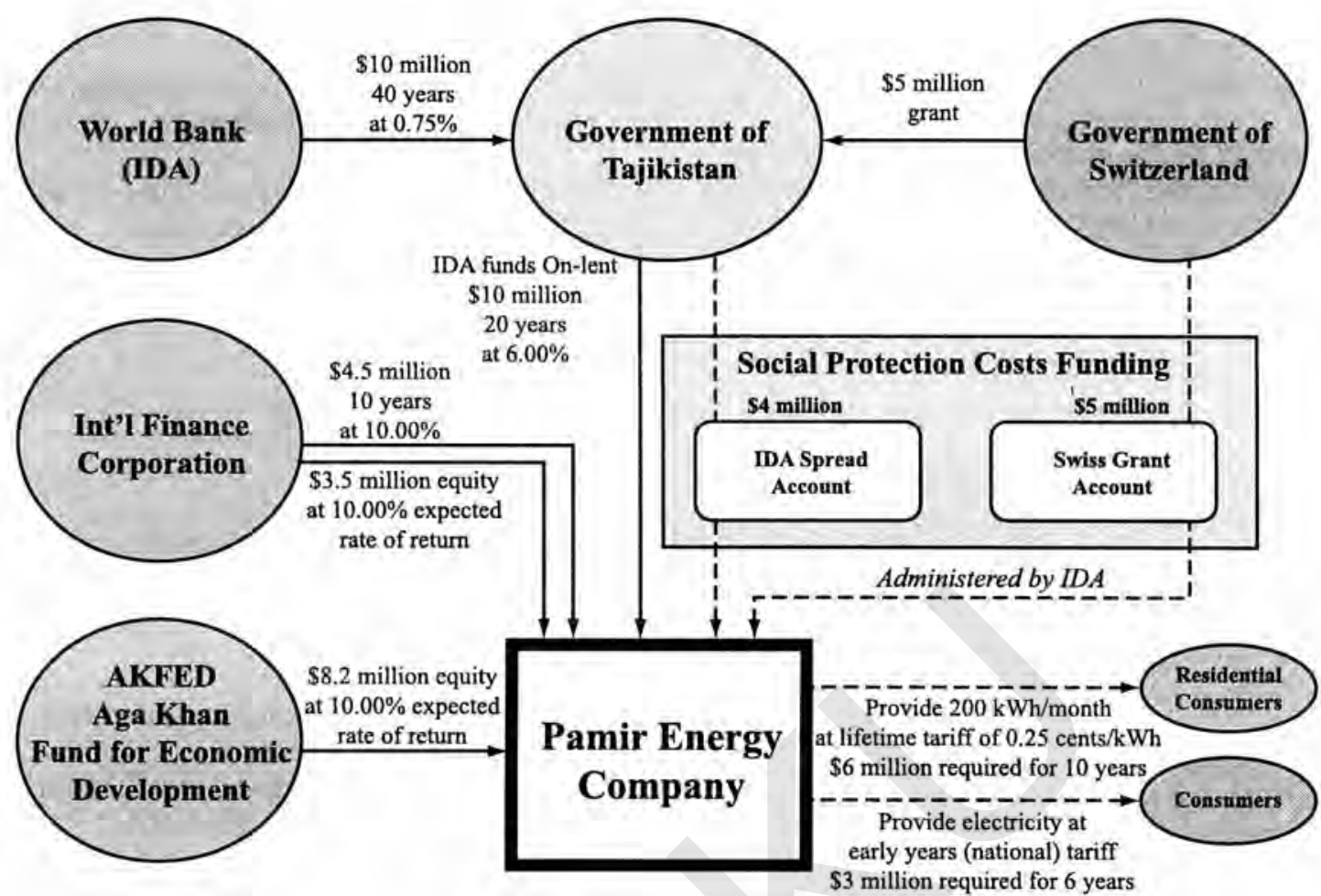

With the collapse of the former Soviet Union, conditions in the mountainous eastern Pamir region of Tajikistan deteriorated dramatically. Electricity infrastructure quickly fell into an advanced state of disrepair and power plants and many distribution lines were destroyed during the civil war in 1992. The ensuing sharp economic decline (GDP contracted by 60 percent) and neglect by the national electrical utility left 43 percent of homes in the region without power during the harsh winters where temperatures reach $-30^{\circ} \mathrm{C}$. Schools, health centres and small businesses were forced to close in cold winter months, stifling economic and human development. With many people forced to use wood for cooking and heating, 70 percent of the region's sparse forest cover was lost. Smoke inhalation from indoor wood fires led to a sharp increase in respiratory disorders. At that time, Tajikistan's estimated per capita income was around US\$ 160 per year, and 60-80 percent of people were living below the poverty line and relying on subsistence agriculture. Those that did have access to electricity were used to paying $0.4 \phi$ per $\mathrm{kWh}$, less than $1 / 10$ th of the production cost. Under these conditions, attracting private sector investment into the energy sector with traditional approaches would have been difficult.

The PamirEnergy Company, jointly owned by AKFED and IFC, with equity of 70 and 30 percent respectively, was established in 2002. AKFED has invested US\$ 8 million in equity and the IFC has committed US\$ 3.5 million in equity and US\$ 4.5 million as debt. PamirEnergy operates under a 25-year concession contract to operate the electrical utility assets in the Pamir region, improve transmission infrastructure and hydro generation capacity, and regulate the level of Lake Yashilkul to ensure adequate water flows in winter. PamirEnergy also assumed responsibility for the utility's 30,000 existing customers and 595 employees.

A key aspect of the project is the social protection scheme that ensures that tariffs paid by households remain affordable, while the tariffs received by the investors provide a rate of return commensurate with the risks involved in such a project.

The World Bank's International Development Association (IDA) loaned US\$10 million to the Government of Tajikistan at a rate of 0.75 percent. These funds are on-lent to PamirEnergy at $6 \%$, allowing PamirEnergy to partially finance its capital investments at less than commercial terms and pass these savings on to customers as lower tariff rates. This 5.25 percent lending margin, plus a US\$ 5 million grant by the Swiss government to the Government of Tajikistan, has been used to finance a tariff subsidy to ensure that a "lifeline" monthly supply of electricity is delivered at a very low rate even to the poorest of households. Also built into the tariff structure is an "Early Years Subsidy" - a long initial grace period that allows tariffs to climb slowly from current levels - thus further reducing risk and keeping tariffs affordable. 


\section{The lessons relevant to Afghanistan are:}

- Attracting private investment for the provision of infrastructure services is possible, even in high-risk contexts, provided the involvement of an MFI from an early stage.

- Innovative combinations of international grant aid with preferential loans can at the same time ensure social protection for customers and acceptable rates of return for the investor.

\section{CONSOLIDATED RECOMMENDATIONS}

In summary, this paper makes specific recommendations in five key areas:

1. The Government should renew its focus on implementing the Power Sector Master Plan to ensure that the economy has an adequate supply of generation at its disposal.

2. More attention should be given to the rehabilitation and expansion of distribution systems throughout Afghanistan.

3. The Government should articulate a rural electrification strategy that defines goals and objectives, clarifies the role and expected scope of subsidies in supporting rural electrification programmes, and emphasises the role of the private sector and rural cooperatives in advancing rural electrification. Key components of such a policy could include:

a) Promoting rural electrification with an emphasis on income-generation/village-level light industries.

b) Designing and implementing capacity building measures in order to ensure that there is adequate technical capacity to run larger-scale electrical systems in remote locations.

c) Adopting a policy of concentrating resources on larger villages or small towns with villages in the vicinity serving as growth points.

d) Identifying the most appropriate supply solution for each particular location by developing a differentiated typology of rural areas identifying, among other variables, the proximity to the regional power grid; the suitability of establishing a rural "growth point" in the area; size and density of population; the structure of the local rural economy; and the availability of hydro, wind, solar and biomass resources.
4. Government should more explicitly take advantage of the potential of the domestic private sector in developing the power sector through:

a) Encouraging private small- and medium-scale providers in smaller cities and towns.

b) Introducing a "laissez-faire" policy in rural electrification to stimulate small-scale entrepreneurial activity and rural cooperatives.

c) Supporting the development of domestic manufacture of energy-related equipment that could be deployed in rural Afghanistan (e.g. turbines for microhydro plants) through provision of microfinance.

d) Introducing light economic regulation that would allow small, self-contained systems to be self-regulating i.e. to charge what the market will bear.

\section{Improve the foreign investment climate by:}

a) Considering "regulation by contract" as a possible alternative to the creation of an independent regulatory capacity which might not be feasible in the foreseeable future given the low level of capacity in the sector and the existence of more pressing priorities. This would give greater comfort to investors than the existence of a flectgling regulatory agency.

b) Simplifying interactions with the Government for domestic and international investors through a "one-stop window" in the Ministry of Energy and Water (or some other appropriately designated agency). This would allow investors to handle all required transactions (licenses, fees, etc.) with the Government in one location, thereby greatly facilitating their work with the Government and reducing the potential for corruption.

c) Having the Government offer guarantees potentially backstopped by a World Bank Partial Risk Guarantee (PRG) or similar instruments provided by other development agencies - to boost investor confidence.

\footnotetext{
'See The Investment Climate in Afghanistan: Exploiting Opportunities in an Uncertain Environment, World Bank 2005, for a more detailed treatment of this subject.

${ }^{2}$ See Regulation by Contract, World Bank Working Paper No. 14, 2003.

${ }^{3}$ See Private Solutions for Infrastructure in Cambodia, PPIAF/World Bank, 2002
} 


\title{
THE OPERATING ENVIRONMENT FOR SMALL AND MEDIUM ENTERPRISES IN RURAL AFGHANISTAN: ENABLING OR DISABLING?
}

Background paper prepared for the Enabling Environment Conference by:

\author{
Afghanistan Research and Evaluation Unit (AREU) \\ Saeed Parto, Anna Paterson and Asif Karimi
}

Government's investment programs in agriculture and rural development reflect the priority needs of the majority of Afghans, who reside in the provinces. Agricultural reform will help to diversify and restructure the agricultural economy, creating high value production... Government's goal is to achieve pro-poor growth in rural areas by enhancing licit agricultural productivity, creating incentives for non-farm investment, developing rural infrastructure, and supporting access to skills development and financial services that will allow individuals, households and communities to participate licitly and productively in the economy.

Interim Afghanistan National Development Strategy,

Pages 131 and 145

\section{INTRODUCTION}

Agriculture and rural development are emphasised in the Afghanistan National Development Strategy (ANDS) as key in effecting the much needed transition from a largely informal economy to a formal and prosperous one geared toward improving Afghan livelihoods and strengthening the revenue base for the national government. The data on rural employment and the extent of the dependence on agriculture are based on estimates and thus not always reliable.

According to the Afghanistan Millennium Development Goal Report (2005), agriculture accounts for over 50 percent of the licit economy and provides employment to almost two-thirds of the workforce. In 2003, the National Risk and Vulnerability Assessment (NRVA) estimated that agricultural activities contributed to the income of 63 percent of Afghan households, with significant diversity on a provincial, district and even village level. Given these statistics, economic development initiatives in rural areas will need to be focused significantly, since in many cases, the manufacturing and service sectors will also be heavily dependent on agriculture.' This focus needs to be contextualised in the broader national economy whose constituent parts must include nonfarm activities such as construction, trade, manufacturing, transport, mining and other services which have significant bearing on rural employment. ${ }^{2}$

This paper provides an overview of the key challenges faced by rural SMEs in Afghanistan. The evidence is drawn from secondary sources as well as primary data collected during fieldtrips to the two provinces of Bamyan and Balkh. The secondary data are from widely available government and non-government sources such as 
reports and briefings, while the primary data are from interviews with SMEs involved in commercial agricultural production, food processing, marketing and trading in the two provinces. The case studies in this paper combine the data from secondary and primary sources (interviews with key informants in Kabul and in the field). The case studies are analysed to formulate a series of recommendations aimed at improving the operating environment for rural SMEs. We begin with a general description of the regulatory context and some of the formal institutions with key roles in rural enterprise development.

\section{REGULATORY AND INSTITUTIONAL BACKGROUND}

This section provides a brief overview of the regulatory context and some of the key formal institutions with major roles in rural enterprise development. It must be noted that these roles are far from settled and, like most other arrangements in the Afghan political economy, are undergoing continual change and evolution. Periodic name changes of key government Ministries are accompanied with redefinition of roles and responsibilities which contimue to change in size and importance and which overlap. This renders attempts to map formal institutional arrangements difficult and perhaps not very useful at the present time because of the constant state of flux.

In the Interim Afghanistan National Development Strategy (IANDS), the Government has committed to develop by the end of 2010 , a policy and regulatory framework to support the establishment of small- and medium-sized rural enterprises in the 34 provinces. IANDS commits to investments in both agricultural and non-farm enterprises in rural areas as part of its growth and employment generating rural economic development. ${ }^{3}$ The document also emphasises the facilitation of light industry in rural areas to add value to agricultural production. A number of ministries and agencies have been charged with the responsibility of implementing measures likely to add value to agricultural products and foster the growth of agri-businesses.

The Ministry of Agriculture, Animal Husbandry and Food (MAAHF), recently renamed as the Ministry of Agriculture and Irrigation (MAI), is responsible for the commercialisation of agriculture, encouraging greater agricultural productivity through use of improved seeds, and the cultivation of crops with good market opportunities. The five-year Agriculture Master Plan contains provisions and budgeted funds for assisting entrepreneurs' and farmers' associations in gaining access to credit and government land, as well as cooperation with other ministries in finding regional and international markets for agri-business products. Donors such as the World Bank have been very supportive of the Ministry's attempts in this regard, committing significant funds for the next five years. Other key donors have been the Asian Development Bank (ADB) and USAID. $\mathrm{ADB}$ is currently preparing a commercial agriculture project that will focus on value addition and support of the private sector in exploiting domestic and regional markets for agri-business products. Over the last few years, USAID's Rebuilding Agricultural Markets Program (RAMP) has focused on elevating Afghan agricultural products along the value chain by encouraging local processing, improving irrigation, enhancing storage capacity, improving road access, identifying foreign markets for Afghan agricultural products and facilitating links between local producers and foreign markets.

Because of the emphasis on the role of the private sector in rural development, the Ministry of Commerce, recently renamed as the Ministry of Commerce and Industry (MoCI), has also been deemed as having a role, though at the present time it is unclear exactly what this role entails. The MoCI could provide advice based on its current endeavours to streamline the regulatory environment to promote and nurture national and international private sector activity in the Afghan economy as a whole.

\section{The Ministry of Rehabilitation and Rural}

Development (MRRD) has had, and will continue to have, a key role in advancing the agenda for further development of agricultural production systems. In the period immediately following the fall of the Taliban regime, the MRRD was at the forefront of emergency aid provision and food security programmes in rural areas. The MRRD's most important role to date in rural business development has been linked with the National Solidarity Program (NSP) and the National Area Based Development Programme (NABDP) under which the Ministry is currently undertaking a significant research project on rural economic development with the aim of producing a detailed policy strategy. ${ }^{4}$ Under the Master Plan, MRRD is charged with leading the efforts in creating an enabling environment for the rural private sectora task inconsistent with MRRD's functions to date, requiring a substantial shift in the Ministry's approach and the "mental model" of providing for people rather than arm's length facilitation for private sector development. However, carried through with diligence, there are grounds for optimism that the implementation of the Master 
Plan objectives will provide the impetus and support for the MRRD to assume its new role.

\section{Reconstruction efforts are generally frustrated}

by a tension between cooperative-oriented approaches promoted and practiced by successive regimes prior to and during the Soviet era, and a private sector-centred approach promoted and practiced by development aid donors (notably USAID, Asian Development Bank, the World Bank and the Government of Afghanistan). One significant result of this tension has been the shifting of the boundaries for government and private sector roles in reconstruction efforts. As one interviewee pointed out, "the discourse should not be about the choice between cooperative or private sector approaches. Rather, policymakers and international donors need to agree on what type of private sector development is suited for Afghanistan, given the badly damaged infrastructure, weak government, diminished trust, and the cooperative institutional tradition."

Adopting this middle approach, as suggested by the interviewee, is likely to maximise the synergy from having a multiplicity of actors on board with varying and/or competing agendas. Efforts in coordinating actions by overlapping or competing agencies and entities could turn the many contenders into de facto stakeholders.

A pragmatic and inclusive approach based on this line of reasoning is also likely to lay the foundation for setting attainable objectives and defining evaluation criteria to assess policy effectiveness. Common rules and the introduction of a clear and transparent division of labour could also ensure that policy objectives are met and set the precedents for the formation of learned communities and social networks that last beyond the lifetime of reconstruction programmes.

\section{A shift is nevertheless discernible from} emergency aid provision to the development of a market-based economy. The 2005 Master Plan, for example, is committed to measurable economic growth in agricultural activity with local participation and ownership also being emphasised. The two sectors targeted are horticulture and livestock. A key feature of this strategy is to create an enabling environment for rural SMEs to thrive in areas and regions with the potential to yield the highest productivity and return on initial investment. This focus raises numerous issues in relation to transport infrastructure, production technologies in use in agriculture and rural wellbeing. In the next section these issues are investigated in case studies drawn from the Balkh and Bamyan provinces.

\section{CASE STUDIES}

This section presents some of the key issues related to the commercialisation of agriculture and related rural SME development through seven sub-sectoral case studies conducted in the provinces of Bamyan and Balkh. These provinces were selected for the following three reasons: (i) the two provinces were isolated geographically and economically, (ii) the two provinces had reasonably stable economies and agricultural production systems, and (iii) Kabul City served as the largest potentially accessible external market for the agricultural goods from these two provinces.

Based on the analysis of the case studies, the picture that emerges for the SME operating environment is mixed. Like most rural and other enterprises, productive activity suffered significantly during the years of conflict which translated into scarce or unreliable supply lines, the erosion or disappearance of existing markets and supporting institutions, and outright hostility toward the farming communities from those in positions of power creating an operating environment best described as "disabling". Although the operating environment has improved significantly since 2001 , certain aspects of business activity continue to demonstrate need for much improvement.

The next section reports on the findings from the seven case studies undertaken for this research. These findings are presented in summary form with the key descriptions highlighted.

\section{Case Study 1: Potato production and marketing in Bamyan}

Mostly people produce potato and wheat. Wheat they produce for themselves to survive. Potatoes they produce for [the] market but because we do not have good facilities like roads ... the people do not have easy access to the markets. This is why Bamyan people are poor.

Bamyan Govemor Habiba Surobi ${ }^{6}$

Potatoes are the most important cash crop produced in the Bamyan province. Key issues related to the commercialisation of potato production are summarised below. 
- Pressure to sell at low prices directly after harvest: Potatoes are harvested from August to September. Farmers needing to sell their harvest to traders directly after harvesting in September receive around $50 \mathrm{Afghanis} \mathrm{per} \mathrm{seer}(7 \mathrm{~kg})$, but at other times of the year they can sell for up to 80 Afghanis per seer. This is particularly a problem for the poorer farmers.

- Ineffective traditional storage methods: The traditional storage method which involves storing potatoes in the ground leaves the stored potatoes vulnerable to frost damage and dehydration, reducing tonnage and quality,

- No direct access to the market: Most farmers in Bamyan City sell their potatoes to traders and truckers, as they are unable to arrange transport to the market in Kabul themselves. Traders selling the potatoes in Kabul can make a profit as high as 30 to 40 Afghanis per seer.

- High costs due to poor road conditions and inadequate road infrastructure: The lack of adequate infrastructure within the Bamyan province and between the province and Kabul and Mazar-eSharif was pointed to by many interviewees as the largest obstacle to development of potatoes as a commercial crop. Poor road conditions result in increased costs for the producers as shipments take longer and the produce is likely to be damaged. As a result, Bamyan farmers cannot effectively compete with potatoes imported from Pakistan and Iran, served by better transportation routes than those leaving Bamyan for Kabul. Pakistani suppliers also have access to cold storage for fruit and vegetables in Peshawar and Jalalabad, putting the Bamyan traders at a significant disadvantage.

- Lack of a market for processed potato products: The potential for further value addition in potato farming is limited not only due to the poor infrastructure but also to a very weak market in Afghanistan for processed potato products. Setting up a commercially viable potato drying project, for example, would need to take place on a larger scale than is currently feasible in Bamyan.

- Lack of knowledge on markets for processed products: There is currently a lack of market research, which makes it difficult to establish whether there is in fact a large enough market in Kabul for potato-based products to justify largescale investment in potato processing.

\section{Initiatives to overcome some of the above listed impediments include the following:}

- The use of genetically modified potato seeds: There has been some assistance to Afghan farmers, including some in Bamyan, in using improved and "virus-free" potato seeds. The International Potato Centre, based in Peru, increased the supply of virus-free potato seeds in Afghanistan for local needs as well as future export to neighbouring countries. The successful training of farmers and the testing of new varieties expanded from Jalalabad to Kabul and Bamyan districts. Some farmers in Bamyan have used virus-free seed produced in Jalalabad since 2003.

- Building modern storage facilities: A number of organisations have been involved in building modern potato storage facilities in Bamyan. The modern storage facilities have helped farmers plan the marketing of their products so as to get a better price. Two organisations are currently involved in building storage sites, the French NGO, Solidarité, and the Citizens Network for Foreign Affairs (CNFA). CNFA has built 22 potato storage facilities in the Bamyan province with funding from the US Department of Agriculture. CNFA provides the wood and stone and oversees the building process, whilst the farmers themselves provide the labour. The farmers involved are not in the poorest categories, as only farmers able to produce beyond subsistence levels require storage facilities.

The size of storage facilities varies, but farmers interviewed in this study reported that the sites had an average storage capacity of around 8,000 seers (1.1 tons) of potatoes. The full impact of these initiatives on the scale of production for the Bamyan province could not be determined. However, it is certain that increased access to storage facilities is likely to lead to increases in the capacity of some farmers to produce a higher volume of potatoes while maximising returns on the sale of their crops.

- Trader-initiated market intelligence system: Digital connection through the Roshan mobile phone network has been very useful as a channel for farmers and traders in Kabul to communicate market information so that farmers can plan their shipments to Kabul more effectively.

\section{Case Study 2: Apricot production, processing and marketing in Bamyan}

The marketing of processed fruits, mainly apricots, has a long tradition in Kahmard and Saighan districts, as well as in some districts of Yakawlang. Traditional fruit drying methods are very smallscale and rudimentary. Apricots are dried in the sun on the roofs of houses. Currently, processing fruit is the only effective way to market Bamyan fruit in Kabul, as the poor road infrastructure and lack of refrigerated trucks make transport of fresh fruit to 
markets outside Bamyan very difficult. There are a number of small-scale, pilot initiatives aimed at increasing the profit margins of producers and traders through improved processing methods and better access to markets. These are implemented through the local NGO, Spring of Construction, Rehabilitation Cultural and Social Organisation (SCRCSO) under the Community Empowerment Programme for Women (CEPW) of the MoWA and the Aga Khan Development Network.

\section{Some of the key issues are as follows:}

- Insufficient supplies: Acquiring sufficient fruit for drying has been difficult as many fruit trees in Kahmard have been damaged by drought and part of the first crop destroyed by frost.

- Lack of electricity and poor road infrastructure: A number of respondents reported that small-scale processing such as the production of juices and jams would be a viable commercial proposition in Bamyan, were it not for the lack of electricity, the prohibitive added cost of running diesel generators and inadequate road infrastructure to transport finished products to various markets. While some villages are gaining access to electricity through small-scale hydroelectric generators constructed as part of the NSP, the electricity produced through these schemes is not sufficient to support smallscale industrial production. The NSP is intended to ensure that households benefit from very basic utilities such as having at least a light bulb per household.

Initiatives to overcome some of the impediments include the following:

- Introduction of new processing technologies: There has been some success in introducing new drying methods using sulphur to improve the appearance of the product and increase the appeal to the consumers in Kabul. Apricots dried without sulphur are sold to traders at around 100 Afghanis per seer $(7 \mathrm{~kg})$ whereas sulphur dried apricots are sold for up to $500 \mathrm{Afghanis}$ per seer.

- Improving access to markets: The SCRCSO project has organised marketing expeditions to take the apricots to the bazaar in Kabul in an attempt to bypass intermediaries between the producers in Bamyan and the retailers in Kabul.

- Product diversification: SCRCSO is aiming to extend the apricot project to more beneficiaries and has submitted a proposal for a small fruit processing plant to produce juice from grapes, apples and cherries.
Despite some of the major issues such as poor road transportation and absence of reliable energy supply, the picture that emerges from the two case studies in the Bamyan province is positive.

Government and donor assistance seem to be directed at areas of rural production which have the potential of increasing productivity and/or moving up the value chain, given the opportunity and facilitation. It is too early to state definitively and in precise terms the impact of assistance initiatives in Bamyan. Future research will be needed to assess this impact after sufficient time has elapsed and production patterns have become better established. However, it is doubtful that the situation would improve significantly over time if the infrastructure issues were to remain unresolved.

\section{Case Study 3: Cotton production and marketing in Balkh Province}

The Balkh province produces a significant quantity of cotton. Two plants were visited to get a sense of the operating environment for cotton processing. One was the formerly state-owned factory called "Jenopress", and the other was a locally owned and operated plant. Since 2005, Jenopress has been operating under the auspices of the Northem Afghanistan Project for Cotton and Oil Development (NAPCOD), a joint venture between DAGRIS, the Agence Française de Développement and the Government of Afghanistan. It is hoped that the consortium now managing the plant will create over 300 permanent and around 150 seasonal jobs when in full operation.

The personnel interviewed had a list of concerns about perceived barriers to business activity.

- Outdated machinery: Most of the machinery at the factory is of German or Russian origin, dating back to the 1940 s and 1960 s.

- Lack of adequately trained staff: The plant does not have a sufficient number of trained technical operating staff. Most of the existing technical staff are Russian-trained and spend most of their time fixing old and dilapidated machinery.

- Unreliable electricity supply: To deal with constant power outages, the plant has recently purchased two large generators to maintain continuous production. The use of generators is more costly than supplied electricity.

- Unreliable supply of cotton through contract farmers: Agreements have been reached with the local cotton growers to sell their crop to the plant at a pre-set price in return for receiving genetically modified cotton seeds and fertilisers. However, the 
black market for harvested cotton offers a higher price than the pre-set price and many of the farmers sell their crops on the black market, depriving the plant of a reliable source of raw material. According to one interviewee the only way the black market could be eliminated would be by raising the pre-set price, something that the plant cannot afford to do financially. Without some degree of assistance from the government to discourage farmers from selling on the black market (through subsidies to the farmers, for example), a senior management official at the plant expressed pessimism about the long-term sustainability of the business.

A more optimistic picture emerged during the interview with the second cotton producer. In the past, this producer used to ship everything to Mazar for processing. In order to increase revenues, the proprietor decided to purchase processing machinery and to do some of the processing on-site, During the past eight years the plant has acquired a number of machines for ginning and seed oil extraction. Steadily, the plant has established itself in the local market and its oils are sold in markets of nearby provinces.

\section{However, a number of issues were raised as} main concerns:

- Lack of quality control systems: In response to a question regarding the quality and the grading of the oil products, the interviewees said that to date they had not felt having a quality control system was necessary. No laboratory tests have been conducted to determine the quality (or the safety) of the products. Testing of the finished product (oil) is particularly necessary since many locals collect their own seeds, bring them to the SME for processing and are allowed to feed the extraction machines with their collected seeds. This represents a potentially serious threat to the reputation of the $\mathrm{SME}$ as the consumption of contaminated cooking oil can be fatal. The safety issue is particularly important since some processes involve the use of toxic and corrosive chemicals such as caustic soda.

- Inadequate energy supply: As with all other SMEs interviewed, concerns were raised at this plant about the higher cost of generator-supplied electricity as compared to power supplied through the grid.

- Fear of demands by government officials to pay taxes, fees and other charges: The plant was not willing to share detailed financial and operational information with the interviewers because of a fear of being forced, by officials, into paying taxes and other charges on the account of owning production machinery and other equipment. This fear of revealing information acts as a major barrier to formalising economic activity.

No information was available on attempts by government or non-government organisations to address these concerns.

\section{Case Study 4: Raisin production and marketing in Balkh}

Despite the over two decades of strife and a long period of drought, agricultural and rural productionrelated business activity has continued in the Balkh province albeit with significant fluctuations in the volume of production, productivity and deterioration in the operating environment for SMEs. While traders of agricultural products have continued to operate during and after the years of conflict, the conditions have not been conducive to emergence and sustenance of other, more productive enterprises involved in value-adding activities. Agro-processing has suffered from a lack of capital investment, which has resulted in outmoded production machinery, reduced product quality and a loss of markets. Of the 30 or so raisin processing factories that once operated in Afghanistan only a few remain ${ }^{7}$. There are five raisin processing operations in or around Mazar-eSharif with only two working at full capacity when fieldwork was conducted.

At the time of our visit, one of the two raisin processing plants was operating at full capacity. In addition to processing raisins, the plant also processes cotton and extracts oil from cotton seeds. Fruit is dried and the nuts processed include almonds, pistachios and walnuts. The plant builds its own packaging cartons using cardboard and polythene and employs about 70 people. The supply of unprocessed products is from numerous local sources as well as suppliers from outside the province. The second raisin processing plant visited has been in operation for only a short while. It employs 30 men and 20 women. The raisins are packaged for export and to reach foreign markets, the plant has an agreement with a Russian trade company which markets the raisins along with many other products from Russia. No specific difficulties were expressed during the interviews anu a general air of optimism about future prospects was noted during the visit.

\section{$A$ dried fruits trader in the bazaar underlined the key issues faced by raisin producers in the province:}

- Lack of processing capacity: Much of the raisin on sale in the bazaar is of Afghan origin but processed in Uzbekistan. This points to inadequate 
or uncompetitive processing facilities within the province for adding value to primary farm produce.

- Loss of local market for local producers: During the height of the conflict and the drought, many traders had to look for new suppliers from the surrounding countries. While this practice has sustained retail trade, it has adversely affected the demand for locally grown produce.

No specific government or non-government initiatives to improve the operating environment for local producers and processors were identified during the visit. Regaining the lost market share by local fruit growers is likely to be a function of time, given sustained socio-political stability, normal annual rainfall and external impetus to re-establish a local production system capable of value addition.

\section{Cast Study 5: Fertiliser production in Balkh province}

Production at the fertiliser plant near Mazar-eSharif has continued during and after the war.

\section{However, production today faces a number of serious challenges:}

- Reduced production volume: Under Soviet occupation, the plant operated 24 hours a day producing 320 tons of fertiliser per year. The plant also produced a number of industrial gases. Currently, the plant still operates 24 hours a day but produces only 100 to 120 tons of fertiliser per year.

- Outdated machinery and lack of technical expertise: The machinery is antiquated and the engineering expertise provided by Russian engineers is no longer available as before.

- Threatened or costly fuel supply: The pipeline from Sheberghan gas fields supplying the plant with natural gas is tapped into illegally by local strongmen. This threatens the supply line and adds to fuel costs for the plant.

- Reduced product diversity: The plant no longer produces industrial gases in order to streamline its production.

\section{- Loss of markets and unfavourable marketing} arrangements: The Soviet-backed government had a purchasing agreement with the plant under which all the fertiliser produced would be purchased and distributed by a government agency (Afghan Koud) to the farmers. This agency no longer exists.

Currently a private dealer purchases the entire production and sells it on the free market to the highest bidder.
The fate of this fertiliser plant is symptomatic of other state-owned or previously state-owned industrial operations. Because of the years of conflict and changing government priorities, in the post-Taliban period state-owned operations in general have suffered from being under-resourced in many respects, particularly in terms of raw material, energy source and market access or selling arrangements for the products or services produced. The move from centrally planned and controlled industrial management to market-based industrial management has meant that during the transition, state-owned operations have been largely neglected. De-prioritisation of support for these operations by the State has meant uncompetitive salary structure, which has resulted in a flight of experienced personnel and expertise, diminished market share and outmoded production machinery. Given the current moves toward corporatisation and privatisation of state-owned operations, it will be sometime before socio-economic stability can act as an impetus for sustained, economically competitive production.

\section{Case Study 6: Carpet and galeem weaving in Balkh}

Carpet and galeem weaving has been and continues to ' 23 an important economic sector in Afghanistan as a whole. Interviews were conducted with two carpet/galeem weaving and cleaning workshops.

Key issues that emerged during the research include the following:

- Domestic supplies: Wool supplies have been chronically unreliable. To meet demand, the carpet weaving and cleaning workshop imports wool from Pakistan, Saudi Arabia and Iran. The dyes are almost entirely imported from abroad with German dyes being of the best quality.

- Market access: Afghan traders work on colíimission purchase carpets and galeems at wholesale prices on behalf of larger and more established Pakistani traders. The interviewees reported that much of this trade is illicit and the purchased carpets are smuggled out for wholesalers and exporters based (mainly) in Pakistan. In Pakistan, the carpets are cleaned and if necessary. repaired, and labelled as "Manufactured in Pakistan" for sale in domestic and foreign markets. Most Afghan producers and traders have little or no direct access to the markets in Pakistan and beyond.

- Institutional support: The main problem was described as a lack of a well-coordinated and inctitutionally supported marketing offensive to capture sizable segments of the very lucrative 
export market for handmade carpets. This problem has been recognised by government and development aid officials who have paid numerous visits to the carpet workshops in the area and have made commitments about increased efforts to increase access to markets. According to the interviewees, however, to date nothing has been done by the officials to remedy this situation.

- Access to credit and corruption: A second problem is the difficulty in obtaining credit from major national banks which, according to the interviewees, have "extremely difficult" qualifying requirements. Some loans intended for business development are reportedly widely misused by the recipients and spent to serve personal purposes.

- Access to import/export licences and corruption: Licences are very difficult to obtain and those who manage to obtain them for importing cleaning materials or certain types of wool, for example, have a de facto monopoly on the supply and thus the prices. The interviewees expressed a wish to have the right to import their own production inputs so as to have more of a say on the quality and the price. There were also remarks about corruption and how the monopolists were being protected by officials so as to maintain the status quo.

- Pressure from imports of finished products from neighbouring countries: A relatively new feature in the business of carpet traders is the import of finished products from neighbouring countries such as Tajikistan, Uzbekistan and Iran. There is also an increase in the importation of raw materials such as dyes and wool from these countries. Nevertheless, much of the value-adding activities reportedly continue unabated in the province.

Despite these difficulties, some carpet weaving workshops have experimented with more innovative ways of organising production. One of the workshops set up a work area for women who had traditionally worked from home. The purpose was to increase productivity and a more structured and controlled work environment. However, this experiment proved impractical: The women found it more convenient to work in their home environment because they could simultaneously attend to carpet weaving and (unpaid) domestic work. Based on a mutual agreement with the employers, the women reverted back to working from home and being paid on the basis of the amount woven.

According to the traders interviewed in the bazaar, rural businesses such as carpet making remained fully intact despite the many years of war: the supplier-producer arrangements continued during the war.

\section{Case Study 7: Animal skin production in Balkh}

The first one of the two animal products SMEs interviewed provided a similar view of trading arrangements and market access as those of the carpet makers:

- Availability of skins: The animal products sector was severely affected by the persistent recent drought, which resulted in wiping out 70 percent of the sheep population in the area. In the post-drought period there has been a rebound in the sheep population.

- Low profits due to lack of direct access to markets and lack of processing capacity: The SME interviewed reported that it collects raw animal skins and intestines, carries out very minimal preparation and ships the packaged products to Kabul and Peshawar for further processing. After grading, sorting and repackaging, the products are taken to Pakistan for distribution and sale. The total value of the trade in animal products was estimated at EUR 10 million, of which a small fraction accrues to the Afghan producers while the rest goes to the larger, technologically better equipped and more established and organised Pakistani traders.

- Lack of security: During the interview a request for taking photographs of the operations was turned down on the account of "unnecessary exposure" which might be used against the SME by illwishers and extortionists.

- Corruption: According to the second animal products producer, SMEs face insurmountable problems with widespread corruption of officials at all levels and a general failure by the Government to create an enabling environment for business activity:

They [the Government] keep telling us about free trade and competition. What does all of this really mean when we have corrupt and unhelpful officials. no title to the land we operate on, no access to finance, insufficient fodder lo feed the sheep from which we get our skins, and no basic services such as electricity?

Despite these difficulties, this SME has been exporting prepared sheepskins to a number of foreign markets for the last 20 or so years. The production volume has varied depending on the availability of fresh skins. The situation is likely to improve further in the post-drought period. However, many of the fundamental issues regarding security, lack of access to markets and inadequate energy and transportation infrastructure 
will continue to undermine initiatives by local producers to expand and grow.

\section{DISCUSSION AND CONCLUSIONS}

Rural business development in the Bamyan and Balkh provinces will continue to be challenging, given the poor infrastructure and lack of liquid assets. There may not be a sufficient surplus in either of the two provinces to support large-scale agri-business development. However, there is clearly room for significant measures to promote the marketing and quality of agricultural commodities in these two poorer provinces to support small businesses. The most obvious measures with a potential to bring tangible and widely distributed benefits are improvements in infrastructure (specifically roads) and the availability of basic services such as electricity and storage facilities.

Efforts toward facilitating more post-farm rural production activity are likely to pay off economically, given the size of the world market for raisins, pistachios, dried fruits and nuts. This market is estimated at US\$ 2.2 billion, only two percent of which is captured by Afghan producers. Many of these products were being produced at much higher volume and quality in the past. Afghan produced raisins used to account for around 60 percent of the world market. The dried fruits and nuts industry has suffered from serious setbacks due to outdated production methods and machinery; and is likely to benefit from modern techniques for sorting, drying, packaging and storage.

A modernised dried fruits and nuts industry is likely to go beyond recapturing its traditional markets in Russia, Pakistan and India by extending its reach to markets in Europe and North America. There are also positive residual effects associated with production modernisation. Traditional raisin production is labour-intensive and capable of providing numerous local jobs. Designed carefully to take full advantage of available production inputs such as abundant unskilled local labour, modernisation programmes could create jobs, and increase production volume and productivity.

To be successful, programmes and projects to revive or expand rural business activity need to be knowledge-based. Projects need to be geared toward the production of commodities suited to the local factors of production and for which there is market demand. Support and representation for existing businesses are important in raising the profile of the rural private sector. The provincial Chambers of Commerce need to have the capacity to provide representation for their business constituents and to support them. In the two provinces, the Chambers of Commerce are particularly weak compared to Chambers in other provinces. If the commitment to broad-based private sector-driven growth at the heart of the Afghanistan National Development Strategy is to be realised, support to the private sector from institutions such as the Ministry of Commerce and Industry, the Afghanistan Investment Support Agency and the Afghan International Chamber of Commerce also needs to be extended into areas where private sector development is more challenging. This could help to mitigate the currently uneven trajectory of economic development in Afghanistan.

There needs to be recognition by government, non-government and international donors that the situation in Afghanistan has evolved from one of emergency aid provision by international donors to one where the parameters for the emergence of a functioning political economy need to be set. The various government ministries and agencies lack experience and suffer from not being fully embedded in Afghan society. A continuing challenge in efforts to rebuild Afghanistan is the common perception of people and their enterprises as "the needy", rather than as a valuable resource for the reconstruction of a civil society. However, recognition alone is not sufficient for changing the mode of development in Afghanistan.

Reconstruction efforts are generally frustrated by a tension between cooperative-oriented approaches promoted and practiced under the Soviet era governments, and a private sector-centred approach promoted and practiced by development aid donors, notably USAID, Asian Development Bank and the World Bank. One significant result of this tension has been the inability to set the boundaries for government and private sector roles in reconstruction efforts. As one interviewee pointed out, "the discourse should not be about the choice between cooperative or private sector approaches. Rather, policymakers and international donors need to agree on what type of private sector development is suited for Afghanistan, given the badly damaged infrastructure, weak government, diminished trust, and the cooperative institutional tradition." 8

\section{Adopting this middle approach to development maximises the synergy from having a multiplicity of actors with varying or competing agendas on board. Efforts in coordinating actions by overlapping or competing agencies and entities would more likely pay dividends simply by making the many contenders de facto stakeholders. A pragmatic and inclusive approach based on this line}


of reasoning is also likely to lay the foundation for setting attainable objectives and defining evaluation criteria to assess policy effectiveness. Common rules and the introduction of a clear and transparent division of labour could also ensure that policy objectives are met and set the precedents for the formation of learned communities and social networks that last beyond the lifetime of reconstruction programmes.

In Afghanistan a shift is discernible from emergency aid provision to the development of a market-based economy. The 2005 Master Plan, for example, is committed to measurable economic growth in agricultural activity while local participation and ownership are emphasised. The two sectors targeted are horticulture and livestock. A key feature of the strategy, as outlined in the Master Plan, is to focus on areas with the potential to yield the highest productivity and return on initial investment. Central to this strategy is creating an enabling environment for small and medium rural enterprises to thrive. This focus raises numerous issues in relation to transport and energy infrastructure, production technologies in use in agriculture and rural well-being.

A necessary feature of a pragmatic and, by default, inclusive approach to policymaking in rural development is a demonstrated capacity to coordinate between economic and social needs. Put differently, reconstruction efforts must be designed or selected for their potential to increase economic as well as social well-being. A recent study commissioned by the MRRD, the Rural Economic Regeneration Strategies (RRERS), is a potentially important step toward a socio-economic policymaking environment. RRERS calls for the establishment of a framework for integrated rural development planning in Afghanistan. RRERS is intended to provide in-depth understanding of local and regional contexts and issues. It will also look at broader social and economic trends, opportunities and barriers faced by rural communities, the potential for growth based on local specificities, and potential regional development scenarios and their long-term viability. A key promise of this study is to identify pathways for scaling out (replicating local success elsewhere) and scaling up (building on local success as the foundation for national development). The recommendations in Section V are formulated in the same spirit as the RRERS study. ${ }^{9}$

\section{RECOMMENDATIONS}

The many improvements needed to overcome the disabling factors in the operating environment for rural SMEs can be grouped as follows: immediate, medium to long-term and general.

\section{Immediate Measures}

\section{Strengthen and expand transportation} networks: Lack of access to transportation routes and poor road conditions have been raised as a major reason for the sub-optimal performance of rural SMEs. While efforts are being made to address these shortcomings, attention must be paid to whether the proposed plans would give rural SMEs access to markets outside their immediate surroundings,

2. Increase energy production capacity: Energy continues to present major challenges for rural value-adding production. This is particularly the case for smaller rural producers who often lack the financial resources to afford generator power for production purposes. Innovative solutions based on micro-power generation from solar, wind and hydro sources should be considered by agencies in charge of improving the operating environment for rural producers.

\section{Strengthen existing markets: Local} institutions such as local government offices, chambers of commerce and development aid agencies need to collaborate on developing monitoring mechanisms to gauge how certain businesses succeed and maintain their markets, while others fail. Such collaboration is also needed to provide assistance when necessary, and to dif ${ }^{i}$ ise learning.

\section{Increase exports by exporting directly to markets, rather than to agents of traders elsewhere in Afghanistan and in neighbouring} countries: This task requires leadership and assistance from different levels of government. In line with the Ministry of Commerce and Industry's recent attempt to simplify the process for obtaining licences and permits for foreign investors, similar attempts need to be made to enable rural SMEs to obtain the necessary licenses and permits to continue and expand. Various levels of government could also help by organising trade missions to other countries.

Is 


\section{Medium and Long-term Measures}

\section{Micro-credit facilities for post-farm} production: Easier access to credit will need to be provided for small producers. This calls for an increase in the current number of micro-credit providers in rural areas with preferential terms for rural SMEs.

\section{Establishing new markets and regaining} traditional markets: Historically, dried fruits from Afghanistan have had market shares in India, Russia, Iran and the Middle East. Many of these markets have been lost due to unreliable supply sources from Afghanistan during the years of conflict. Concerted attempts need to be made to reclaim these markets.

\section{Increase accountability: A number of} interviewees from donor and government agencies had serious concerns about the lack of accountability in how funds earmarked for infrastructure development were being deployed. The example given by one interviewee was the manner in which infrastructure contracts are implemented. Often, because there are so many sub-contractors contracted by other subcontractors, by the time the work commences only a fraction of the initial funds remain to do the actual construction. Awarding infrastructure contracts needs to be re-examined and streamlined through instituting a system of accountability, formalised through legislative (and other) measures.

\section{Formalise rural business activity of SMEs:}

There is no system of registration for businesses in rural areas. Many rural SMEs opt not to expand formally because they fear being "noticed" and coerced by various corrupt elements. Little or no tax revenues are generated from rural business activity, particularly by SMEs. Moving toward a more enabling environment requires formalisation of business activity based on trust, which cannot be established overnight and requires continuous attempts by national and local governments to earn the trust from rural SMEs.

\section{General Measures}

9. Quality Control: A key issue with manufacturing and processing in less developed economies is quality and hygiene in foodstuffs production. Rural SMEs in Afghanistan are not exempt from this problem. To attend to this potentially serious problem, the following measures need to be carried out with the guidance and assistance from government and business communities: a) Providing incentives for rural SMEs to recognise the link between quality and hygiene standards, and maintaining and increasing market share

b) Developing hygiene and quality protocols based on consultations with the nural producers and their representatives (if any)

c) Establishing a monitoring system

d) Establishing a system of certification

e) Creating incentives for meeting hygiene and quality standards

10. Coordination of scientific research: Research and development work carried out by government agencies, donors, the private sector and universities need to be coordinated to eliminate duplication in R\&D and to utilise synergy.

11. Increased collaboration: Linkages between provincial educational institutions and rural SME representative bodies need to be strengthened to increase access by the SMEs to local technical and other areas of expertise.

\section{Strengthen rural business representation:} Establish local producer associations by reaching out to the informal local networks that have traditionally governed business activity in rural areas.

\section{REFERENCES}

- Afghanistan Millennium Development Goal Report (2005).

- Alden Wily, L. (2004). Land Relations in Bamyan Province: Findings from a 15 Village Case Study (Kabul: AREU).

- Interim Afghanistan National Development Strategy

- Lister, S. and T. Brown (2004). Understanding Markets in Afghanistan: A Case Study of the Raisin Market (Kabul: AREU)

- Pain, A. (2006). Water Management, Livestock and the Opium Economy: Opium Cultivation in Kunduz and Balkh (Kabul: AREU)

- Paterson, A. and J. Blewett (2006), Putting the Carl before the Horse? Privatisation and Economic Reform in Afghanistan, AREU Briefing Paper Series (Kabul: AREU). 
${ }^{1}$ English Summary of the Afghanistan Agriculture Master Plan, Ministry of Agriculture, Animal Husbandry and Food (MAAAHF), recently renamed the Ministry of Agriculture and Irrigation (MAI).

${ }^{7}$ Widely reported in research from AREU's rural livelihoods work to NRVA. Cited in IANDS Vol. I.

${ }^{3}$ Existing rural enterprises include the cotton and leather industries, manufacturing and agro-processing including the processing of plant oils, vegetable and fruit conservation, flour milling and dairy production. Additional farm-based enterprises include milk and meat processing. Non-farm rural enterprises include carpet weaving, sewing and tailoring, fertiliser production and collecting and selling of wild plants.

${ }^{4}$ Of key importance in these developments is how Community Development Councils (CDCs) for community-based development will evolve in the local governance structures and the role they will play in rural economic development.

${ }^{5}$ Interview with an FAO / MRRD official on October 25, 2006. For a discussion of this tension and its implications for the privatisation efforts, see Putting the Cart before the Horse? Privatisation and Economic Reform in Afghanistan, by Anna Paterson and James Blewett, AREU Briefing Paper Series, November 2006 (Kabul: AREU).

${ }^{6}$ Selim Saheb Ettaba, AFP, 12 October 2006, In Afghanistan, Bayyan suffers for being calm, http://www.metimes.com/storyview.php?StoryID $=20061$ 012-062048-3480r

${ }^{7}$ Lister and Brown 2004

${ }^{8}$ Interview with an FAO / MRRD official on October 25, 2006.

${ }^{9}$ See also:

http://www.undp.org.af/jobs/projects/nabdp/EOIRRERS-FesibilityAnalysis-BusinessPlans.pdf. 


\section{UNLEASHING ENTREPRENEURSHIP: NURTURING AN ENABLING ENVIRONMENT FOR SME DEVELOPMENT IN AFGHANISTAN}

Background paper prepared for the Enabling Environment Conference by:

\section{UNDP Afghanistan}

\section{INTRODUCTION}

In his message to the international conference "Afghanistan and the International Community - A Partnership for the Future", held in Berlin from 31 March to 1 April 2004, President Karzai averred the commitment "to create the enabling environment for both the domestic private sector, including the Afghan diaspora, and the international private sector to thrive in our country". This commitment has been reiterated in a series of national strategy documents - especially in Afghanistan's National Development Strategy (ANDS) of 2005 - and is being implemented at different levels of government in various sectors of production.

Whatever their persuasions, governments frequently view small and medium enterprises (SMEs) as critical to private sector development, as they can help economies attain more broad-based uniform growth, and help encourage an entrepreneurial mentality in the business sector. Afghanistan's current socio-economic stage of development is characterised by a low absorption capacity and large-scale investment requirements to rebuild the country's infrastructure. This is a process which may take a long time to complete; however, given SMEs' resilience, adaptability and scalability, they are arguably best suited to Afghanistan's current stage of development and natural partners for a step-by-step approach to economic development. Promoting a favourable climate for SMEs to thrive is therefore key to the successful and lasting economic development of Afghanistan.

In view of the importance of SMEs, this paper focuses on the impediments which SMEs face, and proposes ways to tackle them (many of which are already in progress). It follows the blueprint set out in UNDP's Unleashing Entrepreneurship 2004 report and concentrates on ways to create an enabling environment for private sector development (PSD) in general, and SME development in particular - a process which was identified as crucial by numerous private and public sector stakeholders across the country.

The paper's arguments and recommendations focus on a set of five issues identified as central to the successful promotion of SME development in Afghanistan:

i. Taxes, tariffs and customs

ii. Land registration

iii. Skills and knowledge development

iv. Trade promotion

v. Standards and certification 


\section{Box 1: UNDP Afghanistan's approach to private sector development}

UNDP's assistance to private sector development will focus on strengthening national and local capacities to create micro and small enterprises leading to enhanced income and employment opportunities. UNDP will support the creation of an enabling environment for the promotion of SMEs and the development of Afghanistan's traditional export strengths by: encouraging the development of commercial crafts (through support for the formulation of a Small Enterprise Development policy); promoting entrepreneurship; providing education and export skills; and setting up Internet Business Resource Centres to promote livelihood opportunities for the poor (particularly poor women).

To this end, UNDP favours a "bottom up", community-based approach buttressed by:

- Targeted technical assistance attending to impediments to SME growth

- An accelerated build-up of local capacity and physical infrastructure

- The scaling-up of assisted financing to serve SME needs, in line with multi-stakeholder initiatives akin to those exposed [The investment climate in Afghanistan 2005; compare Lister and Pain 2004]

- The recollection and study of good practices for SME development which have been successfully applied in other developing countries especially Central, South, Southeast and Eastern Asia

- A moratorium until 2020 for corporate tax compliance and effective trade liberalisation for SMEs, as defined in a specific enabling regime

Although issues of access to electricity and finance are key areas affecting SME development in Afghanistan, these areas of concern will not be treated here as they are covered by other papers that have been prepared for the Enabling Environment Conference. Corruption is a theme that cuts across nearly all points of contact between the private and the public sector. Unlike micro- and family enterprises, many SMEs are "too big to hide and too small to fight". 'Not surprisingly, an overwhelming majority of 95 to 99 percent of respondents in a recent nationwide poll affirmed that government policies should prioritise the fight against corruption, enforce the rule of law and assure equal treatment to all regions. ${ }^{2}$ While it is recognised that overcoming corruption is an important aspect of creating an enabling environment for SMEs, it is felt that the problem is not specific to SMEs, and too complex to be addressed in this paper. Issues related to the security situation are beyond this paper's scope.

Section II sets out key factors that need addressing in order to create an enabling environment for SME development in Afghanistan. Section III selects a number of particularly promising sectors that could be a special focus of SME promotion policies, and section IV summarises key recommendations.

\section{UNLEASHING ENTREPRENEURSHIP IN AFGHANISTAN - CLEARING THE PATH ${ }^{3}$}

The case study of Arya Co. Ltd. illustrates a range of key problems faced by SMEs and sets the stage for the following discussion of key issues pertaining to SME development in Afghanistan.

\section{Taxes, tariffs and customs}

Afghan entrepreneurs big and small for the most part complain that the tax burden they bear is excessive and that tariffs on their imported inputs are high and unpredictable due to lack of transparency in customs valuation and clearance procedures. Moreover, they claim that, as government is not duly performing its duties, it lacks the moral standing to impose such a load on the productive sector. Although these complaints by the business sector are justified, the gross profit tax rate it is liable for in Afghanistan reaches only 21.4 percent, while the average for the region is 35 percent, and that of industrial countries more than twice as high.

If authorities want to favour SME development through fiscal policy rather than tinkering with the liability side of the tax system, they may introduce explicit tax rebates, devolutions and drawbacks that can go a long way in mitigating tax incidence and cash flow problems in the private sector. For instance, the Private Investment Law, currently in force as published in the Afghan Official Gazette No. 869 of 21 December 2005, does not seem to exempt from import duties the importation of production machinery for approved investments. However, whether in the case of import and export duty exemptions or of tax breaks, subsidisation requires government expertise build-up and discrete attention in the permanent quest against administrative and political corruption. 


\section{Case Study 1: Creeping costs, dumping and government neglect, or poor business planning?}

Arya Co. Ltd., established in 2002, is the largest flour mill in Afghanistan. It employs 220 workers in a compound within the city limits of Herat, and about 80 at the border with Turkmenistan to pack imported wheat. The property of 35 jerib (about seven hectares), the installations and the German and Turkish machinery in operation represent an investment of around USS 5 million, totally self-financed. Although close to Herat's industrial park that already groups 167 factories established after its investment, the Arya Co. has not benefited from the subsidised land and facilities granted to other companies within such a perimeter.

The mill works only nine hours a day because it cannot place any surplus production. Power from Iran and Pakistan is plentiful but expensive (AFN 5 per $\mathrm{kW}$ against AFN 2 per $\mathrm{kW}$ for non-commercial users), with frequent blackouts and voltage fluctuations, which can cause machinery malfunction. The tax and tariff burden is forcing the Arya Co. and other companies out of the market, especially because of the well-oiled public-private response to competition in Iran and Pakistan. ${ }^{4}$ Apart from these deadweight costs, an additional 15 percent needs to be paid to sort out corrupt practices, without counting private security.

For Arya Co. Ltd to inspect the quality of its wheat imports ( 70 percent), it would need to send samples to Kazakh or Turkish laboratories. The company would only need US $\$ 30,000$ to US\$ 100,000 to set up a laboratory of its own but faces prohibitive bank interest rates in the range of 20 to 25 percent per annum to finance it. In a textbook case of lacking support to PSD, the firm claims that the government could do a lot to reduce the tax, utility, private security and corruption bills, subsidise the arrangements for its laboratory and facilitate access to international organisation (IO) and donor procurement. To be sure, practically all flour distributed by IOs, inter-governmental organisations (IGOs) and NGOs in Afghanistan, including the World Food Programme (WFP), is imported.

At the time of a visit to Arya's premises by this research team in October 2006, some bankers in Afghanistan did not seem to know about Arya's plight and the company was not aware of the existence of two seed quality testing laboratories in Badam Bagh (Kabul) and Jalalabad and two satellite stations in Kunduz and Baghlan set up by ICARDA to ensure seed quality. Was this due to a lack of resources or lack of public-private cooperation and coordination?

The key issues are;

- Unreliable electricity at high costs

- Unfair competition (dumping) from Iran and Pakistan

- High tax and tariff burden and additional high costs of corruption

- No access to formal credit

\section{Land registration}

Evidence abounds that Afghan land registries are unreliable and the object of recurrent fraudulent manipulation, while other property registries (industrial property and copyright, for example) are simply not operational. Uncertainty in land tenure prevents many international corporate investors and bankers (who are governed by their countries' restrictive legislation of incorporation) from entering the Afghan market altogether. SMEs are particularly vulnerable to rule of law deficiencies in an environment of land appreciation and legal opacity as they find themselves impotent against the discretionary power of government officials when trying to resolve titling and zoning matters. Afghan entrepreneurs cannot revert to the courts for the resolution of commercial controversies and no alternative adjudication mechanisms are available to them other than informal or traditional ones.
A majority of Afghans have no legal title to their homes. Moreover, the destruction of public records and the existence of conflicting titles to property are well known in countries that, like Afghanistan, have undergone protracted civil and international wars. This is usually addressed through the creation of administrative or judicial bodies especially dedicated to the verification and issuance of definitive titles, not only to land but also to fixed installations and agricultural machinery, for example. The Land Titling and Economic Restructuring in Afghanistan (LTERA) project, implemented for USAID by the Emerging Markets Group (EMG), is engaged in a series of similar initiatives, like the introduction of a new Land Information System (LIS) to address shortcomings in land registration and titling systems. It has already processed over 5.4 million legal documents 


\section{Case Study 2: Access and title to land}

The Kabul Fnuits and Nuts Consortia are a group of Afghan wholesalers (from all over the country) who export raisins, almonds, pistachios and other fruits and nuts to India, Dubai and some European Union countries. Each of the member companies employs around 10 salaried staff and, depending on the season, between 20 to 50 labourers (paid by the day) for processing and packing at headquarters, and about 10 procurement agents in the provinces (paid on a commission basis). Most daily labourers are women, half of them regular, who are trained by other, more skilled workers. Their aggregate exports reach more than US\$ 80 million a year. There are other similar consortia for other products.

They are very proud of the quality of their exports (which contain no chemical additives), and consider them far superior to those of their competitors in China, Turkey and Syria. They only pre-pack for export as final packaging and labelling is done in the countries of destination, with explicit mention of its prestigious origin.

However, the following impediments affect their competitiveness: the cost of power, difficulties in acquiring appropriate machinery, lack of proper health and quality standards, and transportation costs. All the cargo travelling over roads needs to be transhipped at the border, including those sealed for maritime dispatch via ports in Pakistan and Iran. Controls en route are usually dealt with through arrangements sub rosa and corruption is embedded in the price and considered a condition for "regular" operation.

However, the main problem claimed by this group is the lack of access to land within a $100 \mathrm{~km}$ radius of Kabul's centre to set up its processing and packing plant with new machinery from India. The authorisation to do this rests with the capital's municipality and provincial authorities, and is subject to conflicting, non-transparent zoning regulations. The companies are prepared to pay cash for the area of two jerib (about $4,000 \mathrm{~m}^{2}$ ) they need, but require unambiguous title to it to protect their collective investment in machinery. This is a problem that also affects some industrial parks already in operation. Considerable growth resulting from expansion directly depends on tackling this basic pre-requisite.

\section{The key issues raised are:}

- High production costs due to high electricity costs

- Difficult to procure machinery

- Lack of health and quality standards affects international competitiveness

- Endemic corruption

- Lack of access to land results in lack of access to credit

(wasayeq) throughout the country, including some 540,000 restored title deeds. The work includes the use of traditional methods for improving tenure security of urban and rural dwellings, like the use of customary documents (orfi) and working in cooperation with village councils (shuras), ${ }^{5}$ The nostrum here is more of the same.

\section{Skills and knowledge development}

As the Afghan economy acquires a higher degree of sophistication, capacity building will become a key component of long-term growth. And as businesses acquire scale, planning, manning and scanning, the mantra of SME development nowadays will take centre stage in Afghanistan, putting pressure on the organisation and coordination abilities of Afghan entrepreneurs and government authorities. ${ }^{6}$.

SME development heavily depends on an effective public-private interaction that includes civil society to foster capacity building. This will require the allocation of substantial resources. Key areas for business skills and knowledge development that will need much more attention include:

- Investment in productive capacity - best exemplified by the Integrated Framework for Trade-Related Technical Assistance to LeastDeveloped Countries (IF) initiative

- Targeted programmes to mitigate risk for SMEs

- The advancement of flexible financial markets

- Access to and development of online data banks for national trade-support institutions (TSIs)

Many Afghan entrepreneurs and professional associations do not seem to be aware of these challenges and, as a first step, it would be the responsibility of the Government to raise awareness amongst the business community and civil society. 
Technical assistance and capacity building (TA/CB) - International organisations, NGOs, foreign government agencies, universities and specialised think tanks in Afghanistan have been engaged in TA/CB for years. Apart from the merits of their substantive work, they should take special care to involve relevant public sector officials in their initiatives from the planning stage onwards, so that local ownership is nurtured early on. Moreover, all should be interconnected through an informal, forum-like scheme, which encourages information sharing and fosters good practices that show viability.

\section{Trade promotion}

It is tempting to envisage SME development in Afghanistan as a process primarily targeting the build-up of scale in the domestic market; the promotion of certain sectors that could produce quick results; the favouring of a Buy Afghan focus for inputs; the repatriation of the value-added production segments that have been moved abroad due to lack of equipment technology, qualified personnel or know-how (import substitution); and then, and only then, the targeting of export markets. Nevertheless, the scenario is more complicated than that. Afghanistan's competitive advantage concentrates, precisely, on being at the crossroads of trade routes that have existed for thousands of years - the "roundabout of the ancient world", in the words of historian Arnold Toynbee - and will not be phased out by government decree.

Moreover, a land-locked country that is not self-sufficient in energy and food, and is badly dependent on foreign inputs for its incipient and reconstructing industries, will inevitably need to rely on voluntary exchanges involving increasingly complex economic, legal and logistical arrangements. The fact is that improving SME access to imported inputs, especially capital goods, ranks very high among the concerns manifested by Afghan entrepreneurs. There is also increasing evidence of the "born-international" nature of SMEs in a globalised economy (SMEX). ${ }^{7}$ It is hard to envisage an alternative path for Afghanistan to an enlightened international trade policy aimed at capturing new opportunities and diversifying its export markets (now skewed in favour of a few neighbouring countries). ${ }^{8}$

Missing the vanguard of MNE subsidiaries and large national corporations shooting for export volume, what role can Afghan SMEs play in world markets? The options boil down to two, namely:

- Joining regional or international value chains, so that Afghan products and services can reach economies of scale and gain access to advanced export markets.

- Pursuing market niches for highly differentiated products like organic farming, biocultivation, handmade carpets, tapestry, blankets and shawls, "exotic" gems and jewellery, and unique animals like the Afghan hound and the Buzkashi horse."

A number of innovative initiatives of this sort are being pursued at the moment in various parts of the country, all of them rural, either to foster import substitution or to capture foreign markets. Promoting trade will do little good for a landlocked country like Afghanistan if the movement of goods through connecting countries remains too difficult and costly. Trade and transport facilitation in Afghanistan constitutes a multifaceted endeavour, requiring considerable financial and qualified human resources, and extensive negotiations with neighbours (especially Iran and Pakistan for improved access to the closest ports in the Arabian Sea). The Emergency Customs Modernisation and Trade Facilitation (ECMTF) project, initiated in 2004, focuses on the development of physical infrastructure at border crossing stations, inland clearance depots and transit checkpoints. Customs infrastructure development is already in progress in Kabul, Jalalabad, Torkham, Hairatan, Mazar-e-Sharif, Islam Qala, Herat and Torghundi. The creation of the Asycuda central database promises to provide top management at the Afghan Customs Department and the Ministry of Finance with comprehensive information about customs activity at the country level in both Asycuda computerised and non-computerised customs offices. ${ }^{10}$

\section{Also, close cooperation with highly-advanced} trading countries, like Singapore and Malaysia, could speed up the process of skills development in trade facilitation in Afghanistan - a multi-pronged tool to simplify and accelerate import and export procedures, give transparency to the application of customs legislation, regulations and rulings, fight corruption, increase revenue, reduce frictional costs in the transportation and handling of merchandise, and assist in the overall modernisation of the export sector. All countries in Central and South Asia are pursuing efforts toward simplifying and harmonising of international trade procedures and their automation. However, none would seem suitable to serve as a model for Afghanistan. A land-locked country like Afghanistan should place top priority with the trade facilitation agenda, especially the segment on the harmonisation and simplification of trade procedures with neighbouring countries in Central and South Asia. This process requires the dedicated involvement of the private sector, including trade promotion 
organisations, professional associations (PAs) and other national, regional and international business groupings. Similarly, doing away with marketunfriendly die-hards, like government-run chambers of commerce and industry that broadcast the wrong message, is part of the task.

The specific recommendations contained in a recent World Bank publication on economic cooperation in the wider central Asian region should be adopted at once, by namely:

- Developing funding and logistical schemes for the formalisation and control of the cross-border transit of goods and people, including the signing of bilateral or sub-regional agreements.

- Harmonising customs legislation and practices, including the adoption of the Revised Kyoto Convention on the Simplification and Harmonisation of Customs procedures, and improving coordination between law enforcement agencies at cross-border checkpoints. ${ }^{11}$

International trade negotiations - Joining the multilateral trade system (MTS) can sometimes trigger a boom in foreign direct investment (FDI), as in the case of Viet Nam, WTO's newest, 150th member. Indeed, largely as a consequence of WTO accession by the end of 2006, FDI in Viet Nam may reach an all-time yearly high of US\$ 8.27 billion. However, it is important to reflect that Viet Nam applied for membership in January 1995 and that the Russian Federation which applied in June 1993 is still on the waiting list. In other words, the WTO accession process is long, complicated and demands human talents which are seldom within the easy reach of an LDC. Although Afghanistan applied for membership to the WTO in November 2004 , together with Iraq, it is unlikely that there will be major progress about it in the near future, the Afghan government being expected to submit the required Memorandum on the Foreign Trade Regime of the country to the working party established for accession discussions by mid-2007. ${ }^{12}$

Afghanistan may also conclude bilateral trade agreements with Germany, Turkey, Uzbekistan and the United States, after having negotiated investment agreements with them; become a party to the South Asia Free Trade Agreement (SAFTA) of 2004, after having joined the South Asian Association for Regional Cooperation (SAARC) in November 2005; and adhere to the Global System of Trade Preferences among Developing Countries initiative, among other available options. In each case, the Afghan government and its business community will have to make a cost-benefit analysis and determine which paths constitute a priority, allocate scarce human resources accordingly, and discard those options that will not produce quantifiable results in the medium-run.

\section{Standards and certification}

Largely as a result of the Uruguay Round of multilateral trade negotiations (MTNs) concluded in 1994, import and export duties and quantitative restrictions (such as quotas and import licences) have been drastically reduced or eliminated altogether in a number of countries. Afghanistan, for instance, now has a six-band structure for advalorem tariffs, with a maximum rate of 16 percent. ${ }^{13}$ This has shifted the attention of policymakers and producers to issues like product and process standards, technical regulations and trade facilitation. Standards and technical regulations mostly apply to the mitigation of health and environmental risks but also to prevent deceptive practices, by advancing benchmarks for quality, safety, authenticity, good practices, sustainability, traceability, and the like. It is true that their costs of implementation can break the back of many an Afghan SME, but the World Trade Organization has adopted two such multilateral agreements and ultimately Afghanistan will have to adhere to them upon accession - no matter the leeway for implementation granted to LDCs. Afghanistan is a member of the organisations that promote health-related standards: the Food and Agriculture Organization, the World Organisation for Animal Health and the

World Health Organization. ${ }^{14}$

In this context, many Afghan products are technologically handicapped and its industries, short of the mark to compete in international markets. This was the raison d'être for the establishment, with the support of the World Bank's International Development Association (IDA), the United Nations Office for Project Services (UNOPS) and the United Nations Industrial Development Organization (UNIDO), of the Afghanistan National Standardization Authority (ANSA) in 2005. Although not yet fully operational, the initiative is in execution under the framework of the Emergency Customs

Modernization and Trade Facilitation Project in Afghanistan (ECMTF). ${ }^{15}$

This is an incremental and continuing process that is costly to both the public and private sectors of Afghanistan. However, facing no other choice, the expectation is that Afghan entrepreneurs will understand the relevance of these efforts when exposed to the business opportunities that they miss because of non-compliance and that can open to them upon compliance. Awareness-raising and capacity building can be accelerated through national membership to dedicated organisations, 
like the Asian Productivity Organization (APO), ${ }^{10}$ For example, some LDCs in the region boast frontline SMEs that have cleaved their way into intermational value chains and the humanitarian and development procurement of sovereign donors, IOs, IGOs and NGOs, some in medium-to-high valueadded sectors such as generic and brand-named drugs, food and beyerages, and construction materials. $^{17}$

\section{Box 2: CSR-compliant products}

An impressive and growing number of consumers in leading $O E C D$ countries are reportedly prepared to pay a premium for CSR-compliant products, especially identified as such. This is a new development, bound for kindling non-tariff barrier (NTB) claims from developing countries but unlikely to go away. This can also be seen as an opportunity. For instance, the RugMark programme, which currently covers India, Nepal and Pakistan, could be extended to Afghanistan, the fourth largest producer in the world. By agreeing to adhere to RugMark's child labour guidelines, manufacturers receive the right to put the RugMark label on their carpets, thus opening the door to the procurement of large department store chains in Europe and North America. www.rugmark.com

In a world where consumer whims rule, customer satisfaction has become the litmus test for the production and delivery of goods and services. Firms need to be concerned not only about the price and quality of what they offer in the marketplace, but also about design, packaging and the differentiation of their brands. An increasing number of consumers are worried about production processes along international value chains not only out of personal health and safety considerations, but also with respect to the observance of labour and human rights, environmental conservation and the control of corrupt practices in developing countries.

\section{Other}

From a practical viewpoint, once a consensus is reached on the main impediments to PSD and SME development, and their ranking of priority, it is necessary to set up a procedure for the:

- Reporting on impediments and the operation of action mechanisms to deal with impediments

- Ongoing identification of new impediments and the monitoring of old ones

- Identification of best practices in support programmes for SMEs and PSD
- Gathering and elaboration of information on markets, products and services so that entrepreneurs can spot opportunities and act upon them

- Monitoring of the labour intensity of public policy (and of publicly subsidised or guaranteed private endeavours) to prevent "jobless growth"-a constant peril in an economy more prone to wealth circulation than production like that of Afghanistan. $^{18}$

To accelerate progress in SME development, an ad hoc organisation needs to be established to provide direction, vision and coordination of efforts. The structure should be a combination of public-private responsibilities, very much like the AISA model, and once the trade facilitation project in Afghanistan with UNCTAD, UNOPS and UNIDO reaches a more advanced stage, with the resulting National Trade and Transport Facilitation Committee (NTTFC).

\section{SUMMARY OF RECOMMENDATIONS}

The following recommendations point to priority interventions in the public, private and civil society spheres:

\section{Taxes, tariffs and customs}

1. Promote a moratorium to year 2020 in favour of SMEs with respect to corporate tax compliance and trade liberalisation, as defined in a specific enabling regime.

\section{Land registration}

2. Strengthen and expand land titling initiatives as a pre-requisite for investments and privatisations.

\section{Skills and knowledge development}

3. Promote the gathering and elaboration of information on promising markets, products and services so that SMEs can spot opportunities and act upon them.

4. Establish a repository of good practices for SME development that have been successfully applied in other developing countries, especially in central, south, southeast and eastern Asia.

5. Raise the awareness of the business community and civil society about capacity building in SME development, including programmes to mitigate 
risk, monitor the labour intensity of public policy, develop flexible financial markets and facilitate access to data banks for trade promotion.

6. Create mechanisms for mutual information exchange and coordinated dialogue among key actors in technical assistance and capacity building in Afghanistan.

7. Establish close South-South cooperation with highly advanced trading countries in the Asian region, like Singapore and Malaysia, to speed up the process of skills development in trade facilitation in Afghanistan.

\section{Trade promotion}

8. Aim for harmonising customs legislation and practices in central and south Asia, including the adoption of the Revised Kyoto Convention, and improve coordination between law enforcement agencies at cross-border checkpoints.

9. Develop funding and logistical schemes for the formalisation and control of the cross-border transit of goods and people, including the signing of bilateral or sub-regional agreements.

10. Reach agreement on multi-year power trading arrangements in the region and accelerate the development of transmission facilities and regional energy markets.

\section{Standards and certification}

11. Join organisations and tap resources that can add value to product research, development, production, packaging, design and marketing, like the Asian Productivity Organization.

12. Raise awareness on product and process standards and technical regulations as well as on the business opportunities that are missed because of non-compliance.

\section{Other}

13. Enact framework legislation fostering an enabling environment for SME development, including the scaling up of assisted financing to serve specific SME needs, in line with existing multi-stakeholder initiatives.

14. Create a mechanism for the ongoing identification of impediments to SME development, and for the identification and operationalisation of best practices in support programmes for SMEs.

15. Adopt an incremental, "bottom up" approach for key production and trading sectors, like dried fruits, carpets and light machinery.

16. Establish an ad hoc organisation to provide direction, vision and coordination of SMEdevelopment efforts, including the set up of a virtual single window for trade, investment, technology and tourism. This should encompass easy access to relevant information by traders, investors, sectoral experts, service providers and the public at large.

\section{Case study 3: Carving a scalable niche in humanitarian and development procurement}

It is estimated that traditional donors, IOs, IGOs and NGOs procure goods and services worldwide in excess of USS 100 billion per annum. The UN system alone procured US\$ 8.3 billion for operational activities in 2005, including technical cooperation, humanitarian assistance and peacekeeping operations. It is extremely difficult to anticipate demand in this market as it largely depends on imponderable natural and man-made calamities and the aid agencies' procurement officials' rule-of-thumb projections. In other words, personal contact with procurement officials of key organisations is critical to penetration. Above all, firms in cooperation with their governments need to develop a long-term strategy that works in this highly competitive and politicised environment.

Since January 2006, the Canadian NGO Peace Dividend Trust has been operating the Peace Dividend Marketplace project in Afghanistan, with support from CIDA, DFID and USAID. It has implemented an online procurement directory that already includes 2,600 registered Afghan suppliers and producers of goods and services, including seeds, dairy products, handicrafts and business-related services. Due to these screening, divulging and matchmaking efforts geared toward Buying Afghan, in October 2006, the U.S. forces in Afghanistan awarded Afghan Beverage Industries (the local subsidiary of a Dubai company that employs more than 300 nationals) a contract worth over US\$ 600,000 per month to provide bottled water to Coalition troops throughout the country. It is a promising first step given the fact that total water purchases for the Coalition forces reach as much as US\$ 58 million a year, 
The investment climate in Afghanistan 2005.

${ }^{2}$ Global corruption report 2006, Afghanistan Competitiveness Project 2005, Kaufmann, Kraay and Mastruzzi 2006.

${ }^{3}$ The paper adheres to the tenets of UNDP's Unleashing entrepreneurship 2004 report as applicable to the Afghan milieu, including that the private sector can help alleviate poverty in Afghanistan by contributing to economic growth, job creation and poor people's incomes as well as by empowering the poor to acquire more products and services at affordable prices (bottom-of-the-pyramid markets); that Afghan SMEs can be engines of job creation; and that the primary responsibility for achieving growth and equitable socio-economic development ultimately lies with the Afghan people, including creating the conditions for mustering financial capital for productive investment.

${ }_{4}^{4}$ According to Afghan entrepreneurs, Iranian and Pakistani businesses even resort to dumping with the discernible aim of keeping the Afghan markets captive. The assertion is very serious, widespread, requires empirical corroboration by an independent party, and should be the subject of regional and international discussions if proved correct.

${ }^{5}$ Wily 2004; http://www.Itera.org/

${ }^{6}$ Scanning refers to the gathering and elaboration of information on markets, national and international, and determining the focus for production and marketing. OECD-APEC 2006.

${ }^{7}$ Most merchandise-exporting SMEs are surprisingly small, usually having fewer than 20 employees, even in developed countries. OECD-APEC 2006; Etemad and Wright 2003; Asia-Pacific human development report 2006; The investment climate in Afghanistan 2005.

${ }^{k}$ According to Da Afghanistan Bank (2006), almost three-quarters of Afghanistan's imports in 2005 originated in the CIS (20.79 percent), Japan (17.99), Pakistan (15.17), China (12.12), the EU (3.61) and India (2.96) while almost 80 percent of Afghanistan's exports in 2005 had as destinations Pakistan (67.84), India (6.04), the CIS (3.17) and the EU (1.05).

"That promoting the export of Buzkashi horses has not occurred to foreigners does not mean that diligent central Asian entrepreneurs have not pursued it for generations. The question is how to give it a branding of international cachet. Buzkashi is not only the national sport of Afghanistan and the Kyrgyz Republic but also an immensely popular entertainment within the wider Central Asian region, Pato-horseball -the national sport of Argentina and Uruguay, which is astonishingly similar to Buzkashi - is now professionally played in Argentina, Brazil, Canada, a number of European countries and the United States. Furthermore, it is the polo pony horses of Argentina, Uruguay and Brazil which supply their horses, the product of over a 100 years' specialised breeding, to the top polo and pato tournaments of the world.

${ }^{10} \mathrm{http}: / / \mathrm{www}$.adb.org/Documents/TARs/AFG/

\section{i39571-AFG-TAR.pdf;}

http://www.commerce.gov.af/UNCTAD.asp;

http://www.asycuda.org/asycom/wnfiles/AFG\%20-

$\% 20$ Coord\%20Mission.pdf: Central Asia; increasing gains from Irade 2006.

${ }^{11}$ Members to the Revised Kyoto Convention in the region are: Azerbaijan, China, India, Japan, Korea, Mongolia, Pakistan, Sri Lanka and Turkey. http://www.wcoomd org/ie/en/Topics_Issues/Facilitation CustomsProcedures/Kyoto_New/Content/content.html:

${ }^{12}$ WTO's country webpage http://www.wto.org/english/thewto_e/acc e/a1 afghanist an e.htm. Central Asia: increasing gains from trade 2006.

${ }^{13}$ The investment climate in Afghanistan 2005.

${ }^{14}$ The Standards and Trade Development Facility (STDF), a financing and a coordinating mechanism introduced in 2004 by the World Bank, is a global programme in capacity building and technical assistance to support developing countries in the implementation of international sanitary and phyto-sanitary measures established by FAO, OIE, WHO, WB and WTO to improve human, animal and plant health conditions. The WTO Secretariat administers the STDF trust fund that finances the programme.

http://www.wto.org/english/thewto_e/whatis e/tif_e/agr

m4_e.htm, http://www.standardsfacility.org/

${ }^{15}$ The investment climate in Afghanistan 2005. http://Www.commerce.gov.af/pdf/ANSA $\% 20$ newsletter $\%$ 20 Sept $\% 202005$.pdf

${ }^{16} \mathrm{APO}$, a regional intergovernmental organisation headquartered in Tokyo that is open to UNESCAP members, like Afghanistan, and has Bangladesh, Cambodia, Iran, Mongolia, Nepal and Pakistan among them. http://www.apotokyo.org/

01about_conv.htm

${ }^{17}$ http://www.procurementdirectory.af/index.phphttp://w ww.e-ariana.com/ariana/eariana.nsf/ be77f8366cbd693387256b790077eldf/913del3582f24bf d87257203003dad7f? OpenDocument

${ }^{18}$ Asia-Pacific human development report 2006. 

THE ENABLING ENVIRONMENT CONFERENCE

Effective Private Sector Contribution to Development in Afghanistan

\section{CHALLENGES OF ACCESS TO FINANCIAL SERVICES}

Background paper prepared for the Enabling Environment Conference by:

The World Bank with Asian Development Bank

\section{INTRODUCTION}

When the Taliban regime fell in 2002, the legal framework for the financial sector in Afghanistan was essentially non-existent or inappropriate and the formal financial sector inoperative, comprising of a few largely dormant state-owned financial institutions and the central bank (DAB).

Significant progress has been made since 2002 , to introduce substantial components of the necessary legal framework for a modern financial sector, re-establish the DAB as the central bank and revitalise a financial sector capable of intermediating and supporting growth. Existing government efforts are supported by IMF, World Bank, ADB and USAID (with other donor support) and concentrate on the areas of:

- Establishing a facilitative legal framework for private sector development with a list of 10 priority laws to be approved by the Cabinet, four of which were signed by the President and submitted to the Parliament in January 2007.

- Strengthening the supervisory framework for financial institutions with the aims of improving deposit protection and confidence in the financial system, and enhancing the private sector's access to finance. This includes reforms of the banking sector, the bulk of which is scheduled to be implemented by the end of 2008 ; as well as the introduction of regulations of the microfinance sectors by the end of 2006 .

- Broadening and deepening financial service delivery through building capacity in financial institutions, as well as adopting and implementing national accounting and auditing standards. Most of these measures have yet to be implemented, with a target of end of 2008 .

Overall, the major reforms of the financial sector are scheduled to be completed by the end of 2008 .

However, the outreach of financial services in Afghanistan remains very limited and medium- and small-scale businesses have almost no access to bank credit and only limited access to bank services. In the most recent Doing Business (2007) rankings for Getting Credit, a measure of credit information sharing and legal rights of borrowers and lenders, Afghanistan ranked 174th out of 175 countries.

Supplementary to the traditional informal money lenders and other credit sources, which continued to thrive during the long period of conflict, 14 commercial banks have been licensed recently to operate in Afghanistan. These are mostly concentrated in Kabul and primarily provide services to international donors and large 
businesses, foreign NGOs and foreign government agencies. There are also a small, but ever increasing number of non-bank financial institutions, including one credit union and 11 microfinance institutions which provide limited services and small amounts of credit. Furthermore, a new leasing organisation has just become active in Kabul and other areas. However, all of these institutions are nascent and able to provide only a fraction of what is needed.

As a result, Afghan firms are almost entirely reliant on internal funds and money from friends and family to fund their operations. According to the World Bank's recent Investment Climate Survey (2006) of 335 firms $^{1}$ in five major cities in Afghanistan (Kabul, Kandahar, Mazar-e-Sharif, Jalalabad and Herat), only three firms reported having bank credit for new investment, and on average nearly 94 percent of new investment by firms was funded by either internal funds or money from family and friends (Table 1). Remittances are also important, and on average funds from family and friends outside of Afghanistan financed three percent of investment.

\begin{tabular}{|c|c|c|c|c|c|}
\hline $\begin{array}{l}\text { Internal } \\
\text { Funds or } \\
\text { Retained } \\
\text { Eamings }\end{array}$ & $\begin{array}{l}\text { Family } \\
\text { and } \\
\text { Friends } \\
\text { Domestic }\end{array}$ & $\begin{array}{l}\text { Family } \\
\text { and } \\
\text { Friends } \\
\text { Abroad }\end{array}$ & $\begin{array}{l}\text { Bank } \\
\text { Credit }\end{array}$ & Other & $\begin{array}{l}\text { New } \\
\text { Equity }\end{array}$ \\
\hline 78 & 13 & 3 & I & 2.5 & 2,5 \\
\hline
\end{tabular}

Most businesses rely on informal funds transfer systems (hawala) to make payments and transfer funds. Only 30 percent of the sample reported having a bank account. More than 10 percent of domestic customers and over 14 percent of foreign customers usually pay through money exchange dealers. Remarkably, hawala transfers for foreign trade appear to be more than or at least as efficient as bank transfers. Nearly 21 percent of firms in the survey reported having a loan from a hawaladar with an average term of 3.8 months.

Though informal financial sector credit may be adequate for subsistence commercial activities, it is not adequate for long-term private sector development. There is therefore a pressing need for bank and non-bank financial institutions to provide viable alternatives to the informal sector. As the economy grows, the inability of firms to obtain external finance will become a crippling constraint to growth.
This background paper reviews the recent financial sector reforms in Afghanistan and considers the successes that have been achieved against the weaknesses that remain. The paper has a particular focus on:

- the key constraints to increasing access to financial services for enterprises today;

- the impact of these constraints on the private sector; and

- recommendations for further strengthening the enabling environment for the expansion of financial services, especially increasing access for SMEs.

The paper concludes that while some considerable advances have been made with respect to basic legislation, some central banking reform, the introduction of a new currency, and the beginnings of a microfinance sector, much still remains to be done.

In order to provide much broader financial services to a wider range of economic agents, the paper recommends that there is a need for a radical rethink about the way the financial sector operates in Afghanistan.

\section{CONSTRAINTS TO ACCESS TO FINANCIAL SERVICES}

Following 25 years of stagnation and decline, the Afghan financial sector is in fact a "young" financial sector. Principles of openness and transparency, with sound regulation and supervision, have been notionally adopted, but much remains to be done to see the development of a deeper and more inclusive financial sector.

The key issues responsible for limiting access to financial services for the private sector can be summarised as follows:

- There is a lack of an overall Government vision for the financial sector which would both spell out the main objectives, policies, components, instruments of financial sector development and actors whose involvement is envisaged, and would also propose an overall action plan set against a timeline. Understanding of the workings of a modern financial sector and of the corresponding roles and responsibilities needs to be strengthened.

- The past history of state involvement in banking, including subsidised lending, has affected the credit culture in the country. The re-licensed state banks are yet to be restructured and the unlicensed banks yet to be liquidated. 
- The establishment of the legal framework is ongoing. The development and implementation of key components of a modern legal framework for commercial and financial transactions - with supporting legal infrastructure and judiciary - have yet to be completed. Central bank authorities have not yet developed a supportive attitude toward financial institutions, and at the same time, enforcement capacity is also still in its formative stages.

- Financial institutions lack institutional capacity to deliver financial services. Banks lack capacity for management, credit risk management and basic operations. Skills and experiences in the financial sector are lacking at every level.

- Lending is limited by the poor creditworthiness of enterprises themselves, or the inability to demonstrate credit-worthiness (lacking documentation and financial histories, as well as collateral). Without accounting and auditing standards and credit evaluation mechanisms, the creditworthiness of entrepreneurs with financial records can not easily be evaluated. Banks perceive a shortage of bankable propositions. The lack of a secured transaction law and poor property registries add to the extreme difficulties for borrowers to provide the necessary security.

- Low household savings, poor financial infrastructures (including a national payment system), low integration with complementary markets, and high costs of service provision (particularly in rural areas) make it difficult to provide formal financial services.

- The financial sector has little intermediation among institutions across the sector. Access to "clean" financial resources to fund the expansion of financial institutions is lacking.

- The range of financial products offered is limited. However, product development is expected to follow in the wake of the strengthening of the legal and regulatory framework; and of the capacity of financial institutions to develop, introduce and manage a broader range of services. In particular, Afghan firms are faced with the almost complete absence of insurance. Many managers and potential investors have cited the lack of insurance as a major reason that they are hesitating to invest.

Many issues stem from the lack of understanding, experience and the capacity of institutions at all levels. Dialogue and capacity building need to accompany the development of the legal and regulatory framework, the disengagement of the State in financial intermediation and the development of institutions and financial markets.

\section{THE LEGAL AND \\ INSTITUTIONAL FRAMEWORK FOR FINANCIAL SERVICES: ISSUES AND RECOMMENDATIONS}

\section{The legal framework}

The absence of a clear legal framework for commercial activity and financial transactions compounds the high level of uncertainty and risk for investors and entrepreneurs in Afghanistan. There has been progress in the investment framework, with a new investment law enacted in December 2005, which replaced the investment law promulgated in 2002. However, many of the other existing laws relevant for private sector and financial sector development are outdated, in some cases dating as far back as the earlier monarchy. Other existing laws were drafted as part of the framework for the then centrally planned economy.

While a full amendment of the existing commercial code is planned, it is urgent to prioritise the enactment of the core set of basic commercial and financial laws which will facilitate the commercial activities and financial transactions, particularly, the laws pertaining to the setting up of business enterprises, governing accounting and auditing standards, strengthening corporate governance, settling disputes and allowing orderly insolvency procedures. A basic legal foundation for investment, and the establishment and operation of businesses, is critical to providing investors, particularly foreign investors, with sufficient confidence that their investments will be protected under laws that are in accordance with international standards. Moreover, the enactment of priority commercial legislation is clearly important and urgently needed to attract investment, encourage ntrepreneurship and promote the development of private enterprises.

\section{Existing Commitments}

- Various Ministries and the private sector have respectively identified their priority list of commercial laws ${ }^{2}$ - all of which are in the advanced state of preparation. Four laws, namely, Corporation Law, Partnership Law, Mediation Law and Commercial Arbitration Law were signed by the President and submitted to the Parliament in January 2007. 


\section{Constraints}

- Constraints to expediting the process are the absence of an approved prioritised legislative reform agenda; limited capacity for finalising the drafting and translation of the proposed laws; and an urgent need for a more streamlined, transparent and accountable legislative review and approval process.

\section{Recommendations}

- Prioritise the enactment of the core set of basic commercial and financial laws, and fast-track the enactment of the most vital legislation.

\section{Regulation and Supervision: Da Afghanistan Bank (DAB)}

The central bank has made tremendous progress in re-establishing itself and taking on appropriate monetary and supervisory roles. Since the successful introduction of a new currency in January 2003, and the passing of the central bank law in September the same year, DAB has embarked on a process of capacity building that has restored rudimentary monetary and supervisory functions. The inflation rate and the exchange rate have both been reasonably stable over the last few years. However, with respect to access to finance, the agenda remains substantial in three respects:

- Central Bank Branches: DAB has 75 branches, 14 of which are in $\mathrm{Kabul}^{3}$ - the vast majority of which provide commercial banking services. To have a more effective Central Bank - as well as more enhanced, countrywide, commercial banking services throughout Afghanistan - these commercial branches need to be spun off to a commercial bank. ${ }^{4}$ Indeed, there does appear to be a commitment from DAB to spin off these branches. However, it would be of considerable benefit if this could be done sooner rather than later with a well established timeline for divestment (to the extent that this is possible). This would have the twin benefits of ensuring that DAB only focuses on its core central banking functions, and that a commercial bank (DAB branches transferred to a merged Pashtany/Millie or auctioned off to a private sector bank) has a reasonable branch banking network to cover all of the provinces.

- Prudential regulation and supervision: DAB continues to strengthen its regulatory and supervisory role, especially in the face of the more aggressive banking being displayed by some of the new local banks which are using their experience with the informal hawala network to their great advantage. Ensuring that $\mathrm{DAB}$ has the appropriate capacities to oversee and properly regulate such institutions from a bank regulatory (as well as an AML-CTF) perspective, will be exceedingly important going forward, and should be an area of emphasis of donor support.

- Leadership of the DAB in Building an Inclusive Financial Sector: In a situation where it is critical that all efforts are aimed at fostering the development of an active financial system, it is important that the central bank adopt a supportive attitude, one that encourages private investors to invest in financial institutions. In addition, there needs to be a comprehensive financial strategic plan, which will also support the strong leadership of the DAB in building an inclusive financial sector. Concerns have been expressed that the central bank has often displayed mistrust toward commercial banks and that an open dialogue is lacking. To increase both financial sustainability and outreach, there is an opportunity for the DAB to adopt a stance in favour of both strong prudential regulation and supervision, while at the same time facilitating the entry of new players as well as encouraging existing ones.

\section{Existing Commitments}

- By December 2009, DAB will have substantially strengthened its supervision of banks to improve deposit protection and confidence in the financial sector, and enable the sector to provide greater access and a wider range of services to the private sector. Specifics include more stringent and accountable/transparent on-site examinations; strengthened cross border supervision and standard MOUs for cross border supervision protocols; defined minimum risk management requirements and internal control procedures; uniform bank performance reports and a system for tracking enforcement actions; and standard FI audit requirements and publishing of FI audited financial statements.

- By December 2008, a regulatory and supervisory framework for non-bank financial services including informal financial sector and microfinance will be in place.

\section{Recommendations}

- Develop a comprehensive financial sector strategy - with a specific action plan set against a timeline that contains a clear vision statement for the building of an inclusive financial sector, and spells out the main objectives, policies, components, instruments and governed institutions.

- Pursue strengthening the legal, regulatory and supervisory framework of DAB for financial 
institutions. At the same time, ensure that DAB has the appropriate capacities to oversee and properly regulate the range of licensed institutions from a bank regulatory as well as an AML-CTF perspective.

- Set a firm timetable and pursue the spin-off of the commercial activity and branches of the DAB to a commercial bank within 12 months.

- Establish a mechanism to foster dialogue among stakeholders in the financial sectors to reinforce the mutual understanding of roles and responsibilities.

\section{FINANCIAL INSTITUTIONS}

\section{State-owned and private commercial banks}

\section{Afghanistan has a very old banking tradition} oriented toward the private sector. Bank Millie, Afghanistan's first private bank, was established in 1933; and the second, Pashtany Terjaraty Bank (PTB), in 1955. It was only in the 1970s that the State, under the Daoud government, took an ownership interest in both financial institutions. PTB was nationalised in 1974, and Bank Millie in 1976. During the 1970 s the government also established two development banks: Industrial Development Bank (1973) and Export Promotion Bank (1975), in addition to the Agricultural Development Bank (1954).

By December 2001, however, all these state-owned banks were plagued by the same problems as the central bank - weak corporate governance and management structures, unskilled human resources, outdated technological capacity and accounting systems, and grave liquidity and solvency problems. The first financial assessment of the banks conducted in January 2003 concluded that all the banks were in dire financial condition.

Today, following substantial financial sector reforms, basic commercial banking services are available in Afghanistan. Although there are now 14 banks licensed to operate in the country, most are concentrated in Kabul and provide services primarily to international donors and large businesses, foreign NGOs and foreign government agencies. The new private banks have not yet started lending to industry, and it appears that at least some of them will not be inclined to do so in the near future, especially to rural communities. Commercial banks do not really provide a "countrywide" banking service throughout Afghanistan. Therefore, access to finance remains severely impeded in many regions in Afghanistan.
State financial institutions are largely nonfunctional. With the enactment of the new commercial banking law in September 2003, the Central Bank re-licensed three state banks i.e., Bank Pashtany, Bank Millie and the Export Promotion Bank. The remaining state banks were slated for liquidation. Since then, however, little progress has been made in resolving the stateowned banks and in restructuring the licensed stateowned banks.

\section{Box 1. Restructuring of state-owned banks}

Lessons learned from the restructuring of state-owned banks suggest that five conditions must exist:

- Access to an underserved market plus untapped demand sufficient to support the restructured bank

- Adequate funds (sufficient starting capital and government support)

- Strong political support and protection

- International support (in these examples, support was provided by USAID and the World Bank)

- Authority of the external management team to make quick and independent decisions

The potential of state-owned banks is often undone by political interference, poor management, a weak asset base, high administrative costs, low recovery rates and poor supervision. Empirical data has consistently demonstrated that state-owned banks are associated with slower financial development, less efficient financial systems, less private credit and overall slower GDP growth. Systematic analysis of cross-country data indicates that state ownership, particularly in low-income countries, is bad for financial sector development and stability, and for economic growth.

This is largely because state ownership distorts the incentive structure necessary for efficient and sound banking. In Central and Eastern Europe, the governments spent 10 to 25 percent of GDP on several rounds of bank rehabilitation. State-owned banks not sold immediately after recapitalisation usually fell back into insolvency. Agricultural development banks, in particular, have had a difficult time remaining financially viable. Most have become insolvent, many of them several times over, and have required additional capitalisation. As a result, most of these types of banks have been dismantled (Bolivia) or allowed to go bankrupt (Banco Anglo in Costa Rica).

Recapitalisation of state-owned banks should therefore only be considered where there exists a sufficiently large market to support the restructured bank for the long term, and if it is associated with a performance-based restructuring and a privatisation timetable. The decision to attempt such reform hinges upon whether the strengths of a bank (e.g. sizable client base and untapped demand, expansive branch network, fixed assets) justify the substantial costs of technical assistance and recapitalisation. 


\section{Recommendations}

- Pursue restructuring of licensed state-owned banks, i.e. revitalisation of Bank Millie and merger of Bank Pashtany and the Export Promotion Bank, through a time-bound plan, with an explicit policy framework to assure autonomy, sound prudential standards and a level playing field with private banks. Ideally, such restructuring would be accompanied with the spinning off of the commercial banking branches of DAB.

- After appropriate rationalisation, this would yield a bank with a reasonable country-wide coverage. This bank would then need to be professionally structured and operationally and financially viable and would need to develop a business plan with a view of privatising in the medium term. Moreover, the policy framework and support for this bank should be designed in such a way that it does not undermine the development of private commercial banking.

- All banks, including the restructured state-owned banks, need to reinforce governance, management and capacity, building capacity in risk management. Institutional support for capacity building needs to be put in place immediately.

\section{Non-bank financial institutions}

The central bank's efforts have hitherto focused on the banking sector-passing the commercial banking law and subsequently, numerous prudential regulations. However, now more needs to be done to develop the non-banking sector, especially microfinance as discussed above; as well as insurance, factoring and leasing which provide opportunities for non-collateralised lending - a much needed option in conflict-affected environments.

Frequently, more effective financial competition comes from non-bank financial institutions.

Insurance: In addition to the limited access to external finance, Afghan firms are faced with the almost complete absence of insurance, which in turn constitutes a serious hindrance to the new investment and the development of enterprises and financial institutions. The insurance sector in Afghanistan is in dire straits. The sole insurance company, the Afghan National Insurance Company, is substantially undercapitalised and in a weak financial position. The Afghanistan Investment Guarantee Facility was established in 2004 to mitigate political risk for foreign direct investment to the country. Albeit suboptimal, the amendments to the Insurance Law were approved by the Cabinet and gazetted in January 2006, with many actuarial issues left out of the legal framework. The amended
Law has created an independent commission to oversee and regulate the insurance sector, and allowed private insurance companies to be established according to the Investment Law.

Factoring: A project to provide credit to farmers through agriculture input supply dealers is already underway. The International Fertilizer Development Center and Shorebank Advisory Services, supported through the USAID funded RAMP project, have begun an initiative in Kandahar to provide credit and technical assistance to privately owned agriculture input supply dealers. It is estimated that there are about 2,000 such dealers of different sizes operating throughout the country and the number is growing. The importers are more sophisticated, but there are also many smaller dealers, with 60 percent of the total number being illiterate. More could be done to expand this form of finance by encouraging banks to use their own liquidity to lend to suppliers as well.

Leasing: Leasing development is seen as important for its capacity to reach downwards to smaller borrowers, and because (within an Afghan context) it fits within Islamic principles. The Afghanistan Finance Company (a leasing company that is primarily focusing on the agriculture sector) began operations in February 2005, and is providing an important alternative to traditional formal banking finance.

\section{Recommendations}

- Develop a legal and regulatory framework and strengthen the supervisory framework for the nonbanking services including insurance, factoring and leasing. Particularly, special measures, such as further modifications of the existing insurance law, need to be taken to encourage the private sector to participate in the insurance industry.

\section{The emerging role of microfinance}

Microfinance has emerged rapidly in Afghanistan over the past four years, with support of international financial institutions and bilateral partners. There are currently 14 microfinance institutions (MFIs) including one licensed bank, 12 NGOs which are in the process of becoming Afghan companies, and one organisation that supports the development of credit unions. These institutions have been recently joined by the BRAC Afghanistan Bank, which plans to focus on the upper end SME market. The BRAC NGO has more than 60 percent of client outreach while three other organisations, the Aga Khan Rural Microfinance Programme, the First MicroFinanceBank and FINCA have most of the rest of the market. A new 
project to support the creation of more credit unions as well as farmer associations (financial cooperatives) began in late 2006

An apex institution, the Microfinance Investment and Support Facility for Afghanistan (MISFA), was created with donor support to foster the development of a robust sustainable microfinance network intended to form an integral block of the financial system. MISFA became a private company in early 2006 , governed by a Board that includes representatives from the Government and the private sector as well as international microfinance experts.

While the rate of acceleration of outreach has been good, current outreach touches only a small percentage of the demand for microfinance services in Afghanistan, estimated at three to five million clients. At the same time, there are encouraging signs that the gap at the upper end of the market between microfinance and SME financing may well be closing as some MFIs move upwards in their outreach and some SME lenders reach downwards to smaller economic players. MISFA has recently set up a new SME window to encourage this trend.

\section{Legal, regulatory and supervisory framework}

for microfinance: Afghanistan is in the process of putting into place a tiered approach to regulation. The recently published DMFI Regulations (deposit taking MFI regulations) opens the door for a structure in between "finance" companies and commercial banks. This provides a progressive regulatory environment for microfinance, although it will take some time before institutions are in a position to take full advantage of it. The new legislation also permits the mobilising of deposits by registered finance companies - which is a further important step toward ultimate sustainability within a well regulated environment.

\section{At the current time, the biggest barriers to the growth of the microfinance sector are:}

- The absence of a well articulated vision of an inclusive financial sector in Afghanistan. In particular, microfinance development has not always been well understood as part of overall financial sector development. This has resulted in conflicting visions and inconsistent government support. Partly for this reason, funding to the sector has been inadequate at this early stage of development.

- MFI capacity. In a fast growth situation, capacity will always be a constraint. This is further complicated by the growing resentment toward foreign experts (generally) and the desire for Afghans to assume management responsibility.

\section{Recommendations}

- Further develop the legal, regulatory and supervisory framework for all financial sector players to assure coherence across the range of institutions. Design the legal and incentive framework in such a way that it allows for diverse types of financial service providers while not segmenting the financial system. The aim is to have a continuum of financial entities which provides a broad range of financial services, from micro entrepreneurs and small businesses to larger enterprises.

\section{Informal Sector}

In an environment where formal financial institutions play only a very limited role particularly outside of the main urban centres - the informal financial sector in Afghanistan is one of the most extensive in the world. The hawala system - an informal sector financial service provision system in Afghanistan - has potential to act as an effective and accessible credit delivery mechanism for the following reasons:

- Coverage. Hawaladars are able to make remittance payments to most parts of the country:

- Confidence. Highly trust-based, the hawala system has provided both private and commercial institutions and individuals with financial services even during the war;

- Special Expertise. Hawaladars have various core competencies which can be of particular use in the provision of credit to small- and medium-scale enterprises. These include financial and accounting skills, technical know-how, understanding of Islamic finance, and the marketing and selling of financial products and services; and

- Financial Resources. To succeed in the remittance business, hawaladars need to maintain a cash float to meet the remittance demand of their counterparts. For many, the cash float presents an investment opportunity. Based on previous experience with the level of remittances paid, hawaladars like any other financial institutions are able to engage in profitable asset liquidity management manoeuvres.

Despite the advantages noted above, there are a number of risks. The factors responsible for raising risk concerns are the following:

- The general inaccessibility of hawaladars customer records and ambiguities in the settlement process make the hawala system vulnerable to 
abuse. There are no standard documentary requirements for conducting business in the market. Although hawaladars are subject to the central bank's money service providers' regulations (which require regular reporting on number and volume of transactions and allow onsite inspections), implementation is still in its infancy in part because of the absence of standardised documentation, which is generally considered unnecessary because of the high level of trust that exists.

- The degree to which the hawala system is used for money laundering activities in Afghanistan is difficult to document and quantify. However, the level of money laundering activities is likely to be high. It is not easy to separate legal from illicit money flows and trace financial links to criminal activities. Furthermore, law enforcement agencies are often unable to penetrate informal financial systems because of cultural and linguistic barriers and the close business or kinship ties of the participants.

- Additional constraints in Afghanistan include: (a) lack of effective monitoring of cross border currency movements; (b) new reporting requirements mandating reporting of large cash transactions under the Anti-Money Laundering Law will be difficult to enforce; (c) large parallel black market economies; and (d) limited or no ability to share financial information with foreign law enforcement authorities.

While the hawala system has played an important role and will continue to play such a role for many years, it has the potential of facilitating illegal transactions which the regulatory authorities will find hard to detect and curtail.

\section{Existing commitments}

- At the end of 2006, DAB was to approve a regulation on the registration and reporting requirement of money service providers and foreign exchange dealers. This regulation is scheduled to be implemented by the end of 2008 .

\section{Issues}

In a country like Afghanistan, where the financial sector is in the process of being re-established, it must be acknowledged that prescribing regulations alone will not ensure compliance. Regulations, especially restrictive ones, are not a panacea for possible abuse of informal systems. Experience shows that restrictive regulations will not drive out all businesses involved in unlicensed financial transfer activity from the market, but instead drive them underground.

Instead, in a country like Afghanistan, where hawala systems exist alongside a functioning conventional banking sector, it is recommended that operators be registered - as now required in the new Money Exchange Dealers regulations.

Thereafter, additional efforts should be made to improve the level of transparency by bringing the hawaladars modes of operation closer to the formal financial sector without altering their specific nature. The formal sector should tackle its deficiencies and enhance its competitiveness.

Imposing requirements on large numbers of hawaladars beyond basic registration may not be feasible because of a lack of supervisory capacity.

\section{Recommendations}

- Strengthen the registration framework of hawala dealers to minimise the risks associated with informal remittance systems as prescribed in the new Money Exchange Dealers regulations. To achieve this, the Central Bank's supervisory capacity for off-site analysis and on-site inspections will need significant technical support, In the meantime, the commercial banks' adherence to anti-money laundering guidelines should be strictly monitored.

\section{SUPPORTING FINANCIAL SECTOR INFRASTRUCTURE}

In addition to the institution-specific reform agenda discussed above, there is a need for reforms to strengthen the overall financial sector infrastructure for financial transactions, notably in four areas:

- Accounting and audit standards and practices

- Financial sector skills training facilities

- Credit Information Bureau (CIB)

- National payment system

\section{Accounting and audit standards and practices}

There is a pressing need to establish an active accounting and auditing profession in the country. Presently, there are no national accounting standards or an organised profession to improve the quality of account records and auditing practices. There is urgent need to support the creation of an accounting standards board and an Accountants 
Association of Afghanistan. The objectives of the Accounting Board would be to issue new accounting standards, and in time to amend existing ones, in response to evolving business practices, new economic developments and deficiencies being identified in current practice. More importantly, as Afghanistan reintegrates itself with the international economic community, it could work with the International Accounting Standards Board (IASB) to improve the acceptability of Afghanistan accounting practices by international investors.

\section{Existing commitments}

- By the end of 2008, an accounting and auditing law in accordance with the international financial reporting standards and the international standards of auditing will be in place. Within the same timeline, the MoF will establish an Accounting and Auditing Board.

\section{Financial sector skills training facilities}

There is immediate demand for an institute that improves the skills available in the financial sector. While some individual banks are developing their own programmes, this is inadequate to meet the national need. The training institute needs to aim at improving human resources of financial institutions by: (i) upgrading the skills, knowledge and abilities of managers and administrators; (ii) providing the developing banking system with qualified professionals; (iii) promoting discussions among policymakers on development financing issues which are critical to national development; and (iv) conducting, encouraging and promoting research in related areas.

\section{Existing commitments}

$\mathrm{DAB}$ and the Bankers Association will establish a bankers' education and accreditation programme, which will start to offer courses to commercial bank personnel by the end of 2008 .

\section{Credit Information Bureau (CIB)}

Financial institutions have expressed interest in a basic mechanism for gathering, processing and storing information on the payment behaviour of businesses and consumers, which could be used by creditors for their own risk assessments. A study funded by USAID found that: the majority of banks and all MFIs support the creation of a CIB and say that they are willing to share their debtor information. $\mathrm{DAB}$ is supportive of the idea in principle; the demand for loans and credit information is growing fast in rural areas, soon in urban areas, and technical assistance from donors is available to get a basic CIB started.

\section{National payment system}

The development of financial services for the private sector can hardly be achieved without a well-designed payment system. The lack of a formally functioning payments system for international and domestic funds transfers in Afghanistan not only has been a major obstacle to the timely and effective delivery of reconstruction assistance, but has also resulted in inefficient use of financial resources and loss of confidence in the financial system. An efficient and effective national payment system is indeed one of the key reform challenges for Afghanistan.

\section{Recommendations}

The provision of these four supporting financial infrastructures to the financial sector, though challenging in a conflict affected environment, is essential for the growth of the financial sector. It will require a clear and strong buy-in from the financial sector and the Government, as well as adequate investment in staff training, and computer software and hardware for these four financial infrastructures. Specifically:

- Pursue commitments to the development of accounting and audit standards and build institutional capacity for banking training.

- Support the process of establishing a credit information bureau recognising that this will take place over a period of two to three years in line with the development of the financial sector. There are still some challenges that need to be addressed but they can in part be addressed through the proposed project. These challenges include the need for a special CIB law, a data protection law and amendments to existing bank laws; strengthening the accounting standards or appropriate legal/regulatory framework; the use of a unique identifier for individuals; and providing the appropriate IT structure.

- Develop a "national payment system development strategic plan", which will set out a comprehensive and detailed strategy and action plan. Given the nature of complexity and current rudimentary stage of the payment system in Afghanistan, DAB can phase in the physical development of a national payment system, starting with basic check clearing and money transfer coupled with the balanced sysiem upgrade among FIs. It could then move on to a more complex payment system with advanced IT applications. 


\section{CONCLUSION}

The Government of Afghanistan must be credited with the achievements attained in reforming the financial sector over the last three years. Compared with conditions in December 2001 - an outdated legal framework, no functioning commercial banks, a handful of NGOs competing with a vibrant informal financial sector - a basic formal financial system has slowly emerged.

The Government continues to implement a substantial reform agenda which will considerably improve access to finance within the next three years. In support of and in addition to the existing commitments, the following set of recommendations is being proposed:

1. In the short term, within 12 months, the government should give the top priority to: (i) the development of a comprehensive financial sector strategy; (ii) the spin-off of the commercial banking branches of DAB; and (iii) restructuring of stateowned banks with an explicit policy framework.

2. In the medium term, it will be necessary to strengthen the legal, regulatory and supervisory framework for both the banking and non-banking sector, to improve the govemance structures, and to enhance the registration framework and reporting requirements for the informal financial sector. These measures are required to ensure stable and transparent financial operations, and sustainable growth in the financial sector.

3. The long-term financial sector reform agenda should aim at enhancing the quality of the financial sector infrastructure. Given the complexity and importance of the financial sector infrastructure, it is recommended that the government and the DAB design a holistic approach involving clearly defined phases to develop accounting and audit standards, a CIB and a national payment system. 


\section{Table 2: The set of proposed recommendations}

Recommendations

Timeline Responsible (months) agencies $\begin{array}{llll}\text { I Develop a comprehensive financial strategy with a clear vision statement for the building of } & 6 & \text { MoF } \\ \text { an inclusive financial sector, which would spell out the main objectives, policies, } & \text { DAB }\end{array}$ components, instruments and governed institutions with a specific action plan set against a timeline.

\begin{tabular}{|c|c|c|c|}
\hline 2 & Pursue the spin-off of the commercial branches of the DAB to a commercial bank. & 12 & DAB \\
\hline 3 & $\begin{array}{l}\text { Pursue restructuring of state-owned banks through a time-bound plan with an explicit policy } \\
\text { framework. }\end{array}$ & 12 & $\begin{array}{l}\text { MoF } \\
\text { DAB }\end{array}$ \\
\hline 4 & $\begin{array}{l}\text { Pursue the strengthening of the legal, regulatory and supervisory framework of DAB for } \\
\text { financial institutions. At the same time, ensure that DAB has the appropriate capacities to } \\
\text { oversee and properly regulate the range of licensed institutions from a bank regulatory as } \\
\text { well as an AML-CTF perspective. } \\
\text { Improve the dialogue and trust between the DAB and financial institutions. }\end{array}$ & 15 & DAB \\
\hline 5 & $\begin{array}{l}\text { Prioritise the enactment of the core set of basic commercial and financial laws and fast-track } \\
\text { the enactment of the most vital legislation. }\end{array}$ & 15 & $\begin{array}{l}\mathrm{MOCl} \\
\text { MoJ } \\
\text { DAB } \\
\end{array}$ \\
\hline 6 & $\begin{array}{l}\text { Strengthen the registration framework of hawala dealers to minimise the risks associated } \\
\text { with informal remittance systems. }\end{array}$ & 15 & DAB \\
\hline 7 & $\begin{array}{l}\text { All banks, including the restructured state-owned banks, need to reinforce governance, } \\
\text { management and capacity, building capacity in risk management. Institutional support for } \\
\text { capacity building needs to be put in place immediately. }\end{array}$ & 18 & $\begin{array}{l}\text { DAB } \\
\text { FIs }\end{array}$ \\
\hline 8 & $\begin{array}{l}\text { Build upon the framework created by the DMFI regulations to further develop and } \\
\text { strengthen the legal and regulatory framework as well as strengthen the supervision for non- } \\
\text { banking services, including insurance, credit unions, cooperatives, factoring and leasing. }\end{array}$ & 18 & $\begin{array}{l}\text { MoJ } \\
\mathrm{DAB}\end{array}$ \\
\hline 9 & $\begin{array}{l}\text { Pursue commitments to the development of accounting and audit standards and to build } \\
\text { institutional capacity for banking training. }\end{array}$ & 24 & DAB \\
\hline 10 & $\begin{array}{l}\text { Support the process of establishing a credit information bureau recognising that this will } \\
\text { take place over a period of two to three years in line with the development of the financial } \\
\text { sector. }\end{array}$ & 24 & $\begin{array}{l}\text { DAB } \\
\text { FIs }\end{array}$ \\
\hline 11 & $\begin{array}{l}\text { Develop a "national payment system development strategic plan", which will set out a } \\
\text { comprehensive and detailed strategy and action plan. Based on this strategic plan, phase in } \\
\text { the physical development of a national payment system. }\end{array}$ & 24 & $\begin{array}{l}\text { DAB } \\
\text { FIs }\end{array}$ \\
\hline
\end{tabular}

\footnotetext{
'The sample was drawn from manufacturing, transportation, wholesale and trade, and other service sector firms. Financial institutions, consulting companies and security companies were not included.

2The consolidated list exceeds 30 laws.

${ }^{3} \mathrm{http}: / / \mathrm{www}$.centralbank.gov af/branches-dab.asp

${ }^{4}$ The Central Bank law allows the central bank to operate branches in regions where no private banking services are available.
} 



\title{
LACK OF HUMAN CAPACITY IN THE PUBLIC AND PRIVATE SECTORS
}

Background paper prepared for the Enabling Environment Conference by:

\author{
Dr. Sarah Lister \\ Consultant
}

\section{INTRODUCTION}

A lack of human capacity ${ }^{1}$ is a major challenge as Afghanistan recovers from years of civil strife, with most individuals having lost years of opportunities for education, and vocational and professional training. An important component of establishing an enabling environment for the growth of the private sector is ensuring the provision of education, and vocational and professional training.

There is widespread agreement that the private and public sectors in Afghanistan mostly lack the capacity to support private sector development and growth. However, there is relatively little systematic information, beyond anecdote, as to where the greatest skills deficits lie and which issues should be addressed as priorities. This paper will look at what we know about capacity issues at two levels: (a) the enterprise level and (b) the capacity of Government to put in place an enabling environment for private initiative.

The paper makes the following key points:

- The low level of skills and education in Afghanistan's workforce damages productivity and competitiveness, hence reducing growth and employment opportunities.
- There is a critical need for improved labour market information, based on analysis of the sources and trajectories of economic growth. This information will likely come from both training institutions and centralised mechanisms.

- Training activities (whether provided by NGOs, private sector or Government) need to be better linked to the labour market, and appropriately regulated and accredited.

- Government and the private sector should further explore creative arrangements to draw on the resources of the private sector, especially international business, in skills development.

- The ability of government officials to support the private sector is limited and the need for such support is often poorly understood. Capacitybuilding initiatives for the civil service have generally been slow to show results, and attention is also required to ensure that the specific skills needed to support the private sector are developed. This will require increased attention to the Public Administration Reform (PAR) process, including improved political leadership.

- Government and donors should urgently review how Technical Assistance (TA) can be better used to develop sustainable capacity in the public sector. 


\section{CAPACITY CONSTRAINTS WITHIN THE PRIVATE SECTOR}

\section{The diagnosis}

The skills and competencies of Afghan citizens are, in general, very low. Decades of war, a collapsed education system and emigration have undoubtedly left Afghanistan's workforce of 10 million with extremely low levels of education:

- The overall completion rate for primary education in the population is estimated at 45 percent. ${ }^{2}$ Literacy levels are correspondingly extremely low. Overall literacy is estimated at 23.5 percent, with strong gender disparities - men have a literacy rate of 32.4 percent, but women only 12.6 percent. $^{3}$

- There are also strong geographical and urban-rural disparities. High levels of illiteracy are found in a belt which runs from Jawzjan and Faryab in the north via Ghor and Badghis in Central Afghanistan, to Uruzgan, Zabul and Helmand in the south. ${ }^{4}$

- Only about one-third of the workforce in Afghan enterprises has a secondary education or higher. Indeed, only 62 percent of Afghan managers have secondary or higher education compared with 96 percent and 98 percent in Pakistan and India respectively..$^{5}$ Unsurprisingly, a 2003 survey found a correlation between educational achievement and occupation. Farmers and unskilled workers had a literacy rate of five percent, whereas craft/trade and service/shop workers had a 24 percent literacy rate. The literacy rate of business owners was 43 percent. ${ }^{6}$

The poor education and experience level of the Afghan workforce inhibits productivity, and hence competitiveness, in three main ways.

- The low level of skills reduces the absolute quality and quantity of goods produced or services provided. For example, in many overseas markets, Afghan raisins face strong competition from Californian raisins which are of a consistently higher quality, and subjected to much more stringent phyto-sanitary checks. Afghan farmers have limited experience in newer technologies, such as drip irrigation and some approaches to pest control, and the processors and packagers also have less manufacturing and administrative experience than their Californian counterparts. ${ }^{?}$

- The lack of capacity inhibits the ability of businesses to grow and to take advantage of opportunities that exist. In particular, there are serious shortages in general management skills, strategic thinking capabilities and administrative support functions, such as marketing and supply chain expertise. These deficits were highlighted in a
2004 survey, in which almost all business managers/owners responded that they would like to participate in training programmes, especially in business plan development, marketing, customer service and basic business skills. ${ }^{8}$ Some argue that, even if individuals are studying business or economics at universities, they are not being taught the practical skills needed for writing a business plan or analysing growth opportunities. A recent case study of a failed flour mill in Kabul highlighted how a general lack of experience in agricultural lending in Afghanistan, coupled with the lending bank's failure to analyse the business plan properly, and the lack of manufacturing experience of the operators (along with dishonest practices) led to a failed loan and a missed business opportunity. ${ }^{9}$ Other businesses report that they struggle to obtain investment capital because they cannot demonstrate that they have the appropriate people to manage such investment.

The shortage of skilled labour has a structural effect on the economy, affecting wages, which affects output relative to costs. As a result of the shortage of skilled labour, and fuelled by strong competition from the donor community as well as the distorting effect of the opium and aid economies, wages are significantly higher in Afghanistan than in neighbouring countries. In the manufacturing sector, average hourly wages exceed those paid in Pakistan and Iran by a factor of 2.3 and 1.2 respectively. The wage gap is even wider for managers and professionals. While annual salaries for this category of staff are US\$ 3,600 - US\$ 8,000 in neighbouring countries, they are about USS 12,000 in Afghanistan. ${ }^{10}$ Until the shortage of skilled labour is solved, and wages are brought down, it will be extremely difficult for Afghan firms to compete against imports or on the export market. ${ }^{\text {" }}$ As well as affecting competitiveness, high wages also mean that semi-skilled and skilled labour is imported from neighbouring countries, especially Pakistan, depriving Afghans of jobs. While this is partly because of the lack of skilled Afghans, it is also because Pakistani workers are prepared to accept significantly lower daily rates, often working for half the amount demanded by Afghans. ${ }^{12}$ There is thus a vicious cycle of skill shortages, high wages, imported labour and lack of opportunities for Afghans.

Although it is widely understood that there are serious capacity issues, there is little systematic information about what skills are lacking in Afghanistan, and hence where efforts should be targeted and which activities should be prioritised. The limited research that is available, in addition to anecdotal evidence, suggests that there are significant shortages of experienced managers, as well as skilled technicians such as plumbers and 
electricians. However, there is a lack of information about which skills are needed to match the demand of employers or market opportunities. The urgently needed improvements in labour market information should occur once the Labour Market Information and Analytical Unit, proposed under the Government's National Skills Development Programme (NSDP), is established in the Ministry of Labour and Social Affairs (MOLSA). This unit will work together with the Central Statistics Office (CSO) to collect and analyse labour market information. The unit is scheduled to be established by September 2007, with collection and analysis beginning by April 2008. The project has, however, been subject to certain delays. Additional locallevel information could also be gathered by training institutions, although it is recognised that using organisations which have an interest in the results can compromise the objectivity of the information gathered.

Not only is there a shortage of labour market information, there is a more fundamental shortage of comprehensive and realistic analysis of the sources and expected trajectory of growth in the Afghan economy, which would help predict future demand for different types of labour. As the Interim Afghanistan National Development Strategy (IANDS) notes, "Insufficient analysis on the needs of the private sector and potential employment growth areas limits the effectiveness of skills development projects currently operating and prevents a comprehensive strategy from being developed."13 Until such analysis is conducted at different levels, it will be almost impossible to predict areas of employment growth (both nationally and locally) and plan how these can be served through skills development initiatives. However, very complex and costly efforts are probably not needed - the Afghan Investment Support Agency (AISA) as well as the Chambers of Commerce may well prove to be good sources of proxy information which could be better analysed than at present.

In the absence of appropriate economic analysis and labour market information, the main method to date of ascertaining need has been through surveys of demand, but some of the data from such surveys may not be very useful in assessing and prioritising need. There is always a demand for training, and questions in surveys that ask people whether they would like training nearly always elicit a positive response, Moreover, many of the surveys have asked individuals to rank their requests in terms of priorities, and the need for training opportunities often take a lower position than other more apparently pressing needs. ${ }^{14} \mathrm{~A}$ recent World Bank survey found that only 9 percent of surveyed employers in urban areas viewed the level of skills and education of the workforce as a severe constraint. Electricity, access to land, corruption and access to finance were the issues most often cited as either severe or major constraints. ${ }^{15}$

However, this might simply mean that other issues are seen as relatively more critical, or further from the respondents' control and more in need of government or international agency intervention. A number of surveys have also noted the tendency to under-report skill deficiencies. ${ }^{16}$ Perhaps, therefore, the most useful lesson to be gathered from these "one-off" surveys is that there is a critical need to gather consistent and reliable labour market information, linked to economic analysis of the sources and projected trajectory of economic growth.

\section{Addressing Capacity Constraints - Responses to Date}

Government provision of vocational education and training is divided between the Ministry of Education (MoE), whose Department of Vocational Education deals with formal technical and secondary education, and MOLSA. In 2004, recognising the importance of skill development, President Karzai announced a National Skills Development Programme (NSDP) and designated the Ministry of Labour, Social Affairs, Martyrs and Disabled (MOLSAMD) as the lead ministry, in partnership with the Ministries of Education, Women's Affairs, Food and Light Industries, and supported by other ministries and donors. However, many are concerned that the problems of overlapping jurisdiction and fragmented responsibilities between ministries cannot be solved by a programme which is seen to be anchored to one of the main ministries. It is important that, as anticipated, the NSDP develops into an autonomous entity: the National Vocational Education and Training Authority (NVETA).

The Government is now establishing a framework for capacity development. ${ }^{17}$ This framework designates responsibilities to different ministries and agencies:

- Capacity building of the public service is facilitated and coordinated by the Independent Administrative Reform and Civil Service Commission (IARCSC).

- Capacity building of the private sector and nongovernment sector is facilitated and coordinated by the Ministry of Economy and the Ministry of Labour, Social Affairs, Martyrs and Disabled.

- Capacity building of the larger Afghan society is facilitated and coordinated by the Ministry of Education and Higher Education. 
Increasingly the role of the Government is seen to be the provision of the overall policy framework, as well as the regulation and accreditation of skills training. In this context, the majority of skills development activities will come from private initiative - either for-profit or non-profit organisations. In many other countries, it is normal for the private sector to train the workforce it needs. In Slovakia, for example, Peugeot-Citroën is training all the workers needed for its recently established factory, and is even providing vocational training courses at local high schools. ${ }^{18}$ Across Central and Eastern Europe, Johnson \& Johnson has trained thousands of middle managers in the last decade in health care management, even sending a number of outstanding managers to study at INSEAD and the London School of Economics (LSE). However, according to a World Bank survey, only just over five percent of Afghan firms currently offer training. ${ }^{19}$

In some cases, however, training by firms has been successful, particularly when it has been closely linked to job requirements and follow-up has been provided. Both Roshan and the Kabul Serena Hotel, for example, made strategic decisions to employ bright, young Afghans and train them - rather than look for already trained employees. They have used a mix of in-house training supplemented with study abroad to develop a cadre of junior managers who are expected to take on significant responsibilities in the near future. They have also provided training in a number of relevant skills for a broader pool of employees. In the Serena's case, progress while undergoing training has been successfully linked to career promotion prospects. Some manufacturers are now also beginning to look at establishing themselves in Kabul and offering relevant training (see Box 1)

In Afghanistan's difficult investment environment for international business, are there new models of cooperation which could be explored, perhaps with requirements for training as part of the partnership arrangements? The case of HOV is one such example, where aid is being combined effectively with international business to support private sector development and training. Other models are also available from elsewhere in the world. In March 2006, for example, the Grameen Group (a microfinance lender) and Groupe Danone (a French dairy conglomerate) entered into a joint venture in Bangladesh. A small factory will be built by Danone to make cheap yogurt, and local people will be trained in the process. Loans will be offered to help local people buy cows to supply milk. The project will use solar and other environmentallyfriendly energy sources, and profits from the venture will be reinvested in order to develop the project across the country, Danone's chief executive noted "we want to test this economic model; if it works we can think about [using it in] countries where our classic model doesn't work." 20

\section{Box 1: Private Sector-led Training: the case of HOV}

Heidelberger Druckmaschinen Osteuropa Vertriebs $\mathrm{GmbH}$ (HOV) has formed a public-private partnership (PPP) project with GTZ to build a training centre for print and pre-press services. HOV is aiming not only to provide a solid training for its own employees but also to give local employees an opportunity to obtain vocational training leading to recognised qualifications, another example of industry-based certification.

The company is largely handling local implementation itself: HOV is building the centre, developing the training concepts, conducting the courses and supplying the necessary experts. On behalf of the German Government, GTZ is providing important start-up aid, sharing the costs of the courses and ensuring coordination with the Ministry of Labour and Social Affairs.

In the medium term, the aim is to develop the centre into a national print training centre, training qualified print workers for the entire country. The new training courses offer both solid basic knowledge on working with modern machinery and specialist knowledge. For women, there are appealing and socially acceptable job opportunities in the area of pre-press work.

As a result of this effort, it is expected that future print orders will no longer have to be placed abroad.

www.gtz.de

Most vocational training is not provided by firms, and its quality and relevance is very varied. A survey conducted in 2003 in Central, Eastern, Northern and Western regions found that the largest providers of vocational training were NGOs (57 percent), followed by private organisations ( 24 percent) and Government (19 percent). Craft and trade-type occupational courses were most common and 70 percent of all vocational training was for women. Some 65 percent of the businesses surveyed had been offered on-the-job training.

NGOs as training providers: ${ }^{21}$ Many NGOs have taken on training as a new activity, as donor funding priorities have shifted, but most do not have specialised skills in this area. While there are exceptions, in general the standard of training is poor, and in many cases pedagogically untrained instructors are being drawn from the local bazaar to deliver low quality, unsystematic and undocumented training courses. Few such courses are designed to take account of the labour market situation. 
Private training providers: Private sector training provision as an enterprise is developing, but mostly in the areas of information and communications technology (mainly the use of computers) and English language training. Estimates suggest there are 100 to 200 such schools. Course fees tend to be high, so access is limited to those who already have significant education and money to pay.

However, despite the numerous training providers and the many training activities currently taking place, there are a number of key failures in existing initiatives:

- The quality of training is often very low, as in general, trainers are not pedagogically trained and are not using a structured or standardised curriculum.

- There is no policy or framework for vocational education and training, so institutions themselves are not affiliated, courses are not validated and therefore any certificate or credit for learning is arbitrary and does not provide any guarantee of standard for future employers. There is currently no accreditation body that can set and monitor quality and register quality providers.

- Consistency and coordination within and among the various training providers are also poor and there is little information regarding the kind and impact of training being delivered, and which organisations are delivering it.

Indeed, the current situation in the vocational education and training sector has recently been described as "one of chaos, with a myriad of unregulated, unqualified and inexperienced organisations providing what is often an arbitrary range of vocational education and training activities which ignore the needs of the labour market, waste resources, and leads to disillusionment of the trainees." ${ }^{22}$ Other anecdotal evidence supports this analysis, with both employers and employees expressing widespread dissatisfaction with the usefulness of training on offer.

\section{Recommendations for action}

\section{Improve labour market information}

The most urgent need is undoubtedly for improved labour market information. At the moment, there is insufficient data to suggest what needs should be prioritised, and where Government or other efforts should be specifically targeted. The immediate critical requirement is therefore the provision of upto-date and gender disaggregated labour market information, based on sound economic analysis and projections. This is essential to enable training activities to be linked much more closely to projected market demands.

\section{Reform the vocational education and training sector, in line with the NSDP strategy ${ }^{23}$}

There is currently no national policy on technical and vocational education and training. The first step is therefore to develop a national policy on technical and vocational education and training as a framework within which all initiatives will operate.

It is important to establish a national system of registration and accreditation for training providers, which will assess providers on their curriculum, the training of their staff, the quality of the training they deliver and their ability to place graduates in employment. In this context, industry-based certification initiatives are also very important and should be encouraged. For example, CISCO (a leading supplier of networking equipment and network management) has set up three centres in Kabul and awards CISCO network certification.

As planned (in the medium term), it is important to develop the programme implementation unit of the NSDP into a National Vocational Education and Training Authority, with responsibility for policy and planning, standards of delivery and accreditation of training providers. In the mediumlong term, it may also be useful, as is currently being considered, to establish Industry Training Advisory Boards in five sectors - agriculture, business and commerce, building and construction, service industries and mining and manufacturing. These boards will be the source of information about existing and emerging skills shortages within industries, and will also be involved in the development of training curriculum.

\section{Explore how to draw further on the resources of international business to support skills development}

As discussed above, many developing countries develop partnerships with multinational business to support skills development and training. However, multinational corporations are mostly reluctant to commit to investment in an environment perceived as unstable, with weak governance and uncertain regulatory frameworks. Nonetheless, it is important to explore whether innovative public-private partnerships and other arrangements between different players could be further used to support skills development and job creation in Afghanistan, even if international business is currently reluctant to make significant, long-term commitments. 
Businesses employing internationals should also ensure that the transfer of skills to nationals is considered a significant part of their job. Experience to date suggests that this should be prioritised, although it can be problematic finding intemational business people with such a mentality. As one senior manager in the private sector commented, "The problem has not been the willingness among young Afghans to learn. It has been that we haven't found the same willingness from international staff to teach." 24 The requirement to train counterparts should be written into job descriptions and evaluated as part of job performance.

Additionally, donors can ensure that they procure as many products and services locally as possible, helping their Afghan suppliers to meet the necessary standards. This will provide local firms with experience and support in bidding against international companies. $^{25}$

\section{THE ABILITY OF GOVERNMENT TO SUPPORT THE PRIVATE SECTOR}

\section{The diagnosis}

The November 2006 report of the Joint Coordination and Monitoring Board (JCMB) highlighted the limited capacity of government institutions at all levels, the inadequate progress made so far in capacity development, the high cost of technical assistance and the performing of line ministry functions by consultants. This section explores the critical importance of the capacity of government officials and bodies in supporting the private sector.

- In general, there are very low levels of skills in the civil service. In 2003, it was estimated that eight percent of civil servants in Kabul had less than a high school diploma, 67 percent had a high school diploma, 20 percent were university graduates and five percent had Masters degrees or above.$^{26}$ In a 2005 survey, 26 percent of civil servants in the provinces indicated they had a "university education", with 55 percent reporting only secondary education. ${ }^{27}$ Since officials in Kabul generally have higher levels of education than those in the provinces, this suggests that the situation has improved somewhat in the last few years.

- The same survey found that Grades 1 to 2 (senior executives) identified their primary skills needs as being in management, administration and ethics. Grades 3 to 4 (middle managers) requested training in management, administration, ethics, govemance and ICT, with a particularly strong demand for training in management skills. Grades 4 to 5 (general service categories) prioritised training in ethics and governance, as well as skills related to dealing effectively with the public.

- The difficulties of dealing with government officials are undoubtedly a deterrent to potential investors. As one employee of an intemational organisation involved in business enterprises commented, "It is nearly impossible to do business in a professional way. The rules are always changing, staff are changing and everybody wants extra fees... you want to throw up your hands and walk away. If you don't have deep pockets and a lot of time, then forget it."

The public administration reform programme (PAR) is attempting to address all areas of reform in the civil service, including capacity-building. However, the PAR process has run into numerous problems, and progress so far has generally been slow. According to a number of reviews of PAR and the Priority Reform and Restructuring (PRR) programme (responsible for the reform of ministries), much reform has been "cosmetic", with superficial restructuring of ministries and an emphasis on higher pay rather than fundamental change. One major issue has been the slow establishment and weak capacity of the Independent Administrative Reform and Civil Service Commission (IARCSC), the main body responsible for steering and overseeing $\mathrm{PAR}$. Ministries have also had very limited capacity to implement reform, and there has not been sufficient competent technical assistance (TA) to help them do so. Targets and timetables have been unrealistic, and coordination among donors has been poor. ${ }^{28}$

To date, training of civil servants has tended to be ad hoc and uncoordinated. Providers of training include:

- Training and Development Department of the Independent Administrative Reform and Civil Service Commission (TDD- IARCSC)

- Different donor initiatives

- Afghanistan Stabilisation Programme

- UNAMA/ UNDP

- Various non-governmental organisations.

However, the weakness of the TDD- IARCSC has meant that the Government has not played a strong central coordinating role. Similar uncoordinated approaches to training of the civil service have been 
seen in other post-conflict contexts, such as Kosovo, where a multitude of uncoordinated trainings were offered and "training fatigue" became apparent and eventually had a negative impact on capacity building. ${ }^{29}$ Some donors are now suggesting that a National Capacity Development Programme, linked to a Capacity Development Facility, is the most appropriate way forward. ${ }^{30}$

Building the specific skills needed for civil servants to support private sector development is an additional challenge; particularly as in many cases this requires a change of mindset. The World Bank notes, "Promoting private sector development in an era of globalisation requires a good understanding of international and domestic market trends, sectoral knowledge and appreciation of the needs of business." 31 The World Bank and others have identified the following specific areas where capability needs to be built:

- Policy analysis in the Ministry of Commerce and Industries

- Investment promotion and facilitation capacity in Afghan Investment Support Agency (AISA)

- Understanding and facilitation of a market-based provision of business development services and vocational training

- Ability to liaise with the private sector, in particular the development of an effective channel to get feedback from the private sector on the investment climate

- Improving the statistical basis for monitoring developments in the private sector and in the investment climate

There have been some initiatives to improve the skills and competencies of government officials and bodies in dealing with the private sector. However, even those departments or agencies that are seen to be relatively successful still suffer from staff with very low levels of ability. Enquiring into their "success" usually reveals that there are one or several dynamic individuals, often (but not always) internationals, who are shouldering the workload. Usually little longer-term and widespread sustainable competence has been developed. ${ }^{32} \mathrm{~A}$ three year DFID-funded capacity-building initiative is currently underway in the Ministry of Commerce and Industries. This will establish a private sector development directorate. However, the problems experienced to date in establishing the directorate and getting the staff in place have meant that the time remaining for training and other capacitybuilding activities has been reduced.
As the situation in the Ministry of Commerce and Industries suggests, the problems with the public sector's ability to support the private sector are broader than simply the failure of training initiatives. Rather, the problems encountered with the whole PAR process have meant that the appropriate structures are not in place, and mechanisms for hiring qualified and motivated staff are not being properly implemented. Many see this as an absolute prerequisite for development of public sector capacity to support the private sector. They argue that if there are no professional officials with some measure of job security working in appropriately structured and sized teams, then most training efforts will not be useful. Those departments that are now relatively useful in supporting the private sector, such as the Large Taxpayers' Office in the Ministry of Finance, have successfully been through the Priority Reform and Restructuring (PRR) process.

One other area requires urgent action by development actors in Afghanistan. A changed understanding and monitoring of international technical assistance (TA) is needed to ensure a focus on building sustainable capabilities within the civil service. There is sometimes a necessary tradeoff, between "getting the job done" and building local capacities, and there is often no "perfect" balance between the two. However, building capacity in developing countries is central to the Paris Declaration on Aid Effectiveness and it is the responsibility of all signatories to ensure that aid is spent in a way that maximises capacity development. ${ }^{33}$ There are many ways that donors can contribute to this, including improved coordination and better monitoring, careful design of "capacity-building" projects and incorporating capacity-building requirements into the terms of reference of consultants.

An increased focus on mentoring and building the capacity of counterparts might yield significant results, and it would certainly reduce the dependence on training as the primary means of capacity-building. Figures for expenditure on technical assistance and cooperation in Afghanistan are not very reliable, but some estimates suggest that in 2004 it reached US\$ 460 million. ${ }^{34}$ It is certainly very substantial, and it is clear that it needs to be better deployed, used and assessed. However, there is something of a vicious circle domestic capacity is so low that it is hard to manage, absorb and deploy TA and difficult for it to translate into development of sustainable government capacity. 


\section{Recommendations}

\section{Accelerate efforts to achieve reform under the $P A R$ process}

There are a number of decisions on policy and government structure that must be taken to accelerate the PAR process. However, as many observers comment, the most urgent need is for increased political support to the process. ${ }^{35}$ If these broader issues related to PAR are not addressed, the Afghan private sector will continue to encounter a public administration that is poorly functioning, often corrupt and unable to provide it with the support it needs.

\section{Prioritise the development of a private sector development policy}

There is still no overarching policy framework for private sector development, toward which activities to support private sector development can be channelled, and which can be used to ensure coordination between the different actors. This has had a number of detrimental effects, one of which is that capacity-building efforts to improve public sector capacity to support the private sector are ad hoc and often more influenced by the whims of particular donors than their contribution to an overall plan. The urgent development of such a policy is therefore a priority.

\section{Use aid more effectively to support the development of civil service capacity}

Measures such as ministry-wide monitoring and oversight of TA should be considered. These would provide regular feedback on the performance of TA, improve coordination and could ensure that a stronger capacity-building focus is maintained. Additionally, donors should require all TA that they fund to report on their capacity-building objectives, activities and impact. Such a focus on capacitybuilding might mean that donors need to reassess their own time scales and expected outputs.

\section{Prioritise the areas for capacity-building which have already been identified}

These are:

- Policy analysis in the Ministry of Commerce and Industries

- Investment promotion and facilitation capacity in AISA
- Understanding and facilitation of a market-based provision of business development services and vocational training

- Ability to liaise with the private sector, in particular the development of an effective channel to get feedback from the private sector on the investment climate

- Improvement of the statistical basis for monitoring developments in the private sector and in the investment climate

\section{CONCLUSION}

The low level of skills and education in Afghanistan's workforce damages productivity and competitiveness, reducing growth and employment opportunities. It is clear that long-term efforts to improve the skills and competencies of Afghans must be focused on rebuilding the education system, from primary through to secondary and tertiary, and including vocational training. Indeed, this is one of the seven key areas of concern to members of the Afghan International Chamber of Commerce. ${ }^{36}$ Many initiatives are already underway in these fields. However, it is equally clear that this task will take decades, and Afghanistan cannot afford to wait. It is important to consider what can be done in the short- to mediumterm to improve the situation.

There is undoubtedly a need for a variety of skills development initiatives that would target different sectors of the population - senior and middle management, technical skills, business development skills, training for small businesses in both rural and urban areas, and so on. Most of these training activities will be carried out by private initiative.

However, this paper has sought to highlight how dependent such activities are on government initialive:

- The overall regulatory and rule of law environment must be improved, so that international business feels confident in investing (and training) in Afghanistan. Furthermore, private sector and nonprofit training activities must be linked into government plans and frameworks, drawing on improved labour market information.

- Training must be better linked to the labour market, and appropriately regulated and accredited by the Government.

- Overall government capacity to support the private sector must be urgently increased, through expanded efforts to achieve reform through the 
PAR process. Only once restructuring and reform efforts take place, will most training of civil servants prove effective.

- Donors must also urgently review their coordination of activities, and work with the Government to improve the use of technical assistance.

\section{SUMMARY OF RECOMMENDATIONS}

\section{Improve Capacity within the Private Sector}

- Improve labour market information to provide upto-date and gender disaggregated labour market information, based on sound economic analysis and projections.

- Reform the vocational education and training sector, in line with the NSDP strategy, including developing a national policy on technical and vocational education and training, and establishing a national system of registration and accreditation for training providers.

- Explore how to draw further on the resources of international business to support skills development, including whether innovative publicprivate partnerships and other arrangements between different players could be further used to support skills development and job creation.

- Make the transfer of skills to nationals a significant part of the jobs of international employees of businesses.

\section{Improve Capacity within Government}

- Accelerate efforts to achieve reform under the PAR process, including garnering increased political support for the process.

- Prioritise the development of a private sector development policy.

- Use aid more effectively to support the development of civil service capacity, which includes introducing ministry-wide monitoring and oversight of TA. Donors should also require all TA that they fund to report on their capacity-building objectives, activities and impact.

- Prioritise capacity-building in: policy analysis in the Ministry of Commerce and Industries; investment promotion and facilitation in AISA understanding and facilitating market-based provision of business development services and vocational training; liaising with the private sector, particularly in the development of an effective channel to get feedback from the private sector on the investment climate; and the statistical skills for monitoring developments in the private sector and the investment climate.

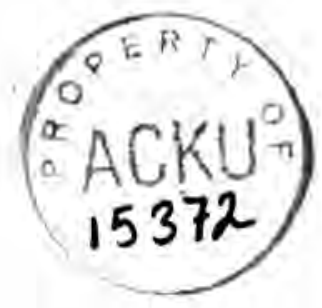


'There are numerous definitions of the term "capacity". The DAC, for example, has defined it as "the ability of people, organisations and society as a whole to manage their affairs successfully". (DAC Network on Governance (2006) "The Challenge of Capacity Development: Working Towards Good Practice"). UNDP defines it as "the ability of individuals, institutions and societies to perform functions, solve problems, and set and achieve objectives in a sustainable manner." UNDP (2006) "Capacity Development Practice Note". ${ }^{2}$ Islamic Republic of Afghanistan (2005) "Millennium Development Goals Country Report: Vision 2020" Kabul, p32

${ }^{3}$ National Risk and Vulnerability Analysis 2005 data. Pers. comm...from NRVA team. October 2006.

${ }^{4}$ Islamic Republic of Afghanistan (2005) "Millennium Development Goals Country Report: Vision 2020" Kabul, p34

${ }^{5}$ World Bank (2005) "The Investment Climate in Afghanistan: Exploiting Opportunities in an Uncertain Environment" Washington, DC: World Bank ${ }^{6}$ IRC (2003) "Afghanistan Labour Market Information Survey".

${ }_{7}^{7}$ Lister, S, Brown, T. and Karaev, Z. (2004)

"Understanding Markets in Afghanistan: a case study of the markets in raisins" AREU Working Paper Kabul AREU

${ }^{8}$ Centre for International Private Enterprise (2004)

"Report on the Supply of and Demand for Business Development Services in Afghanistan". Unpublished document.

9 "Case Study - Flour Mill" developed by ShoreBank International

${ }^{10}$ IMF (2006) "Islamic Republic of Afghanistan:

Selected Issues and Statistical Appendix" Country Report 06/114. March Washington D.C.: IMF

"World Bank (2005) ibid.

${ }^{12}$ See Johnson, C (2004) "Labour Intensive Works Programme Evaluation." Unpublished document. The extent of this is not known as there is little reliable data, and there is some evidence that foreign workers also receive a package of other benefits. Personal

communication, Stephen Vardigans, MOLSA

${ }^{13}$ Islamic Republic of Afghanistan (2006) "Afghanistan

National Development Strategy". p5

${ }^{14}$ When community leaders were asked to choose the most important areas for government intervention in their village/district, only 1.8 percent of male shuras and 9.5 percent of female shuras included vocational training in their top three priorities, with a significantly higher proportion in urban than rural areas. Source NRVA 2005.

${ }^{15}$ World Bank (2005) ibid

${ }^{16}$ See IARCSC (2005) "Subnational Training Needs

Assessment Report" October. Unpublished documen

${ }^{17}$ See IARCSC (2007) "Development of a National Capacity Development Framework for the Public Service in Afghanistan". Discussion paper. January

${ }_{18}^{18}$ Source: press clippings and personal communication

from TA in the Ministry of Commerce.

${ }^{19}$ In comparison, in India almost 17 percent of small

firms train. Source: World Bank (2005) "The Investment

Climate in Afghanistan; Exploiting Opportunities in an

Uncertain Environment" Washington DC: The World

Bank
${ }^{20}$ Source: http://www.grameeninfo.org/dialogue/dialogue63/regularfl2.html and press. reports

${ }^{21}$ Ministry of Labour, Social Affairs, Martyrs and Disabled (2006) "National Skills Development Strategy" draft 24 September 2006

${ }^{22}$ Personal communication from international expert.

${ }^{23}$ See MOLSA (2006) ibid.

${ }^{24}$ Pers. Comm.. Manager, International Company, Kabul. 19 Oct 2006

${ }^{25}$ The work of the Peace Dividend Trust in facilitating this process is particularly notable. See

http://www.peacedividendtrust.org for further details.

${ }^{26}$ Statistics from MOWA and Afghan Audit Office, cited in Evans, A, Manning, N, Osmani, Y., Tully, A., and Wilder A. (2004) "A Guide to Government in

Afghanistan" Kabul and Washington DC: AREU and the World Bank

${ }^{27}$ IARCSC (2005) "Subnational Training Needs Assessment Report" October. Unpublished document

${ }^{24}$ For a broad review of issues related to public administration reform, see Lister, S (2006) "Moving Forward? Assessing Public Administration Reform in Afghanistan." Briefing Paper. Kabul: AREU

${ }^{29}$ IARCSC (2005) ibid.

${ }^{30}$ See Ponzio, R. (2006) "Capacity Development in Afghanistan 2001-06: emerging strategies for sustainable progress". Paper for the UNDP Capacity Development Group. Draft for discussion $10 \mathrm{Sept}$.

${ }^{31}$ World Bank (2005) ibid, pxi.

${ }^{32}$ Several examples were provided while preparing the paper. For sensitivity reasons, the departments or agencies are not named.

${ }^{33}$ DAC Network on Governance (2006) "The Challenge of Capacity Development: Working Towards Good Practice"

${ }^{34}$ World Bank (2006) "Afghanistan: Improving Management of Technical Assistance". Unpublished note. Draft 19 June.

${ }_{35}$ These are laid out in Lister (2006) ibid.

${ }^{36}$ Afghan International Chamber of Commerce (2006)

"National Business Agenda" August. Kabul: AICC 


\title{
CHALLENGES PRESENTED BY THE LEGAL AND REGULATORY FRAMEWORK GOVERNING PRIVATE FOR-PROFIT ACTIVITY
}

Background paper prepared for the Enabling Environment Conference by:

\author{
Altai Consulting
}

\section{FRAMEWORK}

According to the World Bank's 2005 Investment Climate in Afghanistan, "in addition to insecurity, poor land tenure and corruption, the high level of uncertainty and risk facing investors in Afghanistan comes from the absence of a clear legal framework."

Three overlapping systems constitute the legal framework in Afghanistan: the Sharia (Islamic Law), the Shura (traditional systems of informal justice) and the formal system based on the constitution $^{2}$, sometimes overlapping layers of legislation from pre-war times, the communist era and the Taliban. Therefore, few corporate managers are clear about which laws actually apply to them. As The Investment Climate puts it, "given the arbitrary enforcement and lack of effective court, [business people consequently] do not spend much time worrying about it. Only 10 percent of the survey $^{3}$ sample mentioned the legal system as a major or severe constraint. However, establishing a strong legal framework would lower risk and encourage investors." Indeed, the Initial Afghanistan National Development Strategy (IANDS) document claims that "the Government is committed to improving the legal and regulatory environment, with a particular focus on enforcement, to strengthen implementation mechanisms in order to lower transaction costs for businesses and to improve the climate for Foreign Direct Investment."

This background paper aims to present the main challenges Afghan businesses face in dealing with the current legal, administrative, regulatory and fiscal environment governing business activity, and to propose recommendations for the improvement of this environment. Five case studies have been conducted in Kabul and Herat with trading, construction, telecommunications and manufacturing companies. Based on these case studies and other research on private sector development in Afghanistan, key issues currently hampering business development are analysed (cross-cutting and institution-specific issues related to the Commercial Court, Ministry of Commerce and Industries, AISA and Ministry of Finance), along with the responses currently being provided to tackle them. These identified issues then serve as the basis for an initial set of recommendations. 


\section{CASE STUDIES}

\section{Case Study 1: Informal house building company in Kabul}

The "Engineer" is an informal contractor or Tekadar who was educated and trained in Pakistan, worked six years in Tajikistan and returned to Afghanistan four years ago. He has undertaken private house building projects in Kabul, as well as in Jalalabad and Laghman.

The Engineer is currently building a very large house in Kabul for a senior government official. The value of the contract is approximately US\$ 120,000 and the Engineer estimates that he will take about US\$ 15,000 ( 12.5 percent) in profit at the end of four months. Despite the scale of the project, the Engineer has little fixed capital invested in his firm. Aside from a computer and a small generator, his company has no assets. He merely circulates capital from the client and takes the margin as personal income.

Though he is currently in violation of the Afghan law because he does not pay any taxes on his income, the very limited enforcement capacity of the Ministry of Finance is what protects him the most: despite the high visibility of his house building activities, he has never been approached by anyone from the Government demanding taxes or even bribes.

In 1383 (2004), he tried to establish a company and register with the Ministry of Commerce, then responsible for issuing business licences for construction companies, but he reports that he was asked to pay a high cost of bribes (according to him, a commission agent approached him for USS 600 ), so he lost confidence in the government and decided not to register as a legal entity.

The Engineer is not legally compelled to get an AISA licence for his activities; he is technically free to engage in economic activity as a natural person and is under no obligation to form a legal entity such as a corporation. If he were to form a company, registration as a with AISA would cost US\$ 750 .

However, there seems to be only few marginal benefits for him to get an AISA Investment Licence and thus have to pay taxes. With such a licence, he could win small projects with international donors, but it is not clear if these would represent a higher value than his current house building activity. Having a licence would not ensure him a higher legal protection, as he believes that the Commercial Court of Kabul province is barely operational.
Issues

- Negative experience with the Ministry of Commerce affects the overall perception of Government

- Lack of enforcement capacity of the Ministry of Finance reduces the incentive to pay taxes

- Lack of direct benefits of acquiring an AISA licence (limited access to lucrative markets and no additional legal protection as the Commercial Court is perceived to be inefficient)

\section{Case Study 2: Informal manufacturer in Herat}

Ghulam rents a shop in the heart of Herat that doubles as a factory, housing several looms as well as a storefront for his silk wares. In total, he employs 10 loom operators who work on a commission basis. Some of them work in the rear part of the storefront, while others work on looms in their own homes. About half of the home-based labourers are women. The shawls, a mixture of silk and synthetic fabric, are sold out of the storefront. The enterprise has about US\$2,500 in fixed capital (the majority being invested in looms) and limited working capital.

Ghulam expresses interest in expanding. $\mathrm{He}$ believes that if he could secure 125,000 Afs (US\$ 2,500 ), he could first expand his production by purchasing 10 additional looms (thereby directly funding 20 to 40 percent of the loan) and by using the rest as working capital in order to import the raw materials himself. He believes that with the expanded capacity, he could reduce his prices significantly and command a larger market share.

Ghulam, and the other silk makers in the area, are registered with the municipality and make annual tax payments. However, because they do not keep accurate records, their tax burden is assessed through the "Fixed Taxes" 5 system; in this case, at only a fraction of what a formal company would pay. In fact, he and the other informal manufacturers in the cluster do not understand how the Fixed Taxes are currently assessed, and Ghulam is not aware of any alternative to the current taxes he pays. He has no information about AISA and the costs or benefits of its Investment Licence. He also considers his firm to be too small to adopt formal business practices such as using a bank account or accurate record-keeping. Regarding formal financing opportunities, he has no experience of it and, due to a lack of information, overestimates the cost of finance. 
Ghulam's main need is access to credit, but an official licence is a prerequisite to obtaining a loan from commercial banks. Even though US\$2,500 would be sufficient to buy an additional 10 looms and double his output, without any titled land or property he is unable to secure even a microcredit loan. Even if Ghulam formalised his factory, he would probably face difficulties in obtaining financing. Private banks remain reluctant to offer loans without significant collateral (which Ghulam lacks) due to poor legal protection and the absence of key financial infrastructure such as insurance.

\section{Issues}

- Entrepreneurs lack information on how Fixed Taxes are calculated and what the costs and benefits of the AISA licence are

- Difficult to obtain titled land and property

- Financial gap experienced by SMEs which limits their ability to expand

\section{Case Study 3: Informal vehicle trader in Herat}

TR is a small vehicle trading company in Herat which imports cars from Germany. While most car importers in Herat import vehicles via Dubai, from where they are then shipped to Bandar-e-Abbas and driven overland to Islam Qala (at the border next to Herat), some importers also buy vehicles in Europe (mostly in Germany) and then transport them overland - a route made popular in the $1970 \mathrm{~s}$. Taking advantage of the dramatic growth of vehicle use since 2002, TR's owner established his company in 1384 (2005), and registered at the Ministry of Commerce the same year.

Owning a business licence allows TR's owner to pay less customs taxes: two percent of the costs of goods (including duties) as an advance payment, versus the three percent that non-licensed traders pay. TR's owner believes that his licence from the Ministry of Commerce allows him to receive legal protection from the Commercial Courts:

\section{"If these things happen [other businesses break contracts or steal my names and ideas], the Commercial Courts will help me."}

TR's owner describes all government institutions he has dealt with as heavily corrupt. TR paid US\$ 349 in extra costs for the Trading Licence when it should normally only have cost him US\$ 57 . He is very negative about the customs process which he also describes as corrupt:
"At customs, money is the law [...] There is a lot of bribery going on there. It has slowed our business and we are tired of it. The high tax abated our business."

However, bribes can also help him in his business, as they allow him to easily alleviate the customs duties he should face:

"If we give bribes, customs officials will underestimate the value of the goods, and we will pay less tax. If we don't pay bribes, our goods will be delayed in customs,"

Lack of enforcement of the law is apparent in the taxes TR's owner pays. A trader is requested to pay the balance between the Business Receipts Tax (BRT) and his annual Corporate Income Tax payment on one side, and the advance payments made at the border on the other side. However, there is no clear system of enforcement of this balance payment. In fact, TR's owner does not pay it and has not been asked for it.

\section{Issues}

- Discount on advance payment for licensed traders is enforced at customs

- Reported corruption at the Ministry of Commerce and Customs Departments

- Lack of enforcement capacity of the Ministry of Finance reduces the incentive to pay the balance taxes at the end of the year

\section{Case Study 4: Partially formal trading company in Kabul}

STI, a trading company and retailer which sells a variety of cables, bulbs and other electric devices imported from Iran, was established in 2002. It currently employs 20 people and is present in Kabul, Mazar-e-Sharif and Herat. STI's owner registered his company at the Ministry of Commerce in 2002 and obtained an AISA licence in 2005 .

Attitudes of STI's owner seem to have played an important role in his interactions with government institutions. He is convinced that there is strong enforcement of govemmental regulations, and that it is impossible to operate without a Trading Licence or avoid paying taxes.

The owner of STI registered at AISA, even though it was not compulsory for him as a trader, because he wanted to diversify his activity by opening a factory. He therefore expected an AISA licence to 
provide him with some direct benefits, particularly a parcel of land in one of its Industrial Parks. However, he said that he neither received any land, information, training nor assistance from AISA. STI's manager claims to be a victim of corruption and illegal taxes. He resents the registration process at the Ministry of Commerce, as it is lengthy and requires bearing unofficial costs in bribes. He is similarly very negative about the process at customs:

"The process at customs is the same as it is at the Ministry of Commerce. Here also, if you give money or have connections with government officials, your work will be finished in one day. If not, it will take a long time to finish your work there."

STI's owner also suffers, though willingly, from illegal taxation. The Kabul Municipality appears to be collecting a "Customs Tax". Although this tax does not have any legal basis, he perceives it as normal:

"When our goods enter Kabul city, the Municipality takes a two percent tax on the value of the goods. And we comply with this regulation because it is the rule of the Government and it is applicable to every business."

\section{Issues}

- Reported corruption at the Ministry of Commerce and Customs Departments

- Reported illegal taxation from the Kabul Municipality

- Apart from licensing, limited additional services provided by AISA (limited access to land, training)

\section{Case Study 5: Formal scratch dealer, Kabul}

P Tel is an example of the Foreign Direct Investment brought to Afghanistan by returnees. The company was created in 2003 by an Afghan American returnee (Western-educated), who had left the country with his family before the war. This company is a scratch card dealer: the company buys scratch cards from a mobile phone operator and sells them through a nationwide network of outbound sales staff. P Tel's manager is proud of the formal business practices he implements, both concerning his direct employees (the company has contracts with its employees as well as with the outbound sales team) and the modern accounting tools he uses.
For P Tel's manager, registering was compulsory for almost moral reasons. Asked if he thought that registration was an obligation for his type of company, he answered:

"Yes! Of course I didn't come back to Afghanistan to start an illegal company. "

However, the primary benefit of being formal for $\mathrm{P}$ Tel is that the company is able to keep its main supplier, the telecom operator, and to interact with other actors:

"Whenever we work with mobile phone companies or with NGOs, the Ministry of Finance, etc., they are asking us for our business licence. "

The manager of $\mathrm{P}$ Tel is extremely positive about the registration process at AISA:

"AISA has an excellent system, implemented in a proper way. It gives me hope that this kind of modern system is working here in Afghanistan, and I believe that tomorrow I could start several businesses. There are still problems and shortcomings, of course, but compared to the old system of registration at the Ministry of Commerce, AISA's operations are impressive."

However, P Tel's manager reports corruption cases at the Ministry of Finance. According to him, this corruption reduces the enforcement level and will last until fundamental structural changes are made.

"The infrastructure of the Ministry of Finance remains very weak. It just takes one bribe and the clerks will take a zero off of your revenues and reduce your tax burden. As long as there is no good system in place and the civil servants have low. salaries, there will be no progress on this front."

One of the main characteristics of the sector of activity in which $\mathrm{P}$ Tel operates is the very low after-tax profit margin of companies. According to $\mathrm{P}$ Tel's manager, it is often one percent or sometimes close to zero percent when the market is tough. Regarding taxes, the BRT tax seems to him unfair and inappropriate, and he does not plan to pay it next year:

"The BRT tax is very unfair and we probably will not pay it, because as we have such a high turnover and low profit margin, it would obliterate any possible profits."

\section{Issues}

- Owning an AISA licence ensures credibility with suppliers 
- AISA licensing process is reported to be efficient and corruption-free

- Reported corruption during tax collection processes at the Ministry of Finance

\section{ANALYSIS: BEST PRACTICES AND GAPS IN THE LEGAL, ADMINISTRATIVE, REGULATORY AND FISCAL FRAMEWORK}

The aim of this section is to identify the main best practices and issues mentioned in both the Case Studies previously listed and by entrepreneurs interviewed in the context of other research led on private sector development in Afghanistan. First, the main cross-cutting issues are analysed, and then issues specific to the Commercial Court, the Ministry of Commerce and Industries, AISA and the Ministry of Finance are developed.

\section{Cross-cutting Issues}

\section{Lack of Commercial Laws}

Apart from the Private Investment Law, very few commercial laws exist. The risk of doing business in Afghanistan is therefore considerably increased.

The Ministry of Commerce and Industries is the lead government ministry for the implementation of the Private Sector Development (PSD) strategy, determined in the ANDS, "In this context, the "Commercial Law Working Group Project", funded by USAID and hosted at the Ministry of Commerce and Industries, has drafted the following laws for submission to the Ministry of Justice which are currently going through the parliamentary process: Partnership Law, Corporate Law, Contracts Law, Commercial Arbitration Law, Commercial Conciliation Law, Anti-Trust and Unfair Business Practices Law, Labour Law, Secured Transaction and Mortgage Law, and Law on Foreign and Domestic Private Investment. An Insurance Law and a Bankruptcy Law have also been drafted. These laws, some of which existed before, are being made WTO-compliant as Afghanistan is already taking steps to enter the World Trade Organization.

However, it is a slow process. For instance, the Partnership Law, the Corporations Law and the Contracts Law were all drafted by the American Bar Association (ABA) and were submitted by the Ministry of Commerce and Industries to the Ministry of Justice in early 2005. They were reviewed and returned to the Ministry of Commerce and Industries in November 2005, and are still in a draft status.

\section{Complexity of the Licensing System}

Fifty-six licences have been identified by the Investor Roadmap project conducted by the Ministry of Commerce and Industries.

"Investors in 22 sectors have to not only be registered with the Commercial Court to be a legal entity and obtain an AISA licence; they also have to obtain sectoral licences. [...] While licences in some of these sectors have the potential for creating economic value, in many others there would not seem to be any economic rationale for mandating them." 7

The multiplicity of licences creates an important administrative burden to private sector development without necessarily correcting any market failure.

\section{Property Rights Issues}

Many businesses cite access to land as one of the biggest impediments to investment in Afghanistan. The lack of reliable property rights ${ }^{8}$ is an important component of this broader issue, and constitutes a major challenge for business people, as it considerably increases the risk of owning land.

The Land Titling and Economic Restructuring of Afghanistan project (LTERA), funded by USAID and implemented by Emerging Markets Group, handles the land titling problems. One of its main objectives is to build trust between investors and the Government. The LTERA project combines an extensive mapping of the land, with the restoration of almost five million legal documents - including approximately 500,000 title deeds stored in the Registration Courts (Makhzan) which are dependent on the Supreme Court. The LTERA project also aims to improve land tenure, with pilots in two districts of Kabul. It is involved in the drafting of the Anti-eviction Law and the Informal Property Formalisation Law.

\section{Lack of Access to Formal Financing}

Access to credit has been identified as another of the main obstacles to investment in Afghanistan. ${ }^{9}$ Most banks are located in Kabul and provide service primarily to international donors and businesses, foreign Non-Governmental Organisations (NGOs) and foreign government agencies. Because the financial system is not structured enough, Afghan firms rely almost entirely upon internal funds and loans from friends 
and family to fund operations, or on loans provided by hawaladars.

Lack of legislation has been identified by the CEO of a major Afghan Bank as one of the main impediments to formal financing. Large commercial banks are reluctant to grant loans to business people because they do not receive any protection from the legal system or institutions. The absence of well-defined "company laws" (corporate or partnership laws) is a major issue. The lack of a Secure Transaction Law and poor property registries make it extremely difficult for borrowers to provide the necessary collateral to banks. As there is not any Mortgage Law, people who want to borrow from formal banks generally have to sell an asset to the bank, with the clause that they will get it back after having reimbursed their loan. Another issue is the absence of a Bankruptcy Law, which does not allow a secure creditor, such as a bank, to be reimbursed in priority in case of bankruptcy. As there is a separate background paper dealing specifically with finance issues, there is no further discussion of the problems associated with a lack of access to finance in this paper.

\section{Absence of Legitimate and Efficient Chambers of Commerce and Business Associations}

Two groups of chambers currently exist in Afghanistan: the Afghan Chamber of Commerce and Industry ${ }^{10}(\mathrm{ACCl})$, established 75 years ago; and the Afghan International Chamber of Commerce (AICC), founded in 2004 on the initiative of Afghan businessmen. A very limited number of business associations are also active, among which, for instance, is the Afghan Builders" Association (ABA).

$\mathrm{ACCI}$ and $\mathrm{AICC}$ vie ${ }^{\text {"l }}$ for official recognition: ACCI is supported and currently being reformed by the German Agency for Technical Cooperation (GTZ), whereas AICC is funded by USAID and supported by CIPE. This conflicting situation adds uncertainty to the business environment and does not allow businessmen to turn to a legitimate Chamber of Commerce or business association to represent their interests with the Government. Considering the current lack of legal protection for companies, Chambers of Commerce have a major responsibility in helping and promoting Afghan businesses. However, there is no current response provided to ensure that legitimate Chambers of Commerce or credible business associations providing resources, capacity building and governmental support to its members will arise.

\section{Commercial Court (Ministry of Justice)}

\section{Context}

The Commercial Court has three main objectives: registering companies as legal entities ${ }^{12}$, validating the transfer of property rights and ensuring legal protection for entrepreneurs (essentially by solving disputes between merchants).

\section{Issues}

Lack of rigour of the process: Currently all registrations with the Commercial Court are processed by the Ministry of Commerce or AISA most business people are therefore unaware that they have been registered with the Commercial Court. The Property Rights transfer procedure has been described by a specialist in land titling issues as not being rigorous. Two witnesses and reportedly some bribe giving have been sufficient, in certain cases, to allow an individual to become the legal owner of land.

\section{Little protection provided to businessmen:}

Above all, the Commercial Court seems to provide little protection to business people as the absence of commercial laws is a significant impediment to the arbitration of commercial matters. The Primary Commercial Court in Kabul hears only about 10 cases per month: it reportedly suffers from transparency issues, long delays and lacks qualified legal professionals. According to one of the judges, the enforcement capacity of the Court is very limited. Most interviewees in the Informal Sector Survey (ISS) conducted in May/September 2006 by Altai Consulting ${ }^{13}$ were indeed pessimistic about recovering debt, enforcing contracts or protecting trademarks through the Commercial Court.

\section{A dispute resolution system that few}

businessmen use: As a consequence, a large majority of businessmen seem to prefer informal arbitration mechanisms such as the Shura system $^{14}$ or rely, when they can, on other institutions such as the Chambers of Commerce, AISA or the Ministry of Commerce.

\section{Current responses}

According to the I-ANDS document, by the end of 2010 "the Government will continue its efforts to strengthen the judicial sector [...], improve the commercial courts system, property rights and enforcement mechanisms. ${ }^{13}[\ldots]$ A merit and performance-based system will hold officials accountable." 16 At present, the "Rule of Law Program" at the Ministry of Justice funded by USAID, among others, has notably started the training of judges of the whole judicial system and 
disseminated copies of Afghanistan's basic laws throughout the country.

\section{Ministry of Commerce and Industries (MoCI)}

\section{Context: Focus on the Trading Licence}

The process of obtaining a Trading Licence at the $\mathrm{MoCl}$ has been considerably simplified. ${ }^{17}$ The country was $16^{\text {th }}$ in the 2005 Doing Business rankings for starting a business ${ }^{18}:$ a major achievement.

\section{Issues}

Lack of legitimacy of the Trading Licence: The licence is a vestige of a time when Afghanistan had a controlled trading system. At present, the policy is designed to foster the development of an open, liberalised, market-based trade regime; therefore traders contest its use. However, the greatest benefit of the licence is the decreased tax burden paid by business people at customs: two percent ${ }^{19}$ of the costs of goods versus the three percent that nonlicensed traders pay. ${ }^{20}$

\section{Lack of transparency in licensing process:}

Official fees are not posted in all Departments throughout the country; officials interviewed during the fieldwork phase of the ISS produced only conflicting information about the costs and requirements of the licence. In spite of the reforms conducted, survey respondents of the ISS who registered in the last 12 months reported numerous delays and high unofficial costs (as illustrated in Case Study 3).

The difficulties faced by traders to obtain a Trading Licence have, among other factors, generated very negative attitudes toward the Government in general and some procedures specifically.

\section{Current Responses}

The Priority Reform and Restructuring ${ }^{21}$, a key component of the Public Administration Reform, is currently underway in the $\mathrm{MoCl}$. Some of its main objectives are to build a more efficient and serviceoriented public administration and to reduce costs for business people.

\section{Afghan Investment Support Agency (AISA)}

\section{Context}

AISA was established in September 2003 as a "one-stop shop" for investors, and charged with the responsibilities of registering, licensing and promoting all new investments in Afghanistan. It has dramatically streamlined the registration and licensing process, since only one step - at AISA is required from investors who are provided with an "Investment Licence". 22 AISA also helps business people in their interactions with governmental institutions; manages industrial parks; and organises road shows throughout other continents to attract potential investors and clients. AISA serves as a reference point for business people in terms of its efficient licensing process. ${ }^{23}$ According to ISS survey respondents, AISA is the state of the art institution in terms of transparency and they praise it overall as a model of efficiency.

\section{Issues}

Legitimacy of the Investment Licence: Some analysts criticise the legitimacy of the "Investment Licence" According to them, though registering as a legal entity at the Ministry of Justice is the norm in most countries, and adds significant value by correcting for market failure, ${ }^{24}$ the Investment Licence only imposes additional costs on investors: "Essentially, the AISA licence serves as a fundraising device for AISA." 25 Moreover, these additional costs are high: Fees associated with the licence (from US\$ 240 to US\$ 1,290) are very high compared to Afghanistan's per capita GDP (US\$ 300 in 2005), that is, 80 to 430 percent of GDP per capita. As a comparison, the average cost of registration in the OECD countries is 6.8 percent of GDP per capita. ${ }^{26}$

\section{Limited land available in Industrial Parks:}

Acquiring land is by far the most costly, timeconsuming and risky process which investors face in Afghanistan. ${ }^{27}$ AISA can provide options with five Industrial Parks ${ }^{28}$ already built or projected. AISA claims that its Industrial Parks ${ }^{29}$ are "modern, strategically located, well-managed, regulated and attractive" ${ }^{30}$ However, some analysts consider that an Investment Promotion Agency (IPA) should not manage Industrial Parks: "The international best practice is to have an independent economic/industrial zone authority developing and managing industrial parks." 31 


\section{Ministry of Finance - Mustufiats / Customs}

\section{Context}

A major reform of the tax system took place in 2005 with the adoption of the Income Tax Law, which established or confirmed several taxes: the Business Receipts Tax, the Corporate Income Tax, the Wage Withholding Tax and a set of Fixed Taxes for businesses without reliable documents.

\section{Issues}

Unrealistic taxation?: Though the tax burden in Afghanistan remains one of the lowest in the world, ${ }^{32}$ most managers interviewed in the ISS viewed taxes and customs duties as too high and inappropriate ${ }^{33}$ in the current economic situation Afghanistan being a society in which taxes have never been raised to the extent of the Income Tax Law. Many respondents also had the feeling that the money collected was not being used for the common good of the people. The main taxes of the Income Tax Law were regarded as unrealistic. Even though the BRT ${ }^{34}$ is deductible from the Corporate Income Tax, it is particularly unpopular amongst some managers who describe it as being too high ${ }^{35}$; a two percent ${ }^{36}$ tax on sales imposes a heavy burden on companies in a country where most businesses have a very low profit margin. One of the major drawbacks of the BRT is also that it is a cascading tax paid at each transaction, thus inflating by two percent, five percent or 10 percent the product prices at each step of the value chain. Very few ISS survey respondents had paid the 20 percent Corporate Income Tax (tax on profit) because of the lack of enforcement, but also because only large companies which operate with formal business practices actually have the capacity to calculate it.

Lack of transparency of tax collection: The Mustufiats are often pointed out as imposing an array of sukooks ${ }^{37}$ and "nuisance taxes" on a legal ${ }^{38}$ or pseudo-legal basis. The tax and duties collecting system was also reported by ISS survey respondents to break down because of a lack of transparency: Some revenue collectors have been reported to collect bribes. ${ }^{39}$ Managers often seem willing to pay bribes, not only when strictly required, in order to receive preferential treatment or to reduce the costs of registration or tax payment below official rates. ${ }^{40}$ More generally, the opacity of procedures at the Mustufiats and customs is pointed out. Businessmen often complain that the calculation of the amount of taxes they pay is unclear to them. ${ }^{41}$
For example, the implementation of fixed taxes seems to be largely arbitrary, as unregistered businesses without reliable records face highly unpredictable tax assessments. ${ }^{42}$

Unpredictability of the application of the law by the Government: The perceived unpredictability of the Government about taxation issues has created insecurity among investors. In 2003, the transitional Government granted four to seven year tax holidays for new investors, but since then, new investors have been informed not only that they were going to lose these tax holidays, but that they had to pay taxes for the previous years. ${ }^{43}$

Lack of communication: No communication efforts through the mass media currently exist concerning taxes and their use by the Government. The lack of communication appears to be one of the major issues for the Ministry of Finance. An advisor to the Revenue Department of the Ministry of Finance regrets that there is no funding available for advertising how funds that are collected are being used for the public good. Unrealistic taxation, perceived corruption and opacity of procedures, unpredictability of the Government and lack of communication efforts from the Ministry of Finance have generated, among other factors, widespread mistrust in the business community toward that institution.

\section{Current Responses}

Provincial Revenue Offices have been created in order to replace Mustufiats in seven provinces ${ }^{44}$ before being extended to the rest of the country. A competitive hiring process ${ }^{45}$ has enabled the Ministry of Finance to recruit motivated and reliable civil officers. These Provincial Revenue Offices will play a role very different from that of the Mustufiats, as they will not directly collect taxes. Thanks to the "Self-Assessment Program", which suppresses all interactions between business people and Mustufiat employees concerning the payment of taxes, tax payers will have to file a Tax Return Form and bring it directly to the Da Afghanistan Bank where payments will be made. Taxes should be self-assessed in Kabul for the 1385 $(2006-2007)$ fiscal year.

According to customs officials, customs are far from collecting what they should. Some experts estimate that revenue collection is less than half of what it should be. To increase revenues, a "fiveyear reform program" (2003-2007) is currently being undertaken, and tax collection is sharply increasing. A new Customs Tariff ${ }^{46}$ has also been implemented along with a comprehensive Customs Code. 
As a first step to address overly complex and bureaucratic importation procedures and corruption, a Single Administrative Document, ${ }^{47}$ based on the European Union format, was implemented in July 2003 in Kabul and since then in Herat, Kandahar, Mazar-e-Sharif and Nangarhar.

Concerning the sukooks and nuisance taxes, drafts of legislation are currently going through the parliamentary process, in order to amend the Income Tax Law and be clear about which taxes are legal or not. These legislative drafts aim particularly to suppress taxes not coming from the Income Tax Law, such as taxes imposed by stateowned enterprises or Municipalities, and taxes which were imposed by Presidential decrees. They also aim to simplify and make more efficient the "Fixed Taxes", According to an advisor of the Revenue Department of the Ministry of Finance, the BRT could be replaced in three to five years by a VAT system.

\section{RECOMMENDATIONS}

\section{Enhance the implementation of the Civil Service Reform}

A major Civil Service Reform should complement initiatives currently being conducted, drawing, for instance, on the "best practices" of AISA or on the implementation of the new Provincial Revenue Offices at the Ministry of Finance.

These "best practices" include re-hiring of civil servants through a strict selection process, constant training of civil servants, higher salaries and a "one-strike policy" for asking or accepting any bribe. Feedback from users having interacted with these government officials should also be systematically collected by an independent organisation.

To combat corruption, another major emphasis should be made to guarantee transparency of administrative requirements: Fee amounts and procedures should be posted in government offices, booklets should be made available to business people etc. Solutions such as the "Self-Assessment Policy", which suppresses all interactions between business people and civil service officers concerning the payment of taxes, could also constitute a "best practice" to combat comuption.

\section{Foster the adoption of Commercial Laws by Parliament}

Afghanistan is in need of new legislation, particularly of Commercial Laws. Partnership Law, Corporate Law, Contracts Law, Commercial Arbitration Law, Commercial Conciliation Law, Anti-Trust and Unfair Business Practices Law, Bankruptcy Law, Labour Law, Secured Transaction and Mortgage Law, Law on Foreign and Domestic Private Investment, Land Titling and Property Registration Law, Insurance Law, Land Ownership Law etc. have been drafted and are currently undergoing the adoption process by Parliament. Intense lobbying of the Parliament and relevant actors should be encouraged to accelerate the process. Once these laws have been enacted, a major communications effort on the existence and content of these laws should be implemented targeting the business community.

\section{Ensure a consistent application of the law}

An independent commission should be in charge of a permanent assessment of all Ministries, to make sure laws are applied consistently, Systematic assessment of civil servants' knowledge of the laws should be conducted and cross-checked with feedback collected from business people dealing with these civil servants. Training sessions on legislative and regulatory requirements should be conducted routinely in Ministries and be made compulsory for civil servants.

\section{Redefine AISA's mandate: Toward a unique "Business Licence", managed by AISA}

The complexity of the current licensing system in Afghanistan (56 different licences), and the success of the AISA "Investment Licence", suggest that AISA should take charge in the licensing process for all businesses in Afghanistan by providing a unique "Business Licence".

AISA would then become a "one-stop shop" for all businesses willing to get a licence, and would take care of all the required formalities ${ }^{48}$ to register a business in Afghanistan. This "Business Licence" would exist in three formats: one for investors; one for traders (its delivery would then require approval from an official of the Ministry of Commerce detached at AISA); and one for industries formerly requiring a specific licence (its delivery would also require approval from an expert of the relevant Ministry). Involvement of officials from the Ministry of Commerce and from other Ministries 
should ease the transfer of responsibilities. The cost of this AISA "Business Licence" should be much lower than that of the AISA "Investment Licence" so that all types of businesses could afford it. Nonrelevant industry-specific licences should be abolished. This reform would introduce a major change for AISA, which should transfer its investment promotion activities to another organisation such as the Chamber of Commerce. The management of industrial parks should remain under AISA's responsibilities, as it can constitute a powerful incentive for businesses to get the new "Business Licence". These industrial parks should become much more numerous and the Government could consider transferring the industrial parks currently owned by the Ministry of Mines and Industries to AISA to be rehabilitated.

A major communications effort directed toward the business community should also be conducted to make sure the new registration requirements are clear to all.

\section{Help the Ministry of Finance to conduct a major communications effort}

The reforms currently underway at the Ministry of Finance, particularly regarding tax collection (implementation of Provincial Revenue Offices, Self-Assessment policies), should be advertised.

A particular communications effort (TV spots, radio spots, billboards) should be made on the usage of the public money collected by the Ministry of Finance (building of roads, hospitals etc.), as there seems to be a widespread feeling in the country that this money is not being used for the common good.

\section{Foster the solving of land titling issues and access to land}

As access to land remains one of the major challenges Afghan business people face, more aid resources should be devoted to solving this issue. The development of industrial parks should also be fostered.

Most of these recommendations are in line with the Government of Afghanistan's ongoing reforms at the national, provincial and local level, and the efforts of these institutions should be encouraged. Moreover, Afghanistan 's leadership should create an enabling environment through the provision of sustained political support for such a broad endeavour.

\footnotetext{
' World Bank, The Investment Climate in Afghanistan: Exploiting Opportunities in an Uncertain Environment, 2005, p. 24 .

2 This formal system remains limited as a relatively small number of laws have been enacted since 200I.

${ }^{3}$ Survey conducted by the World Bank for the report.

${ }^{4}$ I-ANDS, p. 165.

${ }^{5}$ The Income Tax Law has provisions for assessing taxes
} on the income of individuals and companies which do not keep sufficiently accurate records to pay taxes based on profit and loss statements. These so-called "Fixed Taxes" are imposed in lieu of the formal taxes, such as the Business Receipts Tax or the Corporate Income Tax. "Among the "Strategic Benchmarks" set in the I-ANDS document by the Afghan Government, one statement says that by the end of 2010, "the legal framework required under the Constitution, including [...] commercial law, will be put in place, distributed to all judicial and legislative institutions, and made available to the public." ${ }^{7} \mathrm{MoCl}$, Investor Roadmap, p. 3-4

${ }^{8}$ During the 20 years of conflict endured by Afghanistan, many land titles were lost or damaged, and many others forged - while the population of the country and of its major cities, particularly Kabul, dramatically increased. In Kabul, for instance, according to a USAID official, 70 to 80 percent of people live in informal settlements. The last Master Plan for the city was designed in 1978 for 500,000 inhabitants.

"In the World Bank's 2005 "Doing Business Report", Afghanistan ranks 153 out of 155 countries for getting credit, a measure of credit information sharing and legal rights of borrowers and lenders.

${ }^{10} \mathrm{ACCl}$ was reported by interviewees to have limited activity. According to one of its Commercial Deputies, the Kabul ACCI deals with a reduced amount of issues brought to them by entrepreneurs: less than 15 per month. 11 To solve the conflict between $\mathrm{ACCI}$ and $\mathrm{AICC}, \mathrm{ACCI}$ was at the origin of a survey among businessmen and of several conferences which took place between June and August 2006. The whole process concluded the supremacy of ACCI, but the results are contested: a key advisor to AICC described the survey as "totally illegitimate". A law on the Chamber of Commerce is reportedly being drafted; if $\mathrm{ACCI}$ comes out as the only legal Chamber of Commerce, AICC will then become only an association of businessmen.

${ }_{12}$ This process is comprised of three steps: obtaining police clearance; obtaining a Tax Identification Number (TIN); advertising in the official gazette giving the basic information of the proposed firm: name, business, ownership.

${ }^{13}$ Informal Sector Survey, conducted by Altai Consulting for the Ministry of Commerce and Industries/Adam Smith International, May-August 2006.

${ }^{14}$ World Bank, The Investment Climate in Afghanistan. 2005, p.26; I-ANDS, p. 122.

${ }^{15}$ I-ANDS, p. 165.

${ }^{16}$ I-ANDS, p. 122.

${ }^{17}$ Reforms were conducted under a Bearing Point/TSG Investor Roadmap project in 2004. The number of signatures needed to obtain a Business Licence has been reduced from 53 to five and the time to obtain a licence from six/eight weeks to five/seven days (MoCI, Investor Roadmap, p.4).

${ }_{18}$ This ranking takes also into account the Investment Licence at AISA, which requires only one step. A 
problematic barriers for investors worldwide (investment registration and licensing) has thus been successfully addressed in Afghanistan.

${ }^{19}$ Including Duties.

${ }^{20}$ The rationale behind the discounted rate is that licensed traders are registered with the Government and can be held accountable for the balance ( 2 percent on the subsequent sale price and 20 percent of annual profit) at the end of the year.

${ }^{21}$ Adopted by the Government of Afghanistan in 2003 by Presidential Decree, the PRR is the responsibility of the Independent Administrative Reform \& Civil Service Commission (IARCSC).

${ }^{22}$ AISA takes care of all other formalities: acquisition of a Tax Identification Number, handling the investor's obligations of reporting to the Central Statistics Office, and ultimately registering their investment at the Commercial Court.

${ }^{23}$ As P Tel's manager states in Case Study 5: "It gives me hope that this kind of modern system [AISA] is working here in Afghanistan."

${ }^{24}$ For instance, the registration procedure is necessary so that the investment project becomes a juridical entity that can enter contracts, sue or be sued, etc. (MoCI, Investor Roadmap, p.3).

${ }^{25} \mathrm{MoCl}$, Investor Roadmap, p. 23.

${ }^{26}$ World Bank, Doing Business Database, 2005.

${ }^{27}$ Many companies interviewed during the fieldwork cited lack of land as a major challenge they face.

${ }^{28}$ The first phase includes Industrial Parks in Kabul (Bagrami), Kandahar, and Mazar-e-Sharif; the second phase includes Industrial Parks in Kabul (Kamari) and Jalalabad, and are USAID-funded.

${ }^{29}$ Industrial Parks owned by the Ministry of Mines and Industries seem to provide fewer facilities. The owner of a manufacturing company interviewed during the fieldwork of the survey, who did not manage to get a land from AISA but got one from the Ministry of Mines and Industry in the Industrial Park of Pul-e-Charki, complained about the absence of a canalisation system in his industrial park: He himself had to dump used water in the desert; he also mentioned that he spent a lot of money to keep running a generator for his plant as the industrial park did not provide for any electricity.

${ }^{30}$ Companies can buy land in AISA's industrial parks at US\$ 25 per square meter.

${ }^{31} \mathrm{MoCI}$, Investor Roadmap, p. 30.

${ }^{32}$ The World Bank's Doing Business Database finds that a "typical" company pays 21,4 percent of its gross profits in taxes in Afghanistan, compared to 35.3 percent on average in South Asia and 57.4 percent in Pakistan. Only Iran, which benefits from oil revenues, has lower taxes. The average import duty in Afghanistan is only 4 percent of the cost of the goods imported, the lowest rate in the region.

${ }^{33}$ Customs duties on raw materials are particularly criticised. Many respondents claim they should be lifted to support Afghan businesses.

${ }^{34}$ The BRT is a first step toward a Value Added Tax (VAT). At the moment, according to an advisor to the Ministry of Finance interviewed, there is not the capacity in the Mustufiats to collect the VAT.

${ }^{35} \mathrm{P}$ Tel's manager in Case Study 5 resents the BRT: His profit margin is so low ( 1 percent or lower on average) that it would obliterate any possible profit.
${ }^{36}$ The BRT amounts to 10 percent of income from services used by high-income consumers, such as hotel receipts, restaurants, telecommunication services and airlines; to five percent of passive income, such as interests, dividends, rents, and royalties; to two percent for all other goods and services.

${ }^{37}$ Which amount to additional fees charged to cover the expense of tax collection.

${ }_{34}$ Generally Presidential Decrees.

${ }^{39}$ As illustrated in Case Study 5.

${ }^{40}$ The owner of a construction company interviewed in the survey thus explains that he escapes paying taxes by giving bribes and having his company recorded as not functional during the previous year.

${ }^{41}$ Lack of information about taxes and calculations procedures is illustrated in Case Study 2.

${ }^{42}$ As explained before, the Income Tax Law has provisions for assessing taxes on the income of individuals and informal companies which do not keep sufficiently accurate records to pay taxes based on profit and loss statements. These so-called "Fixed Taxes" are imposed in lieu of the formal taxes, such as the BRT or the Corporate Income Tax.

${ }^{43}$ According to the Government, only firms that did not complete the formalities to receive the tax holidays in a timely manner or were promised them by unauthorised persons are loosing them. However, many firms were not aware of what the exact process was when they made their investment.

${ }^{44}$ Kabul, Kandahar, Nangarhar, Parwan, Balkh, Herat and Kunduz.

${ }^{45}$ Two hundred people have been recruited out of 1,200 applicants through a series of exams.

${ }^{46}$ The Tariff structure has been simplified: The range of tariffs has been reduced from a maximum of 150 percent to a range of 2.5 to 16 percent of the costs of goods. ${ }^{47}$ ASYCUDA (the Customs Automation system promoted by UNCTAD Geneva) will implement and computerise the final version of the Single Administrative Document.

${ }^{48}$ Acquisition of a TIN at the Ministry of Finance, handling of the investor's obligations of reporting to the Central Statistics Office, registration of the company at the Commercial Court. 



\title{
CHALLENGES PRESENTED BY THE LEGAL, REGULATORY, ADMINISTRATIVE AND FISCAL FRAMEWORK GOVERNING CIVIL SOCIETY
}

Background paper prepared for the Enabling Environment Conference by:

\author{
International Center for Civil Society Law
}

Dr. Leon E. Irish and Prof. Karla W. Simon

\section{INTRODUCTION}

This paper aims to address the legal framework for civil society and sector sustainability that would provide an enabling environment for private initiative in Afghanistan. Within this context, it is important to first describe the universe of organisations that will be considered. The organisations are referred to in Dari or Farsi as Jame'a Madani, sozman-e khair-e dawlati, or sozman-e-itjima. The English terms for such organisations are civil society organisations (CSOs) or non-governmental organisations (NGOs). None of these organisations are part of the government, nor are they political parties or business organisations (though they include associations of business organisations). They are all organised as not-for-profit bodies, whether they are mutual benefit organisations (MBOs) meaning that they benefit members of the organisation, or public benefit organisations (PBOs) meaning organisations that benefit a significant segment of the public.

Some examples of MBOs in Afghanistan include:

- Organisations of origin - tribes, ethnic groups, clans, qawm

- Organisations of religion - shias, sunnis, sufis, salafis, wahabis
- Traditional organisations that manage daily life shuras, mirab, haqaba, aasher, komites (for people from Pakistan)

- New organisations that manage daily life - "new shuras", community development councils (CDCs)

- Organisations for the betterment of a profession or trade (bazaar merchants associations, traditional guilds of, for example, weavers or silversmiths, workers or farmers unions and different kinds of cooperatives ${ }^{1}$ )

- Organisations of cultural or recreational life Buzkashi teams, wrestling teams, pigeon flying groups, singing, poetry and dancing associations

Some examples of PBOs in Afghanistan include:

- Zakat committees - usually organised through mosques

- Foundations (e.g. Massoud Foundation, Bayat Foundation) which make grants to local CSOs

- Service providing organisations offering, for example, education (particularly madrassahs), health (e.g., Aga Khan Hospital in Bamyan), loans through microfinance provision, and technical assistance for agriculture, such as irrigation canals 
- Democracy and human rights organisations (e.g., Independent Human Rights Commission, various women's organisations etc.)

- Research organisations - Afghan Research and Evaluation Unit (AREU) and others

- Groupings of CSOs - Forum for Culture and Civil Society (FCCS), ACBAR, ANCB and ACSF

Within reference to these types of civil society organisations, ${ }^{2}$ the consultants have concluded that the current legal framework for civil society organisations (CSOs) in Afghanistan, while somewhat redundant and confusing, has many of the attributes that are requisite for an "enabling" legal framework for CSOs. Many of the laws, however, are old and in need of modemisation. In addition, their application appears haphazard, and certain aspects of the way in which they relate to each other have created considerable confusion for CSOs, the government and funding organisations. Moreover, some legal reform efforts (e.g., the effort to write the NGO Law, which was adopted in 2005) have taken time and attention away from more complex issues raised by the legal system for CSOs in the country.

Finally, there are systemic problems that inhibit the growth of a healthy civil society in Afghanistan.

These include the:

- Lack of a culture of trust and mutual support

- Lack of a culture of philanthropy

- The questionable legitimacy of some organisations that are classified as CSOs

To address these problems, legal reforms should look holistically at what further efforts are needed to make it easier for the Afghan people to establish and fund all kinds of CSOs.

In order to address the systemic problems described above, law reform efforts should:

- Aim to reinforce social development by providing the underpinnings for a more stable and indigenous civil society

- Ensure that the laws are comprehensive and straightforward in their provisions and transparent and consistent in their application

- Adopt a modern view of the traditional Afghan and Muslim legal forms, one that is consistent with notions of Islamic philanthropy developing in other Muslim nations. The approach to legal reforms recommended in this report is structured in terms of the traditional Afghan legal framework, which comes fundamentally from the basic civil laws promulgated in 1921 in a nizamnama of King Amanullah. This framework was updated in the Civil Code (CC) and adopted in 1977, which is still applicable today. The report also suggests revisions in the current framework for CSOs to correct provisions drafted in ignorance of those traditions.

\section{CASE STUDIES}

The report is based on a series of case studies, which are described here. They involve legal problems faced by both domestic and foreign ${ }^{4}$ CSOs seeking to operate in the country, as well as the problems faced by the government agencies seeking to process CSO applications and exercise effective oversight of the operations and activities of CSOs.

\section{Case Study 1: Domestic CSO - membership organisation (association)}

\section{Organisation set up for water project implementation in partnership with a foreign organisation}

A local shura has been contacted by an international development organisation that wishes to implement a project to build water supply systems for drought relief near Kabul. It has been asked to partner with the international organisation or to find a group of citizens that will set up an organisation to partner with the international organisation. The shura would like to assist with the project in the local community because the needs are great, but it will need to be registered as an association in order to do so.

\section{Association of doctors wishing to establish a community medical clinic}

A local group of doctors wants to establish a medical clinic to provide medical care in a poor neighbourhood in Herat. An entrepreneur has donated the building and equipment, so there is little start-up cost. Since the doctors and nurses will volunteer their time, there is little need for additional resources for operations, but the group may need to import some medical supplies. The doctors expect to receive contributions from wealthy members of the community to support the clinic and pay for imports. 
Association set up by deaf people to assist themselves in their social, economic and cultural life

A group of deaf people has decided to establish a self-help organisation because of the lack of job opportunities and insufficient family and governmental support systems for deaf children and adults. The group expects to raise money from membership fees and government grants.

Each of these groups and the shura will need to decide whether to register as an NGO under the 2005 NGO Law or as a Social Organisation (SO) under the 2002 Social Organisations Law. If it registers an SO, it will register with the Ministry of Justice (MoJ), and if it registers as an NGO, it will register with the Ministry of the Economy (MoE). Each of these legal forms requires a membership governance structure, which will be appropriate for the types of CSOs mentioned here, as the contemplated activities are typical membership organisation activities. (See Art. 9 and Art. 23 of the SO Law, which incorporates CC Arts 403-439 by reference; NGO Law Art. 14.5)

Unfortunately, it is difficult to advise these groups as to which registration system to use because certain issues are not settled under one or both of these laws.

These include:

- Issues regarding the application process (including how many members an organisation must have to register and whether it can have foreign members)

- Lack of clarity about reporting requirements once an organisation is registered

- Lack of clarity about internal governance requirements for a domestic CSO registered in Afghanistan

- Whether an organisation can have access to foreign funding

- The extent to which the organisation and its donors will receive tax benefits (including exemption from income taxes and customs duties)

\section{Case Study 2: Domestic CSO - non-membership organisation (foundation)}

\section{Grant-making secular foundation}

A wealthy person in Afghanistan wishes to establish a foundation that functions like foundations in other civil law countries by making grants to support civil society organisations within the country that are engaged in a variety of reconstruction or development projects. The wealthy person does not want to have a membership organisation (an association) because members would be able to elect the Board of Directors; he wants control of the organisation to remain with his family,

\section{Grant-making foundation that will also receive contributions}

The family of a dead Afghan hero wishes to establish a traditional foundation in his name. Similar to the wealthy person, the family does not want to establish a membership organisation because it wishes to control the Board of Directors. In addition, the foundation knows that it will be able to raise money abroad and use it for the support of civil society activities in Afghanistan.

\section{Aufac}

A wealthy figure (an Arbab or Zamindar) wishes to establish an aufac for the benefit of a mosque in a village so that it can continue to provide needed social services to the poor. He has been told that he can do so by consulting with the Ministry of Haj, Ershad and Aufac, but he can find no one to help him or give him information about what he should do.

The organisers of each of these organisations understand that the Civil Code provides for the form of "foundation" or aufac and that other organisations have already registered as foundations (buniyat) or aufac in Afghanistan. Yet, none of them can find good information on how and where to register their organisations. There is also no information available with respect to whether tax benefits are available for gifts to the organisations, either from the founder(s) or others, or what the rules are about fund-raising abroad.

\section{Case Study 3: International/foreign CSO - branch office to carry out an education project for women and girls}

An international or foreign organisation is seeking to set up a branch office to carry out education projects for women and girls in Afghanistan. It realises that it will face political and social problems, but it believes it can resolve these by partnering with local organisations that are already involved in these issues. However, it must deal with the question of how to register a branch organisation to carry out its projects in Afghanistan. 
It is already established as a domestic organisation in Germany, and it has been promised funding from GTZ to carry out its work in Afghanistan.

\section{Case Study 4: Government Ministries}

\section{Ministry of Justice}

Registration and oversight of the approximately 80 political parties and over 450 Social Organisations in Afghanistan is in the hands of the MoJ's Department of Coordination, Evaluation, and Registration of Political Parties and Social Organisations. The MoJ reviews applications for registration to obtain legal entity status, but it appears not to require annual reports from the SOs subject to its jurisdiction.

Ministry of Economy

The Ministry of Economy's NGO Department registers and oversees the approximately 1,100 NGOs registered in the country (of which more than 850 are domestic and 250 are foreign). It is apparently staffed with high quality professionals who understand their work.

\section{Ministry of Haj, Ershad and Aufac}

There is no indication from interviews or in the literature that this Ministry is functioning at all with respect to CSOs despite the role envisioned for it by the Civil Code, ${ }^{6}$

\section{Ministry of Finance / Tax Administration / Customs Administration}

There is no indication that the Ministry has begun to administer Article 11 of the Income Tax Act, which provides tax exemption for various public benefit organisations. It is also unclear to what extent the Ministry is dealing with customs exemptions except on an ad hoc basis.

\section{ANALYSIS OF THE CASE STUDIES AND THE ISSUES THEY RAISE}

\section{Successes and gaps in the current legal enabling environment - technical analysis}

\section{Successes}

One significant success at present is that the numbers of CSOs and NGOs registered in Afghanistan are increasing, and most of them appear to be doing good work focused largely on the reconstruction and development of the country.
It also appears that the government's antagonism toward NGOs has receded in response to the enactment of the NGO Law in 2005. Nonetheless, there is clearly a real desire on the government's part to control foreign funding of domestic CSOs (most certainly those that are registered as NGOs), and this needs to be considered in any legal reform process. In addition, there are the overarching systemic problems mentioned in the introduction, which must be recognised and considered as part of the legal reform process.

\section{Gaps}

Despite these successes, problems arise at the policy level due to a general lack of understanding of good legal structures for civil society. Problems arise at the implementation level due to inadequate funding and staffing, and applications for registration not having been adequately streamlined by the agencies. This report does not suggest that there is any lack of good will on the part of the $\mathrm{MoJ}$, the MoE and the MoF, but rather that the constraints they face make effective, consistent and efficient application of the existing policy framework almost impossible. This section analyses the current gaps in the legal environment for CSOs as it applies to the Case Studies from Section 2. It looks principally at technical issues, reserving the analysis of the systemic issues in the below sub-section (iii) titled "Overview of current successes and current systemic problems".

\section{Domestic membership organisations}

Almost all domestic CSOs currently operating in Afghanistan are membership organisations (associations, in the terminology of the civil law). They have membership governance structures; with a General Assembly as the highest governing body of the organisation (see CC Arts 429-436). The Civil Code, the SO Law and the NGO law require this structure. The three organisations set up to deal with the water project, the medical clinic and aid to the deaf described in the Case Studies will thus be membership organisations.

Aspects of the legal regime that would militate in favour of each of the organisations registering as SOs include the following:

Application process. The application process for NGOs at the MoE, which involves both the "Technical Commission within the NGO Department of the Ministry of Economy" and a "High Evaluation Commission" for final review of registration applications, is problematic because of its complexity and the possibility of inconsistent, or perceived inconsistent, application of the process, 
sometimes for political or personal reasons. The intricacies of the process provide various opportunities for bribery to take place.

Furthermore, it appears that the process set up by the NGO Law confuses two issues: 1) the acquisition of legal entity status and 2) the certification of an organisation to engage in development activities.

It is highly unlikely that a CSO that did not want to engage in development activities would register as an NGO. Even an organisation arguably involved in development, such as the medical clinic, would find it advantageous to register as an $\mathrm{SO}$ with the MoJ rather than an NGO with the MoE because the MoJ process is simpler and quicker. After being registered in Kabul, it could apply for a licence from the appropriate line local ministry office in Herat (e.g., to the Ministry of Health for permission to operate the medical clinic). No licence would be required for the self-help organisation for the deaf; registration under the simpler process for SOs at the MoJ would suffice.

The time period within which the MoJ must act on an application for registration of an $\mathrm{SO}$ is unclear because of a conflict between the Civil Code ( 60 days) and the SO Law ( 30 days) that needs to be resolved. However, since the registration process for SOs cannot take longer than 60 days and is much less cumbersome than the process under the NGO Law, there appears to be a significant advantage to registering as an SO.

Reporting requirements. The NGO Law imposes quite burdensome reporting requirements, and these could become even more burdensome if the amendments proposed by the MoE are passed by Parliament. ${ }^{7}$ A significant reason for this is that the NGO Law seems in fact to be aimed at controlling foreign funding for development and not organisations that are domestically funded either by government or by private donations. The Civil Code imposes reporting requirements on all associations, which would include NGOs as well as SOs, ${ }^{8}$ but these are apparently not enforced by the $\mathrm{MoJ}$ vis-à-vis registered SOs, and the $\mathrm{MoE}$ appears to apply only the reporting requirements of the NGO law.

Confusion about the reach of NGO and SO laws may mean that the domestic organisation set up to carry out the water project, even though clearly a foreign-funded development project, can avoid the reporting requirements of the NGO Law by registering as an $\mathrm{SO}$. There appears to be uneven application of the rules: some organisations register only as an NGO or an SO, while others register as both SOs (to receive legal entity status) and as
NGOs (to be able to engage in NGO-type development activities). This means that such organisations will go through a two-step process (which the NGO Law appears to have been designed to avoid). It is easy to understand why there is confusion and frustration about the system not working properly.

Governance requirements. The SO Law provides significant and useful guidance as to the intemal governance of an organisation, including rights and duties of members and the roles of the General Assembly and the Board of Directors, because it includes by reference the governance provisions of the Civil Code applicable to associations. Thus, all three organisations mentioned in the Case Studies should refer to the formal requirements of the SO Law/Civil Code in drafting their articles of association. Although the NGO Law has no internal governance standards of its own and makes no reference to the provisions of the Civil Code, these Code provisions should be regarded as necessarily applicable, for NGOs are a form of association.

Non-distribution constraint. Both the Civil Code and the SO Law are clear that the non-distribution constraint applies to SOs. ${ }^{9}$ The NGO Law does not have a comprehensive non-distribution constraint, although it does forbid the distribution of profits (Art. 22(4)) and, in a separate article, distributions on dissolution (Art. 37(1)). However, the provision in the NGO Law Art. 22 (4) stating that "Directors, officers, and employees may not carry out any economic transaction with the organisation" is too strict as it forbids transactions favourable to the organisation as well as those that might be unfavourable. This might influence an organisation to register as an SO.

On the other hand, there are also three possible reasons why an organisation may want to register as an NGO instead of an SO:

Access to foreign funding. Some have suggested that the MoJ does not permit SOs to receive foreign grants and that only NGOs - but not SOs - are project implementers. If that were true, then the proposed domestic organisation in the Case Study that will carry out the water project would seek to register as an NGO.

Evidence suggests that both assertions are untrue in terms of actual practice. Many prominent SOs, such as the Afghan Civil Society Forum (ACSF), Foundation for Culture and Civil Society (FCCS) and the Massoud Foundation receive foreign funding and implement projects. Statements by SOs about the situation ${ }^{10}$ also clarify that SOs can both legally receive foreign funds and implement projects. ${ }^{11}$ Nevertheless, confusion about the issue 
continues, and this may cause some development organisations to think that they must register as NGOs.

Foreign members. A domestic organisation might want to register as an NGO as opposed to an SO if it wanted to include foreigners as members. While the Civil Code is at best vague about whether foreigners can be members (and the SO Law does not forbid it), the NGO Law is clear that foreign membership (including as founders) is permitted. It should be clarified that all domestic organisations are permitted to have foreigner members.

Number of founding members. The NGO Law requires only two founders while the SO Law requires 10 . This may cause some organisations to seek registration as NGOs. A useful change in the SO Law would reduce the number of founders to three or even two.

A further issue to consider is one that some think is decisive but which, upon examination, turns out not to favour one form of registration over the other. That is the issue of tax privileges.

Income tax exemption. Any non-profitdistributing Afghan domestic organisations that are organised for and engage in education, cultural, literary, scientific or charitable purposes are exempt from income tax under Art. 11 of the 1965 Income Tax Act (as amended in 2005). Income from commercial activities of such organisations that is "not in keeping with the purposes of the organisation" is, however, subject to tax. What this appears to mean is that all public benefit CSOs will be exempt from income tax on their income from gifts, grants, membership fees, investment income, and perhaps income from commercial activities that further the public benefit purposes of the organisation.

The self-help organisation for the deaf mentioned in the Case Studies can argue that it should be tax exempt because it is both educational and charitable, but whether this argument will prevail is uncertain because the tax authorities have yet to issue regulations or guidance as to what will be considered to fall within Art. 11.

Customs duties. Art. 27 (2) of the 2005 Customs Code by its terms grants exemptions for goods imported into the country "by or for public and private foreign and International relief and development agencies approved by the Government". Therefore, if a domestic CSO (whether an SO, an NGO or a foundation) were carrying out a relief or development project for an approved foreign or international agency, it would have a strong argument that goods imported for that project should be exempt from customs. ${ }^{12}$ The provision of the NGO Law allowing for a "Customs Law" exemption for NGOs for goods "related to and necessary for not-for-profit and charitable purposes," however, is both broader and more narrow than the Customs Code, as it is limited to NGOs and purports to make exemptions available even for projects not carried out for approved foreign or international relief or development agencies. The Customs Code states specifically that "[i]f any provisions from this law are in conflict with the provisions of any other legislation, the provisions of this law shall prevail." 13 This would make the provision in the NGO Law invalid to the extent it is inconsistent with the Customs Code Furthermore, any goods imported for the water project should be exempt from customs even if the organisation registers as an SO, at least if the intemational organisation funding the project has been approved by the government. On the other hand, medical supplies imported by the medical clinic would not be entitled to customs exemption under Article 27(2) of the Customs Code (unless funded by an approved foreign or international agency), though it might be entitled to exemption under other provisions that, at least in translation, are not clear. ${ }^{14}$

Benefits for donations. At the present time, there are no benefits for charitable contributions to public benefit CSOs, which may limit the possibility for the medical clinic to receive the donations it needs to sustain itself.

\section{Domestic non-membership organisations}

\author{
Although most CSOs in Afghanistan are \\ associations, with a membership governance \\ structure, some call themselves foundations (e.g., \\ Foundation for Culture and Civil Society (FCCS), \\ Massoud Foundation, Bayat Foundation, \\ Foundation for Free and Fair Elections). It is \\ difficult to determine in each instance whether or \\ not they really are foundations in the traditional \\ civil law meaning of the term (i.e., non- \\ membership organisations); some organisations \\ either are or want to be, such as the Bayat \\ Foundation.
}

Unfortunately, although the Civil Code provides for foundations and aufac, there appears to be no interpretation or implementation of these Civil Code provisions, whether the organisation is a private foundation that makes grants, a publicly supported foundation, or an operating foundation carrying out its own projects. There is also a lack of clarity about what the rules are for aufac and whether or not the Ministry of Haj, Ershad and Aufac is currently registering such organisations. The Ministry does not appear to exercise any 
oversight with respect to them. In addition, although some of the current foundations raise funds abroad, it is not clear what the legal rules are for bringing these funds into Afghanistan.

The 1977 Civil Code provisions on foundation registration either are no longer implemented or have been overtaken by developments in society they specify registration at local registration offices, which appears not to occur (in keeping with the centralisation of government functions). ${ }^{15}$ Although no registration or supervisory role for foundations has been assigned to the national office of the $\mathrm{MoJ}$, some foundations apparently have registered there. The 1977 Civil Code assigns oversight responsibility with respect to oversight of all foundations or endowments to the Ministry of Haj, Ershad and Aufac, but this is not currently occurring due to a lack of capacity with regard to both aufac and foundations, and a lack of competence with regard to foundations.

In addition, regardless of how the question of the registration of foundations is resolved, the current legal framework leaves large gaps with respect to the internal governance and reporting requirements for foundations and aufac, and the extent to which they may receive foreign funding. The customs duty issues raised above regarding associations should presumably be resolved by making the treatment of foundations and aufac consistent with the treatment of domestic membership organisations. $^{16}$

The inadequate and uncertain regulation of foundations and aufac not only represents a huge gap in the legal framework for domestic CSOs, but also raises concerns for one of the most potentially important vehicles of resource development and financial sustainability of the CSO sector in Afghanistan. Without a functioning system for registering foundations and aufac and exercising oversight with respect to them, there are, in principle, no legal vehicles for the development of local fund-raising structures such as private zakat funds (which resemble Western community foundations but could be established as aufac) or private endowed foundations that could provide grants to domestic CSOs for the support of social and economic progress. Other civil law countries, including Muslim ones such as Yemen, have welldefined legal rules for non-membership CSOs, which support the formation and functioning of foundations. The gaps in the Afghan legal environment, as well as practices elsewhere, suggest that there are significant legal issues for non-membership organisations that need urgent resolution as part of a comprehensive reform process in Afghanistan. In sum, the foundation for the dead Afghan hero and the aufac to aid the poor through a local mosque mentioned in the Case Studies are currently left without any useful legal guidance.

\section{Foreign and International CSOs}

An international CSO, like the German one in the Case Study, which wishes to conduct projects in Afghanistan, faces different issues from those that confront a domestic organisation. Consistent with rules applied in other countries, a foreign or international CSO is able to establish a branch in Afghanistan by applying first to the Ministry of Foreign Affairs for clearance and then registering a branch office with the $\mathrm{MoE}$ (it really has no choice but to use the NGO Law to register its branch, as the SO Law would not apply to it). If the GTZfunded organisation does successfully complete the $\mathrm{MoE}$ registration process, it will be recognised as a foreign or international organisation under Art. 5 of the NGO Law, and it will be subject to the oversight provisions contained in the NGO Law. The rules for registration and oversight of foreign and international CSOs under the NGO Law are fairly straightforward.

Problems arise, however, with respect to all sorts of administrative issues once the organisation begins to do its work in the country (licence plate renewals, visas, etc.). It is doubtful that complete resolution of these issues is possible in the present climate, where there is considerable suspicion about foreigners and foreign funding.

One current confusion in the NGO Law as written (but apparently not as applied) will be cleared up once the proposed amendments to it are made. This concerns the scope of the law as it applies to foreign organisations, which clearly do not want to have to establish themselves as separate, domestic organisations. ${ }^{17}$

With regards to taxes, foreign and international CSOs are on the same footing as domestic organisations when it comes to income taxes. They are, however, currently treated more favourably than domestic organisations with respect to customs duties (Art. 27 (2) of the Customs Code by its terms grants exemptions for goods imported by or for approved international and foreign organisations, at least to the extent that import of construction materials is not involved), ${ }^{18}$ although it does appear that some domestic organisations have been receiving customs duty exemptions through special, one-off applications. 


\section{Roles and responsibilities}

There is significant confusion about roles and responsibilities between the $\mathrm{MoE}$ and $\mathrm{MoJ}$ because of confusion about which laws apply to which types of organisations and how they should interact with each other. It would be possible to clear up much of that confusion by making the entire NGO "registration" process a second step after acquisition of legal entity status. Thus, all domestic CSOs, whether membership or non-membership organisations, would obtain legal entity status by registering with the MoJ as set out in the Civil Code and the SO Law. If they were then to desire to engage in reconstruction or development projects, they would register as "NGOs" with the MoE. This would force all CSOs to have effective oversight if they were to receive foreign funds for social and economic development activities. This separation of functions would allocate responsibilities between the two ministries according to their relevant competencies; this is suggested in the Recommendations in Section 4.

\section{Ministry of Justice}

Various studies ${ }^{19}$ of the MoJ Department of Coordination, Evaluation and Registration of Political Parties and Social Organisations indicate that the Department is understaffed (it has only 15 staff members and they are all based in Kabul) as well as underfinanced. Its role is complicated by the fact that the laws governing reporting obligations and oversight responsibilities are unclear with respect to the organisations it registers. While there is some guidance in the Civil Code and the SO Law about how SOs are supposed to function in terms of internal governance, there seems to be no oversight exercised by the MoJ in this regard. ${ }^{20}$ Clearly, the laws regarding the MoJ duties and powers need to be clarified and its competence and capacity strengthened.

\section{Ministry of Economy}

The MoE NGO Department appears to be adequately staffed and competent. Nevertheless, the Department is under-funded which could lead to future problems with bribery (because salaries are so low). More financial resources should be allocated to this Department in order to prevent this from happening. In addition, a proper division of duties between the MoJ and the MoE might relieve some of the pressure on the MoE. The MoE's NGO Department is currently most concerned with operating a licensing system for CSOs seeking to conduct development projects in Afghanistan with foreign funding. It seems to be little engaged with ensuring that such organisations practice good governance or have high standards. We suggest that the best division of labour would be to have the MoJ engage in registration (to achieve legal entity status) and oversight functions for all CSOs, with the $\mathrm{MoE}$ in charge of overseeing only those that receive foreign funds (to certify them to pursue their development activities and to oversee them to ensure they do so properly). This separation of functions would be similar to that in other countries, such as Bangladesh, India and Pakistan.

\section{Ministry of Haj, Ershad and Aufac}

Studies indicate that this Ministry, which administers the registration of all mosques in the country, is incapable of even achieving this task, not to mention the other responsibilities it may have with respect to aufac. ${ }^{21}$ It is difficult to discern what other functions it might be able to accomplish with respect to philanthropy in Afghanistan at the present time, due to the heavy concentration of its resources on the Haj. Serious consideration needs to be given to providing the Ministry with adequate resources and a clear mandate to register and oversee aufac or to transfer these responsibilities elsewhere, presumably to the MoJ.

\section{Ministry of Finance / Tax Administration / Customs Administration}

No regulations have been issued by the Ministry or the tax authorities to define what constitutes a "public benefit" CSO in Afghanistan within the meaning of Article 11 of the Income Tax Act. This makes it difficult for organisations like the self-help organisation in the Case Studies to know whether it is entitled to income tax exemption. ${ }^{22}$

Regarding its duties to enforce the Customs Code, the Ministry appears to be granting applications for exemptions to domestic organisations with respect to their imports for development projects. This appears to be an area of some confusion for CSOs registered as NGOs, because they think that NGO registration guarantees them automatic exemption, and, as indicated above, this is not necessarily the case.

Thus, lack of understanding of the process has led to frustration and the belief that there is an uneven application of the law to various organisations. It would be useful for the Ministry to issue a circular with detailed guidance about when exemptions will be available to domestic organisations. ${ }^{23}$ It would also be appropriate to amend the NGO law to be consistent with the Customs Code, or even to rethink the entire question of customs exemption. 


\section{Sector and government agencies}

Unlike countries with powerful umbrella organisations of indigenous organisations that can enforce internal governance and external accountability and transparency standards, there is an absence of effective self-regulatory mechanisms in Afghanistan that would help the two functioning oversight ministries to do their jobs. For example, requirements or methods for publishing annual reports do not exist, and there are no effective selfregulatory bodies that include all or most CSOs.

\section{ACBAR and ANCB have promulgated an NGO} Code of Conduct that sets up processes for accountability and for obtaining relief in case of harm done by NGOs. ACBAR and ANCB have agreed to hold their members accountable to it, but it is too early to gauge whether they have had any success in doing so. In addition, this Code focuses only on NGOs and deals principally with their accountability to donors. There should be a rigorous Code of Conduct for all Afghan CSOs, principally for the benefit of Afghans who are their beneficiaries, and it should have clear enforcement mechanisms.

\section{Overview of current successes and current systemic problems}

Despite all the technical problems discussed in the previous section, and as indicated at the outset, there are many successful civil society organisations in Afghanistan among domestic SOs (e,g., ACSF, FCCS), domestic NGOs (e.g., Afghan Women's Organisation, Afghan League for Human Rights), and foreign CSOs (e.g., Counterpart International, BRAC). There also appear to be successful secular foundations (Bayat and Massoud Foundations, though it is unclear whether they are actually registered as non-membership CSOs). There are also two networks for NGOs (ACBAR and $\mathrm{ANCB}$ ) and one for NGOs and CSOS (ACSF). The numbers of registered organisations appear to be rising, and both the Ministry of Economy and the Ministry of Justice are working to improve their respective registration processes.

Nonetheless, the current system is not as healthy as it might appear because of the systemic problems mentioned in the introduction.

Most of the CSOs in Afghanistan are funnels for foreign development aid, whether directly from bilateral or multi-lateral donors or indirectly from foreign/international NGOs with bilateral or multilateral funding. As such, they are not what some would define as "legitimate" civil society organisations -- those that are home-grown and are accountable to domestic beneficiaries/constituents instead of foreign donors. ${ }^{24}$ Others have classified $\mathrm{NGOs}$ in Afghanistan as civil society organisations but also question the "genuineness" of this inclusion. $^{25}$

The other issues of great significance to many of those interviewed are the lack of trust and mutual support, and the absence of a culture of philanthropy in Afghanistan. Many of the people interviewed by the consultants described Afghans as having little ability to work together for the common good (for example, through mutual aid associations or community foundations) because of the tremendous problems they have faced in recent decades and deep ethnic and religious animosities. And, although there are a substantial number of people in Afghanistan with considerable wealth, most of them do not appear to be supporting. charitable causes and social and economic development. Some good work is surely being done by aufac (e.g., poverty alleviation) but there is no data or hard information available to judge the nature and magnitude of this potentially important charitable activity.

Concerted efforts need to be started to indigenise civil society and to create a climate of self-reliance, mutual support and philanthropy. Difficult as this is, it is clearly not enough to merely provide the legal mechanisms for supporting truly indigenous organisations. The need to do this becomes all the more acute when one considers that foreign funding will not be available to sustain Afghanistan's social and economic development forever. At some point, the donors will become fatigued or will turn to other priorities. When that time comes, it will be critically important to have a mature system in place so that a functioning indigenous civil society can take on the necessary tasks of providing humanitarian relief and social and economic development.

\section{Possible consequences of maintaining the status que or of not following through on the recommendations}

The current system is, to a measurable extent, operating to deliver important reconstruction and development aid to Afghanistan and its people at this crucial time in their recovery from decades of war and civil strife. Both NGOs and SOs are being registered and are carrying out their work, but the current situation is not sustainable over the longer term. Although it is entirely possible for a strong civil society sector to develop and carry out important tasks when the legal situation is confused and incomplete, it is uncommon for this to happen. ${ }^{26}$ In addition, the systemic problems for 
Afghanistan are pervasive and reduce the capacity of CSOs to address long-term issues without fairly major legal reforms. Leaving the status quo as it is, or not following through on the recommendations, would not accomplish the goals of achieving a well-regulated and well-funded sector that could contribute extensively to the social and economic development of Afghanistan over the long-term.

\section{RECOMMENDATIONS}

This section proposes a set of recommendations to resolve some of the problems mentioned in the previous section, by reference in part to international practices.

\section{Opportunities in the present context}

Because the current situation is fluid, it provides an opportunity for a rational and thorough legal reform process that is led by Afghans and carried out by Afghans, with foreign technical assistance as appropriate. It is a major plus that the basic underlying law, the Civil Code, has not been repealed, so that the needed structures for civil society can be created in the context of a systematic set of laws related to civilian life (family law, torts, contracts, property, etc.) in Afghanistan.

\section{Recommendations for discussion}

Recommended changes in the current legal and sustainability frameworks include the following:

CSOs. CSOs should be defined broadly to include all organisations that permit both natural and legal persons to associate, whether or not such entities aim to provide public goods (e.g., environmental protection organisations, humanitarian relief organisations, private schools/madrassahs) or are for mutual enjoyment and protection (e.g., self-help organisations, singing clubs, professional shuras, Buzkashi teams). This can be accomplished by bringing the current Civil Code definition of associations up to date and moving most of the detailed provisions to a separate law on associations.

Non-membership CSOs. Defining nonmembership CSOs to include both secular (buniyat) and religious (aufac) foundations and reinvigorating the civil and religious law systems applicable to them in a way that would once again make them important vehicles for charity as well as social and economic development (strong private and community foundations - zakat funds), could contribute significantly to the social and economic development of Afghanistan. It may well be that the current shari ah law is adequate with respect to the aufac, and that more clarity is needed only for the buniyat, though further research and investigation is necessary to confirm this. International practice would suggest both updating the Civil Code to provide for general rules and having separate laws for each type of foundation (secular, on the one hand, and religious, on the other). Zakat funds deserve separate legal attention, because the pattern in other Muslim countries is that they operate more like Western community foundations and are devoted to a wider range of social and economic development and relief issues than are traditional aufac. ${ }^{27}$

Registering CSOs. It would be important to ensure that purely private CSOs could easily establish themselves as associations and foundations (thus achieving consistency with civil law traditions and giving effect to Article 35 of the 2004 Constitution of the Islamic Republic of Afghanistan) as well to make certain that they were subject to adequate oversight by the Ministry of Justice. ${ }^{28}$ Achieving an easy, inexpensive and fairly quick registration process is extremely important because only by permitting CSOs easy access to legal personality can the law ensure the adequate protection of the freedom of association. This would mean that, consistent with international good practices, all domestic secular CSOs, whether associations or foundations, would be registered with the Ministry of Justice.

NGO certification. It would also be important to confine the NGO registration and oversight process to certification of organisations engaged in reconstruction and development who are entitled to receive foreign funding, as is done in other countries, such as Bangladesh, India and Pakistan. Qualifying as an NGO authorised to carry out foreign-funded development projects in a country is entirely separate from the process of conferring legal status, and should be seen as such.

Determination of PBO status. There is the question of whether public benefit CSOs (often called public benefit organisations or PBOs) should have their status as PBOs determined by a special independent CSO, such as the Pakistan Centre for Philanthropy (PCP). At the present time the Ministry of Finance seems to be incapable of administering the special income tax benefits that are available to the PBOs. As was done in Pakistan in a similar situation, perhaps it is best to delegate this responsibility to an outside organisation.

Effective self-regulation. There is a need to develop effective self-regulatory mechanisms that are applicable to the entire CSO sector and that have their roots and legitimacy in Afghan society. 
This would suggest that more time be spent on developing a Code of Conduct that applies not just to NGOs but to all CSOs, though such a Code is unlikely to be adopted in the present climate given the antagonism among organisations. As other countries with experience in this regard such as South Africa have learned, such a process is often a long and difficult one. ${ }^{29}$

Public accountability. There is also a need to rely principally on public accountability - as opposed to donor oversight - to ensure that Afghanistan's indigenous civil society remains attuned to the needs of Afghans and not primarily to the foreign policies of donor countries implementing relief and democracy-building programmes. This will require amending the laws to provide for effective public reporting by all public benefit CSOs, as well as ensuring that the government oversight bodies, and whatever self-regulatory agencies are developed, fully implement the newly developed rules. ${ }^{30}$

Some of the recommended reforms for Afghanistan have precedents in other Muslim countries, such as Indonesia, Malaysia, Pakistan and Yemen, and these models will prove to have a more lasting impact on legal and sector sustainability reforms than the import of ideas from non-Muslim traditions.

\section{v. CONCLUSION}

This paper has discussed an approach to reform Afghanistan's current legal and sectorsustainability frameworks. It suggests a reform agenda that could be developed to look holistically at what further efforts are needed to make it easier for the Afghan people to establish and fund CSOs, and it seeks to place that reform agenda in the context of Afghan legal and social traditions. In addition, it shows that the approach to reform must ensure that the written laws are comprehensive, straightforward and consistent, and that they are transparent and consistent in their application. It also makes clear how important it is to adopt a modern view of traditional Afghan and Muslim legal forms that is consistent with notions of Islamic philanthropy developing in other Muslim nations.

\section{LIST OF ANNEXES}

- Annex A: Defining "Civil Society Organisations"

- Annex B: A description of the different types of Afghan CSOs

- Annex C: Discussion of proposed amendment to NGO Law

- Annex D; Comments on possible amendment to SO Law

- Annex E: Non-distribution constraint under Afghan law.

- Annex F: Bibliography 
ANNEX A: DEFINING "CIVIL SOCIETY ORGANISATIONS" IN AFGHANISTAN

How is civil society defined in Afghanistan, and to what extent do the various definitions reflect various cultural biases? What are the roles of CSOs, broadly conceived? How do the definitions affect reform proposals?

Determining the scope of what constitute "civil society organisations" or "CSOs" in Afghanistan is important to provide a baseline for the reforms suggested in this paper. This issue has been the subject of several recent analyses and surveys, all of which understandably demonstrate some cultural biases.

\section{Richard Holloway describes Afghan CSOs as} follows:

- Organisations that a person is born into - tribes, ethnic groups, clans, qawm

- Organisations of a person's religion - shias, sunnis, sufis, salafis, wahabis

- The organisations that have traditionally managed a person's daily life-shuras, mirab, haqaba, komites (from Pakistan)

- New organisations that have been set up to manage daily life - "new shuras", community development councils (CDCs)

- Organisations for profession or trade (bazaar merchants associations, traditional guilds of, for example, weavers or silversmiths, ex-Soviet Union of Afghan Workers, Farmers unions, different kinds of cooperatives etc.)

- Organisations for cultural or recreational life Buzkashi teams, wresting teams, pigeon flying groups, singing, poetry and dancing associations

Harpikven, Strand and Ask (2002) (HSA), academic experts from Norway, criticise Amnesty International's 1999 Report for suggesting that civil society in Afghanistan is comprised of organisations formed by the educated elite. In their definition of civil society, HSA include community councils, religious networks (ulemas), NGOs, voluntary associations and interest groups, ${ }^{31}$ but as to NGOs they state:

"A large part of the NGO sector can more appropriately be seen as an extended arm of the UN-backed Transitional Administration of Afghanistan than as genuine civil society fostering popular participation and social organisation, or being representatives of the local communities or groups."

Thus, HSA assert that more traditional organisations are part of civil society in Afghanistan and must be perceived as such.

The Foundation for Culture and Civil Society (2005) (FCCS), an indigenous Afghan organisation, does not include shuras/jirgas and ulemas in its definition of civil society because it views them as "regressive forces in society [which are] not elected and only rarely include women and youth." FCCS are also highly sceptical about the inclusion of most NGOs in its definition, because many of them are not indigenous and comprise "a new social elite, unaccountable to both the population and the government."

Counterpart (2005), a U.S. development agency funded by USAID, includes "voluntary organisations" formed by donors to carry out projects, 32 shuras/jirgas, as well as NGOs and social and cultural organisations, noting also the presence of umbrella organisations.

For purposes of the proposed legal reforms, the consultants have chosen the broadest possible definition of CSO, while at the same time remembering that there are inherent cultural biases in such a definition; FCCS would insist, for example, that it is Western-inspired. On the other hand, the aim of the recommendations is not to limit the scope of reform but rather to try to develop a rational policy for registration and oversight for all CSOs, consistent with the Civil Code and respectful of Afghan social and legal traditions. Thus, shuras/jirgas have traditionally been treated as community associations pursuant to the Civil Code, and they should not fall by the wayside as the legal reform process moves ahead. In addition, ulemas are in many cases quite helpful for Afghan development and should also be included in a comprehensive reform effort.

By the same token, local NGOs ${ }^{33}$ should be included as CSOs for the proposed reforms. At least those that are genuine $\mathrm{CSOs}^{34}$ should be required to register as associations in accordance with the Civil Code and its related legislation (the Social Organisations Law 2002) or as NGOs under an amended NGO Law. Those that are not subject to the non-distribution constraint should be required to register as commercial entities. ${ }^{35}$ Such a legal regime would be consistent with traditions in the civil law and in Afghanistan under the Civil Code as interpreted by the 2002 Law on Social Organisations 
In addition, religious or charitable auqaf and the secular buniyat are also CSOs, despite the fact that they have not been counted in previous surveys of the sector. Article 354 of the Civil Code provides that all charity endowments (for mosques or public institutions) must be permanent, and Article 359 forbids the person who endows such a waqf from revoking all or part of the endowment. It is thus clear that such institutions are subject to the nondistribution constraint and thus are part of civil society as broadly conceived. Zakat funds which pool the zakat of many people and distribute it for community benefit probably come within the provisions of the Civil Code dealing with augaf, though it would be appropriate to have more clearly articulated legal rules for them. These funds, which are like community foundations derived from religious contributions, could either exist in perpetuity or have a limited existence/purpose.

In short, the report proposes a broad definition of CSO for purposes of this analysis that includes.

- All organisations in which the assets and revenues are dedicated to public benefit purposes and are subject at all times to the non-distribution constraint $^{36}$

- Mutual benefit organisations that may distribute assets to members upon dissolution but which serve as important building blocks of civil society (e.g., community and professional associations; social clubs; certain types of cultural organisations, etc.)

\section{ANNEX B: DIFFERENT TYPES OF CSOS IN AFGHANISTAN}

Civil society organisations currently subject to regulation in Afghanistan, the law(s) that regulate(s) them, the functions of those laws and the oversight ministry:

\begin{tabular}{|c|c|c|c|}
\hline $\begin{array}{l}\text { Traditional } \\
\text { organisations } \\
\text { (shuras / jirgas) }\end{array}$ & $\begin{array}{l}\text { Civil } \\
\text { Code } \\
1977 \\
\text { SO Law } \\
2002 \\
\end{array}$ & $\begin{array}{l}\text { Registration to } \\
\text { obtain legal } \\
\text { existence; } \\
\text { oversight }\end{array}$ & MOJ \\
\hline $\begin{array}{l}\text { Associations of } \\
\text { all types } \\
\text { (including } \\
\text { public benefit } \\
\text { and charitable } \\
\text { associations, } \\
\text { including those } \\
\text { regulated by } \\
\text { SO Law 2002) }\end{array}$ & $\begin{array}{l}\text { Civil } \\
\text { Code } \\
1977\end{array}$ & $\begin{array}{l}\text { Registration to } \\
\text { obtain legal } \\
\text { existence; } \\
\text { internal } \\
\text { governance, } \\
\text { oversight }\end{array}$ & MOJ \\
\hline $\begin{array}{l}\text { "Social, } \\
\text { cultural, } \\
\text { educational, } \\
\text { legal, artistic } \\
\text { and vocational" } \\
\text { activity } \\
\text { associations }\end{array}$ & $\begin{array}{l}\text { SO Law } \\
2002\end{array}$ & $\begin{array}{l}\text { Registration to } \\
\text { obtain legal } \\
\text { existence and } \\
\text { oversight of } \\
\text { specific types of } \\
\text { associations, but } \\
\text { not all that are } \\
\text { permitted by the } \\
\text { Civil Code }\end{array}$ & MOJ \\
\hline $\begin{array}{l}\text { Foundations } \\
\text { (auqaf, buniyat) }\end{array}$ & $\begin{array}{l}\text { Civil } \\
\text { Code } \\
1977\end{array}$ & $\begin{array}{l}\text { Registration by } \\
\text { Document } \\
\text { Registration } \\
\text { Office to obtain } \\
\text { legal existence } \\
\text { (or MOJ?) }\end{array}$ & $\begin{array}{l}\text { MRA } \\
\text { (or } \\
\text { MOJ?) }\end{array}$ \\
\hline "NGOs" & $\begin{array}{l}\text { NGO } \\
\text { Law } \\
2005 \\
\text { (and } \\
\text { Civil } \\
\text { Code } \\
1977 \text { ) }\end{array}$ & $\begin{array}{l}\text { Registration; } \\
\text { oversight }\end{array}$ & MOE \\
\hline \multicolumn{4}{|c|}{$\begin{array}{l}\text { MOJ - Ministry of Justice } \\
\text { MRA - Ministry of Haj and Religious Affairs } \\
\text { MOE - Ministry of Economy }\end{array}$} \\
\hline
\end{tabular}




\section{ANNEX C: DISCUSSION OF PROPOSED AMENDMENT TO NGO LAW}

Comments on the Proposed Amendments to the Law on Non-Governmental Organisations, 2005, of the Islamic Republic of Afghanistan

Amendments Prepared by the Ministry of Economy Tabled in Parliament

September 24, 2006

\section{Introduction}

The International Center for Civil Society Law, a U.S. not-for-profit corporation, was requested to provide these comments to assist in the analysis of the amendments proposed by the Ministry of Economy (MOE) to the 2005 NGO Law as they are considered by Parliament; ICCSL's comments will also aid NGOs and donors in understanding the scope for improvement both in the amendments and in the 2005 NGO Law itself. Although more technical comments on the Law and the proposed amendments will be made at a later time, the comments contained in this document provide an overview of both strengths and weaknesses of some of the most significant of the proposed amendments.

Major issues to be addressed include the following.

- The scope of the law and its application to domestic organisations

- A proposed reorganisation of the law so as to make it clear how it applies differently to domestic organisations and branches of foreign organisations

- The need for expanded and clearer definitions in the law

- The expansion of permitted activities to allow construction projects by NGOs

- The advisability of adding yet another Commission (the Dissolution Commission) to what is already a very complex structure

By and large the proposed amendment tends to clarify issues of concern raised by ICCSL and other commentators; ${ }^{37}$ however, adding an additional new Commission may not be helpful or necessary.

\section{Specific Issues}

The scope of the law and its application to domestic organisation

One of the most troublesome of the provisions in the 2005 NGO Law (NGO Law) is the assumption that it could be made applicable to all domestic "non-governmental, non-political, and not-forprofit organisations". That would be entirely inconsistent with the Civil Code (CC), which contains extensive provisions for both associations and foundations (auqaf), as well as the Social Organisations Law of 2002 (SO Law), which was enacted to give additional substance to the Civil Code provisions on certain types of associations. ${ }^{38}$ Thus, limiting the application of the NGO Law to domestic organisations "established within Afghanistan according to this law," is more consistent with both reality (many Afghan organisations register as Social Organisations, not NGOs) and Afghan legal traditions. ${ }^{39}$ The NGO

Law as amended will continue to allow a domestic organisation that seeks to become a legal entity to do so under the NGO Law by registering with the Ministry of Economy. It also respects the fact that social organisations and other associations may not be interested in registering as NGOs and will seek registration with the Ministry of Justice, under the SO Law and the applicable provisions of the $\mathrm{CC}^{40}$

A proposed reorganisation of the law so as to make it clear how it applies differently to domestic organisations and branches of foreign organisations

Consistent with the reduction in the NGO Law's scope as it applies to domestic organisations, we would suggest that there be some careful redrafting and reorganisation of the NGO Law so that it is clearer in its application to different types of entities (domestic and foreign).

Legal entity status. First and foremost, it is important to recognise that a domestic organisation can be established and obtain legal personality as an NGO under the NGO Law. But obtaining legal personality in Afghanistan is generally irrelevant to a foreign organisation; most such organisations will want only to establish a branch (which is not a separate legal entity that needs legal status) to operate in the country for as long as they expect to carry out their projects. ${ }^{41}$ There is some confusion on this point in the current text of the NGO Law Article 5 (3) refers to a foreign organisation as one that is "established" (in other words, has legal entity status) in a foreign country. On the other hand, Article 20 says that an organisation acquires legal entity status in Afghanistan when it is 
registered under the NGO Law. Thus, Article 20 should be amended to make it only applicable to domestic organisations. Once that is clarified, then the application of the NGO Law to foreign organisations becomes less confusing.

Reorganising Chapter Two. Consistent with the suggestion in the previous paragraph, it would be useful to reorganise Chapter Two in the following manner:

- Chapter Two itself should contain provisions applicable to both domestic organisations seeking to be established pursuant to the provisions of the NGO Law and foreign organisations seeking to register branches to work in Afghanistan (such as not using a similar name, what needs to be in an application for registration, etc,).

- Chapter Two A should contain provisions that are only applicable to domestic organisations (such as the contents of statute 43).

- Chapter Two B should contain provisions that are only applicable to foreign organisations that are registering branches in Afghanistan (such as the requirements of Article 15 (3) and (4) with regard to Ministry of Foreign Affairs (MOFA)).

The following chart explains how the NGO Law should apply to registration of domestic organisations (D-NGOs) and foreign organisations (F-NGOs).

\section{D-NGOs:}

- Step One: Application to MOE

- Step Two: Registration by MOE

- Step Three: D-NGO is established and becomes a legal entity

F-NGOs:

- Step One: Application to MOFA (with information on establishment in foreign country)

- Step Two: Application to MOE for registration of branch in Afghanistan; accompanied by MOFA certification of establishment in foreign country

- Step Three: F-NGO's branch registered in Afghanistan

The need for expanded and clearer definitions in Article 5 of the NGO Law and for clearer language throughout

One of the current failings of the NGO Law as enacted in 2005 is that while Article 5 contains a number of useful definitions of terms that are applicable throughout the Law, it does not include nearly enough. For example, the NGO Law usefully defines such terms as "nongovernmental," "nonpolitical," "line ministry," and "board of directors." In addition, the Law should use terms with consistency and clarity - it is obvious that the NGO Law means to provide that both an organisation's objectives (purposes) and its activities must be stated in its statute and must conform to various other requirements (not be partisan, political or terrorist, for example), but the language used, at least in English, is not always consistent and is confusing as a result.

\section{The expansion of permitted activities to allow construction projects by $\mathrm{NGOS}$}

Although this was an issue of some contention when the NGO Law was originally enacted, the solution in 2005 was to not permit any registered NGOs to engage in such projects. That was clearly a mistake - if an NGO has a health project that requires the building of a clinic, why should it be forbidden to do that? While it is clear that some forprofit construction companies abused the term NGO, that problem has a different solution. ${ }^{42}$ The problem, even though it is a real one, does not require the forbidding of all construction activities by legitimate NGOs. The solution that is now proposed seems reasonable - it will require the NGO to pay customs duty on any supplies it imports so that it will not have an unfair advantage vis-a-vis a for-profit construction company.

\section{The advisability of adding yet another} commission (the Dissolution Commission) to what is already a very complex structure

The NGO Law currently provides for two commissions: the High Evaluation Commission ${ }^{43}$ and the Dispute Resolution Commission. The former, as described in Article 21, is made up of government officials, and is supposed to review the documents submitted for registration of an NGO. The latter, which includes both government representatives and representatives of the coordinating bodies of the NGOs, is described in Chapter Six. It is charged with "resolv[ing] disputes between organisations and governmental departments resulting from implementation of this law." While it might have been useful to combine the activities of the two commissions into one, which would function in a way that is similar to the Charity Commission of England and Wales or the Charities Commission in New Zealand, that issue can be explored at some other time. ${ }^{44}$

It is troubling to us that the amendments that have now been proposed would add yet another commission, with a third function, to this regime. 
According to proposed Article 35 (2) "The Dissolution Commission shall be established upon proposal from the Ministry of Economy and approval of the Presidency of the Islamic Republic of Afghanistan for the completion of the dissolution process of NGOs in the centre and in the provinces." It seems that this new commission would act on behalf of the Ministry of Economy and its decisions would be "verified" by the High Evaluation Commission and subject to appeal to the Dispute Resolution Commission. With limited staff and limited financial resources, it also seems that it might be unnecessary to set up such a commission. The safeguards of review by the High Evaluation Commission and appeal to the Dispute Resolution Commission are already in place in the current NGO Law.

\section{Conclusion}

Our review of the proposed amendments to the NGO Law indicates that they will provide for some improvements in the Law, particularly in reducing the scope of its application to domestic NGOs and in permitting wider latitude for the conduct of construction activities by NGOs. We would urge the Ministry and the Parliament to go further, however, and to clarify some aspects of the law's application to foreign NGOs. We would also urge consideration of our proposal that the new Dissolution Commission not be developed, in part because precious resources will be saved and, most importantly, because safeguards are already in place to ensure that dissolutions are appropriately carried out.

\section{ANNEX D: COMMENTS ON POSSIBLE AMENDMENT TO SO LAW}

The National Assembly will soon be considering the Law on Social Organisations, which was adopted by the Cabinet in 2002 . It will be possible to propose amendments to the Social Organisations Law (SOL), and consideration should be given to amending the SOL to bring into it some of the more important provisions of the Civil Code as it applies to associations. You have asked us to provide you with comments that will be relevant in the course of the amendment of the SOL. While avoiding controversial issues, this memorandum proposes amendments to the SOL that would improve it and that should be acceptable to the Ministry of Justice, which has oversight of SOs, ${ }^{45}$ and the National Assembly.

Accepting the relevance and primacy of the Civil Code. Background information for considering what amendments would improve the SOL must place it in context: it was adopted in $2002^{46}$ to implement the provisions of the Civil Code of 1977 dealing with associations, Articles 403 to $439 .^{47}$ The general principle of civil law systems, and Afghanistan follows the civil law, is that the Civil Code is superior to the laws that implement it, so that in the event of inconsistency, the Civil Code prevails. This memorandum thus assumes that the Civil Code of Afghanistan prevails over any inconsistent provisions of the SOL.

With this background, and as a first step, it seems necessary to amend Article 23 of the SOL which currently, in English translation, states that "those Provisions which have not been anticipated to this law the command of articles no. 403 to 439 of civil [code] is applicable." This wording suggests that the Civil Code is only to fill in gaps in the SOL and that, in the event of an inconsistency between them, the SOL will prevail. This is contrary to the general principle of the civil law. It would be appropriate to amend Article 23 to read as follows: "Articles 403 to 439 of the Civil Code apply to all matters dealt with in this law and will prevail in case of any inconsistency." Additionally, some of the more important provisions from the Civil Code could be carried over into the SOL when it is amended. These are indicated below. 
Correcting inconsistencies with the Civil Code. The next step should be to amend the SOL to correct any significant inconsistencies with the Civil Code. The following suggestions are listed in the order in which they appear in the SOL, not according to their importance, although the amendments to Article 2 may well be the most important:

\section{Article 2}

- Art. 403 of the Civil Code (CC) allows associations to be established to achieve "charity, public welfare, scientific, literary and artistic objectives," while Article 2 of the SOL [mis-numbered " 1 " in the English translation] permits social organisations (SOs) to be established for "social, cultural, educational, legal, artistic and vocational" objectives. SOs could be formed directly under the CC for any of the purposes listed in Art. 403, so it seems appropriate, and indeed highly desirable, to amend Art. 2 of the SOL to permit all objectives allowed under the $\mathrm{CC}$.

- CC Art. 403 does not limit the persons who may form an association to domestic persons, and therefore neither should the SOL. Permitting foreign persons (both natural and legal) to be founders and members of associations is consistent with international good practice. ${ }^{48}$ The statement in Art. 18 of the SOL that foreign persons may have "honorary membership" in a social organisation should be eliminated as unnecessary. ${ }^{49}$

- In implementing the $\mathrm{CC}$ the SOL has appropriately expanded the objectives for which an SO may be formed. These ought to be retained in the new SOL to be enacted by the National Assembly. Taking these three points together, it would be appropriate to suggest that Article 2(1) of the SOL be revised to read as follows:

Social organisations (communities and associations) are the voluntary unity of domestic or foreign real persons or bodies corporate organised to achieve charitable, public welfare, ${ }^{50}$ scientific, literary, artistic, cultural, educational, legal, social, or vocational objectives.

\section{Article 6}

- Article 403 of the CC does not specify how large the group of founders of an association must be, while the SOL specifies that 10 founders are needed. This would seem to be an acceptable limitation on the vague provision of Article 403, though it would be more consistent with international practice if only seven members were required. ${ }^{5 i}$

- The time period for consideration of an application for registration is stated to be 30 days in SOL Art. 6 (2). CC Art. 411 provides that the Ministry of Justice has 60 days within which to make a decision, but if 60 days elapse without any action on the part of the Ministry "the association shall be considered as legally proclaimed." ${ }^{52}$ This inconsistency must be resolved, and it appears that the Civil Code has primacy.

- Art. 6(3) of the SOL refers to the issuance of an "activity permit" by the Ministry of Justice. It is not clear what this refers to. Normally a permit of this type would be issued by a line ministry (e.g., the Ministry of Health for a rural health clinic). The Civil Code does not mention such permits, but providing for them, including that they be issued by the relevant line ministry, would not contradict the Civil Code.

\section{Article 8}

- SOL Art. 8 states only that social organisations "must keep proper accounting records and books." While this is a useful general statement of the record-keeping requirements for associations, the $\mathrm{CC}$ provides considerable detail as to what sorts of records must be kept (e.g., Art. 413). The National Assembly should consider adding the more detailed provisions of the CC to the SOL.

\section{Articles 10 - 15}

The rules in these articles regarding the dissolution of SOs need to be looked at in light of Arts. 437439 of the $\mathrm{CC}$, both as to the grounds for dissolution and the procedures to be followed. These items in the SO law need to be revised so that they are not inconsistent with the Civil Code.

\section{Grounds for dissolution}

CC Art. 437 specifies the grounds for dissolution as follows:

- When an association cannot meet its obligations 
- When it allots its properties to the aims provided

- When it "violates the provisions of its constitution or acts against the law, the objectives of its establishment and public decency standards and manners"

SOL Arts, 10 and 11 specify the grounds for dissolution as follows:

- When an association decides to dissolve in accordance with its constitution

- For "non-observance of commitments mentioned in th[e] constitution"

- For "performance of the activity against the provisions of the constitution"

\section{Procedures for dissolution}

In general the procedures for dissolution of a social organisation under Arts 13-14 of the SOL should be amplified by incorporating provisions $438-439$ of the CC. Article 16

- SOL Art. 16 says that "financial resources of the social organisations are open."

- CC Art. 421 says "Gifts and donations can be collected only in the name and account of the association in accordance with regulations enacted by the government."

- It would appear that the SOL intends to permit SOs to have access to all types of gifts and donations, whether from inside or outside Afghanistan. Thus, the Ministry of Justice should not attempt to apply to social organisations its January 2005 decree restricting the right of political parties to access foreign funds, at least without amending the Civil Code. ${ }^{53}$

\section{Adding provisions from the Civil Code to clarify} the SOL. The third step should be to amend the SOL to add several important amendments that will bring some of the salutary provisions of the $\mathrm{CC}$, which apply in any event, explicitly into the new SOL.

- Stressing the applicability of the non-distribution constraint to social organisations.

While it seems to be clear that the SOL intends that neither income nor assets of an SO may be distributed to members, founders, etc. either during an organisation's lifetime or upon its dissolution, the provisions of the $\mathrm{CC}$ may be clearer in this regard. Therefore, it might be useful to consider amending the SOL in light of Arts. 406(1) and 415 of the CC.

- Adding governance provisions from the CC to the SOL.

The current SOL is seriously deficient because it does not include any provisionș on governance of social organisations. The provisions of the Civil Code dealing with the Board of Directors ${ }^{54}$ (Arts. 424-428) and the General Assembly (Arts. 429436) do apply, however, and could, and perhaps should, be introduced into the SOL in their entirety.

- Adding reporting provisions from the $\mathrm{CC}$ to the SOL.

Under CC Art. 422 associations are required to inform the Ministry about meetings of their General Assembly. This is an outdated kind of provision that is not found any longer in progressive laws on associations, and, if literally applied, would be too intrusive. The potential problem raised by $\mathrm{CC}$ Art. 422 would be resolved if the SOL were to state that an annual report filed with the Ministry of Justice satisfies the requirement of Art. 422. Art. 454 already requires such a report for cultural organisations, and it would be consistent to apply that rule to all social organisations.

\section{Other issues:}

- Intermediate sanctions

Although the SOL and the CC provide for dissolution as a sanction when an SO does not comply with its legal obligations, there is a need for some sanctions short of dissolution. These might include warnings, fines, etc. We can provide examples of intermediate sanctions legislation if requested.

- Building the capacity of the Department of Coordination, Evaluation and Registration of Political Parties and Social Organisations of the Ministry of Justice.

Various commentators have suggested that the MOJ Department needs substantial additional capacity, including better trained staff, additional physical resources, etc. Although this is not something that can be remedied by amendments to the SOL, it is something worth the attention of the MOJ and the National Assembly. 


\section{Definition of Public Benefit}

After five years of intensive public debate, England has settled on the following definition of public benefit or, in its terminology, "charity":

\section{Charitable purpose}

An organisation having any of the following purposes has a charitable purpose if it is for the public benefit:

(a) The prevention or relief of poverty

(b) The advancement of education

(c) The advancement of religion, including a religion that involves belief in more than one god or does not involve belief in a god

(d) The advancement of health or the saving of lives, including the prevention or relief of sickness, disease or human suffering

(e) The advancement of citizenship and the promotion of civic responsibility, volunteering, the voluntary sector, or the effectiveness or efficiency of charities

(f) Economic and social development of communities, including rural or urban regeneration

(g) The advancement of the arts, culture, heritage or science

(h) The advancement of amateur sports that involve physical skill and exertion

(i) The advancement of human rights, conflict resolution, reconciliation, or the promotion of religious or racial harmony, equality or diversity

(j) The advancement of environmental protection or improvement

(k) The relief of those in need by reason of youth, age, ill-health, disability, financial hardship or other disadvantage, including the provision of accommodation or care

(l) The advancement of animal welfare

(m) The promotion of efficiency of the police or armed forces of England and Wales

(n) Any purposes that may reasonably be regarded as analogous to, or within the spirit of, any purposes falling within subparagraphs (a)- $(\mathrm{m})$

(o) Any other purpose beneficial to the community as determined from time to time by the [Charity] Commission
In 2001 a group of civil society law experts in Central Europe, as part of developing Model Provisions for Public Benefit Laws, agreed upon the following list of public benefit activities:

A Public Benefit Activity is any lawful activity that supports or promotes public benefit by supporting or promoting one or more of the following:

(a) Amateur athletics

(b) Arts

(c) Assistance to, or protection of, physically or mentally handicapped people

(d) Assistance to refugees

(e) Charity

(f) Civil or human rights

(g) Consumer protection

(h) Culture

(i) Democracy

(j) Ecology or the protection of environment

(k) Education, training and enlightenment

(I) Elimination of discrimination based on race, ethnicity, religion or any other legally proscribed form of discrimination

(m) Elimination of poverty

(n) Health or physical well-being

(o) Historical preservation

(p) Humanitarian or disaster relief

(q) Medical care

(r) Protection of children, youth and disadvantaged individuals

(s) Protection or care of injured or vulnerable animals

(t) Relieving the burdens of government

(u) Religion

(v) Science

(w) Social cohesion

(x) Social or economic development

(y) Social welfare

(z) Any other activity that is determined by the Public Benefit Commission to support or promote public benefit

No list of public benefit activities is perfect, and each needs to be tailored to the needs, traditions and capacities of the country in question. These two lists, however, may be useful in the future as the National Assembly considers how best to give greater precision and clarity to the terms "charity" and "public benefit." 


\section{ANNEX E: NON-DISTRIBUTION OF THE ASSETS OF AN ASSOCIATION}

\section{Provisions of the Civil Code of Afghanistan Chapter One (Legal Persons), Topic (Chapter) Three (Associations) (all references to Civil Code preceded by CC)}

CC Article 406 (1) provides: "The members of association cannot include such points in the constitution of the association which would permit the transfer of goods to them, to their families or heirs upon dissolution of the association."

CC Article 415 provides in part: "Properties belonging to the association shall be used for achieving the defined aims set."

CC Article 438 provides: "Where the court orders the dissolution of the association, it shall appoint one or several persons to clear up its accounts and distribute the property of the association with due consideration to the provisions of the respective constitution. Where there is no provision in the constitution of the association about the distribution of the property of the dissolved association, the court may transfer such property to another association or institution which would have common aims."

\section{Provisions of the Social Organisations Law} (2002)

Article 15 is similar to CC Article 406 (1) and provides as follows: "The founders of the social organisation cannot include the subjects in the constitution, which authorise to transfer the revenue (sic) of the social organisation to the individuals, families or their heirs after its dissolution."

Article 16 second sentence is similar to CC Article 415 and provides as follows: "The social organisation can spent (sic) its resources only for achieving the goals of the organisation."

Article 14 is similar to CC Article 438, above, and it provides as follows: (section 2) "If there is no provision in the constitution on distribution of revenue (sic),the court can transfer this revenue to the social organisation, institution or association which their goal and objective are close to the dissolved social organisation."

\section{Provisions of the NGO Law (2005)}

\section{- Article 22}

(3) "Income derived from the economic activities of the organisation may not be used or distributed, directly or indirectly, for the personal benefit of any founder, officer, member, director, employee, or donor of the organisation."

(4) "Directors, officers, and employees may not carry out any economic transaction with the organisation."

\section{- Article 32}

(1) "In case of dissolution or transformation (from the not-for-profit to profit), the movable and immovable properties... shall be distributed to an organisation with similar activities....If there are no such organisations, the movable and immovable properties belong to the government."

(2) "The movable and immovable properties of the dissolved organisation shall not be distributed to any of the founders, members, directors, officers, employees, donors and/or their relatives," 


\section{ANNEX F: BIBLIOGRAPHY}

\section{Laws and regulations}

- Afghanistan Constitution (2004)

- Civil Code of Afghanistan (1977)

- Income Tax Act (2005)

- Customs Code (2005)

- NGO Law (2005)

- Social Organisations Law (2002)

- Regulations for the activities of the national and international NGOs in Afghanistan (Taliban Regulation) (2000)

\section{Articles and other documents}

- ACSF, organisational overview

- Antuono, Meeks, Miller \& Watchou, "Evaluating NGO Service Delivery in South Asia: Lessons for Afghanistan" (2006), University of Wisconsin La Follette School of Public Affairs

- AREU, GUIDE TO GOVERNMENT IN AFGHANISTAN (excerpt) (Evans, Manning, Osmani, Tully \& Wilder)

- AREU, "Land Rights in Crisis" (Liz Wily, 2003)

- Badwi, "Zakat: A New Source of Development Finance?" available at http://www.iol.ie/ afifi/Articles/zakat.htm

- Counterpart Consortium, "Afghanistan Civil Society Assessment" (2005)

- FCCS, "Afghan Civil Society Baseline Report, Provincial Analysis" (2005)

- Habib, "The Role of Zakah and Awqaf in Poverty Alleviation," (2004),

http://www.isdb.org/english docs/idb home/Occasi onal $\% 20$ Papers/OP_IRTI_Role_zakat_Awqaf $\% 20 \mathrm{i}$ $\mathrm{n} \% 20$ poverty\%20alleviation.pdf.

- Harpviken, Strand, and Ask, "Afghanistan and Civil Society" (2004)

- Islamic Republic of Afghanistan, "Peace Reconciliation and Justice Action Plan" (2005), available at http://www.aihrc.org.af/ tj_actionplan_19_dec_05, htm

- Padamsey, "Toward a Legitimate Civil Society in Afghanistan, in Review of International Social Questions" (2004), available at http://www.risq.org/article391.html.

- Rahmani, "Local Governance and Provision of Social Services in Afghanistan," (OSI, 2006)

- Saito, "Perception Change of NGOs in Afghanistan: The Next Step" (undated) (First Secretary of the Embassy of Japan in Afghanistan)
- Sedra \& Middlebrook, "Beyond Bonn: Revisiting the International Compact for Afghanistan" (2005), available at www.fpif.org

- Sayara, "NGO perception assessment" (2004)

- TLO (Tribal Liaison Office) "Strategy and Background, Southeast" (2005-2006)

- United States Institute of Peace, Establishing the Rule of Law in Afghanistan (2004), available at www.usip.org)

- Wardak, "Jirga: A traditional Method of Conflict Resolution in Afghanistan" (undated)

- Zakhilwal, "State-building in Afghanistan: a Civil Society Approach" (CIPE, 2005)

\section{Websites}

- Afghanistan Independent Human Rights Commission:

http://www.aihrc.org.af/indexeng.htm.

- Bayat Foundation: http://bayatfoundation.org

- Massoud Foundation: http://www.ahmdshahmassoud com

- Pakistan Centre for Philanthropy: http://www.pep.org.pk

- University of Michigan Law Library: http://www.law.umich.edu/library/refres/resguides/ pdfs/afghanistan.pdf 

At least those that cannot distribute profits
${ }^{2}$ Others have defined Afghan civil society more
narrowly. See Annex A.
${ }^{3}$ Annex B contains a description of the different types of
CSOs subject to regulation in Afghanistan at the present
time. ${ }^{4}$ Although the working definition of CSOs refers only to domestic organisations, foreign organisations remain a very important part of the development process in Afghanistan. Thus, one Case Study will consider a foreign organisation.

${ }^{5}$ The consultants visited with Engineer Shah Aqa, who has recently taken over the leadership of the Department. He has been at the Ministry for 30 years. The Department appears to have a competent staff that he assured us is not corrupt.

${ }^{6}$ Its energies and resources appear to be devoted almost exclusively to the Haj.

${ }^{7}$ These are discussed in Annex C.

"These provisions should be revised, updated, and enforced as soon as possible.

${ }_{10}^{9}$ See Annex E.

${ }^{10}$ Apparently MoJ issued a decree in spring 2005 stating that political parties could not receive foreign funding. The Directorate of Political Parties and Social Organisations sought to apply this to SOs, but apparently backed off when confronted by the SOs. See research of the Forum for Culture and Civil Society.

"The Civil Code contains no restrictions on SOs with respect to the receipt of foreign funding or any on development implementation. See CC Art. 421. It does allow the MoJ to set restrictions more generally on the collection of gifts and donations. This may only mean that the government can set up procedures regarding public solicitations, but clarification would be useful. Art 16 of the SO Law states that the "financial resources of the social organisations are open."

${ }_{12}^{12}$ Goods imported for government projects funded by loans are also exempt. The exact language of Art. 27 (2) 5 reads as follows: "Goods provided for government projects funded by loans or imported into the country by or for public and private foreign and International relief and development agencies approved by the government." Translation available at http://www. commerce.gov.af/ pdf/AfghanCustomsCodeEnglish.pdf.

${ }^{13}$ Customs Code Art. 193.

${ }^{14}$ Medical supplies might come under the special provisions of Art. 27(16) and (17), despite rather confused translation of the terminology; most countries exempt medical supplies from the application of duties, at least those imported for humanitarian purposes.

${ }^{15}$ The Civil Code actually says that they are supposed to be registered in the Document Registration Office, which implies that they could register with the local branches of the MoJ instead of the Kabul national office as required for SOs.

${ }^{16}$ This is currently the case under the Income Tax, which treats all organisations the same depending on their activities, not their legal form.

${ }^{17}$ See Annex C.

${ }^{18}$ The controversy over construction project materials is addressed in the Comments on the Proposed Amendments to the NGO Law, attached as Annex C

${ }^{19}$ The consultants were unable to visit the MoJ officers in charge of the Department, but they did have a meeting with Judge Ashraf Hegazy, who is an Egyptian jurist working with the Embassy of Italy "Italian Justice Ministry Project," which is helping to build capacity for the MoJ.

${ }^{20}$ Annex D contains comments on possible amendments to the Social Organisations Law, which were requested by ACSF.

${ }^{21}$ Most people interviewed believe that the Ministry spends almost all of the budget allocation it receives on administering the $\mathrm{Haj}$.

${ }^{22}$ The other two domestic associations would clearly be public benefit CSOs, as would the three foundations.

${ }^{23}$ The law appears to be clear with respect to foreign organisations, which receive exemptions if they are "intemational relief and development agencies approved by the government." Failing to provide uniformity between foreign and domestic organisations in this regard may be one source of enmity between them.

${ }^{24}$ See, e.g., Salima Padamsey, Toward a Legitimate Civil Society in Afghanistan, in Review of International Social Questions, 17 December 2004, available at

http://www.risq.org/article 391.html.

${ }^{25}$ See Harpviken, Strand and Ask (Annex A).

${ }^{26}$ See Lester M. Salamon and Stefan Toepler, The Influence of the Legal Environment on the Development of the Nonprofit Sector, Center for Civil Society Studies: Working Paper Series No. 17 (Baltimore, MD: Johns Hopkins University, 2000), 4.

${ }_{27}$ Although the Koran directs that zakat be used only for "the poor, the needy, the Zakat collector, the slaves to buy their freedom, those whose hearts you seek to win those who have crippling debts or loss of property, the warriors, and the needy traveller," some argue that zakat can be used for development projects aimed at alleviating poverty and need. See Zaki Badwi, "Zakat: A New Source of Development Finance?"

http://www.iol.ie/ afifi/Articles/zakat.htm. Government administered zakat, such as in Pakistan, is increasingly being used for education. See http://www.sindhedu.gov.pk/Links/zakat\%20topstory.ht $\underline{\mathrm{m}}$. In Indonesia some nongovernmental zakat collector institutions have joined together to form the Committee on Zakat for Humanity. See Asia Pacific Philanthropy Consortium, Strengthening Philanthropy in the Asia Pacific: An Agenda for Action - Background Paper: Indonesia (July 2001), 14-15. In Kashmir zakat is increasingly paid into community controlled zakat committees (bait-ul mals) which use the funds for education, training, and income generation projects for the poor. In December 2005 the Prime Minister of Malaysia convened an Extraordinary Summit of the Organisation of Islamic Countries (OIC) to promote the formation of an International Zakat Board to distribute zakat to relieve poverty in OIC member countries. See http://webevents.bernama.com/events/zakat/index.php?na $\mathrm{v}=2$. See generally Ahmed Habib, "The Role of Zakah and Awqaf in Poverty Alleviation." (2004),

http://www.isdb.org/english docs/idb home/Occasional \%20Papers/OP IRTI Role zakat Awqaf $\% 20$ in $\% 20$ pove rty \%20alleviation.pdf. This scholarly paper, prepared for the Islamic Development Bank Group, surveys the historic role of these institutions and explores how they can be modernised to play a more effective role in social and economic development.

${ }^{28}$ This approach would suggest that local branches of international NGOs should, as a matter of policy, also be able to be established easily, but it is important to bear in 
mind that foreign organisations have no right under international law or the Afghan Constitution to establish branches. As a practical matter, however, it is obyious that many have been permitted to do so, and the suggestion here is that this practice should continue, probably under the registration process of the "NGO Law" of 2005.

${ }^{29}$ In 200317 Asia and Pacific nations had adopted or were developing self-regulatory mechanisms. See http://www asianphilanthropy.org/pdfs/post/appcpostconf issue pdf.

${ }^{30}$ The most effective organisation promoting public information on the non-profit sector is Guidestar, which is now operating in a number of countries. See http://www.guidestar.org.

${ }^{31}$ They also include political parties, but we will not do so in our analysis.

${ }^{32}$ This terminology appears to have a broader scope than the Community Development Councils or CDCs.

${ }^{33}$ Foreign NGOs should be permitted to register branches in Afghanistan; see separate annex on amendments to the NGO Law.

${ }^{34}$ Those that are subject to the non-distribution constraint. See note 9 , infra.

${ }_{35}^{35}$ Pursuant to the Commercial Code.

${ }^{36}$ The importance of the non-distribution constraint is underlined by existing legislation in Afghanistan.

${ }^{37}$ David Moore, Civil Society Law Reform in

Afghanistan, available at http://www.icnl.org/knowledge/ijnl/vol\&iss1/art 1. htm.

${ }^{38}$ The Social Organisations Law omits reference to charity associations and public welfare associations, which are clearly provided for in the Civil Code. Further comments on the Social Organisations Law will also be provided in the course of the next few weeks.

${ }^{39}$ Afghanistan is a civil law country, whose Civil Codes date back to one promulgated by a royal nizamnama in 1921. The current Civil Code, adopted in 1977, remains in force, as is amply clear from other legislation, such as the Social Organisations Law.

${ }^{40} \mathrm{Or}$, in the case of auqaf, with the Ministry of Haj and Auqaf.

${ }^{41}$ Some organisations will want to set up a separately organised domestic entity, in which event that entity will be a domestic organisation.

${ }^{42}$ There is no question that for-profit organisations set up as NGOs should be dissolved and required to re-register as companies.

${ }^{43}$ This Commission is similar to the High Council described in the NGO Regulation from the year 2000 (and it may have the same name in Dari).

${ }^{44}$ One important concern is how to rationalise the ways in which the various laws apply to domestic civil society organisations (CSOs). Putting aside foreign NGOs, which should be required to register a branch with the MOE before carrying out activities in Afghanistan, our research reveals a great deal of confusion among domestic civil society organisations about whether they are NGOs or SOs or something else entirely. If a "charity commission" structure is adopted, it would be useful to discuss the ways in which it should certify all public benefit CSOs as such.

${ }^{45}$ The Civil Code refers to the "Competent Authority" having oversight of associations and responsibility for their registration. The responsibility for registration and oversight has been delegated by the SOL to the Ministry of Justice, which includes a Department of Coordination, Evaluation, and Registration of Political Parties and Social Organisations, See Art. 19, SOL.

${ }_{47}^{46}$ The 2002 SOL was an update of a Soviet era law.

${ }^{47}$ The SOL specifically refers to these articles of the Civil Code. There are additional provisions of the Civil Code specifically dealing with public welfare, charity, and cultural associations, as well as institutes, which may be relevant to some or all social organisations, but those are not referenced in the SOL.

${ }^{4 k}$ See Irish, Kushen \& Simon, Guidelines for Laws

AFFECTING CIVIC ORGANISATIONS (Open Society

Institute, 2d ed., 2004) Section 3.1 J, p. 29.

${ }^{44}$ It may well be, however, that CC Art. 413(5) was intended to include such special category of membership for foreigners. This needs to be resolved, but it should be resolved by allowing foreigners to be members of associations/social organisations.

${ }^{50}$ Defining "charitable" and "public welfare" more precisely will be necessary at some point, but it may be appropriate to defer that rather intricate and difficult discussion until less controversial amendments and updates to the SOL have been made. Attached are two relatively recent lists of what constitutes "public benefit" or "charity." These may provide useful starting points for the National Assembly when it decides to deal with this complex and difficult issue.

${ }^{51}$ For example, the German Civil Code requires a registered association to have seven members.

BürgerlichesGesetzBuch $\$ 56$.

${ }^{52}$ Such a "default registration" rule can be found in the Law on Associations and Foundations of the Republic of Yemen, Art. 9.

${ }^{53}$ We are informed that when the social organisations protested the application of the decree to them, the Ministry of Justice backed down and does not apply the decree to them. It is, in any case, not consistent with international good practice to limit the access of associations to foreign funds.

${ }^{54}$ Interestingly the Board of Directors referred to in the SOL appears to function more like a management board than an oversight (supervisory) board, though the practice of SOs seems to be to use the term "board of directors" to refer to its oversight (supervisory) board. Either now or later, it would be desirable to amend the $\mathrm{CC}$ and the SOL to provide that each association have both a supervisory board, to set policy and exercise oversight, and a management board, to handle day-to-day operations. This would make Afghani law consistent with the traditional approach of the civil law. 

THE ENABLING ENVIRONMENT CONFERENCE

Effective Private Sector Contribution to Development in Afghanistan

\title{
POTENTIAL FOR PUBLIC PRIVATE PARTNERSHIPS IN AFGHANISTAN
}

\author{
Background paper prepared for the Enabling Environment Conference by:
Private Sector Operations Department, Asian Development Bank
Michael Barrow and Martin Tornberg

\section{RELEVANCE AND IMPORTANCE OF PUBLIC- PRIVATE PARTNERSHIPS FOR POST-CONFLICT COUNTRIES}

A number of factors common to many post-conflict countries such as Afghanistan make the concept of public-private partnerships for the delivery of public services particularly relevant:

- People in countries emerging from conflict typically face increased needs for basic infrastructure, due to (i) disruption of services or destruction of existing assets, and (ii) limited or no development of new projects during the conflict.

- At the same time, these countries' public and private sectors lack adequate resources, both financially and in terms of skills, to re-establish these services quickly. Therefore, many postconflict countries turn to international donors and private investors for resources.

- International private investors are reluctant to expose themselves to excessive country risk by investing before there is a clear path to a stable investment climate - both in terms of security and a steady economic setting.
- The public sectors are typically constrained by weak absorptive capacity. At the same time, policy priorities in the initial period may dictate a focus on aspects other than establishing the necessary investment climate to spark the interest of potential private investors in areas of public interest.

- Therefore, there is often a "bitter paradox" in the first few years of reconstruction governments can neither absorb reconstruction aid nor attract much private investment to offset the Government's low absorptive capacity.

While it is important to point out that PPPs cannot be the solution for every challenge that the public sector faces in delivering infrastructure or services, they can help alleviate or even overcome some of the previously listed problems when the right environment and support structures are put in place. 


\begin{abstract}
What is a Public-Private Partnership?
The concept of public-private partnerships (PPPs) is not new, with PPPs taking on a variety of forms. These partnerships basically involve various aspects of private initiative working with the public sector in a relationship that entails reciprocal obligations and mutual aecountability, including either voluntary or contractual ties; sharing of investment and risks; and joint responsibility in planning, design and implementation. PPPs allow government to transition from managing and providing services, to enabling and regulating private initiative which delivers the services.
\end{abstract}

More specifically:

PPPs are used for products and services that are considered to be a universal service to the population. They do not usually cover industrial or commercial activity that is routinely undertaken by the private sector on a "market" basis.

The basic principle at the heart of a PPP is that the relevant risks should be allocated to the party that is best able to absorb or mitigate them - some risks will stay with the public sector, and that fair allocation of risks requires commensurate allocation of rewards.

The degree of private sector involvement and risk sharing can vary enormously depending on a number of factors. The scope of involvement can range from (a) limited "outsourcing" contracts for the provision of technical or management services by the private sector to (b) full scale operating concessions and/or partial privatisation.

Typically PPP projects are classed in two main categories:

- Economic infrastructure. Services for which sustainable levels of revenue can be derived to pay for investments, operations and risk-related rewards. For such projects, the private sector may be prepared to take all or a substantial portion of the market/revenue risk. Prime examples typically include toll roads and other transport projects, power generation, water treatment concessions and telephone services.

- Social infrastructure. Projects for which it is not feasible or inappropriate to expect users to pay all aspects of the actual cost of the services necessary for the private sector to take market/revenue risk, but where private sector operation and management expertise and risk sharing is seen as beneficial. Typical examples include hospitals, schools, government accommodation, and water and electricity distribution.

\section{The main benefits of PPPs include:}

- By bringing the private sector into certain portions of infrastructure, the government can leverage its own budgets, increasing the amount of infrastructure that can be developed with a limited budget while allowing government to concentrate on the social infrastructure and other social spending that is not of interest to the private sector.

The potential size of private sector investment in public services infrastructure is illustrated by the World Bank estimate that since 1990, the transfer of operating risk of power, water, telecommunications and transport projects to the private sector (through a wide range of PPPs in over 130 developing countries) has resulted in the mobilisation of about US\$750 billion in investment commitments. '

- PPPs allow for a combination of public sector administration and oversight whilst harnessing the strengths of the private sector in the provision of goods and services. Public service provision can therefore benefit from private sector strengths in the areas of, for example, cost-benefit analysis, financing, expertise, innovation, speed, flexibility and management.
- PPPs provide the benefits of genuine risk transfer to the private sector. This translates into less uncertainty about future expenditure, relief from budgetary constraints, and the freeing up of management capacity within government.

Depending on the exact form and scope of the particular PPP, this includes key project risks such as:

Construction (risks of cost, specification and timing of completion all tend to lie with the private sector in PPPs)

Operations (most technical operating risk-i.e. meeting certain specified outputs with penalties for failure to perform - typically lie with the private sector in a PPP)

Revenue risk (the extent to which this risk might lie with the public sector, the private sector, or might be shared between them, will depend upon the particular strengths of the project and the appetite for such risk within the private sector)

Other risks including interest rate risk, macro economic risks, forces majeures ("acts of God" such as floods or earthquakes) and political risks (including riots and terrorism) tend to lie most naturally with the public sector 


\section{PPPS IN POST-CONFLICT COUNTRIES (PCC): THE CHALLENGES}

The previous section has discussed the potential benefits that a country can derive from applying the PPP concept to the provision of parts of its public services. However, a number of conditions must be met for public private partnerships to be able to yield the desired results. Particularly in developing, and even more so in post-conflict countries, these conditions are often not or only partially met.

\section{Problems are particularly related to the following} three areas:

- Weak institutional and legal structures can substantially increase the cost of putting PPPs together

- A low ability and willingness of consumers to pay for or of government to subsidise increases revenue risk and lowers project viability

- Due to the higher perceived risks of investing in a $\mathrm{PCC}$, the required returns for the private sector are higher than in politically stable environments

The combination of these three factors can result in a project "viability gap", leaving only the very best projects feasible. Therefore, adoption of PPP models in developing (and post-conflict) countries is particularly challenging (which explains why so far very little has been done).

\section{The key challenges include a lack of:}

\section{Requisite laws}

There is a need for a body of legislation relevant to PPPs, and the effective and even-handed enforcement of such laws. Key laws that are required typically include laws that:

- Allow the public sector to procure goods and services from and cede interests in infrastructure on a long-term basis to the private sector (sometimes existing legislation can be adapted to allow this, other times new PPP laws need to be enacted or bilateral contracts are used as the basis for discrete PPP initiatives or in advance of wider legislation)

- Govern ownership, mortgaging / monetisation and foreclosure of land and other assets. This needs to address not only domestic concerns, but also develop the necessary legal basis for non-domestic companies to own, dispose of and operate assets. For example, for international bidding to be successful, the international partner will want to exert a certain level of control over the venture
- Allow for effective and efficient dispute resolution

- Pertain to bankruptcy, accounting, etc. and other general aspects of doing business

\section{Government understanding and capacity to implement and oversee PPPs}

Both as a contract party and as a PPP initiator, the government needs to have the capacity and capability to undertake PPPs. This includes the ability to:

- Select projects for PPP procurement

- Undertake some initial due diligence and feasibility studies to determine appropriateness for the PPP and the optimal PPP structure

- Prepare a bidding process to include short-listing criteria and process, preparation of bid instructions, preparation of PPP contract forms, dissemination of information, bid evaluation, and process of selection and award

- Negotiate the terms of the PPP with the awarded concessionaire

- Oversee the PPP implementation

- Stand by the government's obligations under the PPP

Managing this competitive process in a valuemaximising way is an enormous challenge for the public sector. Even the most experienced governments tend to recognise their own limitations and call upon experts (technical, legal, financial etc.) to assist in this process.

One way to address management issues is to establish dedicated PPP units within central government (typically at the Ministry of Finance level) and often also within line ministries and other relevant government departments to manage the PPP process, amend and disseminate policy, spread best practice and publicise lessons learnt.

As just one of many examples, in 1999 the Netherlands established the PPP Knowledge Centre (within the Ministry of Finance) which is staffed with experts from the private sector and from Government. It has the job of making the PPP experience known to participants, designing clear rules and templates for PPP identification and procurement. It also outlines the rules governing the interaction between the public and private sectors, suggests appropriate projects for PPPs, and 
produces studies and reports on PPPs including lessons learnt and best practice recommendations.

\section{Requisite transparency to ensure that PPPs are procured in an open and value- maximising way}

The key to fostering successful PPPs - that deliver the expected long-term benefits in terms of service and asset provision - is competition. Only by fostering and managing a truly open, competitive and fair tendering process for PPPs will the desired outcomes be met.

\section{Government financial capacity (and/or creditworthiness) to share revenue or other financial risks in a PPP}

Post-conflict governments, including the Government of Afghanistan, will often not be able to shoulder their share of the financial risks involved in PPP projects without the backing of international donors or credit institutions.

\section{Government track record in terms of honouring contracts and performing under a PPP}

All PPPs rely on contracts between the public sector and the private sector. The private sector needs to be comfortable with all underlying aspects of both a particular project as well as the underlying relationship with its partner, the government. This particularly involves:

- Consistent long-term commitment on the part of the government to implement and stand behind PPP policy and projects

- The recognition that the private sector should be allowed to earn adequate returns to compensate it for the risk taking

- The private sector having reasonable certainty that it would be able to implement the PPP on the agreed basis free of interference once the PPP was awarded

- The private sector being confident that the laws would be fairly and consistently applied, and more importantly, that it would have redress against the government itself should the government fail to honour its contractual obligations Local private sector expertise and ability to
absorb the risks associated with a PPP

A common constraint is the lack of interest and capability within the domestic private sector to competitively bid for PPPs, and then to manage them for the term of the contract. Experience shows that it can take considerable time for the domestic private sector to build up the capability, capacity and appetite for PPP project bidding and implementation.

\section{International private sector interest in the country}

In countries such as Afghanistan, international investor interest is often weak or limited to a few key sectors and/or the expatriate community.

- There needs to be "buy-in" for PPPs from the government, the private sector and from the ultimate beneficiaries: the public

- There also needs to be assurance of no renewed conflict or disturbance to economic activities

For the above to be sustainable, given the long-term nature of PPP investments, there needs to be a reasonable level of political and economic stability.

\section{HOW TO MAKE PPPS WORK IN POST-CONFLICT COUNTRIES}

Despite all these challenges, experience has shown that public-private partnerships can work in postconflict environments and that they have the potential to contribute to the efficient and sustainable delivery of public services over time. A report from the Commonwealth Secretariat ${ }^{2}$ found that: "Experience to date suggests that the potential for PPPs in infrastnucture, that is, for the private sector to assume a degree of risk in investing in and/or delivering a service, will increase over time and with the onset of greater stability - even though this can be a slow and not necessarily a linear process."

\section{In what sectors are PPPs most likely to be successful}

In post-conflict countries, initial PPPs tend to come in the most commercially viable sectors where little government support is required and particularly where foreign currency revenues can be earned. The principal example would be 
telecommunications, which tends to be one of the first sectors to take off (as has occurred in Afghanistan as well as in several African PCCs). Natural resource extraction, such as oil and gas or various metals, are also sectors ripe for early stage PPPs (this is particularly true in Afghanistan given its rich resource base) and given the established risk appetite of international oil and gas and mining companies for making investments in challenging environments worldwide.

Experience has shown that transport PPPs tend to take some time, and that the focus is usually on ports and airports with their ability to earn hard currency from international travellers/shippers and higher net worth consumers/companies. Purely domestic transport projects tend to be very challenging, not only in PCCs but in developing countries in general. Nevertheless, oftentimes local communities show a willingness to get together and provide the required service, with a minimum of government oversight and support.

In power, the experience has been that it takes many years after stabilisation (six to seven according to the Commonwealth Secretariat report) for PPPs to be feasible - and then only in power generation.

In water and sanitation even more time is generally required, and the examples of PPPs in post-conflict countries are few. Even in developing countries, typically PPP structures tend to be of the shorter/simpler variety.

In Africa, electricity and rail transport have accounted for over half of the limited volume of PPPs. However, this is unlikely to be initially applicable to Afghanistan due to the lack of existing infrastructure - the management of which was the driving force behind many of the African examples.

\section{Specific considerations for PPPs for social infrastructure}

A key difference to economic infrastructure is that typically for social infrastructure projects, expecting users to pay all aspects of the actual cost of the services necessary for the private sector to take market and revenue risk is politically not feasible or inappropriate from a social perspective (this also applies to projects in or projects to remote parts of the country, but which may have been sustainable in an urban setting). At the same time, the services are seen as essential and merit early focus in the rebuilding process. This, coupled with the constraints on subsidies from the government, make PPPs a delivery mechanism worth considering.

Key sectors where social sector PPPs can be useful include health, education and cultural heritage.

Social sector PPPs can also act as pilot projects, where the government and private sector gain experience in delivering services in partnership. Often, this role can be played by NGOs. In Afghanistan's health sector, for example, the bulk of public health expertise resides in the NGO community. ${ }^{3}$

Some of the aspects of working with non-profit NGOs include:

- Just like other agents in the private sector, NGOs can be more flexible than government (e.g. in the recruitment of staff) and also be more innovative.

- Non-profit NGOs are able to work with lower return requirements compared with for-profit companies. This is particularly useful in the "bitter paradox" situation described in Part 1, and can be a first step toward demonstrating sustainable funding modes when standard PPPs are initially less feasible.

- It is important, however, to look at the long-term sustainability of the services. As demand grows, so can the expectation of free or subsidised service delivery, and mechanisms must be in place to cater to this need. Some NGOs (the larger international organisations) may supplement contract funds with their own resources. In others, a path to sustainability with increasing rates may be considered.

- Mechanisms for interaction between government and the not-for-profit sector can reinforce constructive dialogue.

Just as in economic infrastructure, contracting needs to be competitive to encourage providers to maintain efficiency and quality. Likewise, contract specification and implementation monitoring need to be addressed, with the cost of monitoring linked to government capacity to carry out the stewardship.

\section{How to maximise the potential of PPPs in post-conflict countries}

Given (i) viability gap issues, (ii) the discrepancy between what the private sector expects and what the government can deliver and/or the public can afford, (iii) the paucity of rules and regulations and (iv) the lack of credibility of local governments as a 
contracting counterparty, PPPs will necessarily be highly dependent on support from outside agencies, including the various donor agencies (MDBs).

To allow PPPs to happen, donor agencies will need to help with:

- Design

- Procurement

- Provision of significant credit enhancement (essentially guaranteeing or backing up the government's obligations) and/or subsidies

There are many examples of this kind of support from donors even in more developed markets:

- WB and ADB provide guarantees to backstop the obligations of the Government in the sale of the national electricity transmission company in the Philippines

- The provision of subsidies by various donor agencies to allow the Pamir Power Project to happen in Tajikistan

There is also a need to think small - to look at PPPs on a local community scale. An example would be the provision of power solutions at a local/rural level with the involvement of local participants/ entrepreneurs - typically this would involve a simplified form of PPP with fast-tracking and might involve participation by NGOs.

The lack of government capacity can also be seen as an opportunity - many aspects of government service are suitable for private sector contracting or outsourcing. This can be anything from civil servant payroll management, to catering, to processing of passports or other statutory documents, to provision of new buildings and training. All of these can be possible subjects of PPPs. The key is to start with the ministries or government agencies that are most open to private sector contracting, and start a few pilot projects which can then expand across services and different areas of government.

Use investment opportunities in tradable sectors to mobilise investments in infrastructure (business licence + obligation for service provision) ${ }^{4}$

Initially contracts may be shorter-term, to enable sector planners to learn and incorporate changes to future PPP structures, and to the Government's own organisation and strategic direction.

Don't expect too much: private infrastructure in the low-income markets is taking off slowly.
Be flexible and creative: Look for opportunities that may not fit the traditional definition of a PPP anything that harnesses private sector expertise and financing to help provide or support public services.

\section{Case Study 1: Creative interim solutions to encouraging private sector involvement in the provision of basic services to the public (Cambodia)}

A common occurrence in conflict and post-conflict countries is the emergence of unregulated, smallscale private providers of infrastructure, particularly in electricity and water supply.

Because small-scale private service providers evolve as a response to the lack of government, they are generally unlicensed, unregulated and often targeted as nuisances by the public utilities that are trying to reinstate their exclusivity rights.

The quality of services provided by these private companies is often low, while prices are high. However, the real alternative available to the rural and peri-urban communities in many conflict affected countries is not a world-class investor or even a struggling state-owned utility - it is no service whatsoever.

Despite their shortcomings, these small-scale private companies often provide vital services to communities that cannot be reached in the short to medium-term by the State.

In recognition of this role, post-conflict countries as varied as Mozambique, Sri Lanka, El Salvador and Cambodia are now introducing regulatory arrangements that recognise private providers: encourage efficiencies through associations, mergers and convergence; and introduce minimal levels of oversight to alleviate extreme cases of rent seeking and quality of service deficiencies.

\section{Cambodia: Small-scale provision as an interim solution to service delivery ${ }^{5}$}

It is estimated that between 600 and 1,000 small private power systems are operating in Cambodia, serving about half a million customers (or nearly as many households as the national power company). Most of these entrepreneurs set up their businesses prior to the formation of the interim Government in the mid-1990s and continue to provide services to communities who otherwise would have no network connections. In their totality, these small independent companies have about half of the country's generating capacity. The majority meter their customers and charge either a flat rate or a 
single block decreasing tariff. They average 200 households per business. In recognition of their importance, the country's Rural Electrification Strategy - supported by the donor community envisions the convergence of these small power providers into local distribution companies as transmission is rolled out across the country.

Private companies that treat and deliver water through piped and metered systems can also be found throughout the Cambodian countryside, albeit with much less frequency than the minipower companies. These water companies were built almost entirely with local equity and offer a service desperately needed by villages and periurban communities. Recognising the importance of these providers, recent donor activity in Cambodia has attempted to encourage their spread throughout the provinces through targeted subsidy incentives and Design Build Lease contracts that reduce investment risk.

\section{Conclusion}

The example provides important lessons for the Afghan context, particularly for the provision of electricity and water to rural populations in remote areas that will not receive government services in the foreseeable future.

\section{Case Study 2: Pamir Energy, Tajikistan: Donor support ensures social protection within a PPP for power generation in a post-conflict setting}

With the collapse of the former Soviet Union, conditions in the mountainous eastern Pamir region of Tajikistan deteriorated dramatically. Electricity infrastructure quickly fell into an advanced state of disrepair and power plants and many distribution lines were destroyed during the civil war in 1992. The ensuing sharp economic decline (GDP contracted by 60 percent) and neglect by the national electrical utility left 43 percent of homes in the region without power during the harsh winters, where temperatures reach $-30^{\circ} \mathrm{C}$. Schools, health centres and small businesses were forced to close in cold winter months stifling economic and human development. With many people forced to use wood for cooking and heating, 70 percent of the region's sparse forest cover was lost. Smoke inhalation from indoor wood fires led to a sharp increase in respiratory disorders.

At that time, Tajikistan's estimated per capita income was around US\$160/year and 60 to 80 percent of people were living below the poverty line and relying on subsisterice agriculture. Those that did have access to electricity were used to paying $0.4 \phi$ per $\mathrm{kW} / \mathrm{h}$, less than one-tenth of the production cost. Under these conditions, attracting private sector investment into the energy sector with traditional approaches would have been difficult at best.

The PamirEnergy Company, jointly owned by AKFED and IFC, with equity of 70 percent and 30 percent respectively, was established in 2002. AKFED has invested US\$ 8 million in equity and the IFC has committed US\$ 3,5 million in equity and USS 4.5 million as debt. PamirEnergy operates under a 25-year concession contract to operate the electrical utility assets in the Pamir region, improve transmission infrastructure and hydro generation capacity, and regulate the level of Lake Yashilkul to ensure adequate water flows in winter. PamirEnergy also assumed responsibility for the utility's 30,000 existing customers and 595 employees.

The PamirEnergy project demonstrates an innovative public-private approach in overcoming a number of challenges, including the limited ability of customers to pay for electricity services. The project has pioneered a new way of collaborating between investors, development agencies, bilateral donors, governments and the project sponsor.

A key aspect of the project is the social protection scheme that ensures that tariffs paid by households remain affordable, while the tariffs received by the investors provide a rate of return commensurate with the risks involved in such a project.

The World Bank's International Development Agency (IDA) loaned US\$ 10 million to the Government of Tajikistan at a rate of 0.75 percent. These funds are on-lent to Pamir Energy at 6.00 percent, allowing PamirEnergy to partially finance its capital investments at less than commercial terms and pass these savings on to customers as lower tariff rates. This 5.25 percent lending margin, plus a US\$ 5 million grant by the Swiss Government to the Government of Tajikistan, has been used to finance a tariff subsidy to ensure that a "lifeline" monthly supply of electricity is delivered at a very low rate even to the poorest of households. Also built into the tariff structure is an "Early Years Subsidy" - a long initial grace period that allows tariffs to climb slowly from current levels - thus further reducing risk and keeping tariffs affordable.

\section{Lessons for Afghanistan}

- Attracting private investment for the provision of infrastructure services is possible, even in high-risk contexts, provided the involvement of an MFI from an early stage. 
- Innovative combinations of international grant aid with preferential loans can at the same time ensure social protection for customers and acceptable rates of return for the private investor.

\section{PPPS IN AFGHANISTAN: EARLY SUCCESSES}

Afghanistan is seeing strong market-based private sector entrepreneurial activity at the very smallscale end of business, but enormous impediments remain to scale such efforts up to higher levels. Much medium-scale activity is geared to donor funded construction or toward consumer goods (e.g. Coca Cola bottling plant, trading in tea, cigarettes, fuel products, etc.), but not yet toward long-term service delivery.

Afghanistan's positive policy stance on private sector investment is very encouraging (e.g, through AISA), but while several key pieces of legislation have been passed or are being tabled, enormous concerns remain regarding the legal and regulatory environment, especially with respect to:

- The transparency process, including the role of ministries vs. regulators

- The future stability of recently implemented legal and regulatory frameworks

Nevertheless, some clear successes in terms of private sector involvement in quasi-PPPs have already demonstrated viability under the right conditions:

- Telecoms - licence awards for cellular telephony

- Well-regulated banking sector has attracted investment and is now competitive and thriving although still on a minute scale. The rudiments of a microfinance climate are also emerging

Some other sectors are opening up for private sector invesiment:

- Oil and Gas, Mining - awards of exploration and refining licences ongoing

- Fuel Products - more on a private sector basis than through PPPs

- Cement - a good example of a "licence" structure, where the winning bidder undertakes to maintain certain social obligations (e.g. retention of staff and provision of excess electricity to the grid)

The GoA is already implementing a number of very successful large-scale social infrastructure programmes within PPP-similar arrangements in the health sector (Basic Package of Health Services, BPHS) and in rural development (the National Solidarity Program, NSP). Both are implemented in partnership with the not-for-profit national and international NGO sector.

Many issues remain before a vibrant PPP market can emerge. Some of the more basic building blocks that are still lacking include corporate bank lending with longer tenors and larger amounts (and in the medium to long run, corporate bond markets); commercial insurance; land use and titling systems; a reliable judicial system, including enforcement of awards; as well as foreign investor appetite due to a worsening security situation.

In addition, the typical PCC institutional gaps discussed in Part II also apply to Afghanistan:

- Government PPP understanding and processing capacity

- Local private sector capacity to undertake PPPs (including requisite skill sets within businesses to, for example, put together a business plan)

\section{Case Study 3: Basic Package of Health} Services (BPHS): The provision of social infrastructure - government and the nonprofit sector working together

In 2002, Afghanistan had some of the worst basic health indicators in the world. Infant mortality was at 165 per 1,000 live births, there were 1,600 maternal deaths for every 100,000 births and over 25 percent of children were dying before their fifth birthday. The provision of health services to the population was characterised by low capacities and reach of MoPH facilities, with health service delivery effectively having been taken over by NGOs during conflict years. This resulted in the absence of effective quality controls, and uniform systems and standards across the country. Over 60 percent of the population had no access to any basic health services whatsoever.

The Basic Package of Health Services (BPHS) was developed to improve the dramatic health indicators of the country by:

- Ensuring access to basic health services for the entire population

- Unifying the health service delivery and bringing the existing extremely fragmented health activities back under government control 
- Establishing consistent standards for the provision of basic health services

\section{The main structures and mechanisms include:}

- Government as a steward and owner of the public health system, but not directly involved in delivering basic health services

- Private health service providers (currently 27 national and international NGOs) implementing the BPHS through various contractual arrangements with the Ministry of Public Health

- Each NGO providing the services detailed in the BPHS including clear definitions of which staffing, equipment, diagnostic services and medication requirements have to be provided by various basic health facilities

- Communities as active partners through the provision of land and labour for constructing health facilities, the training of community-based health workers and the establishment of health committees

- 100 percent of the BPHS being currently donor funded. Donor agency grants are channelled through a grant unit within the MoPH. Contracts are allocated through competitive bidding

A major success of the BPHS since its inception in 2002 has been the considerable increase in the proportion of the population with basic access to BPHS services from under 40 percent to nearly 77 percent as of mid 2005. It has also brought coherence and unified the priorities of the Afghan health system, facilitated unambiguous decisions about the direction of the health system and standardised the classification of health facilities.

Key challenges of the approach relate to issues of financial sustainability, competition and the longterm role of Government in the delivery of basic health services:

- The BPHS is 100 percent donor funded and while the charging of user fees is allowed, the potential cost recovery from users, particularly in remoter/ poorer areas, is low.

- Funding a large amount of the BPHS budget through government revenue is not realistic in the foreseeable future. Therefore, the question arises of what happens when donor fatigue sets in.

- Particularly for remoter parts of the country, competition for awarding contracts has been low. This will be even more the case for reaching the remaining 33 percent of the population. An important factor for higher service delivery efficiency through the private sector might therefore not be given.

- There are reservations within Government about using NGOs for health service delivery in the longrun. This is connected to uncertainties about the long-term commitment of international NGOs on the one hand, and about Government seeing a chance of increasing its legitimacy through the direct provision of basic health services on the other.

\section{Conclusion}

- An effective way of using private not-for-profit sector expertise and infrastructure while ensuring government control and ownership, quality and systematic coverage of the population

- In the absence of strong competition, the long-term efficiency and performance of the system need to be monitored

- Experience gained in the process of negotiating and managing contracts with a large number of actors could be used for other PPP-type arrangements

\section{RECOMMENDATIONS FOR THE DEVELOPMENT OF SUCCESSFUL PPPS IN AFGHANISTAN}

In the words of a PPP policymaker at the EU Commission $^{6}$ : "PPP arrangements work best where there is an explicit policy commitment by national governments to involve the private sector, a clear Iong-term political will, a high-quality partnership, transparency, clearly specified financial guarantees and an established, stable legal environment." Obviously, much of this is still missing in Afghanistan.

Some specific, practical observations on what can be done to start the PPP development process include:

\section{Implement pilot projects}

Gain experience in some pilot projects which have strong economic fundamentals and require minimum government intervention ("low-hanging fruit"), but where "lessons learnt" can be applied to other projects in the future: 
- Create the enabling environment - including some model contracts

- Use lessons from overseas

- Ensure an open and transparent bidding exercise

- Have donors provide requisite credit/contractual support for the first PPPs and support in the overall PPP procurement process

- Harness the ability and resources of the NGOs

Also need to look at some small-scale PPPs on a fast-track basis at the local/rural level leveraging off microcredit. Look at providing service contracts for core government services backstopped by IFIs, NGOs, etc.

\section{Continue to improve the general business environment}

Given the enormous challenges for PPPs in Afghanistan, the country has to go out of its way to create a friendly enabling environment and attractive terms of investment for the private sector. This is nevertheless covered elsewhere in the Conference and will not be elaborated upon here.

\section{Further develop the regulatory framework}

- Create truly independent regulators (such as TRAA) for key sectors

- Allow of fshore arbitration or other neutral dispute resolution proceedings

\section{Focus on government policy and capacity building}

- GOA needs to make a clear commitment to PPPs as a part of private sector development - political leadership is essential

- Work to maximise government credibility as contract party - starting with the parts of government most amenable to change

- Build capacity (including a PPP unit) within the government (MOF) and key line ministries as and when needed in tandem with the pilot PPPs

- Start the medium-term capacity building to allow PPPs in core utility sectors such as power, water and transport, while recognising that immediate results are unlikely

\section{Enlist the assistance of donors and multilateral finance institutions}

- Have donor and specialist agencies (such as Partnerships UK and similar outfits around the world) provide capacity building support and resources for the Government to get PPP projects off the ground and to manage the process

- Use and expand the political risk guarantee facilities (such as AIGF - MIGA and ADB) to provide comfort for PPP investors and lenders

- Prompt donors to look at incorporating PPP elements into their public sector infrastructure programmes where this is at all feasible (but not over-promising as opportunities are initially likely to be limited)

- Have donor and specialist PPP agencies provide assistance to the private sector so that capacity can be built up for PPP investment (through a facility with AISA or a new PPP window which would act as an investor advisory service, helping investors to present bids, write business plans and undertake financial modelling, etc.)

\section{Be realistic}

There will be limited PPP opportunities, at least for some time, but if a handful of strong examples can be built up, then the market could eventually take off.

\footnotetext{
'World Bank, The Investment Climate in Afghanistan: Exploiting Opportunities in an Uncertain Environment. 2005 , p.24.

${ }^{2}$ Harnessing Existing Financing Facilities to Promote Public-Private Partnership for Infrastructure Investment and Service Delivery in Post-Conflict Countries, Draft Final Report February 2005

${ }^{3}$ Reference: Natasha Palmer, Lesley Strong, Abdul Wali and Egbert Sondorp, \& Contracting out health services in fragile states, w BMJ, Volume 332, 25 March 2006.

${ }^{4}$ Reference: Public Policy for the Private Sector: Rebuilding Infrastructure, WB Private Sector Development Vice Presidency, Note Number 306, March 2006.

${ }^{5}$ (from: 'The Private Sector's Role in the Provision of Infrastructure in Post-Conflict Countries: Patterns and Policy Options' by Jordan Schwartz, Shelly Hahn, Ian Bannon, Social Development Papers, Conflict Prevention \& Reconstruction, Paper No. $16 /$ August 2004)

${ }^{6}$ Deputy DG of DG TREN, European Commission at the 2005 PPP Transport Summit
} 
THE ENABLING ENVIRONMENT CONFERENCE

Effective Private Sector Contribution to Development in Afghanistan

\section{CORPORATE SOCIAL RESPONSIBILITY: BUSINESS AND CIVIL SOCIETY WORKING TOGETHER}

Background paper prepared for the Enabling Environment Conference by:

Pakistan Centre for Philanthropy

\section{EXECUTIVE SUMMARY}

Opportunities for civil society organisations (CSOs) and businesses to achieve shared goals and individual aspirations by working together are unprecedented. Such collaborations, from initial dialogue to active and operational partnerships, are increasingly expected to deliver solutions to some of the world's most pressing developmental problems.

This paper examines the scope and nature of such potential partnerships in the Afghan context and aims to lay out key issues and recommendations for discussion and debate. The recommendations are based on a field survey in Afghanistan and an analysis of international experiences conducted to determine the possibilities and best course of action for promoting an enabling environment for philanthropy and private initiative in Afghanistan.

\section{Partnerships will occur if:}

- Businesses see it as being in their interests to work with civil society organisations for the public good

- CSOs are trusted by businesses as being reputable and competent

- There are institutions and organisations that promote and build capacity in such partnerships
- The government puts into place the legal and fiscal environment that encourages both parties to work in partnership

The study found that the notion and practice of philanthropy in Afghan society is well established, evident in its traditional, religious and modem forms. However, the potential of philanthropy has so far been under-recognised and philanthropic engagement in social development mostly remains sporadic and unstructured due to various hindering factors such as the lack of:

- An enabling regulatory environment

- Trust, accountability and transparency

- Organised institutional mechanisms

- Effective coordination and partnerships

- Organised research and capacity building institutions

Mobilising the potential for private sector contributions to the economic and social development of the country could help Afghanistan overcome its heavy donor dependency and support a sustainable and self-determined development path,

There is a visible and encouraging willingness 
amongst locals and the diaspora to increase philanthropic giving for social and economic development, if a more enabling, facilitative and conducive environment for private-civil society partnerships were provided. Ideally, such an enabling environment would be characterised by:

- Political stability and confidence in the future

- Mutual trust and understanding, democratic dialogue and collaboration amongst stakeholders

- Rule of law, protection of the rights of citizens and a diversity of stable democratic institutions

- A streamlined legal, fiscal, regulatory and administrative framework governing all spheres of private initiative, which is predictably, consistently and impartially applied

This paper identifies some concrete steps to move toward such an enabling environment:

For civil society and business this includes:

- Building structured, facilitative and synergistic partnerships amongst the primary stakeholders by creating institutional mechanisms, such as the establishment of a dedicated organisation to promote philanthropy

- Building trust, transparency and accountability through the introduction of credibility and quality assurance ISO and NPO certification

- Engaging in concerted capacity building, research and coordination by creating a dedicated capacity building/training and research organisation

Government has a crucial role in providing incentives and creating an enabling fiscal and regulatory environment for the promotion and growth of multi-sector partnerships. This is so that not only philanthropy flourishes and is effectively channelled toward the development effort, but so that business and civil society are also strengthened to achieve the overall aim of economic and social development.

The paper has been divided into five parts:

- Case studies and issues

- Examples in Afghanistan and internationally

- Suggestions for Business/CSO partnerships

- Issues that need to be addressed

- Recommendations

\section{CONTEXT, DEFINITIONS AND ISSUES}

\section{Prevailing Environment}

Since the 1980s, a large section of the CSO community has been re-examining its basic strategies, based on the realisation that by acting on their own they cannot hope to benefit more than a few favoured locales, and that self-reliant local initiatives are only likely to be sustained if local public and private organisations are linked into a wider support system. At the same time, the process of economic globalisation has been accompanied by the increased concentration of resources and economic power within the business community. Whatever the cause "it is now obvious to many CSOs that most of the world's resources are owned by the private sector (Phillips, 2000)." This refers not only to economic but also to knowledge resources.

Today it is generally recognised and reflected in development planning that social development cannot be achieved by government alone and requires broad-based public and private partnerships, which involve the citizens at all levels. The role of philanthropy and philanthropic resources as a complementing factor in social investing and development is a widely acknowledged fact across the globe. The potential for a healthy private philanthropic sector in every country is strong, even more so in Muslim societies.

\section{Context}

For business and civil society to work together for development, the government is an important and vital actor, which actually makes for a triangular relationship in the context of providing an enabling environment. A government can choose to foster a climate that is hostile or supportive not only for CSOs or business, but also for active collaboration between CSOs and business for effective development. The Government of Afghanistan is hard-pressed to meet basic needs and to perform basic functions. Fostering alliances for development with and between business and civil society through a supportive policy framework therefore becomes all the more important. The two sectors have their own characteristics.

Civil Society in Afghanistan is unique and diverse in its manifested traditional and modern forms:

- Traditional Civil Society includes a variety of indigenous groups for social action that are deeply embedded in society. These groups are based on 
traditional, quasi-traditional and quasi-modern values formed around family, tribe, location or profession. These include shuras, jirgas and councils of elders, peace committees, community councils and informal professional associations such as those of traders, barbers and carpet workers.

- Modern Civil Society includes modern social groups stemming from Western concepts of social action. The diversity and range of modern civil society includes mutual benefit organisations such as CBOs; ethnic and political organisations; professional associations; employees and trade unions; cooperatives; women, youth and students groups; chambers of commerce \& industry; business associations; and public benefit organisations such as non-governmental organisations, non-profit organisations, private or public philanthropic organisations, civic organisations, advocacy and human rights organisations, research organisations and different collaborative development forums including networks and CSO coalitions.

The distinction between traditional and modern civil society largely reflects rural-urban differences which over time may become less pronounced. Due to the displacement and exile experience of rural Afghans who have been exposed to modern values and procedures, traditional and modern forms of social action are becoming increasingly integrated.

In this process, traditional civil society, largely built around "family" and "clan" structures, is adopting some of the more formal structures and configurations characteristic of modern civil society. This is encouraging as it enhances civil society's potential as a vital catalyst and engine of economic and social development.

Business: Afghanistan's business fabric is special in that the private sector mainly comprises traders and small farm agriculture. In the last few years, new sectors have emerged as a result of the reconstruction efforts, particularly in the areas of physical infrastructure and human capacity building/education. New sectors are expected to grow including banking, telecommunications, food processing and mineral extraction. However, not only are business concerns mainly family-run, but 80 to 90 percent of economic activity is informal. ! The manufacturing sector which is weak, but has seen some recovery since 2001 , is dominated by textiles, carpet manufacture, leather goods, semiprecious mineral and marble production and dried fruit production. Policies and actions aimed at enhancing organised philanthropic contributions need to take the special features of the economic landscape of Afghanistan into account and target both traditional as well as emerging business sectors.

\section{Scope for Collaboration}

In Afghanistan, most people deem it part of their Islamic religious obligation to give to those in need and, as Muslims are motivated by their belief in social equity, manifested by zakat, sadkas, fitranas and wakfs etc. Mostly, giving is faith based but directed to social causes. This study has found that there is great scope for philanthropic Muslims in Afghanistan to be the drivers of citizenled initiatives for social development.

Today there is a growing recognition within Afghan society that social development is not the responsibility of Government alone; there is a space for social activism on the part of citizens and there are social development needs that business and CSOs together can address successfully. Within an environment of extremely scarce human and capital resources, it is particularly important to channel and structure the good intentions of prevalent philanthropy effectively around business and civil society partnerships for development.

International examples clearly indicate the advantages to all actors involved in economic, social and cultural development endeavours and provide important lessons of partnerships based on the principles of reciprocity, mutual needs and benefits. These lessons include:

- Through partnerships with business, CSOs are able to extend their outreach, learn new skills and disciplines and find new, innovative and more efficient ways of carrying out their mandates and missions. They also have increased financial access to support their programmes.

- Businesses too have a wide variety of reasons for working with and through CSOs. They can generate goodwill for their firms through supporting social activities, have a more loyal workforce when the business is seen as socially responsible, and express the personal philanthropic impulses of their leaders.

- Governments, acting as the catalysts to help such partnerships flourish, derive extra resources for development, and increases in skill and experience in social development issues which they can draw on for their own programmes.

- Business-CSO affiliations can provide Afghan communities with an alternative method of addressing community problems without having to wait for Government. 


\section{CASE STUDIES}

\section{Afghanistan \\ Most money that is being sent by Afghan expatriates is channelled toward families. Some money is also given to community development work, but this is not institutionalised. Much of this mostly undocumented giving comes from a new class of successful Afghan businessmen and women that has emerged as a result of trading.}

The following Afghan case studies look at examples which have moved from personal or family charity to more professional and organised philanthropy.

The Bayat Foundation is one example of largescale, institutionalised corporate giving in the country. It channels parts of the corporate profits of the Bayat business group toward development works across the country. The Foundation is mainly involved in the reconstruction of damaged schools and clinics. As one of its largest projects, the Foundation has not only sponsored construction of a 100-bed hospital in Mazar-e-Sharif, but also runs it on a non-profit basis. This hospital is equipped with modern medical facilities and provides medical services to people on cheaper and subsidised rates. The inauguration ceremony of the hospital was attended by government officials, politicians and philanthropists, which speaks of their contemporary interest and support to such social causes. The Foundation has also sponsored the library of the American University in Kabul.

Apart from investing its own revenues into the development ventures, the Foundation also generates significant philanthropic revenues from diaspora individuals and businesses operating in the United States of America, Pakistan and from local businesses and philanthropists. Bayat has a strategy of trust building and informing the public of not only its own social ventures but of highlighting other philanthropists' endeavours and public messaging services through the medium of its Ariana Television. Ariana is aired internationally and particularly attracts Afghan diaspora communities. Expatriate Afghans respond generously to calls for funding by the Foundation.

The example of the Bayat Foundation demonstrates the importance of the media in promoting and informing the public about philanthropic giving. Since Roshan's launch in July 2003, giving back to the community has been a high priority, providing access to mobile telephony, training and employment opportunities. In addition, Roshan's Social Programmes Division has identified four sectors for development: Commerce, Health, Social
Welfare and Education. Through partnership and direct grants in these key sectors, the aim is to improve the quality of life of Afghans, reduce distress and provide opportunities for a better future. These efforts will also help build human potential and capacity to drive the reconstruction of Afghanistan.

The initial philanthropic activity of Roshan focused on assistance to street and working children and their families in Kabul. In 1995, ASCHIANA, with the initial assistance of Terre des Hommes, opened its first centre for street and working children in Shar-i-Naw district of Kabul to provide meals, health education and medical treatment.

ASCHIANA is now established in Kabul, Mazar-eSharif and Parwan Province and more recently has been functioning with the support of Roshan and others. Roshan has concentrated its support on the provision of soup kitchens to feed the children, health promotion training and sponsorship to ensure that as many children as possible can enter full-time education. The main aim of ASCHIANA is to bring change and improve the social, economic, cultural, physical and mental situation of the vulnerable groups of children. The Roshan Social Programme has invested resources in technology and brought on other technology partners (such as Cisco) for the groundbreaking telemedicine programme which links doctors in Afghanistan to doctors in other countries for expert advice and ongoing professional development. The number of beneficiaries of Roshan's philanthropic and social development efforts is increasing with the expansion of services.

While there are many worthy projects that are in need of assistance, the criteria set by Roshan for the selection of projects are: the identification of needs that affect their constituents; addressing the mission that falls within one of the identified target sectors; clearly defined, deliverable objectives that secure real benefits to the target communities; and ensuring the ability to monitor and measure outcomes and synergy with Roshan values of social responsibility and ethical conduct. An overall policy of Roshan is to be involved with the initiatives it supports, to share its expertise and learn from its partners.

Afghan Women's Business Association (AWBA) was set up by Ms Mina Sherzoy, who returned to Afghanistan five years ago after having lived in the United States as a refugee. As head of the forum, she demonstrates a strong interest in socially and economically uplifting women, and works both in an individual capacity and on behalf of AWBA as part of the process to promote philanthropy in Afghanistan. AWBA's main goal is to alleviate poverty and generate philanthropic resources from 
both local and international sources. The association has a wide network of women entrepreneurs (over 780 members) and helps build the capacity of destitute women to start their businesses. The Association also tries to raise awareness about women's issues, empower women, and also undertakes research.

A few other examples of sporadic social work being done by individuals and business groups that are not well-known are included below. These examples may not be completely representative; however, they reflect a range of giving practices which were documented during the field survey conducted and corroborated by local newspaper stories:

- The Dawee group which has built several schools and has renovated the Eid Gah mosque in Kabul

- Al-Khuzay Tea has offices in 52 countries and has grown very rapidly. The owner started as a small trader in tea and used to trade small quantities of tea from Pakistan. Al-Khuzay has recently donated to the American University in Kabul along with other philanthropists such as Habib Gulzar (CocaCola) and Najib Zarab.

- Businesses in Herat joined together to provide philanthropic support for the development of Herat province. Working with Government, the business community contributed toward developing the Bagh-e-Millat, a 25-acre park in the heart of the city. Similarly, roads, clinics and schools were also developed. Traders provided certified seed to farmers for developing agriculture in the province.

- The Afghan Times, in Kabul, Kandahar and Mazare-Sharif prints information on philanthropic initiatives of Bayat Foundation, Dawee Centre and others. The newspaper plans to establish a school for Afghans providing high quality English language teaching, which would be free of cost and would develop the linguistic potential of promising individuals.

These examples of passion from businesses and individuals for philanthropy and development are on the one hand very encouraging, but on the other hand, they also point toward certain gaps and inadequacies.

\section{Observations}

Corporate social responsibility is generally irregular and not financed by a certain percentage of profits. It does not derive from a professional scan of the social needs and problems, or a scan of existing implementing organisations, and is not well known to the general public, or for that matter, to the business sector.

\section{International Experience}

The following paragraphs provide some successful international examples of corporate philanthropy with important lessons for the Afghan context. They are drawn from India, Pakistan, the Philippines and multinational contexts and illustrate.

- The scope, scale and impact institutionalised corporate giving can attain

- How the private sector's potential for innovation and know-how can help address complex social development problems

- That intermediary institutions can have a catalysing role in mobilising and channelling philanthropic giving

\section{Scope, scale and impact of institutionalised corporate giving}

As one of the largest companies in the world, Coca-Cola takes seriously its ability and responsibility to positively affect the communities in which it operates. Coke India's Corporate Social Responsibility (CSR) initiatives are both community and environment-focused and are good examples of business, CSOs, government and community partnerships for social and economic development. Priorities include education, where primary education projects have been set up to benefit children in slums and villages; and health. where Coke India partners with local CSOs and governments to provide medical access to poor people through regular health camps. In addition to outreach efforts, the company has committed itself to environmental responsibility through its own business operations in India.

The company's support for community-based rainwater harvesting projects to restore water levels and promote water conservation could be used as a model. Coca Cola is partnering with the Central Ground Water Authority (CGWA), welfare associations, local governments and communities to set up Rainwater Harvesting structures all over the country. Local govemment and local CSOs identify 
critical areas and mobilise community participation, while Coca Cola facilitates the project and serves as the principal funding agency. The partnership with CGWA ensures availability of technical expertise. Coca-Cola employees also play an active role, helping with project coordination, selection of vendors, execution and maintenance. The projects are designed in a way that they require minimum recurring expenses and involve community residents from the start.

\section{Two examples are given below:}

- The Thar region of Rajasthan is one of the world's most densely populated arid zones, with a human population of more than million and a still larger population of livestock. Along with Jal Bhagirathi Foundation (JBF), Coca Cola is supporting water hamessing projects in this area through the revival of traditional structures with proactive community participation. Local communities contribute 25 percent of the cost with voluntary labour, with Coca Cola India providing the balance of 75 percent.

- In Varanasi the unit partnered with the local CSOs and village communities to augment the water resources and facilitate better availability of potable water by repairing and cleaning community wells, supporting the digging of bore wells and installation of hand pumps. Similarly, in Wada, Maharashtra the unit supplied potable water during the dry season.

Bharat Petroleum, India: BPCL's first corporate responsibility activities were initiated in 1986 in Mahul, a village located in the neighbourhood of its Mumbai refinery. The inhabitants of Mahul were a wealthy fishing community, but as far as education, health and other basic necessities were concerned, they needed help. BPCL volunteered to provide these services and the initial success brought such gratification that BPCL extended its initiative to a second village, Karjat. Today, 37 villages across India have been adopted. This includes making substantial and long-term investments in local communities with the aim of fostering self-reliance. The company is providing fresh drinking water, and sanitation and medical facilities. It also has a strong focus on enhancing income levels through education, including vocational training and agricultural innovations, as well as providing grants for opening schools and adult literacy camps.

\section{Several factors contributed to making BPCL's} social responsibility endeavours work:

- The successful mobilisation and motivation of its own employees: There is a high level of trust between the company and its employees, which ensures a high level of participation in BPCL's corporate social responsibility activities from the start. Employees are made equal partners in carrying out activities and decisions are transparent. BPCL successfully involves people of all cadres, from the managers to the workers of various departments in the different unions. Employees are kept motivated by colleagues' success stories.

- Need-based activities: Projects are undertaken as and when people demand, including BPCL's own employees or people from the communities.

- At the community level, all the people are involved right from the planning level. People take decisions together.

Apart from these outreach activities, BPCL has also been one of the first companies in India to help employees suffering from drug addiction. A successful long-term partnership has been undertaken with Kripa Foundation's De-addiction Centre (Kripa Foundation is one of the largest NGOs in India helping people suffering from chemical dependency and HIV infection). The recovered addicts in turn help others with similar drug addiction problems.

Pakistan Petroleum Limited's community development and welfare activities are aimed at enhancing the quality of life of the people living in the vicinity of its areas of business operations. For this purpose it has set up a PPL Welfare Trust (PPLWT). Services are organised in consultation with all stakeholders, particularly the local community. The fully equipped Sui Field Hospital, a mobile dispensary with regular organisation of free medical camps has been instrumental in treating thousands of patients. The provision of free medicines and the donation of hospital equipment and ambulances has remained a regular feature in PPL's welfare plans. Realising the additional medical need of the Sui population, PPL Welfare Trust is also setting up a 50-bed Welfare Hospital at a cost of US\$ 1.66 million on over 10 acres of land.

Providing and improving educational facilities run parallel with health care programmes. Sui Model School is providing education to over 2,700 students in two shifts, at a very nominal fee. School buildings have been expanded and renovated. Books, furniture and science laboratory equipment are provided on a regular basis to different institutions. To encourage education, yearly scholarships are provided to deserving students.

Construction and repair of roads and culverts on a regular basis facilitate easy access to adjoining areas to fulfil commuters' day-to-day requirements Laying and maintenance of water and gas pipelines have immensely benefited locals. PPL has 
constructed several mosques and installed a number of water hand pumps in the villages, built badminton and squash courts, and donated fire fighting trucks to municipal committees. Its welfare project includes supply of one million gallons of water per day to Sui Toem from Khewali Pump Station (65 kilometers away) near Guddu through a 90-kilometre pipeline distribution network. Construction of a metalled airstrip and an impressive airport terminal building with related amenities provides express and uninternupted air travel facilities. PPL also makes substantial donations to different education and health institutions every year. A hallmark of the design and nature of PPL's various public welfare initiatives is the consultation with local communities and responsiveness to these needs.

\section{Observations}

The examples of the Indian and Pakistani oil companies can be a replicable model for the involvement of Afghanistan's mineral and extraction industry in the development of village communities based in their area of exploration and production.

\section{Private sector innovation and know-how for social development}

Johnson \& Johnson's (J\&J) commitment to social responsibility is exemplified by a number of key community initiatives. Through the contributions programme, a worldwide social responsibility effort, Johnson \& Johnson aligns philanthropic initiatives with its expertise in four key platforms: access to health care, children's health, professional development and education and community responsibility. J\&J sponsors a number of programmes including the Vatsalya Trust, voluntary health services, a rural midwives training programme, and mobile AIDS counselling.

Engro Chemical Pakistan Ltd. was awarded the prestigious Asian CSR Award in the Concern for Health category for its "Project Hope", a telemedicine intervention that provides state-ofthe-art tertiary health care to poor rural communities in the interior of Sindh province. Started in August 2005, Project Hope links rural patients via video conferencing to a hub in Karachi, where specialist doctors assess $\mathrm{x}$-rays, ECGs and other diagnostics in real time. The project covers some of the least developed areas in the country, with low literacy and high poverty rates, and with a ratio of doctors to population of $1: 2,915$. Fifteen medical specialists ranging from neonatology to cardiology are available on a daily basis to rural communities located hundreds of kilometers away. Engro also financially supports CSOs through various philanthropic initiatives. In 2005, Engro's philanthropic contributions exceeded US\$ 0.86 million and directly benefited over 130,000 individuals at the grassroots level. The focus remains on health, education and infrastructure development. This is an inspiring example of the business sector's approach to social problemsolving.

\section{The role of intermediary institutions}

In many cases, businesses are unaware and/or inexperienced in how to make valuable contributions to the public good. At the same time, CSOs are unused to working with businesses and are sometimes distrustful of them.

\section{There is a need for an intermediary form of organisation which can carry out the following functions:}

- Help to educate businesses about CSR and how it can be practiced

- Help businesses to implement a CSR policy for their own company, or look at the possibility of combining with others

- Introduce businesses to relevant CSOs

- Research, certify, and if necessary, train CSOs to be worthy partners for businesses

- Organise publicity about these multi-sector partnerships and encourage these practices

In many countries of the world, such an intermediary organisation is seen as being a very vital component in the process of business/CSO partnerships, and it is something that Afghanistan could consider carefully.

In some cases the intermediary organisation originates with the CSOs - an example is the Pakistan Centre for Philanthropy (PCP). In other cases, it originates with the businesses - the best example being the Philippines Business for Social Progress (PBSP). Both are described below:

\section{The Philippines Business for Social Progress}

(PBSP) was set up as a response to social unrest and economic downturn by the Philippines Council for Economic Development, the Philippines Business Council and the Philippines Association for Social Action. PBSP is a means by which the Philippines business community could rationalise 
and coordinate its funding and technical support to socio-economic projects and programmes across the country.

Although PBSP is a corporate programme, it is essentially community-group focused using the community development model to reach its clients, It has a primary commitment to foster the establishment and improvement of local community organisations, such as cooperatives; marketing groups; village-level NGOs involved in delivery of community services; education bodies; and civic and local professional groups. PBSP's credit-based income generating programme (CIGP) is largely implemented through loans and grants. PBSP sees itself as being able to play an important part in poverty alleviation in the Philippines as a broker between micro-entrepreneurs and those domestic and foreign agencies in the formal modern economy that have resources which are currently denied to the poor. In both the brokering role and as a direct lender to community-based groups, PBSP channels resources that are on-lent for incomegeneration purposes.

Extension activities include CIGPs plus a range of training, expert consulting services and administrative support designed to improve the prospects of successfully establishing institutions and community structures that can ensure the viable continuation of the programme after PBSP is no longer involved. PBSP has the distinction of being a self-reliant indigenous NGO. Its major sources of income are contributions from member companies (67 percent) and interest income from funds loaned to PBSP's poverty programme ( 28 percent).

\section{The Pakistan Centre for Philanthropy is an} independent, non-profit support organisation. It was established in August 2001 to lead philanthropy promotion in Pakistan. Central to this promotion remains the effort of mobilising resources from the private sector, in particular the corporate sector for development initiatives. In doing so, the Centre also supplements the Government's poverty reduction agenda.

The Centre does not engage in direct philanthropy. Instead it seeks to facilitate such efforts of others through support services. These services include action research, policy and legislative reviews and focused strategies to ensure meaningful collaboration among stakeholders in the philanthropic arena. Key stakeholders are corporate and individual philanthropists, citizen organisations, communities and the Government.

The Public Private Partnership (3Ps) initiative implemented by the Pakistan Centre for Philanthropy (PCP), mobilises Corporate
Philanthropy for education with the objective of improving physical infrastructure in government primary schools and enhancing access to and quality of primary education. Eight publicly listed companies (Engro, Unilever, Pakistan Petroleum Ltd, English Biscuits Ltd, Petronas Carigalli Pakistan Ltd, Tullow Developments Pakistan Ltd. Dewan Mushtaq Group and Thatta Cement Company) have used PCP's 3 Ps programme to channel their corporate contributions toward education in their areas of operations. To date, USS 0.88 million have been generated through the adoption of 74 government primary schools in rural districts of Sindh province (Thatta, Ghotki, rural Karachi, Kamber-Shahdadkot and Kashmore).

Corporate contributors support physical infrastructure and human capital. Physical infrastructure ranges from provision of utilities like water and electricity, to boundary walls, lavatories and learning aid materials. The human capital side includes recruitment of new teachers and provision of teacher training.

This is a good example of how a non-governmental, intermediary institution can leverage and structure support to the Government's social development efforts.

\section{SUGGESTIONS FOR BUSINESS / CSO PARTNERSHIPS IN AFGHANISTAN}

Although the above examples from Afghanistan have shown that philanthropic practices have to date remained largely unorganised, unstructured and informal, the fact that the culture of philanthropic giving is deeply rooted and widespread suggests that there is potential for a much larger contribution of business to social development.

\section{Business-CSO collaborations could be particularly successful in the following areas:}

As most of the business money comes from trading, economic centres like Mazar-e-Sharif, Herat, Jalalabad and Kabul's emerging market have the greatest immediate economic potential for launching such collaborative initiatives in Afghanistan.

Field-based survey/interviews and analysis of the above examples allow us to additionally identify and suggest the following priority areas for business-CSO interventions: 
- Health and Education: The review of international business-CSO collaborative experiences indicates that interventions in the health and education sectors are the most prevalent; these can be replicated and expanded in Afghanistan in line with the goals of universal primary education, vocational/technical education and skill building centres by relevant businesses. Similarly, the goals of alleviating sufferings of masses and eliminating diseases can be achieved by establishing free, subsidised or low-cost health facilities.

- Community Physical Infrastructure: In light of the damaged infrastructure and wide-scale poverty in Afghanistan, one area where businesses could provide support is in infrastructure development, i.e., rebuilding schools, hospitals and clinics, and providing financial assistance to communities.

- Human Resource Development: This is an important area for collaborative intervention, demonstrating successes worldwide through capacity and competence building and professional and skills training. Examples include handicrafts and cottage industry in Afghanistan where businesses and CSOs have collaborated to make their employees more productive and products more marketable.

- Environment: There are great opportunities for collaborative efforts in the domain of sustainable environment. Successful examples of Pakistan's oil and gas sector (such as obligated spending by such business concerns on the welfare of local communities through CSOs) could be followed by the Afghan mineral industry.

- Power: Generation of electric power in unserved areas is beneficial to communities as well as to business. By providing access to power in these areas, business itself expands the options for where it can set up manufacturing concerns as factories are normally located outside city limits. As the development process continues, more manufacturing businesses will open.

- Advocacy and awareness raising: Most of the work of businesses and CSOs either goes unnoticed or is not perceived positively because both businesses and CSOs suffer from credibility, transparency and image issues. The media plays an important role in this regard, and can be tapped as a support mechanism for partnerships.

\section{ISSUES THAT NEED TO BE ADDRESSED}

Issues around business-CSO collaboration include but are not limited to:

\section{A lack of trust in CSOs by the business community and Government}

The lack of mutual trust amongst all actors is very evident in Afghan society and has proven to be one of the major impediments in any collaborative development effort. This is a result of a number of factors:

- Difficult operating conditions for both business and CSOs often stifle their individual and collaborative efforts.

- CSOs are perceived to be politicised, particularly since funds to the mujahedeen movement were channelled through CSOs. This factor, coupled with the fact that CSOs and businesses performed state functions in times of state collapse has made people associate them with political goals.

- Past experience with CSOs in Afghanistan has shown that many conducted themselves as private businesses, with some in fact transforming into private for-profit initiatives. As long as CSOs are perceived as for-profit endeavours in disguise, businesses will not want to partner with them.

- Government ín many cases perceives civil society to be working in competition with it particularly since Civil Society has taken over state functions during the prolonged conflict as highlighted before. An example of the Government's suspicion of CS is a clash that occurred between the Ministry of Trade and Commerce and local businessmen who were attempting to create a lobby group for trade and investment at a workshop engaging the private sector and Civil Society. The organising body was accused of placing foreign ideas into the minds of Afghans.

- A large segment of society views CSOs as an extended administrative arm for the $\mathbf{U N}$ and other international agencies rather than as "genuine civil society organisations fostering popular participation and social organisation or being representative or advocates of the local communities and groups. $^{2}$ 


\section{A lack of coordinating structures for CSO/ business/government collaboration}

\begin{abstract}
Although a tradition of faith-based individual and corporate philanthropy is strong and there are anecdotal examples of philanthropy and businesscivil society collaborations, the modalities, processes, scale and scope of these endeavours are not documented. Neither is there any documentation on the efforts organised, channelled or formalised on modern professional practices.
\end{abstract}

This situation is compounded by the absence of a dedicated institution/organisation to fill the gap focusing on philanthropy promotion and building effective business-civil society linkages/partnerships, coupled with a lack of sustained institutional operational frameworks. Institutionalised structures to promote $\mathrm{CSO} /$ business collaboration could help to unleash the full potential of philanthropic support to development in the country.

Promoting collaboration based on mutual commitments to common goals, ensuring transparency, building in mechanisms for reporting and monitoring, and demonstrating delivery can build trust between the two sectors. Moreover, communities seeing the trust that businesses place in CSOs through collaborations will view CSOs less negatively. Both parties will see a broadening of perspectives along with increased access to research and viewpoints. They will both experience increased access to advocacy networks. Such collaboration will also increase the understanding of emerging issues and trends leading to synergistic efforts for development.

Stronger collaboration between CSOs and business would also support a process of overcoming the current lack of financial sustainability and donor dependence. The sustainability of a large number of CSOs created solely through donor funding is questionable. Lacking self-generating capacity, it is likely that once donor funding is withdrawn, these CSOs will cease to exist. Increasing the share of indigenous philanthropic resources for development is therefore a prerequisite for the long-term sustainability of the sector.

\section{CSO operations to date in Afghanistan are} responsible for the weak links between communities and local administrators as the number of CSOs working closely with local authorities is very low. Thus, what we see is a lack of coordination with local authorities who are major players in the social development agenda. This problem needs to be addressed for any collaborative framework to be implemented successfully.
Apart from weak inter-sector coordination between government, business and civil society, within the CS sector coordination between traditional and modem civil society is also lacking. As a result of the current "modernisation" agenda, traditional civil society has been largely excluded, particularly by the international community. Experience of the last five years has shown avoidance of engagement with traditional civil society as it is perceived to be backward and undemocratic. This implicitly ignores the larger part of Afghan native, indigenous and traditional civil society, and drives home that the views of traditional segments are not given the same value as views of modern civil society.

\section{Lack of public awareness about the development work of CSOS and businesses}

Development agencies, CSOs and businesses generally do not realise the importance of reporting their philanthropic or collaborative initiatives through the media to create awareness about their activities. There is very little public awareness of the existing efforts of philanthropy and collaborations between CSOs and businesses. Also, community involvement in these efforts seems to be limited. The media could play a much larger role in creating awareness, promoting philanthropy and informing the public about CSO-business collaborations and opportunities. The CSOs and businesses can also opt for modern tools such as establishing their websites, making their annual reports public, publishing and disseminating informative pamphlets and brochures highlighting their social investment activities, and having mutual interactive dialogue on both $\mathrm{CSO}$ and business forums etc.

\section{Lack of organised research and capacity} building institution: The importance of evidencebased research in any sector pertaining to development is essential for informed policy formulation and for the creation of an enabling environment. Examples from international experience, especially from neighbouring countries, show that they have not only realised the importance of research on philanthropy related issues, training and capacity building, but have established specialised institutions to serve the purpose and fill in the gaps. In Afghanistan, the absence of these enabling provisions proves to be a stumbling block in the promotion of philanthropy and business-civil society collaborations. 
A lack of a well structured enabling fiscal and regulatory environment both for business and CSOS

Despite the fact that the government has recognised the increasing supportive role of business and civil society in development in its policy papers (such as the Afghan National Development Strategy (ANDS) and Poverty Reduction Strategy (PRSP)), and has even partnered with them, there is a lot more to be done. Since there is no social security or health insurance in the country, philanthropy through partnerships can be acknowledged as a viable source for social safety nets.

The Government can encourage formalising philanthropy and business-CSO partnerships for economic and social development by providing an enabling legal and regulatory framework which considers the following points:

- The importance of democratic dialogue, fair rules of play for all actors, expeditious grievance-setting mechanisms and adjudicatory systems

- The endorsement of quality and credibility standards by promoting ISO certification for businesses and non-profit certification for CSOs

- Tax rebates on donor/philanthropist/business income; rebates on import of vehicles, machinery, and equipment; and concessionary rates on land allotment and utilities for CSOs etc.

- The official recognition of philanthropic endeavours for social causes through, for example, national philanthropy awards

\section{RECOMMENDATIONS}

A few relevant recommendations are presented here to generate more fruitful discussions at the Conference so that a way forward can be unanimously agreed upon for future concrete action.

\section{Recommendations for Government}

Create an enabling environment through the adoption of action-oriented ground-based policies for both business and civil society. This could include:

- Adding fiscal and regulatory provisions to laws, and providing incentives for CSOs and businesses. Incentives could include tax rebates (such as the provision of land at subsidised rates); donor status to philanthropists (giving them tax concessions on their incomes); tax exemptions to businesses for social giving; and tax exemptions to CSOs on income, machinery, vehicles, utilities etc.

' The development (with stakeholders' consultations) of a guiding and enabling operational policy framework for collaborations. For example, at the Enabling Environment Initiative (EEI) in Pakistan, stakeholders reached a consensus after extensive dialogue on the drafting of a non-profit law for the Government of Pakistan on governance and support of CSOs.

- Granting recognition. For example the establishment of an award system, such as an Annual Philanthropy Award, for top individual or corporate philanthropists. This would serve as an incentive for businesses to raise their company profiles as socially responsible businesses.

- Formalising the collection and distribution of zakat. With no state-guided system for zakat, people calculate their zakat voluntarily and give it privately to individuals. Formalised state-guided zakat collection and distribution systems (prevalent in Pakistan and Malaysia) may be looked at as examples. This could be a source for an indigenous informal social safety net and could provide a good opportunity to channel zakat through non-profit institutions for social development.

- Matching grant funds by donor agencies, Government and business may also be considered where CSOs generate and commit a certain percentage of money for a project and donors/Government/business give a matching contribution for projects of private initiative.

\section{Foster a climate of mutual trust amongst stakeholders through the promotion of good governance, transparency and accountability.}

Government should encourage and promote collaborative partnerships through a structured institutional approach. This could include:

- Introducing legislation that encourages businesses to adopt practices of documentation and disclosure

- Introducing and promoting quality assurance through business-related ISO certification

- Establishing corporate social responsibility principles and practices that businesses should follow

- Introducing a system of certifying "good practice" and credible CSOs. A transferable successful example would be an NPO Certification 
programme akin to the one used by the Pakistan Centre for Philanthropy or the Philippine Council for NGO Certification. This could build upon the code of conduct for CSOs in Afghanistan, so that credible and effective partners for development could be identified and partnerships built.

\section{Recommendations for CSOs and Business}

\section{Create an institutional infrastructure to promote philanthropy.}

International experience has shown that permanent institutions dedicated to promoting and facilitating effective philanthropy can have a strong positive influence on the scale and impact of philanthropic contributions to development. It is suggested that the establishment of the following institutions be considered:

- A Centre for Philanthropy (or similar institution) that would synergise and catalyse the efforts of all private development actors; enhance the volume and effectiveness of philanthropy; and provide facilitative linkages and support services to ease business-CSO collaborations. The Pakistan Centre for Philanthropy (PCP) may be examined as a model. Such an organisation would be able to tap into the potentially vast philanthropic resources within Afghanistan and channel them institutionally as is done by the Indian Centre of Philanthropy or the Canadian Centre of Philanthropy and their equivalents in many other countries. A key approach would be to work through diaspora organisations, business and civil society, with the pre-condition that those institutions to/through which the money is channelled should themselves be credible and enjoy a good reputation in the country.

- Trusts for key sectors such as Education, Health, and for vulnerable people (such as orphans and widows) need to be established. Trusts could offer costed options of public welfare programmes toward which philanthropists could contribute according to their economic ability.

- A dedicated research, training and capacity building institution, similar to the NGO Resource Centre (NGORC) in Pakistan, needs to be established. Systematic research on individual, corporate and diaspora philanthropy could lead to better policies and would inform efforts to raise more indigenous resources for development and overcome the current extreme donor dependency.

\section{Recommendations for Government, CSOs and Business working together}

\section{Better coordination and institutional networking amongst the various stakeholders is of prime importance and needs to be built. This includes:}

- Developing an enabling regulatory framework that encourages coordination with local authorities. International examples show that successful business-CSO collaborations always need support and assistance of local authorities to facilitate processes, e.g. district governments are involved in the Corporate Philanthropy for Education programme in Pakistan. CSO-business collaboration should also involve Government in order to be open to wider scrutiny and also to deter the practice of politically motivated policies.

- Bringing traditional civil society into the loop of all development efforts.

- Afghan CSOs being prepared to collaborate visibly with business and assisting business in achieving visibility for their efforts. For CSOs to think in these terms though requires a paradigm shift, from "fundraising" to "partner-raising", and to partially subordinating themselves to businesses with purposes considerably different from their own. In order for this to be accomplished, capacity building and strategic planning is required.

- Raising awareness about the benefits, procedures and processes of business collaborating with civil society requires the participation of all stakeholders - the business sector, civil society, policymakers (particularly those involved in the legal and regulatory framework) and communities. Information and awareness-raising sessions which bring people from various backgrounds together could bring new perspectives and focus, whilst also having an impact on how various groups perceive each other. Such sessions could also build the capacity of CSOs by bridging the information gap. Moreover, the presence of businesses at these sessions would not only help businesses learn about effective ways to partner with CSOs, but would also elevate the credibility of the process by demonstrating the trust businesses place in communities and Civil Society. The media could play an important role in the facilitation of linkages between local Afghan associations in the social sectors. 


\section{ANNEX A: KEY PLAYERS, PARTNERS AND FORUMS}

- The Afghan Rehabilitation and Environment Agency (AREA) has offices in Kabul, Jalalabad, Mazar-e-Sharif and Herat. The organisation has offered its services to promote philanthropy in Afghanistan and has also asked for certification from the Pakistan Centre for Philanthropy to raise its profile and enable itself to play this role effectively. AREA supports a vast network of Shuras of which 150 are found in Kabul alone.

- Other NGOs that could serve as potential partners are the National Program Office/Afghan Reconstruction and Rehabilitation Agency (NPO/RRAA) and the Afghan Development Agency (ADA).

- The Afghan Civil Society Forum, formed in late 2001 parallel to the Bonn Conference process, represents Afghan civil society at the annual Afghan Development Forum.

- The Afghan NGO Coordination Bureau was founded in 1991 and aims to build capacity and coordinate activities of Afghan NGOs. At present, 330 NGOs are registered with ANCB. ANCB membership is restricted to Afghan NGOs. In 2004 and 2005, ANCB was involved in coordinating draft NGO legislation and an Afghanistan NGO code of conduct. ANCB is a member of the International Council of Voluntary Agencies ICVA and is actively involved in the activities of the Afghan Civil Society Forum.

- The Agency Coordinating Body for Afghanistan Relief (ACBAR) includes all local and international agencies; the advocacy group meets every two weeks. It has a strong information sharing role and has offices in Kabul, Jalalabad and Peshawar.

- There are also business associations which help generate philanthropy e.g. the Afghan Intemational Chamber of Commerce, Afghan Chamber of Commerce, Afghan Women's Business Federation and Afghan Women's Business Association.

- An example of a partnership between the business community and an autonomous government agency is the Afghan Investment Support Agency (AISA). AISA manages to cover all of its conference costs through sponsorships. The cost of one such international conference was US\$ 70,000 . The major contributors were Kam Air, Azizi Bank, Kabul Bank and Siemens. A lesson from AISA's experience is that skills, contacts and trust building are critical elements for the success of such initiatives. Another lesson is giving due promotion and recognition to businesses that do well. Many
Afghan businessmen will contribute only at public gatherings or through media channels in order to enhance their public profile. AISA could formalise its collaborative interventions on the model of the Philippines Business for Social Progress (PBSP). 


\section{ANNEX B: PUBLIC PRIVATE PARTNERSHIPS FOR EDUCATION}

\begin{abstract}
"A public-private partnership is defined as any arrangement between a government and a private sector (inclusive of CSOs) in which partially or traditionally public activities are performed by the private sector"' (Savas, 2000).
\end{abstract}

Education is the prime catalyst for national development. Despite the high importance attached to it (reflected in a multitude of policy packages passed by successive governments), the state of affairs is far from desirable. The present Government fully realises that the public sector alone cannot meet the myriad challenges to providing the necessary resources, services and expertise to effectively address educational issues. There has been a clear realisation on the part of the Govemment of shifting its role from being the sole provider of resources and education delivery to also acting as a facilitator of the private sector and of civil society's efforts in Pakistan. Public Private Partnerships (3Ps) have been expanding over time and it has been estimated that the private sector (including non-profits) contribute about 0.7 percent of the GNP in education.

There has been an increasing recognition of the Pakistan Centre for Philanthropy's (PCP) role in supporting public sector institutions through private providers, especially through the Adopt-a-School (ASP) modality. PCP's role remains facilitative: bringing together NGOs, corporate donors and district governments in a productive partnership with effective management of cost and time. In July 2003, PCP initiated a project known as "Public Private Partnerships - Facilitating Corporate Philanthropy for Quality Education". The project aims at creating linkages between the public sector primary schools, corporate philanthropists and nonprofit organisations.

There are three types of investments involved in 3Ps: capital investment from the Govermment and the corporate sectors, social investment by civil society and technical cum catalytic investment from a professional body like the Pakistan Centre for Philanthropy. Each participant gains from the partnership.. Skills and assets of each sector (public and private) come together in delivering a service or facility for civic benefit, thus multiplying inputs to achieve sustainable development outcomes. Bureaucratic procedures are minimised by the use of tested template agreements to accelerate the process. At the same time, partnerships are formed only where the community identifies a need and expresses willingness for the private sector to become an active social investor. This translates into a healthy corporate-community relationship and builds company goodwill. Most importantly, the arrangement ensures long-term success, by engaging the coalition of partners including the beneficiaries in planning, implementation and monitoring.

The most common 3 Ps programmes being delivered by Education Foundations, NGOs, $C B O s$, the private sector, the corporate sector and other providers include:

- Contracted management of public schools by NGOs

- Afternoon Institutions System: upgrade of institutions through the Community Participation Programme (CPP) in Punjab and Public-Private Collaboration (PPC) in NWFP

- Adopt a School/School Improvement Programme (SEF, PCP)

- Community School

- Capacity Building of School Management Committees (SMCs)/Parent Teacher Associations (PTAs)/School Councils

- Community Learning/Literacy Centres (using school premises and facilities)

- Education Extension and Enrichment Programmes

- Teacher Training

- Volunteer teachers or other individuals sharing skills, donating time etc.

- Individuals donating funds to provide missing infrastructure and educational materials

\footnotetext{
'Country Profile (2006): Afghanistan. Accessed from www eiu com/schedule on October 3, 2006 ${ }^{2}$ Harpviken, K.B, A. Strand, K.ask (2002): "Afghanistan and Civil Society" Commissioned by the Norwegian Ministry of Foreign Affairs, Peshawar/Bergen
} 


\title{
GOVERNMENT AND THE PRIVATE SECTOR WORKING TOGETHER TO CREATE THE AFGHAN TELECOMMUNICATIONS INDUSTRY
}

\author{
Case study prepared for the Enabling Environment Conference
}

\section{BACKGROUND INFORMATION: TELECOMMUNICATIONS IN AFGHANISTAN}

The growth and development of the telecommunications sector in Afghanistan is often cited as a success story, an example of how the Government of Afghanistan (GoA), specifically the Ministry of Communications (MoC), has worked with the private sector to establish a sectoral environment conducive to driving significant private sector foreign investment into Afghanistan since early 2003 .

Total projected investment into the sector at the end of 2006 (including licence fees and network expansion investments) made by Telecom Development Company Afghanistan Limited (Roshan), Afghan Wireless Communications Company (AWCC), Areeba (part of the MTNInvestcom Group) and Etisalat is estimated to be approximately US\$ 500 million.' This investment has lead to the rapid buildout of national telephony networks in Afghanistan for the first time in the country's history. Telecommunications operators in Afghanistan are thriving in a market where, after decades of war and a non-existent telecommunications infrastructure, the demand for telecommunications services is extremely resilient.
Growth in the sector relative to similar underdeveloped markets with similar socioeconomic characteristics (e.g. per capita purchasing power) has been unexpectedly rapid. Mobile penetration in Afghanistan has risen from approximately 0.2 percent in early 2003 (two in every 1,000 Afghans had a mobile phone) to an estimated 6.9 percent at the end of 2006 . As of April 2007, mobile penetration is estimated to have passed eight percent. ${ }^{3}$ Comparative studies suggest that the market in Afghanistan is growing at a pace equivalent, proportionately, to the Chinese mobile telecommunications market. Further, in India, it took almost 10 years for the mobile telecommunications market to reach seven percent penetration, as opposed to the 3.5 years it took in Afghanistan.

The emergence of a competitive telecommunications sector has resulted in telephony coverage for 40 percent of the population of Afghanistan, and in significant reductions in access and usage pricing. The price of SIM cards has dropped from over USS 150 in early 2003 to approximately US\$ 10 today. National retail tariffs have dropped from approximately US\$ $0.30 / \mathrm{min}$ in early 2003 to approximately USS $0.10 / \mathrm{min}$ in 2007 with some operators offering promotional or offpeak national tariffs as low as US\$ $0.03 / \mathrm{min}$. 
Table 1: Overview of telecommunications sector in Afghanistan

\begin{tabular}{lccl} 
Operator & $\begin{array}{c}\text { Licence / } \\
\text { Launch Date }\end{array}$ & $\begin{array}{c}\text { Est. Market Share } \\
\text { Subscriber Base }\end{array}$ & Shareholders \\
\hline $\begin{array}{l}\text { Telecom Development Company } \\
\text { Afghanistan (Roshan) }\end{array}$ & $\begin{array}{c}\text { Jan 03 (licence) } \\
\text { for US\$ } 5 \mathrm{~m}\end{array}$ & $\begin{array}{c}\text { Est. } 50 \% \\
1,250,000\end{array}$ & $\begin{array}{l}\text { Aga Khan Fund for Economic } \\
\text { Development - 51\%; }\end{array}$ \\
http://www.roshan.af & Jul 03 (launch) & &
\end{tabular}

Monaco Telecom Int'l (majority owned by Cable \& Wireless PLC);

MCT Corp (USA).

\begin{tabular}{|c|c|c|c|}
\hline $\begin{array}{l}\text { Afghan Wireless Communications } \\
\text { Company } \\
\text { http://www.afghan-wireless,com }\end{array}$ & $\begin{array}{l}\text { Jan } 03 \text { (licence) } \\
\text { for USS } 5 \mathrm{~m} \\
2002 \text { (launch) }\end{array}$ & $\begin{array}{l}\text { Est. } 35 \% \\
835,000\end{array}$ & $\begin{array}{l}\text { Telephone Systems International } \\
\text { Inc. (USA) }-80 \% \text {; } \\
\text { Government of Afghanistan }\end{array}$ \\
\hline $\begin{array}{l}\text { MTN (Areeba) } \\
\text { http://www.mtn.co,za } \\
\text { http://www.mtninvestcom.com }\end{array}$ & $\begin{array}{l}\text { Oct } 05 \text { (licence) } \\
\text { for US\$ } 40.1 \mathrm{~m} \\
\text { Jul } 06 \text { (launch) }\end{array}$ & $\begin{array}{l}\text { Est. } 15 \% \\
380,000\end{array}$ & $\begin{array}{l}\text { MTN - MTN purchased Investcom } \\
\text { LLC for US\$ } 5.5 b n-100 \%\end{array}$ \\
\hline
\end{tabular}

\begin{tabular}{lcll}
\hline $\begin{array}{l}\text { Afghan Telecom } \\
\text { http://www.afghantelecom.af }\end{array}$ & $\begin{array}{c}\text { Incumbent - } \\
\text { formally awarded } \\
\text { an operating } \\
\text { licence }^{6} \text { in } 2006\end{array}$ & N/A & $\begin{array}{l}\text { Government of Afghanistan - } \\
100 \%\end{array}$ \\
\hline Etisalat & $\begin{array}{c}\text { May 06 (licence) } \\
\text { for US\$ } 40.1 \mathrm{~m}^{7} \\
\text { Yet to launch }\end{array}$ & N/A & $\begin{array}{c}\text { Etisalat - Dubai owned } \\
\text { telecommunications operator }\end{array}$ \\
\hline
\end{tabular}

Telecommunications operators have been the source of significant direct value to the GoA - in 2004,2005 and 2006, it is estimated that between 10 and 20 percent of the GoA's domestically generated revenues were derived from licence fee, import duty and tax payments made by telecommunications operators to the GoA. ${ }^{8}$

The combination of the scale of private sector investment into the telecommunications sector; the role played by the MoC in engaging with the private sector and establishing a policy, legal and regulatory framework that has encouraged private sector participation; and the results which such investments have generated have, to date, not been replicated in any other sector of Afghanistan's economy.

\section{THE STORY OF REGULATING THE TELECOM SECTOR IN AFGHANISTAN: IMPLEMENTATION OF THE GOVERNMENT'S APPROACH OF NON-INTERVENTIONISM}

By November 2003, there were two licensed mobile telephony operators in Afghanistan AWCC and Roshan. AWCC had originally been licensed during the Taliban era. Roshan received its licence in January 2003, for an initial fee of US\$ 5 million after a competitive tender process, and commenced commercial operations in July 2003. Toward the end of 2003, the MoC published its first draft policy (Policy) ${ }^{9}$ on telecommunications since the fall of the Taliban regime. The Policy embodied a commitment to private sector-led reconstruction of telecommunications within Afghanistan, committing the MoC and the GoA to:

- create a "legal and regulatory environment that nurtures and accelerates industry growth" and "establish a level playing field for competition"

- "engage private investment to the greatest extent possible"

- "introduce market liberalisation" i.e. increase competition through transparent licensing processes

- 'rapidly separate the Ministry's

Telecommunications Department into a stateowned enterprise to be known as Afghan Telecom"10

Significantly, the Policy also acknowledged that the role of the Government was not to own and operate telecommunications assets but instead "to create an enabling environment for private investment, competition and industry growth." 
Certain parts of the GoA have sometimes found it difficult to discard a dirigiste impulse or tendency toward economic growth and the private sector (a possible legacy of the Soviet intervention in Afghanistan). However, the $\mathrm{MoC}$ has consistently held itself back, sometimes with difficulty, from intervening in the businesses of telecommunications operators in Afghanistan, by and large allowing competitive market forces to meet demand and drive the delivery of telecommunications services within the country.

From time to time, the $\mathrm{MoC}$ has cited retail prices in India and Pakistan and questioned why Afghan retail prices are higher. The industry has always responded by stating: (i) that the costs of doing business are higher in Afghanistan than in India and Pakistan (e.g. security costs, substitution for lack of infrastructure costs, electricity generation costs, relatively high costs in terms of access to capital factoring in a risk premium for Afghanistan); (ii) that any intervention on retail pricing would limit the private sector's ability to generate adequate returns and would therefore lead to a dramatic slowdown on further investment; and (iii) that market forces would drive down retail tariffs over the medium-term which has been the case since 2003.

\section{Effective Implementation of Public Policy Goals}

A regurgitation or "cut and paste" of best practice policy goals is easy. Delivering on such policy goals in the Afghan context is not. Yet, since $\mathbf{2 0 0 3}$ the $\mathrm{MoC}$ has gone some distance in delivering on its stated objectives:

- In the absence of a Telecom Law, the MoC established, by ministerial decree, an ad hoc regulatory agency, the Telecom Regulatory Board (TRB) to regulate telecommunications operators on the basis of their operating licences.

- In the middle of 2005 , the MoC initiated an auction process for third and fourth mobile telecommunications licences, keeping to its policy commitment to introduce further competition. ${ }^{11}$

- In September 2005, the MoC completed the corporatisation of Afghan Telecom (AT), thereby preparing $\mathrm{AT}$, in principle, for privatisation.

- In December 2005, the Telecom Law of Afghanistan (TLA) was enacted laying the formal groundwork for the formation of a partially independent industry regulator - the Afghanistan Telecommunications Regulatory Authority (ATRA). ${ }^{12}$

\section{Importance of Legal and Regulatory Frameworks}

The $\mathrm{MoC}$ has perhaps, along with the financial and banking sectors, achieved most in creating a legal and regulatory framework which makes for a marginally easier case for further foreign direct inyestment into the sector in Afghanistan.

Concrete examples of legal assurances that have been extended to telecommunications operators by the gradual emergence of a commercial legal and regulatory framework include:

- Expropriation Protections. Article 57 (1) (5) of the TLA extends the expropriation protection provisions in the Private Investment Law (PIL) (2005) to telecommunications operators.

- Transparency in Decision-Making. Articles 8,9 and 10 of the TLA lay the foundations for the process by which ATRA must reach any regulatory decision. The provisions did not exist a year ago and extend some comfort to telecommunications operators that decisions must be made in a transparent and consultative manner. In principle, a route to appeal extends further assurances that the operations of telecommunications operators in Afghanistan will be subject to fair and non-arbitrary regulation.

- International Arbitration Protections. The PIL allows for any dispute between a foreign investor and the $\mathrm{GoA}$ to be resolved through an international arbitration rather than the Afghan courts.

- Competitive Processes. Article 14 of the TLA makes it mandatory for ATRA to establish transparent competitive bidding processes when issuing new licences. Such a provision enshrines a transparency requirement and, in principle, reduces the opportunity for inefficient allocations of licences on the basis of patronage or political influence as opposed to merit, resource and qualification.

The enactment of laws is, however, only a first step, albeit a significant first step in the evolution of a robust legal and regulatory framework. During 2006 , Roshan closed a US\$ 65 million round of senior financing that included the participation of multilaterals as well as foreign commercial banks including Standard Bank PLC. The transaction represented the first time a foreign commercial bank had made a significant cross-border loan into Afghanistan in the post-Taliban era. Such a loan would not have been approved by a foreign commercial bank such as Standard Bank had some of the legislation above not been enacted. 
Nonetheless, any legal and regulatory framework must be tried and tested before it can be claimed as effective.

- Would an Afghan court or ATRA have the capacity and technical expertise to adjudicate a complex telecommunications dispute?

- How would a foreign bank enforce security over an asset in Kandahar in an event of default?

- Would Afghan courts uphold such security?

- If they did, would the physical security situation in Kandahar permit that foreign bank to repossess such an asset?

- Would an international arbitration award for the fair market value of an expropriation be honoured?

\section{Public-Private Dialogue: From Dirigisme to a More Enabling Environment}

Since 2003, telecommunications operators have consistently attempted to convey to the GoA the importance of (i) fiscal and legal predictability in ensuring steady future flows of investment into the telecommunications sector and (ii) reaching a fiscal understanding whereby the $\mathbf{G o A}$, in its eagerness to grow its domestic tax base without really having the capacity to broaden that base, does not overtax a sector that is already contributing heavily to Afghanistan's reconstruction in the short-term, when such overtaxation may have an impact on the GoA's long-term fiscal revenues.

In 2005, the Government of Afghanistan enacted a new Income Tax Law (ITL). The ITL introduced a 10 percent Business Receipts Tax (BRT) on the provision of telephony services and effectively voided earlier investment agreements that Roshan and $\mathrm{AWCC}$ had entered into with the Ministry of Finance (MoF) in 2003. The combination of licence fee and BRT obligations effectively meant that the sector would be paying the GoA 20 percent of gross revenue prior to paying corporate tax on net income. As a result of the ITL's enactment, Roshan and AWCC jointly lobbied the $\mathrm{MoF}$ on two fundamental issues. First, the GoA's discarding of the investment agreements would set an alarming precedent for foreign investors looking to invest in Afghanistan. Such unpredictability could create a perception that the GoA is not a reliable long-term partner of the private sector, which in turn would diminish flows of foreign investment into Afghanistan.

Second, a capricious, short-term approach to increasing domestic tax revenues by overtaxation of the telecommunications sector would also impede future investment, job creation and economic development generated by the rapid growth of the telecommunications sector.

After a lengthy period of negotiation with the $\mathrm{MoF}$ and the MoC, the industry entered into a comprehensive settlement agreement with the GoA that resulted in a reduction in the aggregate BRT and licence fee burden from as much as 20 percent to 14.5 percent of gross revenue. Whilst the GoA's readiness to enter into such an agreement is an encouraging testament to its willingness to listen to and accommodate the concerns of the industry, the true test will be its adherence to the terms of the settlement agreement for the next 10 years. Although the settlement agreement is a fair example of constructive public-private dialogue with positive outcomes, the $\mathbf{G o A}$ is still caught between reformist elements within it that accept the necessity for consultation, dialogue and predictability and the dirigiste tendancy for whom (i) the considerations of the private sector are secondary and (ii) there remains an element of suspicion about the motivations of the private sector in spite of the stated constitutional commitment to nurturing private sector driven development. ${ }^{13}$ The Attorney General's Office has recently initiated an investigation within the Ministry of Finance and has intimated that the Minister of Finance did not have the legal authority to enter the settlement agreement on behalf of the Government of Afghanistan in spite of the fact that the terms of the settlement agreement were approved by the President of Afghanistan and the cabinet of the Government of Afghanistan. ${ }^{14}$

The lack of predictability and suspicion of the private sector continues to exert influence within the GoA. Two further recent examples illustrate the tension between reformists who acknowledge the need for rapidly expanding the scope of private sector initiative and conservatives suspicious of any form of private sector involvement and success. First, in December 2005, elements within the GoA launched an initiative to nationalise the international gateway operations ${ }^{15}$ of telecommunications operators. This initiative was not supported by the $\mathrm{MoC}$ and after considerable lobbying by the $\mathrm{MoC}$, telecommunications operators and sector stakeholders such as the Asian Development Bank, the initiative was shelved. Second, on two separate occasions during 2006, the MoF increased import tariffs on telecommunications equipment, from five to eight percent and then subsequently from eight to 10 percent, in spite of assurances to the industry that import tariffs would remain at eight percent for "a number of years" after the first increase. Whilst the MoC and ATRA have supported the industry in lobbying against unpredictable increases, it remains 
to be seen whether the second increase will be reversed. This will be an important step in reinforcing an ethic of transparency, forbearance, consultation and predictability.

In a context of a still somewhat uncertain environment, the lack of adequate, transparent and impartial dispute resolution mechanisms in Afghanistan is a disincentive to investment. The enactment of laws is only a first step in creating an enabling legal framework in Afghanistan. Laws must be backed by an administrative capacity to interpret and enforce. For example, the TLA provides for an appellate body to which telecommunications operators may appeal ATRA decisions. In principle, this may be acceptable; in practice, that appellate body has yet to be formed.

Overall, through the end of 2006 , telecommunications operators (perhaps due to the relative scale of investments they have made into Afghanistan) have largely succeeded in working with the GoA to develop and create an environment in which dialogue and consultation is an accepted means to the end of good policy and decent legislation.

\section{General Impediments to Growth and Investment}

Significant obstacles to further investment and growth remain. Some of these obstacles, such as lack of security and a lack of electricity raise the cost of doing business for all Afghan enterprises irrespective of the sector in which they operate and their size.

The continued expansion of the telecommunications sector will be hampered by:

- A chronic and increasing lack of security, particularly in southern parts of the country

- A lack of infrastructure, including a lack of access to stable sources of electricity

- The high costs of financing given the risk premium attached to investing in and lending to Afghanistan

\section{- A lack of terrestrial telecommunications} infrastructure linking urban centres within Afghanistan by fibre-optic cable. It should be noted that on April 15,2007, digging work commenced on the construction of a national fibre-optic ring. In 2006 , the MoC entered into a contract with ZTE of China for this construction which would, once completed, lower costs of doing business for operators thereby potentially leading to lower retail tariffs, provided that operators may lease fibre-ring capacity from the Government of Afghanistan on a reasonable commercial basis. ${ }^{16}$

Security concerns in southern Afghanistan are preventing operators from expanding their operations into southern parts of the country. In the face of an inability to invest in the south, it is expected that operators will re-allocate investment earmarked for southern Afghanistan into more peaceful parts of the country. In the event that the instability in southern Afghanistan spreads to other parts of Afghanistan, it is likely that foreign investors may consider re-allocating investments originally destined for Afghanistan out of the country altogether.

Irrespective of the situation in southern Afghanistan, telecommunications sites throughout Afghanistan are manned by at least two security guards (in some instances the number of armed security guards at a site is as high as 20) 24 hours a day. The high level of expenses for security represents an amount that is considerably higher than in comparative markets.

\section{Sector Specific Impediments to Growth and Investment - Interconnection Dispute Resolution}

In late 2006, ATRA intervened in the market to regulate interconnection charges. An analysis of the dispute and of the scope of ATRA's intervention serves to highlight broader concerns that may drastically limit future investment. ${ }^{17}$ On January 16, 2007, ATRA determined that charges for interconnection would be regulated at US\$ $0.029 / \mathrm{min}$ for 2007 dropping to US\$ $0.026 / \mathrm{min}$ in 2009 . Subsequent to the decision, Roshan and AWCC both notified ATRA of their intention to appeal on the grounds that the decision set rates below the operators' actual costs ${ }^{18}$ and did not account for the Afghan specific costs highlighted in Table 1. An application of the decision would result in Roshan and AWCC being forced to carry interconnection traffic at a financial loss. In the companies' opinion, the decision to impose sub-cost rates is effectively an intervention that will force them, as net recipients of traffic from other operators, to lose money.

The decision has removed the incentive for further investment in network expansion. In light of the negative investment environment created by the decision, it is probable that the rapid growth in mobile penetration to date will slow down significantly and that growth in revenues to the $\mathrm{MoF}$ generated from import duties applied on 
capital imports and use of mobile phones will also be negatively affected.

The decision has also highlighted some continuing deficiencies in the sectoral legal and regulatory framework. For example, Article 10 (3) of the TLA allows for an aggrieved party to appeal an ATRA decision to a Financial Services Tribunal formed under the Central Bank Law of Afghanistan. However, the Tribunal has yet to be established. Further, the Central Bank Law only permits financial institutions to bring appeals before the Tribunal, excluding telecommunications operators. Whilst a reading of the TLA may offer comfort to an aggrieved operator, in reality, Article 10 (3) of the TLA provides no practical comfort to that aggrieved operator.

It is understood that Roshan and AWCC have jointly written to ATRA highlighting mathematical errors in the cost model used by ATRA's consultants, Piepenbrock Schuster Consulting, to calculate interconnection costs. Roshan and AWCC have requested that ATRA correct the mathematical and formula based errors that have been identified in the interconnection model. ATRA and the Minister of Communications have given verbal assurances that any mathematical errors found in the interconnection model would be corrected. As of the middle of April 2007, ATRA has yet to make any form of public announcement on how it intends to revise the interconnection model and correct the errors. Although ATRA should be commended for transparency in sharing the interconnection model with operators who had challenged its correctness, the manner in which ATRA resolves the interconnection dispute is likely to set a fundamental precedent for future foreign investment into Afghanistan.

\section{Afghan Telecom and Perceptions of Impartial Regulation}

In spite of stated policy commitments to do so, the Government of Afghanistan has yet to privatise Afghan Telecom. AT remains wholly owned by the GoA. The Minister of Communications is the Chairman of AT. Afghan Telecom's continued operation in the sector as a state-owned enterprise gives rise to a material conflict of interest in that the $\mathrm{MoC}$ is performing two contradictory roles. First, the role of the MoC and ATRA is to create policy and to regulate the sector. Second, the MoC continues to manage AT on a day-to-day basis, an operator which it also is bound to regulate. By delaying the privatisation of $\mathrm{AT}$, the $\mathrm{MoC}$ perpetuates a perception of partial regulation. In turn, such a perception, irrespective of whether or not ATRA is regulating in favour of Afghan
Telecom, will serve to impede future private sector flows of investment into the sector. The uncertainty regarding the availability of a fully functioning legal and regulatory framework highlighted above, combined with the potential partiality of regulation arising from the Government of Afghanistan's continued ownership of Afghan Telecom are fundamental issues that still remain to be resolved.

In addition to the regulatory issues, market distortion is a significant issue in that Afghan Telecom is being run on an ongoing basis at a significant commercial loss. This enables Afghan Telecom to charge retail rates that, according to ATRA calculations, are far lower than Afghan Telecom's costs as well as far lower than the retail charges of the other private operators.

\section{SYNTHESIS AND ANALYSIS OF ISSUES}

Overall, through the end of 2006 , telecommunications operators, perhaps due to the relative scale of investments they have made into Afghanistan, have largely succeeded in working with the GoA to develop and create an environment in which dialogue and consultation is an accepted means to the end of good policy and decent legislation. The MoC has perhaps, along with the financial and banking sectors, achieved the most in creating a legal and regulatory framework that makes for a marginally easier case for further foreign direct investment into the sector in Afghanistan.

A number of factors have contributed to the growth of the sector in Afghanistan since early 2003. At the same time, other factors have impeded and may continue to impede investment and growth:

\section{Framing and Effectively Implementing Public Policy Goals}

- The Policy published in 2003 embodied a commitment to private sector led reconstruction of telecommunications within Afghanistan. Since 2003 the MoC has made considerable progress in delivering on its stated objectives, consistently holding itself back from intervening in the businesses of telecommunications operators in Afghanistan.

- It has kept to its policy of introducing further competition (issuing the third and fourth licences in 2005). It completed the corporatisation of Afghan Telecom (AT), thereby preparing AT, in principle, for privatisation. 
- Telecom Law of Afghanistan (TLA) was enacted in December 2005, laying the formal groundwork for the formation of a partially independent industry regulator.

- The legal assurances that have been extended to telecommunications operators by the gradual emergence of a commercial legal and regulatory framework include expropriation protection (under the TLA), transparent regulatory decision-making following a consultation process (TLA), competitive bidding processes for new licences (TLA) and international arbitration protection under the Private Investment Law.

- A compromise was found following the introduction of the Business Receipts Tax in addition to licensing fees. Operators could convince the MoF that this change would set an alarming precedent for foreign investors, and that the overtaxation of the telecommunications sector would also impede future investment, job creation and economic development generated by the rapid growth of the telecommunications sector.

\section{Ongoing Concerns about the Regulatory Framework and Cost of Doing Business}

- The GoA is still caught between reformist elements within it and dirigiste tendancies. The lack of predictability and suspicion of the private sector continues to exert influence within the GoA. It is still uncertain whether a second, unpredicted increase in import tariffs will be reserved or not. In a context of a still somewhat uncertain environment, the lack of adequate, transparent and impartial dispute resolution mechanisms in Afghanistan is a disincentive.

- Significant obstacles to further investment and growth remain. Some of these obstacles, such as lack of security and a lack of electricity, raise the cost of doing business for all Afghan enterprises, irrespective of the sector in which they operate and their size.

- At the present time, the ATRA decision to regulate interconnection charges by imposing sub-cost rates may drastically limit further investment in network expansion and could slow down the rapid growth of the sector (and the resulting Government reyenues).

\section{CONCLUSIONS AND RECOMMENDATIONS}

The establishment of a generally conducive legal and regulatory environment, the emergence of the two newest operators, the planned privatisation of Afghan Telecom and increased predictability, transparency, consultation and forbearance all mark notable progress in the development of the telecommunications sector. It is fair to call this a major accomplishment. There is every incentive for both the public and private sector to respect the framework and to put into place the final pieces of the puzzle, such as assurances of greater predictability and the dispute resolution mechanism.

\section{Recommendations}

- Formation of an industry association during 2007 to formalise joint representation of operator concerns to the Government of Afghanistan

- Commitment by the Government of Afghanistan to a roadmap and timeline for the privatisation of Afghan Telecom

- Formal adoption of, and adherence to, Rules of Procedure for ATRA

- Rapid establishment of the Telecom Development Fund in 2007 with transparent and clear procedures governing disbursement of funds to qualifying projects. In the event of a failure to establish the TDF by end of 2007 , funds paid into the TDF (approximately US\$ 10 million) should be returned to licensees pro rata to their contributions to fund further network expansion

- Completion of a study in 2007 , in conjunction with the World Bank, on the fiscal burden on the telecommunications sector in Afghanistan relative to similar markets, as well as completion of an analysis on the impact on MoF revenues of implementing a fiscal regime taxing telephony usage over the taxation of imports of capital equipment

- Continued investments in capacity building at ATRA and the MoC and the rapid formation of a transitional appellate telecommunications tribunal to which operators could appeal ATRA decisions. The tribunal should comprise the Government of Afghanistan, parliamentarians, as well as representatives of key stakeholders from the World Bank and other sector specialists. 


\section{v. DISCUSSION QUESTIONS}

1. What have been the factors of success in the case of the telecommunications industry working with Government to create an enabling environment whereby dialogue and consultation is the norm? Are there lessons learnt that can be transferred to other sectors?

2. What has been the significance of the legal and regulatory framework for the telecommunications operators? Which of the legal assurances (expropriation protection, transparency in decisionmaking, international arbitration protection and competitive bidding processes) are particularly important for investors? Which elements of the legal and regulatory framework are missing?

3. In cases of fiscal or legal unpredictability in other sectors, has public-private dialogue been able to resolve issues? How? To what extent have issues been resolved on a case-by-case basis, as opposed to systemic solutions?

4. What is required to improve dispute resolution? What will it take to establish the industry specific tribunals already provided for in legislation (telecommunications, financial services)? How will the recently signed arbitration legislation improve dispute resolution across all business sectors?

5. In which other sectors do state-owned enterprises running at commercial losses compete with commercial based companies? What is the impact on the competitive environment? Are there other instances of potential impartial regulation, whereby Government is at the same time the owner of an enterprise and the regulator of the industry in question? What measures can be taken to resolve this issue?

This case study was prepared by Roshan in consultation with other telecommunications operators.
' Source: Roshan and Ministry of Communications estimates.

${ }^{2}$ Source: MTN - hitp://www.mtn.co.za. In their annual report for 2006, MTN cited ARPU (Average Revenue Per User Per Month) at \$14 which is markedly higher than ARPU in other emerging markets. ARPU for India is at US\$ 7, Pakistan US\$ 4. ARPU is expected to decline as lower pricing and increased coverage enables less well of Afghans to purchase and use mobile phones.

${ }^{3}$ For the purposes of this case study and for calculating penetration rates, no accounting has been made for "dual" or "triple" users - i.e. users who may have more than one or two mobile telephones from different service providers.

${ }^{4}$ Source: Operator estimates as of April 2007.

${ }^{5}$ AWCC was issued a new licence in January 2003 similar to that issued to Roshan. Prior to January 2003, AWCC was authorized to operate under a licence issued to it by the Taliban regime.

${ }^{6}$ Afghan Telecom was awarded a "unified" licence, the scope of which is arguably more expansive than the GSM licences awarded to Roshan, AWCC, Areeba, and Etisalat. For example, Afghan Telecom may offer internet services under its licence whereas other GSM licensees would have to obtain Internet licences in order to be able to offer commercial intemet services, for which a fee would have to be paid.

${ }^{7}$ Etisalat was awarded its GSM licence in May 2006 after Warid Telecom (an Afghan-owned company that had previously provided a range of telecommunications services to Afghan Telecom) failed to pay an entry fee of USDS $40.1 \mathrm{~m}$ to the Ministry of Communications. Warid Telecom was awarded the $4^{\text {th }}$ GSM licence

${ }^{8}$ [Source IMF - GoA historical domestic revenue figures along with analysis of sectoral contributions].

${ }^{\text {http: } / / \text { www.moc.gov.af/Documents/Policies } \% 20 \text { an }}$ d\%20Laws-MoC/Telecommunication $\% 20$ policyEnglish.pdf

${ }^{10}$ The corporatisation of Afghan Telecom is a necessary precursor to Afghan Telecom's (AT) privatisation. This is seen as a final step in fulfilling the MoC's commitment to remove itself from management and operations of telecommunications assets, and to focus on impartial regulation and policymaking. AT's privatisation was expected to take place during 2006 but may have been delayed due to a perception of a lack of investor interest in the sale and a fear of the negative signals that a failed privatisation would send internally within the GoA and externally to the foreign investment community.

"Investcom, since acquired by MTN http://www.mtn.co.za - and Etisalat http://www.etisalat.ae - were awarded the third and 
fourth mobile telecommunications licences. Investcom and Etisalat each paid US\$ 40.1 million for their licences. The fact that these licence fees were so much higher than the 2003 licence fee paid by Roshan is often cited as an example of the positive progress being made by the Afghan economy. In 2005, the fees paid were higher and were paid by large sector conglomerates which may have baulked from entering the bidding process in 2003.

${ }^{12}$ Whilst the enactment of the TLA was viewed as a positive step in the development of a legal and regulatory framework for the sector, the manner in which the TLA was drafted concerned a number of operators. The TRB discouraged any form of comment process whereby operators could contribute to the draft TLA. Further, significant substantive changes were made to the version of the TLA submitted by the MoC to the Ministry of Justice apparently without the approval of the MoC These changes were made by the Taqnin, the legislative department within the Ministry of Justice.

${ }^{13}$ Article 10 of the Constitution of Afghanistan states that: "The state shall encourage, protect as well as ensure the safety of capital investment and private enterprise in accordance with the provisions of the law and market economy."

${ }^{14}$ A signed extract of the minutes of the cabinet session approving the terms of the settlement agreement was appended to the agreement itself in order to avoid the validity of the settlement agreement being questioned at a later date.

${ }_{15}$ The international gateway operations are the facilities which telecommunications operators use to send telecommunications traffic to and from Afghanistan.

${ }^{16}$ In a recent interconnection (see also note 16 below) dispute resolution exercise, ATRA assumed a weighted average cost of capital (WACC) of between 10 and 15 percent on the industry. WACC typically factors in a country's risk premium. The latest edition of the Euromoney country risk index lists Afghanistan as the second riskiest country in the world with a rank of 185 , alongside Iraq and North Korea. See "The Repercussions of Oil and Conflict, Euromoney, Setpember 2006, pp. 400408. The Telecom Regulatory Authority of India assumes a WACC of 14 percent for operators in the Indian market (Telecom Regulatory Authority of India (Forty Fourth Amendment) Order, 2007, p. 49). Euromoney attributes a country risk rating of 55.99 (out of 100) for India, compared with a rating of 4.24 for Afghanistan.

${ }^{17}$ Interconnection is the wholesale price that telecommunications operator 1 pays telecommunications operator 2 for sending traffic to telecommunications operator 1 's customers. A fundamental economic principle of interconnection regulation is that operator 1 must be able to recover the costs of carrying operator 2's traffic.

${ }_{18}$ In September 2006, Roshan reported to ATRA that its actual costs of providing interconnection was approximately US $\$ 0.07 / \mathrm{min}$. 
8 


\title{
THE ENABLING ENVIRONMENT CONFERENCE
}

Effective Private Sector Contribution to Development in Afghanistan

\section{THE AFGHANISTAN BEVERAGE INDUSTRIES LIMITED: "CRISTAL"}

\author{
Case study prepared for the Enabling Environment Conference
}

\section{BACKGROUND}

Afghanistan is in the process of reconstructing its post-conflict economic and physical infrastructure, a vital part of which is the provision of clean and safe drinking water. However, Afghanistan's capacity to provide safe and clean potable water is limited, despite the booming domestic demand for it. Currently, Afghanistan imports most of its beverages, as well as food products, from the outside. The potential for the production of mineral water is enormous, with a population of 25 million and very little domestic production of it thus far.

The experience of Afghanistan Beverage Industries Ltd. (ABI) demonstrates the potential for new businesses in the current context and, at the same time, underlines the multiple challenges companies face to achieve their business objectives.

\section{The "Cristal" Story}

Afghanistan Beverage Industries Ltd. (ABI) was the first company in Afghanistan to undertake the complex task of providing safe bottled water which it called Cristal Quality Mineral Water. ABI's objective is to satisfy the demand of the Kabul municipality, in the absence of an adequate municipal water supply. Representing a US\$ 16 million investment, the company was registered with the Ministry of Commerce in 2002 and with AISA in 2003, as well as with the Kabul Municipality (for permission to manufacture and sell within the city of Kabul). It currently has 170 local employees and 15 expatriate employees.

In addition to the much needed locally produced safe drinking water, $\mathrm{ABI}$ plans to manufacture and sell high quality non-alcoholic beverages, juices and UHT milk in special PET and aseptic packaging. ABI is aiming to expand and increase the variety of its products and become a full spectrum local supplier of milk, juice and soft drinks at affordable prices.

\section{ISSUES}

\section{Inconsistency in customs tariffs}

ABI worked with three other main beverage companies in the context of an informal industry association to build understanding within the government that the tariff structure applied to raw materials for their production, relative to the tariff structure applied to foreign-produced imported beverages, was a disincentive to domestic production. Import tariffs of 10 percent were being applied on raw materials, whereas import tariffs of only 2.5 percent were being applied to finished goods coming in from neighboring countries. This 
was a strong disincentive for industries, such as that of beverages, which had to import raw materials (e,g. bottles, labeling, concentrates and bottle caps) from the outside.

Working together in a process of dialogue with the Ministry of Finance, the informal industry association of beverage companies asserted the importance of distinguishing between traders and domestic production industries, and argued successfully in favour of a tariff structure that would encourage domestic production by levying higher tariffs on finished goods than on raw materials (as is the case in most countries).

The two main companies in the sector were able to obtain, through the intervention of His Excellency the President, the Minister of Finance and the CEO of AISA, a new import tariff structure of 40 percent on finished goods and one percent on raw materials for production industries. This decision was an important breakthrough for the companies. The application of such a tariff structure across other industries would represent a more systemic solution in line with international practice.

\section{Unpredictability in the fiscal and legislative environment}

In order to encourage and improve the investment environment, eight years of tax exemption for foreign investment were offered by the Government under the 2002 Law on Foreign and Domestic Investment in Afghanistan, provided that companies started their production within a year. In the subsequent 2005 revision of the investment law, the tax holiday was not incorporated and several companies had their tax holidays denied. The two major beverage companies challenged this revision up to the President, and the tax holiday was ultimately respected for the two companies.

\section{High cost of security measures}

The current insecurity in Afghanistan is a major constraint to attracting foreign investment. The primary concern for companies is of course the physical safety of its staff. Following the loss of several ABE employees, there has been an understandable reluctance for expatriates to come or to continue working with $\mathrm{ABI}$.

Beyond the primary concern of human security, the expense of providing security protection takes up a significant part of the cost structure of ABI: out of the 185 staff, 36 are security personnel. Compared to other parts of the world, this considerable extra expenditure for maintaining a security presence represents a distortion in the cost structure of the company, and thereby puts $\mathrm{ABI}$ in an unfavourable position in the face of foreign competition.

\section{Lack of qualified local man power and high capacity-building costs}

Despite a clear policy to hire locally, $\mathrm{ABI}$ is forced to bring in key staff members from outside of the country due to the absence of qualified skilled labour in the local market. Bringing in staff from abroad in the areas of finance and HR, for example, is costly for the company; and where skilled labour is available within the country, the cost is double that of Pakistan.

\begin{abstract}
$\mathrm{ABI}$ 's preferred approach is to have expatriate staff provide on-the-job professional training to locallyrecruited personnel. At present, the local staff consists of 20 young Afghans educated in Iran and Pakistan.

Like many Afghan organisations, ABI faces competition in hiring from better paying international organisations and from newly established companies seeking to capture the investment in human resource development from longer established companies. A gentlemen's agreement has been signed by the beverage association, stating that no company will poach staff from another, helping to assure that staff trained in the specific skills of the industry will remain on the job.
\end{abstract}

\section{High cost of electricity}

In the absence of a reliable supply of power, dieselfuelled generators have been imported. The cost of electricity is high, stemming from both the diesel fuel and the cost (including customs) and maintenance of the generators. In Afghanistan, ABI pays US\$ 70,000 to USS 80,000 for its power. In Pakistan, by comparison, a similar plant would pay US\$ 5,000 to US\$ 6,000 per month. This puts domestically made products at a further disadvantage in terms of competition with imported products.

\section{Lack of quality control}

The Ministry of Health is charged with assuring quality control of foodstuffs production, but has no capacity to do so. Therefore, ABI controls its own quality, in addition to meeting the standards used by the Ministry of Public Health. Currently, there are many poor quality goods in the market due to age (past the expiration date) and inconsistent 
quality at the time of production. Increasing the knowledge and capacity of public health officials to set standards, and assure that they are respected, will serve to increase the quality of Afghan products.

\section{CONCLUSION AND RECOMMENDATIONS}

$\mathrm{ABI}$ has been able to introduce a high quality product in Afghanistan and expand its market share. It has solved a number of issues regarding the business environment, but only with a considerable time investment and continuing uncertainty as to the final result. The solutions found in the cases of the tax holiday issue and import tariffs have been industry-specific rather than systemic.

Based on their experience thus far, ABI's investors outline the five straightforward elements required, from their point of view, to attract investors to Afghanistan:

\section{- Good Governance}

- Security

- Clear decision-making structures

- Consistency in laws and their application

- The promise of a reasonable rate of return

Their specific experience suggests the following set of recommendations:

1. Change the short-term mentality of the Govemment and increase its commitment to creating a better environment for business. In order to increase confidence among local as well as outside investors, a clear commitment from the Government is required to create a better environment for business by constructing roads, providing power and applying investment laws consistently.

2. Apply fiscal regulations consistently. (i) The tariff structure for imports should provide fair incentives for domestic production, charging higher tariffs for finished goods than for raw materials. This tariff structure should be applied consistently across manufacturing and processing industries, (ii) Where tax holidays are legitimately granted, they should not be reversed.

3. Introduce quality control mechanisms. Increase the capacity of the Ministry of Public Health (in the case of ABI, and other ministries in the case of other industries) to set quality standards and to put into place technically sound control mechanisms with trained staff.

4. Providing power (energy). Work to continue to increase the supply of power; introduce a schedule of lower tariffs for industry.

5. Eradicate corruption within Government. Build confidence of government officials about their future by providing wages which will provide for their livelihoods. Dismiss corrupt officials.

\section{QUESTIONS FOR DISCUSSION}

1. From the perspective of a company such as $\mathrm{ABI}$, what are the most important conditions required for foreign investment in Afghanistan? What did ABI's investors look for before launching the company in Afghanistan?

2. What are the main challenges that other companies/SMEs have faced since 2002 ?

3. What lessons can be learnt from the successful resolution of ABI's fiscal issues? What experience of other countries provides insights into government decision-making structures? How could government decision-making be improved?

4. How has the informal beverage industry association been able to work together to resolve common problems? What lessons can be learnt for the future of this association and for the future of other industries?

5. What can be done to counter what has been described as the short-term mentality of Government? How can businesses increase the confidence level of Government and vice versa?

6. What are the main changes in the investment environment that would be required to attract a far higher level of foreign investment in Afghanistan in companies such as $\mathrm{ABI}$ ?

This case study was prepared based on a series of interviews with Sameh Panah, CEO of Afghanistan Finance Company, the lead investor in $A B I$ and Cecil Galloway, Operations Director at ABI. 



\title{
ESSENTIAL OILS AND NATURAL PERFUMES: A RURAL DEVELOPMENT OPPORTUNITY IN AFGHANISTAN - GULESTAN ARIANA COMPANY
}

\author{
Case study prepared for the Enabling Environment Conference
}

\section{CONTEXT AND BACKGROUND}

Gulestan' Ariana Company produces essential oils and floral waters for fragrance, personal care and pharmaceutical products. The company operates a distillery in Jalalabad and supports the development of organic rose plantations in Afghanistan. It has also started wild plant collection $^{2}$ in the remote Hisarak district of Nangarhar.

The idea of the company started in 2003 in Kabul, in the context of discussions about potential economic alternatives to opium poppy production. The horticultural crops needed for the fragrance, personal care and pharmaceutical industries are high-value, labor-intensive, with excellent export prospects and could therefore be ideal licit substitutes for opium poppy production. It is also the type of industry singled out for attention by the Interim Afghanistan National Development Strategy:

"The ideal type of agricultural activity for Afghanistan is labor-intensive production of highvalue horticultural crops that can be processed and packaged into durable high-value, low-volume commodities whose quality and cost would be adequate for sale in Afghan cities or export to regional or world markets." I-ANDS (chapter 5)
Initial market research was financed by UNDP and carried out by Altai Consulting in Kabul and Paris. The study indicated that a private company would be best able to foster development of this sector. Gulestan Ariana Co. Ltd officially registered as an Afghan company in December 2004.

Private investors, both Afghan and international (French and American), started Gulestan by investing US\$ 88,000 in capital. FKH Group, Barnett R. Rubin, Mathieu Beley and others decided to invest capital in this venture. Gulestan shareholders understood that restarting an industry from the ground up would be a difficult business, with the initial focus being more on the development contribution of the endeavor rather than on significant economic returns on investment.

In the long term, the opportunity for Afghanistan is sizeable. Natural raw materials (including but not limited to essential oils) represent US\$900 million worldwide. Rose essential oil is a US\$ 20 million market.

The main producers of rose essential oil (Bulgaria, Turkey) and orange flower essential oil (North Africa) are becoming more expensive with the cost of labour in rural areas. Afghanistan may be part of the next wave of producers. These flowers 
represent thousands of hectares and rural livelihoods in producing countries.

The main focus to date has been on roses and orange flowers. Gulestan identified a local variety of scented roses (Rosa Damascena), and has started reproducing them in nurseries. There are many bitter orange (naranj) orchards around Jalalabad. In 2007 , Gulestan harvested 1.5 tons of naranj flowers and obtained two kilograms of néroli, the essential oil of orange blossom. French perfumers in Paris and Grasse tested the 2006 production and would like the company to produce much more of it. Worldwide production is more than two tons of essential oils, mostly produced in North Africa, and Afghanistan could ultimately take a decent share of this market.

But rural capacity building is the issue. It has been very difficult to convince farmers to invest in production of flowers, since it is not yet an established industry.

This case study discusses the challenges Gulestan has faced thus far in establishing and running its business. Issues have emerged particularly in the areas of taxation, infrastructure (roads and electricity) and human capacity. It also includes issues that are more specific to this industry, namely working with donors and the civil society on building agricultural capacity.

\section{EXPERIENCES OF GULESTAN TO DATE: KEY ISSUES}

Since the start of its operations, Gulestan has been faced with a range of issues that are common to many new enterprises in Afghanistan. This section lays out steps that have worked well and other areas that have been impediments to a smooth start-up of operations.

\section{Setting up the company}

Registering the new company with AISA was very easy. AISA worked very efficiently throughout the registration process. Since starting the company in December 2004, dealing with AISA has been without issue.

\section{Access to land and utilities}

Nangarhar Valley Development Authority (NVDA) operates an olive oil factory in Hadda Farm next to Jalalabad. NVDA management let Gulestan install a distillery within the olive oil factory. Gulestan used factory space, access to water, a Russian-built steam generator and the help of Russian-trained engineers.

In the fall of 2006, Gulestan was prevented from accessing the olive oil factory for more than two months because it was being used as the elections HQ for Nangarhar. More recently, in the Spring of 2007 , Gulestan was not able to use the equipment in the olive oil factory during critical orange blossom season because of a management issue at NVDA (NVDA's Director was jailed on corruption charges, while lower management was afraid of making any decisions).

\section{Installing the Jalalabad Factory}

The distillery equipment was purchased in Turkey in March 2005, half of the cost of which was financed by a U.S. Department of Agriculture matching grant obtained through CNFA's Afghanistan Agricultural Development Program.

When the distillery was imported from Turkey, bad roads and a lack of capacity at the Islam Qala customs point, as well as the requirement that all cargo had to be packed and unloaded into Afghan trucks, delayed the arrival of the equipment. As a result, the new company missed the spring season by a few days in 2005 . This delayed our work by a full year.

\section{Taxation}

The tax regime and the process of paying taxes are very burdensome. Key issues are listed below:

- High tax burden for starting businesses: The fledgling company already had to pay taxes before having made any revenue: a 24,100 Afg (US\$ 480) fee was collected to register the balance sheet from 1383 (2004-2005). This is a fixed amount regardless of the size of a company, thereby imposing a heavy cost on small companies that join the formal sector. With the addition of the AISA registration (US\$ 700), Gulestan had to spend more than two percent of its initial US\$ 50,000 capital on taxes in the first half year of operations, before production even started

- Complicated, labor-intensive and nontransparent process of paying taxes: While the new tax law suggests that meeting tax obligations is easy, actual interactions with the mustufiat have been complicated. Despite the fact that the forms were filled out on the basis of a careful reading of the tax law, it took a Gulestan employee more than two weeks time to complete the tax filing 
process. The unwillingness to pay any money that could not be accounted for (by getting a receipt) made it difficult for him to complete this process.

When Gulestan reported this problem to the Ministry of Finance, it was asked to go to the Large Taxpayer Office (LTO) and was able to work directly with the LTO's professional advisers, foreign and local alike, who helped make decisions regarding accounting and amortisation regulation.

But Gulestan is still required to pay taxes with the mustufiat, and is currently experiencing major problems in paying taxes.

- Antiquated tax paying methods: All taxes must be paid in cash and in person, because of a lack of checking or electronic payment systems. For example, the company has to withhold taxes from its employees' wages every month, and is required to pay in cash and in person every month, which takes two working days. Gulestan would prefer to pay at the end of the quarter instead. Eventually, the company should be able to pay through check or an electronic payment system.

- Uncertainty about tax laws and nuisance taxes: On his first visit to LTO in June 2006, Gulestan's CEO asked advisors how much tax would be charged on its local product sales and was told that two percent BRT would apply, which was consistent with the written tax law. But on a subsequent visit, he was told that an extra 10 percent tax would apply to all sales, including past sales. This tax, mal e mawad e estehelaqi, is part of the old tax law; it has been identified as a "nuisance tax" by Ministry of Finance advisers, but Gulestan is still obliged to pay it, although the rate is not yet clear (perhaps six percent rather than 10 percent). It is a major problem for a fledgling company to not know how much tax it must pay on past and present sales.

\section{Skills development}

Operations started at the olive oil factory in Jalalabad. The French-based Robertet, a world leader in natural raw materials for perfumery, sent an engineer to help train the team on a pro bono basis. As a result, Gulestan now has a well-trained master distiller.

Beyond the successful training of a master distiller, Gulestan needs to train technicians, farmers and wild plant harvesters. No expertise from universities or ministries is available to help with training. (Any knowledge there of organic agriculture or wild plants is not used systematically and takes a lot of research to find.)
Trained accountants and engineers are very difficult to find, as these professions are in very high demand. The demand for skilled workers far exceeds the current supply, leading to higher labor costs and therefore higher production costs. All these points add up to make production relatively expensive in Afghanistan.

Employees that have been trained by Gulestan are very happy to work in a new and promising industry. But they are getting offers for much better salaries in United Nations or NGO offices.

\section{Physical infrastructure}

The lack of infrastructure, roads in particular, constantly causes delays, bottlenecks and high costs. The very bumpy roads to rural areas of Nangarhar prevent economies of scale by reducing the area that can be covered with a distillery.

Flowers have to be brought to the distillery within a few hours of harvest. The journey from Hisarak to Jalalabad would take only a few hours on a good road, but the actual travel time is over eight hours. Hence, the distillery cannot use fresh materials from Hisarak for production in Jalalabad.

\section{Central government cannot ensure security and rule of law}

Gulestan cannot rely on the Government to provide security, and it cannot rely on the courts to resolve any disputes. It has no way to operate in Nangarhar or to contact local villagers except through the tribal structure, which is dominated by a few big families. Although this structure has enabled the company to enjoy security and to have access to villages and other properties from which they purchase raw materials, and find space and land to locate their facilities, it makes it more difficult for Gulestan to maintain autonomy.

\section{This has implications in terms of:}

- Not being able to maximise the social benefits of operations, as these families monopolise the role of intermediary between the company and the society

- Running a risk of being drawn into interfamily rivalries that could negatively affect the company

- Not being able to steer clear of the competing politics of the various clans

- Having to constantly allocate resources to the balancing act that is required in order to reduce insecurity. This takes energy away from focusing on the company's core operations 


\section{Working with rural communities: developing agricultural capacity by involving civil society?}

The main flowers on which Gulestan focuses are roses and orange flowers. Unexpectedly, it turned out to be very difficult to convince orange garden owners to work with the company. They are afraid of losing their fruit production, even when experts agree that harvesting flowers actually improves fruit production and quality. In other countries, farmers hire harvesters themselves and bring the flowers to the distillery. But in Nangarhar, Gulestan has to pay first (to get access to the gardens) and also carry out the harvesting.

It is difficult to find farmers who are ready to plant roses. It will take some time for the roses to produce flowers, thus farmers need public support in order to plant roses. Overall, agricultural capacity remains an issue as farmers are not able to invest in new crops and market opportunities, and they demand support (usually in cash) before taking any risk.

\section{It has been difficult to raise funds for} programmes aimed at helping farmers plant flowers. Gulestan, as a private company, cannot invest in farming capacity. Gulestan invested in a distillery, and provides access to the market. The management is trying to convince more donorfunded programmes to help farmers invest in this market opportunity.

A potential solution to this problem might be through working more closely with civil society, by encouraging farmers' groups to own distilleries and produce essential oils. The company is currently trying to build sustainable relationships with groups of farmers.

UNOPS recently provided funding for a shura in Nimla Bagh (a mughal garden in Khugyani district of Nangarhar) to plant roses and build a distillery on government land. But with no effective enforcement of contracts, and lack of transparency in the Government, Gulestan is not sure to be able to work efficiently with this community in the long run.

Gulestan has not been able to find support for groups of farmers to plant roses on their private land. Consequently, Gulestan is thinking of starting a non-profit entity that the company would contribute to while looking for other sources of funding which would specifically focus on supporting farmers that want to plant roses.

\section{Coordination or competition with public (donor-funded) projects}

As donors get involved in income-generation programmes, there is a risk of creating unfair competition to the private sector, if these programmes are not properly coordinated. For example, German Agro Action (GAA) obtained funding to build a distillery and plant roses that it imports from Bulgaria into Nangarhar, with the objective of producing rose oil for a German company. Today the GAA team is planning to sell their distillery to a new private company that they would create for this purpose. This could create unfair competition, since the distillery at stake was started using grant money and NGO personnel.

Gulestan is now working on fostering consultation with donor-funded programmes in order to develop win-win relationships: donors and NGOs should focus on increasing agricultural capacity, while Gulestan provides distillation expertise and access to markets. Recently it found two interesting partners who are ready to plant roses and other flowers in nurseries and pilot farms in order to help build agricultural capacity, namely AKDN in Badakhshan and MRRD in Shomali.

\section{International standards do not include Afghan products}

Several medicinal and aromatic plants are found only in Afghanistan, and are famous for their uses in the traditional unani dawakhana medicine. But there has been no modern research concerning these plants and their medicinal uses. Many of these plants are not registered as raw materials on important American and European markets, and thus cannot be exported there.

In addition, traders of neighboring countries have been adulterating the products for a long time. Today, where international standards and market prices for resins (such as galbanum or asafoetida) or their essential oils do exist, they are based on the adulterated product, which makes it difficult for Afghanistan to position itself in the world market.

With high production prices and low bulk prices for essential oils on world markets, Gulestan will need to focus on value-adding segments, such as perfume, naturals and organics, fair trade and direct sales to end consumers.

Certification (for organic agriculture, sustainable use of wild resources) is very costly in Afghanistan, since certification bodies have not yet established operations here. Import regulations on finished products (especially cosmetics) make it difficult to 
reach end users in foreign countries without going through importers or traders.

\section{CONCLUSION AND RECOMMENDATIONS}

Gulestan has been successful at building processing capacity in Nangarhar. The quality of essential oils obtained so far has been very good, and markets are showing interest. The main difficulty is to scale up.

Gulestan's leadership is convinced that until the Government addresses the obstacles listed above, normal investors will still hesitate before investing in Afghanistan. The I-ANDS and the Afghanistan Compact contain commitments to addressing all these issues. These commitments must be made into realities soon for Afghanistan to extricate itself from poverty and insecurity.

In addition to the above raised issues, Gulestan believes that the following steps would make sense:

1. Identify agro industries that have potential (e.g. essential oils, juice concentrates, medicinal plants), and invest in expertise to help farmers with these. Expertise can be available close by, in neighboring countries.

2. Help civil society to invest in agricultural and post-harvest capacity to take advantage of market opportunities and create non-farm employment.

3. Help private companies gain access to international markets and add value to Afghan products. For example, public initiatives could help create an Afghan brand or certification, especially when it comes to traditional (organic) agriculture or sustainable exploitation of biodiversity/wild plants.

4. Donors should work with private companies to identify key infrastructural needs (e.g. roads and agricultural capacity) and address them to facilitate access to markets.

5. Aid systems should have one-window shopping for project needs, since the current system wastes an incredible amount of time.

6. Transparent, simple procedures should be available to help law-abiding companies pay taxes smoothly.

7. Industrial parks with subsidised access to power and water should be made available for agro industries.

\section{DISCUSSION QUESTIONS}

1. What measures would help newly starting businesses to get started smoothly and at reasonable costs? Specifically:

a) How can the high tax burden for starting businesses, particularly SMEs, be alleviated? Is it possible to reduce costs related to the AISA licence and the registration fee for balance sheets, particularly for SMEs?

c) Would a substantial lowering of these costs provide an effective incentive for SMEs to enter the formal economy?

2. How can bureaucratic procedures at customs be streamlined to increase planning security and decrease time lost at customs and associated costs?

3. Gulestan has experienced very burdensome, expensive and unpredictable tax paying obligations. Are the experiences described in the case study representative of SME problems with tax paying authorities? Specifically,

a) How could the process of paying taxes be made less labour intensive? For example, are there alternatives to having to pay taxes in person on a monthly basis?

b) How could transparency and clarity about tax paying obligations and procedures be improved?

4. Companies that are processing agricultural products in Afghanistan often face a problem of unreliable, low quality supply of raw materials. How can agricultural capacity be strengthened to increase opportunities for processing/value adding activity? Specifically:

a) Would the promotion of a more organised rural civil society, for example through strong farmers' associations, facilitate better interface between producers and processors and also provide an effective channel for capacity building measures? How could such organisations be supported by government, civil society and private sector?

b) Often, farmers are opposed to the introduction of new crops or methodologies, as they cannot take any risks associated with new products. Are there solutions to this problem? How can the risk for farmers be lowered and information flow on new crops and technologies improved?

c) Could international aid be better targeted to support agricultural capacity and thus contribute to an enabling environment for rural, private and nonfarm economic activities? 
5. What can government do to improve domestic companies' access to international markets? For example, through introducing quality certificates and facilitating/promoting the registration of Afghan products on international markets?

6. The lack of qualified staff is a recurrent theme in many accounts of businesses, and costs related to recruitment and training are particularly high for SMEs. Are there possible short- and medium-term solutions to this problem? Would the introduction of short-cycle, certificate level education in areas such as accounting, bookkeeping, office skills, etc. provide relief to the private sector?

This case study was prepared by the President of Gulestan Ariana Co. Lid., Mathieu Beley.

\footnotetext{
' Gulestan means "rose garden." Gulestan is also the title of a $13^{\text {th }}$ century mystic poetry book by Saadi of Shiraz. Ibn Sina, the famous doctor and philosopher who was born in Balkh in the $10^{\text {th }}$ century, invented the refrigerated coil and thus distillation as we know it. In Jalalabad, orange blossoms are celebrated with a Pashto language poetry festival held annually in April. Flowers and perfumes are important topics of sufi poetry.

${ }^{2}$ The biodiversity of wild plants and flowers also offers a huge economic potential for Afghanistan: The biodiversity of wild plants is exceptional, and knowledge of the traditional medicinal uses of local plants has been preserved in unani dawakhana (Greek pharmacy).

Medicinal plants are a specialty of Afghanistan that can be (re-)developed to tap their economic potential.
} 
THE ENABLING ENVIRONMENT CONFERENCE

Effective Private Sector Contribution to Development in Afghanistan

\title{
SOCIALLY RESPONSIBLE ECONOMIC DEVELOPMENT: THE SHAMALI MODEL FARMS
}

\author{
Case study prepared for the Enabling Environment Conference
}

\section{BACKGROUND}

Afghanistan has a long tradition of exporting raisins. This tradition is continuing today but with mixed success. The quality of the export product does not often meet international standards and therefore obtains only sub-optimal prices. The fertile Shamali Valley north of Kabul is renowned in Afghanistan for its superior conditions for growing grape varietals, fruits and vegetables.

The Shamali Model Farms (SMF) is located in the Shamali Valley approximately $20 \mathrm{~km}$ north of Kabul. SMF is a private enterprise started in 2004 by an Afghan businessman and is entirely selffinanced. Initially designed as a recreational "hobby" farm, the idea has now grown into the concept for an enterprise that combines significant and long lasting benefits to the local farmers and a strong ethical corporate profile with sustained economic growth and profits.

Although the initial preparations for launching SMF began in 2004, SMF was registered with AISA as a private limited operation in 2006. It is anticipated that all preparatory work, including the building of a processing hall, land preparation, drip irrigation systems, access roads, etc. will be completed by mid 2007 , when the company will be fully operational.
It is being planned to introduce the first SMF grape products to the Afghan market in 2008 and to international markets in Dubai in 2009. For this purpose, a separate export business has been established. The farm also intends to produce fresh vegetables, herbs and salads for the Kabul-based market, particularly targeting international hotels, embassies, ex-patriots and foreign agencies.

In this initial stage of the development of the enterprise, Shamali Farms has been able to take advantage of a number of factors in its favor. Particularly, the typically small plot sizes of five to ten acres helped shape the concept of a niche farm, producing high quality export products through a concept of winning over adjacent small farmers who would become Affiliate Farms and produce under a standardised brand name. ${ }^{1}$ Also, the low level of interference from the Government - although this may have been more the result of a lack of government capacity than a pro-business attitude - has meant that SMF has set up operations with relative ease.

SMF has a strong commitment to high quality products and business standards, as well as to high ethical standards with regard to the treatment of employees and customers and adherence to sound and legal business practices (see Vision and Values statement in the annex). Key aspects of the SMF "idea" include: 
- SMF aims to introduce concrete methods to improve the quality of the grapes and the resulting raisins in order to meet the demand in high-value international markets. All products will be processed under the "Shamali Farms" label and will meet the highest food safety and hygiene standards.

- The Model Farms is used as a practical and tangible learning tool for the local farmers for using new, more productive and more environmentally responsible farming and processing techniques to increase value and yield.

- SMF uses, wherever possible, local or regional materials that local farmers can procure inexpensively and affordably in Afghanistan or in neighboring countries.

- The enterprise promotes sustainable and informed farming methods to reinvigorate Afghanistan's traditional farm products and increase exports to better markets.

- Farmers that take up SMF farming methods can receive a "Stamp of Affiliation" to the Shamali Farms brand, and benefit from SMF processing, packaging and marketing their products. Affiliated farms can also benefit from financing opportunities for farm conversion.

- By marketing its products directly, SMF intends to showcase a comprehensive "seed to shelf" process of farming, processing, logistics and marketing.

\section{THE BUSINESS ENVIRONMENT: ANALYSIS OF CONSTRAINTS AS EXPERIENCED BY SMF}

The post-war conditions and continued hostilities and uncertainty in Afghanistan create an acutely challenging environment. Any business person in Afghanistan swims against a stronger current than he/she would in other countries and has to be more creative in navigating these waters.

SMF's experience with establishing an agro-based business in Afghanistan includes the continuing struggle with a range of constraints related to regulatory frameworks, government attitudes and the lack of appropriate infrastructure.

\section{Land titling and related uncertainties}

Most business owners and private citizens would agree that at this time it is nearly impossible to receive a clear title from the Government of
Afghanistan. Unclear ownership records create space for widespread corruption leading to:

- High costs: It has been communicated to SMF by more than one source that it will cost Shamali Farms US \$ 10,000 to US\$ 15,000 to get its title processed. This cost is not bearable for only 15 acres of land.

- No transparency: Going back to even before the war to the present time, land titles are not changed in the government books/logs at the time of inheritance, marriages and sales and new title sheets are not provided. Untangling the mess and verifying ownership is complicated at best and bribes are required to get access to the books.

- Falsification of documents and claims on property is widespread: This is often done in collusion with government officials. This causes uncertainty on the part of the new buyer.

The negative impact of these issues translates into the following constraints:

- Lack of security of land tenure: Any business requires assurances that the property that one pays for in eamest is rightfully, recognisably and clearly titled. In the absence of legal protection, investors and entrepreneurs limit their investment, given the real risk that ad hoc claims could be made on their property.

- No access to external finance: Shamali Farms requires financing for its drip irrigation system, modern processing plant for fresh fruits and logistics support such as refrigerated trucks, containers, etc. Following standard procedures. banks and other lending institutions ask for clear titles for the property where the equipment will be used. Since Shamali Farms only has a "Horfee" title $^{2}$, financing opportunities do not exist.

The Government of Afghanistan, as it was highlighted directly to the President at the London conference, must address this critical issue of land tenure head on. Open economic policies and other market-based regulations will remain meaningless without legal property ownership documented in titles.

\section{Business logistics and infrastructure}

Logistics cover the movement of farm products from the farm to the processing centers, to markets and export points while maintaining freshness, hygiene and food safety standards (i.e. HACCP, GAP and GMP). The particular issue is lack of processing centers located within reach of small 
farmers, refrigerated transportation and paved roads to keep the look and feel of the product consistent and predictable:

- There is no use producing the best product if the product cannot make it to the market maintaining its qualities.

- As a result, farmers and agro-businesses are faced with a considerable loss of income potential. ${ }^{3}$

Generally speaking, encouragement should be given to farmers to form cooperatives where processing and refrigeration facilities can be shared. Shamali Farms, through its own processes and initiative, advocates the conversion of farms to new farming and handling techniques where the converted farms obtain a seal of "Affiliation" from Shamali Farms. This seal would also permit those farms to participate in the processing, logistics and sales processes owned by Shamali Farms. The cost to the farmer is limited to adapting good farming techniques and he thereby has the opportunity to sell his products at a higher price or simply has an improved chance to sell all of his harvest.

\section{Human Capacity}

The lack of skilled and educated personnel is generally seen as a major constraint to business development in Afghanistan. SMF has made the experience that training efforts face a number of challenges:

- Illiteracy and lack of training in structured learning itself can prevent knowledge transfer to happen effectively. Only repetition and knowledge transfer in small doses and with consistency eventually produce results;

- Time to change is generally long. Afghan farmers that have worked with Shamali Farms are receptive of the new ideas, but will not adapt them to their farms until and unless they see real results. This is understandable as their livelihoods depend so much on their small harvest. Risk taking becomes unthinkable without tangible proof. They prefer to see someone else take the risk first.

SMF has, however, had the experience that although human capacity is at an overall low level, there is a strong willingness to learn across the board. Shamali Farms' experience in the last three years clearly indicates that from its own hired labour to the visiting farmers, everyone is ready to learn new farming techniques, to understand what their counterparts in other parts of the world are doing and to generally improve their knowledge base about their primary livelihood. The motivation is clearly to get more out of their land, reduce risks and in summary earn more income.

According to the experience of Shamali Farms thus far, the farmers are likely to be more responsive to learning new techniques if the following conditions are in place:

- All knowledge transfer is practical/ hands-on and on the farm

- Actual results are more important to farmers than talk of more yields or better quality. This is not a question of suspicion but of caution and risk management

- Learning is much more effective when the knowledge transfer is from Afghan to Afghan and from farmer to farmer

\section{Institutional capaeity}

Afghanistan has had a rich tradition in agriculture which was more or less institutionalised during the 1970 s, specifically through government services. Extension of agricultural support went as deep as districts and sometimes villages. With the destruction of these capacities as a result of the war, the relevant constraints here are lack of institutional capacities to provide clear guidance on best practices (GAP, HACCP, etc.), define product quality standards, certification, disease management, information management, technical support and other critical support that governments are expected to provide to their citizens.

As a result, many income opportunities are lost, leading to an overall stunted growth in the agrobusiness sector. Specifically, Afghan agricultural products have less access to international markets, or to the local, substantial expatriate market for high quality products. They also lose out on the domestic market, as they cannot compete with products imported from Iran and Pakistan.

SMF sees possible solutions through enhanced partnerships between the public sector, the private sector and civil society. Although tradition in Afghanistan dictates that the Government is seen as the sole responsible party for delivery services to the citizens, the reality is that the Government should accept the limitations that will exist if it does not reach out to the private sector and civil society for joint efforts. The challenge will be to define mutual benefits and the mechanism for cooperation to create a lasting and bonding relationship. 
As an example, the Ministry of Agriculture could get more engaged with private sector efforts like Shamali Farms to gain an understanding and to seek ways in which it could carry and enhance the message from this farm, and other enterprises similar to it, to other parts of the country.

True partnership between government agencies that plays a part from farming to sales of Afghan products is a must. There must be a chain of services that are offered in varied levels of quality and competencies through the Government which must be synchronised. Organisations such as the Export Promotion Agency of Afghanistan can play a significant role in coordinating this synchronisation effort. This is an immense challenge but there is hardly any choice.

\section{Water shortage}

For the most part where the farm is located, the traditional sources of water (Karaiz and surface) have dried up and are no longer viable. This is the result of years of drought but also ill-conceived and unplanned water diversions. As a result:

- The land area for cultivation is reduced due to the higher costs of inyestment in creating water sources and operations.

- Yields are substandard and do not meet the quality expectations of the market.

Digging deep wells is the only way to reach any water source. The cost of digging each well and the related equipment is nearly US\$ 3,000 to US\$ 4,000 and most farmers cannot afford the operational costs. A potential solution lies in digging community wells combined with drip irrigation systems, which can serve the needs of several adjacent farms. The world over, drip irrigation is now the preferred method of watering farms even in areas where water is found in abundance. Drip systems are simple to design and implement, and can be sourced at low costs from India, Pakistan, Iran and China where multiple manufacturers and distributors exist. ${ }^{4}$

\section{Cost of conversion to new techniques}

Farmers who have visited the Shamali Model Farms have been very positive and would like to adapt the new techniques based on evidence of improvements in yield and quality. They understand the link between change and better income.
In addition to their reluctance to change before they can see concrete evidence, there is a cost involved in the change process. As an example, planting grape vines as per the new recommendations, installing drip lines and trellises would require upfront funding ${ }^{5}$.

As long as the environment is such that farmers a) feel they cannot take any risk and b) do not have access to appropriate external financing mechanisms, the private sector has to try to find its own solutions to this problem. SMF sees a potential solution to this problem in the following approaches:

- Keep the cost of investment low by developing techniques that use local materials. As an example, Shamali Farms will freely donate poplar tree saplings so that farmers can mature them and then later use them to build their trellises. Each farmer will then do the same for the next farmer, repaying his debt for the trees he received. The poplar trees are of a hyper variety which can grow three meters or more per year and are extremely easy to proliferate.

- By keeping the investment low and scheduling the conversion over several years, the amount of required funds may likely fall in the range where microfinancing could apply. Further investigation is obviously required but there is merit in the solution.

- Buyers could be convinced to enter into exclusive buyer/seller relationships with those farms that have converted and would produce a better product. In this case, the buyers would provide the investment upfront and would be guaranteed that the product be sold only to them. Affiliations similar to Shamali Farms would be the facilitators. 


\section{CONCLUSION AND RECOMMENDATIONS}

Having created a healthy farm with an outlook of good yields to come, SMF has good cause to view the overall picture from its own vantage point as positive and optimistic. It is already a laudable demonstration of the combination of a for-profit company, operating on the basis of a strong ethical corporate profile, which offers long lasting benefits to local farmers.

However, summing up the young experiences of Shamali Farms and weighing the challenges that have existed for the private sector in general, the overwhelming conclusion is that as a nation,

Afghanistan will only be able to resolve its issues and reach its goals if the Government and private sector work better together.

The first steps must be taken by the Government to address the following issues in priority order:

1. Solve the issue of land titles. Having proper property titles from the Government will open up financing opportunities and will build the confidence of investors who are staying away.

2. Remove the deep seated corruption that exists throughout the country.

3. Encourage model activities and encourage more of them by providing real incentives. The Government should do what it can to reduce the initial cost of investment.

4. Widely propagate and make accessible information on best practices such as drip irrigation and hygiene management.

5. Government agencies must make a choice on how they interact with the private sector in the business of exporting agricultural goods. Many existing export issues could be addressed successfully if Government assumed a true caretaker role, which would include ensuring that barriers are removed and facilities are created that ease the process of exporting:

a) Product testing - Availability of labs with low cost and easy accessibility

b) Certification for various international hygiene and food safety standards (depends on destination)

c) Low cost collection and processing centers with transparent and efficient processes d) Assistance to farmer groups to procure and operate refrigeration centers and cool trucking services

e) Encouragement by Government with low cost financing to establish production facilities for materials that support and enhance the capacity of the country to export. Specifically this includes carton boxes, PET clear plastic containers, wax paper and other similar items that are required routinely by international buyers.

f) Unhindered paperwork management at customs. A dedicated service for fresh products to move the process forward very efficiently with knowledge of cost and damage that can occur to fresh products. Exporters are willing to pay their share of tariffs but they expect proper and considerate service in return.

\section{DISCUSSION QUESTIONS}

1. In the case of the Shamali Model Farms, land acquisition was based on tapping into the traditional land tenure system, by acquiring land from a known party and on obtaining sufficient de facto assurances that the "Horfee" would not be put into question.

a) What are the challenges of dealing with overlapping land tenure systems?

b) How often have enterprises abandoned investment projects due to difficulties in obtaining land with clear titles?

c) In other cases, how have entrepreneurs worked through the challenges?

d) What recourse does an investor have in case of land dispute? Have the court system and/or alternative dispute resolution mechanisms been able to resolve disputes?

e) What can be done about the land title issue in the short to medium term, until land reform programmes have been fully implemented?

2. The initial investment in Shamali Model Farms could be financed by the capital of the investors. SMF will have to do the same for further expansion if it cannot turn to banks to obtain a loan. In most cases, investors would need to borrow investment capital and/or working capital.

a) What are the principal challenges that investors face in obtaining bank credit? 
b) What limits the access to credit?

c) What other financial services are required (e.g. insurance)? What needs are unserved?

3. As the case study indicates, "there is no use producing the best product if the product cannot make it to the market maintaining its qualities."

a) What are the primary challenges in terms of transport? Export?

b) What market linkages are missing?

c) Can Government play a role in providing a supportive regulatory environment to encourage the creation of farmers' and traders' associations and their investment in relevant processing centers, refrigerated transport, etc.?

4. Afghanistan's agricultural extension services were decimated during the years of conflict. It is noted in the case study that institutional capacity is lacking in terms of guidance on best practices, quality standards, certification, disease management, information management and technical support.

a) What extension services are most acutely missing?

b) What capacities to deliver in this area are missing?

c) What would be the best way to move toward working relationships between Government, private sector and civil society groups on this issue?

5. What other constraints are faced by other agricultural and agro-processing firms in Afghanistan? What features of an enabling environment are lacking? 


\section{ANNEX: SMF VISION AND VALUES STATEMENT}

\section{Vision}

- Significantly increase yield and quality of traditional export products from Afghanistan.

- Be the best and exceed expectations at all times. Be the best grower, the best processor and the best marketer of superior Afghan agricultural products.

- Create a marked difference from the old to the new. Practically and convincingly demonstrate improved farming practices for traditional export products to the local farmers and win them over.

- Be a change agent and improve the income level of every farmer who adopts the new techniques. The local farmer must be able to replicate and apply methods given the limited resources available to him/her.

\section{Values}

- At Shamali Model Farms we believe in making a positive improvement in the conditions in which we find ourselves in. We are in business to earn a fair income from the product and services that we provide, and in the process, we will seek to improve the conditions in Afghanistan.

- We are passionate about our employees and farmers and share a deep respect for their humanistic needs, regardless of gender, ethnicity or rank. Respect at Shamali Model Farms means:

- Fair and reasonable salary or earnings from the farm

- Ideas will be given a fair chance to be proven there are no bad ideas and no bad sources

- Safety and well-being

- Learning and self improvement

- Pleasant and clean workplace

- Dignified and pleasant interactions with all

whom we have contact with

- Information about the enterprise will be provided with most clarity and honesty and no one will be spared from opportunities
- Our customers and fellow farming associates will be treated as our guests and partners at all times. We will provide them with unparalleled services and will aim to solve their problems and add value to their lives with our work.

- We will steer clear of any corruption - directly or indirectly - in all matters of our business.

This case study was prepared by the Proprietor of Shamali Model Farms, Mr. Tamim Samee.

\footnotetext{
${ }^{1}$ Smaller plots are usually seen as a problem in developing large and industrial farm businesses. For SMF, however, the availability of smaller plots of land for purchasing and leasing within a reasonable distance
} from major urban settlements turned out to be an opportunity. Overall, it was felt that small plot sizes have a positive impact as they allow initial investments to be lower for those willing to start smaller agro-based businesses and can run entirely on local labor. The chance for converting existing and antiquated farms in the surrounding area of the new farm is also much more feasible. Since the labour will be from the area and more than likely from farming background themselves, good practices will be adapted more quickly as they will have first-hand and practical contact with the benefits and improvements.

${ }^{2}$ When purchasing land parcels, in the event that government issued titles are not available, the owner and the buyer can execute a customary "Horfee" title. Most Afghans are familiar with the process and accept its genuineness. The document is signed and fingerprinted by the local Malek and the land owner. However, this is only a temporary arrangement until a government issued title can be obtained. With a "Horfee" title, the new buyer can occupy the land, start work and build on the land, but not gain access to financing.

${ }^{3}$ As an example, on a wholesale basis a kilogram of Shondol Khani grapes in the local Kabul market will fetch 20-30 Afghanis. If processed properly for export, the same grapes will fetch more than three times in Dubai.

${ }^{4}$ Shamali Farms has reached agreement with several brands in the region and will represent them in Afghanistan. In addition to providing the product, SMF will provide design, implementation and training services.

${ }^{5}$ To convert one acre of land with existing grape vines to the new method, the average cost will be between US\$ 3,800 to US\$ 4,600 . The farmer would have created 350 percent more capacity for production, but the upfront cost cannot be recovered until at least four to five years down the road. 



\section{PUBLIC-PRIVATE PARTNERSHIPS IN ECONOMIC DEVELOPMENT: THE NEW BAGHLAN SUGAR COMPANY}

Case study prepared for the Enabling Environment Conference

\section{BACKGROUND}

\section{Sugar production and the sugar market in Afghanistan}

Sugar production in Afghanistan dates back to the 1930s, when Afghan investors, with technical support from a German company, established the Baghlan Sugar Factory (BSF). At the time, it was a purely private investment with the then private Bank-e-Milli as the principal owner. (Bank-e-Milli then held approximately 80 percent of the shares.) From the start of operations in 1940, small farmers in the area were the main suppliers to the factory. BSF was nationalised in 1976, at the same time as all major industries and banks in the country, and ownership of BSF was officially transferred to the Ministry of Light Industry and Foodstuffs. It continued working at full capacity until 1979 , when the Soviet invasion and the ensuing civil war slowed down production, which eventually came to a complete standstill in 1991. Although much of the equipment was lost or damaged during the war years, the original plant site and machinery were basically maintained by the factory staff throughout the decade following the end of production. Currently, 100 percent of the domestic demand for sugar, approximately 830,000 metric tons (MT) per year, is covered by imports. Due to the high transport costs of imported sugar, domestic market prices for sugar are high. Under these conditions, local sugar production should be a viable business opportunity. It was in this context that the idea for the restructuring of BSF was born.

\section{The New Baghlan Sugar Company}

With the regime change in late 2001, the Afghanistan Transitional Authority (ATA) realigned government policies toward private sector driven economic development, including a decision in favour of privatisation of state-owned enterprises. As part of this policy, and encouraged by an expressed interest in re-engagement in the sugar industry from a German seed company, the Government of Afghanistan (Ministry of Light Industry and Foodstuffs) approached a number of Afghan businessmen, encouraging them to invest in the rehabilitation of the old Baghlan Sugar Factory.

Negotiations to conclude a public-private partnership agreement for the re-establishment of the Baghlan Sugar Factory were initiated in 2002. A detailed feasibility study was carried out in 2003 , which was very positive overall about the prospects of reviving sugar production in the area. Given the size of the investment required, additional partners were brought in. The agreement for the establishment of the New Baghlan Sugar 
Company (NBSC), signed in October 2004, mobilised initial capital of EUR 13,6 million, and included the following investors:

- The Government of Afghanistan (through the Ministry of Light Industry and Foodstuffs, succeeded by the Ministry of Agriculture in 2006) contributed the value of the land, buildings and machinery of the existing Baghlan Sugar Factory, valued at EUR 4.6 million ( 29.5 percent)

- Four Afghan private investors signed a total capital of EUR 8 million ( 51,3 percent)

- The German seed company KWS Saat AG signed EUR one million ( 6.4 percent)

In June 2005, The German Deutsche Investitionsund Entwicklungsgesellschaft mbH (DEG) through funding from the German Bundesministerium für Wirtschaftliche Zusammenarbeit (BMZ) signed a joint venture agreement with the existing shareholders, contributing a total of EUR two million (12.8 percent). This raised the total signed capital for NBSC to EUR 15.6 million.

NBSC also benefits from a comprehensive, German funded aid package in the form of technical assistance: the Food and Agriculture

Organisation (FAO) provides technical assistance to farmers in the project area to ensure the supply of sufficient quantities of high quality sugar beets to the factory. Technical assistance, particularly in the areas of building human capacity of key technical staff at the factory, is also provided through Internationale Weiterbildung und Entwicklung GmbH (InWEnt) and the Centrum für Internationale Migration und Entwicklung (CIM).

NSBC started operations in 2005 after having been officially registered with AISA in February 2005. Once the factory is operating at full capacity, it is planned to produce up to $15,000 \mathrm{MT}$ of sugar per year, thus becoming an important economic activity in the area, providing not only direct employment opportunities, but contributing indirectly to additional economic activities and jobs. Given the much larger domestic demand for sugar, an expansion of the factory and a diversification of the production are envisaged by the shareholders as a mid-term objective.

Actual production of sugar started only in $\mathbf{2 0 0 6}$ with a trial production of $300 \mathrm{MT}$ of sugar. Production was curtailed significantly in the first season due to plant disease affecting the sugar beet crop, sufficiently serious to dissuade farmers to commit to further production. Technical advisers are working intensively with farmers to ensure conditions for a more successful season in 2007

\section{ISSUES}

Although all parties involved in the project remain optimistic about its future success, viability and profitability, the NBSC has been struggling with a number of problems as it seeks to ramp up production. These problems provide some valuable insights into the establishment of PPS and into agro-business development in Afghanistan in general.

\section{The relationship with Government}

Although the rapid privatisation of state-owned enterprises is official government policy, implementing this policy in the case of NBSC has proven to be a major challenge. Problems stem from the following factors:

\section{- Lack of support for the project within} government institutions: Private local and foreign investors alike report that Government has shown little interest to date in supporting the project, despite the fact that a) it is fully in line with the official government policy, b) it has mobilised substantial local and international capital and c) it is investing in an industry that has a huge potential for the Afghan economy. The general impression is that of not only an overall lack of interest, but even hostility on the part of government officials. This attitude has substantially slowed down the process of getting the NBSC off the ground.

An illustrative example of Government's seeming indifference is the fact that a bilateral Agreement on Promotion and Protection of Investment (APPI), signed in April 2005 by the German and Afghan Governments has still not been ratified by the Afghan Parliament, thus depriving German investors (including KWS in the case of NBSC) of the opportunity to obtain a risk guarantee from the German Government. The ratification and effectiveness of the agreement would create incentives for German investors to engage in a country still considered very high risk, without additional costs or risks to the Government.

The unsupportive attitude of Government vis-à-vis the NBSC project is also illustrated by the following points:

- Unclear roles and responsibilities: Government had initially nominated the Ministry of Light Industry as a shareholder in the factory. Given the history of the nationalisation of the old Baghlan 
Sugar Factory in 1976, the investment agreement between the Government and the other shareholders explicitly protected the new investors from any eventual claims of the original, pre-1976 proprietors of the factory. Nevertheless, and although it is now part of Government under the authority of the Ministry of Finance, Bank-e-Milli claimed ownership at the beginning of negotiations The issue had to be brought in front of the Supreme Court and the President, who decided ultimately in favour of the signed agreement. The final agreement now involves only the Ministry of Agriculture as the government shareholder. It took the Government nearly two years to settle this internal issue, and in the meantime no agreement could be signed with the other investors. The resumption of sugar production was delayed accordingly.

\section{- The valuation of government property: The} government contribution and share in the project consist of the value of the land ( 35 hectares), buildings and equipment of the old Baghlan Sugar Factory. It took over two years to reach agreement on the actual value of these assets, with Government initially insisting upon a valuation of EUR 10 million. The final agreement valued the government contribution at EUR 4.6 million, judged well above the real value of the more than 60 -year old equipment and facilities.

\section{- Legal obstacles to the transfer of government} property to the company: To date, land and property titles have not been legally transferred to NSBC. This has been a major subject of contention and has negatively impacted the relationship between Government and the other shareholders of the company. The Ministry of Finance has so far refused to authorise the legal transfer of property to NSBC on the basis of the fact that, according to the Afghan Constitution, foreigners are not allowed to own land in Afghanistan. The Government argues that, should the company go bankrupt and the assets distributed among shareholders, the German shareholders could theoretically become owners of part of the land. ${ }^{1}$

In order to resolve this issue, the German stakeholders sent an official letter to the Ministry of Finance stating that should the company go bankrupt and remaining assets distributed among shareholders, the foreign investors would not exercise any claim on the land, taking only the cash equivalent of the value of their share of assets. As of March 31, this issue was reportedly still unsettled. DEG and KWS have made it clear that, should additional capital be called for, they will not transfer any additional capital until the transfer of the title deeds has occurred.
How this issue will be finally resolved is understandably of major interest for those considering possible joint ventures involving foreign and Afghan investors.

\section{Management and technical capacity for the factory}

Finding and keeping well trained and skilled workers has been a challenge for the factory. Apart from up to 300 unskilled workers employed during the peak times of sugar beet harvest, the company employs approximately 40 skilled technical and administrative staff on a permanent basis. One of NBSC's recruitment strategies has been to find and repatriate former factory staff that had migrated to Pakistan and Iran. During the first campaign in 2006 , the company drew also upon international technical expertise from Germany, Hungary, the Czech Republic and Iran. In addition, the company has finally been able to recruit a number of new staff, including a General Manager with the right educational background and experience.

Until a new General Manager was successfully recruited in March 2007, the company's day-to-day operations were managed by the General Manager of the old Baghlan Sugar Factory. Since he did not have the experience and education for the running of the new factory, his decision-making authority was limited. This meant that shareholders, often fairly removed from the local situation, had to take decisions on day-to-day management issues of the factory. Although the problem was not dramatic as the factory did not work at full capacity during 2006, NBSC's experience highlights the investors' challenges regarding the lack of local management capacity.

\section{Key issues with regard to human capacity are:}

- It is difficult to attract highly skilled Afghan staff to posts outside Kabul, where access to quality education for children, health care, acceptable living conditions and levels of personal security do not compare to the capital.

- The deteriorating security situation in Baghlan has made the work and recruitment of expatriate staff more difficult and costly. For example, at times, the German technical staff could not leave the factory compound, and the expatriate FAO staff had to adhere to strict security regulations, including driving in convoys, when carrying out their field work with local farmers.

The company coped as best it could by offering inhouse training and sending staff for specialised training abroad. 
- In-house training of locally recruited staff was one response to this difficulty. NBSC conducts its own training with the risk of losing staff it has invested in to better paying parties (NGOs or international organisations); this has occurred only once so far, with an NBSC-trained accountant leaving the company shortly after completing his training.

- The company has also sent two young Afghan graduates from Mazar University for a one-year specialised training abroad in sugar technology at the Technical University of Berlin, Germany. The graduates returned in time for the $\mathbf{2 0 0 6}$ campaign, to which they contributed successfully. They are still working for NBSC. While the experience with training Afghans abroad has been very positive, and NBSC is keen to continue the programme, the main challenge remains to identify suitable candidates with the appropriate educational background. The initial training target was to send seven young Afghans for higher qualifications, but NBSC was only able to identify two qualified candidates.

\section{Technical Issues}

A series of other issues have plagued efforts to move rapidly toward production levels foreseen at the outset. A number of problems resulted in an insufficient supply of the factory with sugar beets. Given the potential impact on future production, they are noteworthy.

- Low skill levels of participating farmers: Since the production of sugar had come to a complete stop in 1991, the great majority of local farmers were no longer familiar with the cultivation of sugar beets. NSBC is therefore dependent on a successful reintroduction of sugar beet production in the area to ensure a reliable, high quality supply of sufficient quantities of raw materials. FAO has taken on the technical support of farmers in the area. This includes credit to farmers for inputs and extension workers providing technical assistance on an ongoing basis. The German seed company KWS is responsible for the testing, introduction and supply of seeds of suitable high yielding sugar beet varieties to local farmers.

The plant diseases and insect infestation that caused widespread crop failure in 2006 did not occur on all plots and were attributed mainly to the very poor conditions of the soil after years of overexploitation and of vegetable monoculture production by farmers (who did not adhere to proper crop rotation methods) as well as poor farming methods, Overall, an average of 19 to $20 \mathrm{MT}$ of sugar beets per hectare was produced, against the original expectation of $40 \mathrm{MT}$. As a result, and although FAO covered the financial losses of the participating farmers, ${ }^{2}$ farmers are now very reluctant to plant sugar beet. High quality, largescale beet production will only be possible in the area, if the project manages to improve people's understanding of good farming methods.

- Unrealistic price expectation of farmers: Given the poor results of the initial season, conflict has emerged between farmers and the company over the pricing of raw sugar beets, which has not been resolved to date. The initial price foreseen was US\$ 26 per ton of raw sugar beets. In the face of the poor experience of 2006, the farmers insisted on a price of US\$ 40 per ton. NBSC agreed to pay US\$ 30 per ton ${ }^{3}$ and additional incentives (transportation costs, upfront payments on beet production, etc.) for the 2007 harvest. ${ }^{4}$ However, farmers have not agreed to this price. As a result, the shareholders have now decided not to enter into agreements with the farmers in 2007 and only continue with trial sugar beet production.

- In order to become more independent from local farmers, the company is trying to lease $3,000 \mathrm{ha}$ of government land, which it wants to sublease to landless farmers of the area for sugar beet production. If successful, the main supply side constraints could be overcome, thus allowing the factory to work at a higher capacity. ${ }^{5}$ In addition, NBSC has also decided to explore the possibility of importing raw sugar for processing at the factory, until the local production issues are resolved.

- Lack of regulation of use of agricultural land: Rice production in the area has considerably increased over the last years. Formerly, Government controlled how much land was allowed to be used for rice production, given the high irrigation needs. This regulation no longer exists and rice production has increased, creating a competition for land for other crops and increasing demands on the irrigation systems. 


\section{CONCLUSIONS}

The technical challenges left aside, the problems NBSC has faced during its start-up phase (and in part continues to face) are of considerable interest from the perspective of public-private partnerships.

1. Government is clearly still struggling with operationalising its privatisation policy. In its interaction with local and international investors, government institutions are in all appearances disinterested and unsupportive. This joint venture has taken a long time to get started and has been burdened with unnecessary and costly complications. This is particularly alarming when one considers the importance of local and international investments into the domestic economy for the mid-term development and political stability of the country.

The formal transfer of assets from Government to the company would be an important signal for not only the shareholders of the company, but also for any investors considering joint ventures with Government.

2. In addition, roles and responsibilities of the various government agencies have been subject to ongoing negotiations and shifts. At the same time, the legal basis for privatisation and the transfer of property to private owners is still subject to interpretation - and in this case, the situation is complicated by the question of foreign ownership of land.

Clarification of the question of the right of Afghan companies with foreign shareholders (whether minority or majority investors) to purchase land would be an important step to set the stage for more domestic-foreign joint ventures. Overall, resolution of the problem of access to land by foreigners is an important consideration for the improvement of the climate for foreign investment.

3. Attracting and keeping qualified staff to positions outside Kabul remains a major challenge for any enterprise. The low level of skills has proven to be a major constraint and the number of possible solutions is limited.

As NBSC looks to the future, cautious optimism prevails. As one of the stakeholders of NBSC put it. "these are not unusual obstacles and problems in a situation such as that of Afghanistan - they will eventually be sorted out." However, the process NBSC has been through illustrates the amount of patience and energy that stakeholders in a privatisation or PPP-type project need to have in order to get their business off the ground.

\section{DISCUSSION QUESTIONS}

1. What are the principal challenges Government and potential investors face in entering into joint ventures (public-private partnerships)? To what extent do difficulties result from a lack of clarity on roles and responsibilities? How can signatories to such agreements increase the confidence level of all parties and how can they be sure that agreements will be respected?

2. What could be done to shorten the negotiation phases of privatisation projects, particularly with regard to:

a) Clearer roles and responsibilities of various government agencies?

b) Transparent and uniform procedures for the valuation of government property?

c) Smoother and transparent processes, procedures and criteria for transferring government property?

d) A more positive and proactive role of Government in facilitating and supporting much needed private investment in the domestic economy?

3. How representative is the case in terms of difficulties on the transfer of land titles? To what extent has foreign ownership of domestic Afghan companies been a constraint to the transfer of land titles?

4. How severe is the lack of management skills in Afghanistan today? Where is the constraint felt most acutely?

5. What options and potential options exist for the training of skilled workers and management?

6. What could be done to increase incentives for qualified staff to move outside Kabul?

7. What potential exists for the establishment of PPPs? Would this instrument be of interest for the partial privatisation of state-owned enterprises? How does the establishment of PPPs articulate with the Government's privatisation policy?

8. What are the success factors for launching PPPs in Afghanistan today? What changes in laws, regulations and administrative procedures are required? 
This case study was prepared based on a series of interviews with the Directors and management of New Baghlan Sugar Company, as well as technical advisers from the Food and Agricultural Organisation (FAO) and KWS Saat AG involved in the project.

\footnotetext{
'However, since NBSC is registered as a local company, this argumentation should not apply. This is a question that has been raised in other cases; the proposed resolution of this issue is to prohibit the ownership of land in Afghan companies when foreign shareholders are in the majority.

${ }^{2}$ Under the FAO-supported programme, supply credits were extended to farmers, with the expectation that repayments would serve to constitute a crop risk insurance fund. Given the poor productivity because of plant disease, farmers were not required to reimburse at the end of the first season the credit extended.

${ }^{3}$ It takes 8.2 to 9 tons of sugar beets to produce one MT of refined sugar. The price of refined sugar in the Dubai market is currently just under US\$ 300 .

${ }^{4}$ It takes 8.2 to 9 tons of sugar beets to produce one MT of refined sugar. The price of refined sugar in the Dubai market is currently just under US\$ 300 .

${ }^{5}$ Government has been slow in responding to the request of NBSC to lease currently unused government land.
} 


\section{HELPING AFGHANISTAN'S STREET WORKING CHILDREN: ASCHIANA}

\section{Case study prepared for the Enabling Environment Conference}

\section{BACKGROUND}

Over the past decades, Afghans, particularly women and children, have suffered greatly from the consequences of conflict, from periodic natural disasters and from the ongoing insurgency. Over five years after the ouster of the Taliban, "peace dividends" are hard to come by for the most vulnerable segments of the population. In this context, it is estimated that at least 20 percent of primary school age children in Afghanistan undertake some form of work. ${ }^{1}$

The children in Afghanistan's capital are by no means spared from hardship. There are an estimated 60,000 children employed on the streets of Kabul, 98 percent of whom are sent out to work in order to help their families survive. Each morning the children leave home in order to go into the streets to try and make a little money by either being involved in begging or gathering scraps of paper or wood for fuel, collecting pieces of metal to sell, burning incense, polishing shoes, or selling items such as plastic bags, phone cards, magazines, chewing gum and cigarettes and washing windshields.

To address the multiple needs of these children, the "Afghanistan's Street Working Children - A New Approach" ("ASCHIANA," from the Dari word meaning "the nest") has been providing assistance to street working children in Kabul since 1995. ASCHIANA, an Afghan NonGovernment Organisation, currently serves close to 10,000 children in total, as well as 1,500 internally displaced children through additional outreach programmes. ${ }^{2}$ This case study lays out ASCHIANA's story and the challenges this unique organisation has faced.

\section{The ACHIANA Story}

ASCHIANA began its activities in March 1995 in the Shar-I-Naw area of Kabul to address the needs of children begging and working on the streets in this area. ASCHIANA was established initially as an NGO under the Minister of Planning, before the existence of the 2005 NGO Law. It was reregistered with the Ministry of Economy in 2006 as an NGO under the NGO Law.

The organisation's mission is to assist the thousands of war-affected Afghan children at risk and their distressed families, and to ensure them a more positive and more productive future.

ASCHIANA operates seven centres in Kabul and three in the provinces Mazar-e-sharif, Parwan and Herat. The centres provide much needed education facilities for street working children. Each day, over 
4,500 girls and boys attend ASCHIANA centres and receive a hot, nutritious meal.

ASCHIANA offers a variety of education and vocational training programmes. Children aged between eight and 10 years learn to read and write to enable them to join the regular Afghan schools. Those aged from 10 to 13 are given a basic education, recreational activities (art, music, sport) and some vocational training, Children aged 14 to 18 concentrate on vocational training to assist them in earning a living. Vocational course offerings include plumbing, electronics and small-machine repair, masonry, carpentry, woodwork, computer skills, photography, tailoring, embroidery and hairdressing. ACHIANA offers a unique accelerated education programme for older-aged girls whose education was disrupted, compressing two years of school into one.

All children attend health and hygiene education classes. ASCHIANA's mobile clinic visits the Kabul area centres to provide check-ups, diagnosis and treatment of minor health problems. Social workers visit the children's home and workplaces. To promote financial and entrepreneurial skills, a Children's Development Bank is managed by the children. Finally, ASCHIANA has earned a reputation for its art and music programmes for children.

ASCHIANA plans to open centres in other provinces. It will also begin construction this year on a new, larger centre in Kabul.

\section{CHALLENGES ENCOUNTERED}

Since its establishment, ASCHIANA has encountered a series of problems that have been obstacles to effective operations.

\section{Access to land}

Rising property prices in Kabul resulted in ASCHIANA's loss of previously rented properties for centres. In the context of rising property values and rents, the owner of the land where

ASCHIANA's main compound was located (an Afghan entrepreneur) ended the lease in order to construct a hotel. ${ }^{3}$ ASCHIANA had then to face the issue of finding land for its headquarters.

After the BBC World news service highlighted ACHIANA's plight in April $2005,{ }^{4}$ the Government allocated $2,500 \mathrm{~m}^{2}$ of land, which was purchased by ASCHIANA from the Kabul Municipality in February 2006. In spite of the fact that Kabul Municipality issued a land title, it was later discovered that staff of the Kabul Municipality were leasing the same plot of land to an American construction company. After extensive discussions with the Municipality and relevant ministries, and in particular due to the substantial support provided by the U.S.-based ASCHIANA Foundation, the land problem was resolved in January 2007. The remaining problem of confirming the right of way to the land was resolved recently. ASCHIANA lived this experience as an uphill battle against the municipal authorities and business interests.

\section{High power (energy) costs}

A relatively substantial amount of money from the programme must be allocated to ensure a consistent supply of power to the centres. At present, only the main office has a more or less consistent power supply from the power utility. At the centres where the need for power is the greatest in order to run the equipment required for training purposes, generators are the only course of power.

\section{Burdensome reporting requirements and administrative procedures}

The government reporting requirements are burdensome for indigenous CSOs. ASCHIANA's experience is that different reports must be submitted to different line ministries depending on the programme focus. Every three months, ASCHIANA sends reports to the Minister of Economy as well as to the Ministry of Social Affairs. In addition, reports are completed for the Minister of Health, the Minister of Education and the Minister of Justice due to ASCHIANA's education and health programmes. As of last year, the Minister of Foreign Affairs also asked ASCHIANA to submit reports on its operations, to fulfil UNHCR requirements.

Aside from reporting requirements, every time ASCHIANA develops a proposal and submits it to potential donors, one copy has to be submitted to the Ministry of Economy. These proposals are often not approved by funding bodies/concerned agencies. However, in the government files the proposal is usually classified as approved. As a result, difficulties arise later, when govermment officials require submission of reports on these "projects".

\section{Capacity development}

The low salary levels that ASCHIANA can afford to pay is the major reason for the departure of 
staff. Given the low wages offered by indigenous CSOs compared to those offered by international NGOs, staff who have been trained by ASCHIANA leave in order to join other intemational NGOs that provide higher salaries.

As a result of this frequent loss of qualified local social workers, the organisation must go through a recurring recruitment and training process to find and then train new personnel, only to lose them several months later. This vicious circle costs the organisation time and money, both of which indigenous CSOs are sorely lacking.

\section{Delays in disbursement of funds}

Due to burdensome bureaucratic procedures, it takes from six months to a year for the Government to disburse development funds that are channelled through Government by donors for implementation of projects. As a result, delays in disbursement significantly slowed the pace of implementation and, moreover, the payment of salaries of the field staff was delayed for months. For instance, in Mazar-e-Sharif, the field staff of ASCHIANA did not receive their salaries for six months.

Furthermore, the Government has assigned tasks to ASCHIANA without allocating the funds necessary to reimburse ACHIANA for its implementation costs, further weakening its financial position.

\section{Unfavourable environment for private donations}

Govemment requirements oblige the private sector donors to pay import taxes on aid brought in from outside, as they are for-profit entities, adding an additional bottleneck to private donations. Two consequences arise from this: (i) the activities of the indigenous CSOs are affected (ASCHIANA reports that it is very difficult to import the financed goods given the absence of the human and financial capacity to do so); and (ii) the level of external private donations is reduced.

\section{Lack of understanding of roles and responsibilities of Civil Society Organisations}

ASCHIANA's leaders expressed concern about negative and false perceptions of indigenous CSOs, which are engaged for the long term, rooted in Afghanistan, but fragile in terms of overall support and financial sustainability. ASCHIANA recognises that it needs to engage in some form of revenue producing activities (such as the sale of children's art and handicrafts).

According to ASCHIANA, the problem of negative perceptions toward civil society results from a lack of clear roles and responsibilities, and a lack of understanding of the contribution of civil society organisations to economic and social development and how to foster this contribution. Addressing these shortcomings can lead to a greater appreciation of the contributions of CSOs.

\section{RECOMMENDATIONS}

From ASCHIANA's perspective, moving forward on the following recommendations would create a sounder environment for its operations:

1. Simplify reporting requirements: Allow CSOs to report to only one entity, e.g. the Ministry of Economy, with the single reporting format that can be transmitted to other ministries.

\section{Develop a cadre of qualified local social} workers: In order to provide highly qualified local social workers, a faculty of Social Studies should be launched within Kabul University.

3. Increase opportunities for "income" in order to ensure financial sustainability: Given the fact that ASCHIANA children involved in the art programme produce Afghan handicrafts and paintings with an Afghan context, it could be possible to establish a small boutique, perhaps in collaboration with the domestic private sector, where the children's handmade products would be exhibited and sold. This could be the stepping stone toward financial sustainability of the organisation.

4. Encourage domestic philanthropy: Given the importance of the revitalisation of philanthropy work within domestic as well as external private enterprises, the Govemment could possibly introduce tax reductions for those private sector businesses which work closely with the CSOs. This would create a fruitful and encouraging environment for those involved in charity work.

5. Involve Government in the development of a joint NGO Code of Conduct: In order to bridge the gap between the Government and indigenous CSOs and intemational NGOs, the Code of Conduct should be developed in consultation with the Government and all relevant stakeholders in order to ensure uniform adherence to it, and in particular allow the Government to understand the operational procedures of indigenous CSOs as well as international NGOs. 


\section{DISCUSSION QUESTIONS}

How can one frame the responsibilities of Civil Society Organisations and the responsibilities of Government toward these organisations?

1. How will the proposed changes in the NGO Law affect domestic NGOs?

2. What simplification of the registration process would be beneficial to domestic NGOs?

3. How could reporting requirements be streamlined? What standards would be meaningful for an organisation like ASCHIANA in terms of financial reporting, governance and transparency?

4. What role could a Code of Conduct play in encouraging CSOs to adhere to certain standards and to allow them to be better understood within Afghanistan?

5. Are there changes in the tax regime that would be justified to ease the fiscal burden on organisations such as ASCHIANA?

6. What steps could be taken to improve the environment for contributions from businesses in Afghanistan? What could Government do to make it easier for businesses to support domestic CSOs/ NGOs with logistics, including the import of aid?

7. Many Afghan NGOs/CSOs lose their best staff to international organisations, INGOs and international businesses, due to the much higher salaries these institutions can afford to pay. This clearly undermines efforts to strengthen and build up a truly Afghan civil society. Are there potential solutions for this?

How could international institutions/ organisations and domestic organisations better complement each other rather than compete for resources with Afghan organisations usually losing the competition?

Is this an issue that should be given more serious consideration by international donors as well?

8. ASCHIANA managed to resolve difficult land ownership and transfer issues with the help of the media. What lessons can be learnt from this experience? Have other domestic NGOs/CSOs faced similar problems, and have they been able to mobilise public opinion in their support? In what ways could the public support base for CSOs be strengthened to help them handle issues of corruption or powerful business interests?
This case study was prepared based on a series of interviews with the Founder and Director of ASCHIANA, Engineer Mohamed Yousef and ASCHIANA staff.

\footnotetext{
'UNICEF, Afghanistan country report, 2007, p.1.

${ }^{2}$ Recognising the need to provide care for street working children and other vulnerable children, the Government launched in 2006 a National Strategy for Children at Risk designed to improve care and support for the country's most vulnerable children. A key focus of the strategy is on developing community and family-based support for vulnerable children. With endemic poverty underlying most of the risks facing children in Afghanistan, the strategy also points to the need for the capacity of communities and families to be enhanced, to enable them to best support children at risk within the community itself.

${ }^{3}$ Later on, the Government forced ASCHIANA to close its centres in Microrayon III to take back the premises for programmes for "normal" children.

${ }^{4}$ Coghlan T., (2005) "Kabul street children may lose 'nest"'

(http://news.bbc.co.uk/2/hi/south_asia/4441503.stm)
} 


\title{
THE RAPID EXPANSION OF DRIED FRUIT AND NUTS EXPORTS: THE KABUL DRIED FRUIT AND NUTS CONSORTIA AND ANGAZA LIMITED
}

\author{
Case study prepared for the Enabling Environment Conference
}

\section{CONTEXT AND BACKGROUND}

\section{The dried fruit and nuts sector}

After decades of war and economic isolation, Afghanistan's historical reputation for the production of quality, uniquely flavored dried fruit and nuts, exported throughout the world, has diminished considerably. The years of war destroyed vineyards, orchards and infrastructure and degraded the irrigation system, leading to the destruction of the entire sector. Four years of drought, from 1998 to 2001, further exacerbated the already fragile situation. As a result, the current production and exports are far below historical levels: in 1977, the export revenue from dried fruit and nuts was at US\$ 82.1 million, and by 2003 it had fallen to US\$ 41.7 million. ${ }^{1}$

Currently, between 300,000 and 400,000 farmers $^{2}$ are working in the dried fruit and nuts sector with an estimated gross income per unit (from vineyards and orchards) that is three to seven times higher than for wheat. ${ }^{3}$ Research over the past several years has indicated that if Afghanistan's dried fruit and nuts sector regained its past levels of production, and if value-added processing were increased, the impact on Afghanistan's economy would be enormous. ${ }^{4}$

\section{Domestic and international markets}

Presently, two-thirds of Afghan dried fruit and nuts production is consumed within the country. The strength of the domestic demand for high quality products is reflected in the fact that, in addition to the demand for Afghan products, domestic consumers favour higher quality products imported from the U.S. ${ }^{5}$

Internationally, the Afghan dried fruit and nuts sector and its products have a mixed reputation. In India, the largest and the most accessible external market due to its proximity, Afghan dried fruit and nuts are very popular. Indian consumers are prepared to pay high premiums for Afghan dried fruit and nuts as opposed to similar Indian products: one can expect to pay US\$ 5.60 to US\$ 7 per $\mathrm{kg}$ for Afghan products in comparison to US\$ $3.26 \mathrm{per} \mathrm{kg}$ for Indian products. ${ }^{6}$ However, in sharp contrast to the Indian market, Afghan dried fruit and nuts have a very poor reputation in the European and U.S. markets. This is primarily due to the quality of production, processing and packaging. Afghan traders are not considered to be reliable, and their uncertified products are not considered to meet hygienic standards. 


\section{The story of the Kabul Fruit and Nuts Consortia and Angaza Limited}

\section{The Kabul Fruit and Nuts Consortia}

The establishment of the Kabul Fruit and Nuts Consortia, a group of seven small to medium-scale dried fruit and nuts traders and processors, ${ }^{7}$ is an OTF Group initiative. An assessment of Afghanistan's internal and external market for Afghan dried fruit and nuts recommended that only consortia of dried fruit and nuts would be able to compete in the world market. The Kabul Fruit and Nuts Consortia has proven to be very successful in increasing the revenue from exports and overcoming transportation and trade constraints with India. The Consortia employs 4,100 people and has a production capacity of 200 tons per month.

\section{Angaza Limited}

Angaza Limited is one member of the Kabul Fruit and Nuts Consortia. Its Director inherited the current dried fruit and nuts processing, packaging and trading business from his father, who established it 80 years ago. He is also the Director of the Kabul Fruit and Nuts Consortia.

Until 2001, the business did not have a legal status. During the Taliban period, with little trading going on within Afghanistan, products were exported to Pakistan without their being recognised as Afghan products. With no recognised status as traders, there was no access to India.

Once the new Government came into power in 2001, Mr Haji M. Hassan expanded the family business and established Angaza Limited. The business licence was initially granted by the Ministry of Commerce; an AISA licence was obtained subsequently. Angaza Limited's main focus is the packaging and marketing of the processed products, with exports primarily to India and sales in the domestic market. The raw material is brought in either directly from farmers or from the markets where the farmers sell their products.

In addition to four permanent staff members, unskilled labour is employed on a daily basis and paid a daily rate. The unskilled labour force is comprised primarily of very poor and widowed women, hired for sorting and packaging the dried fruit and nuts. Fruit and nuts are manually sorted and packed, negatively affecting the quality of the product offered to consumers. Yet the skill level of the staff would not allow them to operate machinery, were it available. The number of unskilled employees varies with each harvest collected during the year and the seasons. During peak time (August, September and October), about 80 employees work on cleaning and packing the products. During the months of June, July and half of August, considered to be the low season, 15 to 20 employees work in the factory.

The company has grown by 45 percent since 2001 . The period of most rapid growth was from 2005 to 2006 , with the growth due essentially to the identification of new export outlets outside Afghanistan, particularly in India.

In 2005, Angaza Ltd expanded its trade to Hamburg, Germany via Karachi. Even though the volume of exports to Hamburg is still not significant compared to the volume exported to India (one container per year versus two containers per month respectively), the Director considers it as an initial attempt to win the hearts, minds and trust of European consumers and wholesalers by offering high quality Afghan dried fruit and nuts.

\section{Future prospects}

In the absence of much needed land upon which to erect the necessary industrial premises, it is difficul for the private sector to create a long-term business development strategy. The management of Angaza Ltd is focusing on how to overcome the land issue:

"Until the problem of land is resolved I cannot think about further expansion of my business. At present I am not thinking about Angaza Ltd. My only concern as the Head of the Dried Fruit and Nuts Association as well as the Director of the Kabul Fruit and Nuts Consortia is to find and procure much needed land. It is difficult for me even to think about exploring the wider international market since we are not able to provide either the required quality or the volume required." 


\section{ANALYSIS OF KEY CHALLENGES ENCOUNTERED}

As their businesses grow, Angaza and the other members of the Kabul Fruit and Nuts Consortia have been able to demonstrate successful business development over the past years. The creation of the Consortia has been a key factor in the ability to develop exports to India. They have faced and continue to face a range of challenges, some in terms of their own business development and others in relation to the environment in which they operate. This section lays out the main challenges in relation to the business environment.

\section{Access to land}

Processing, packing and storing dried fruit and nuts require plants and warehouses, for which land is required. Currently, Angaza Ltd operates in very poor conditions on a small plot of land in a poor residential area of Kabul, surrounded by ruins and refuse dumped by traders from a nearby local market. In the case of Angaza, there is an urgent need for land away from the residential areas and from an unsanitary environment with no electricity. In 2004, the Director began to look for a plot of land to build a new facility and install new machinery, allowing the enterprise to operate under proper sanitary conditions, resulting in higher quality products.

"The Government raises the issue of poor quality of Afghan products and the fact that Afghan dried fruit and nuts are not competitive in the world market. However, if you are looking for the ways to improve the quality of goods, it all comes to land. Once we have land we can build and equip factories that will allow us to improve the quality of our products by allocating special places and sanitary standards required for processing, and, most importantly, it will allow us to reach the high standard of quality for the Afghan product which is vital for external trade. As you see, whichever door you choose to go in you hit your head on the same wall."

In the view of the Director of Angaza, access to land is the most urgent issue in Afghanistan. The experience of the Consortia is that procurement of land from the Government through either purchase or lease is a long and painful process, further complicated by complex administrative procedures that can take years to complete.

"Being a Director of Fruit and Nuts Consortia as well as head of the Dried Fruit and Nuts Association, which embraces 21 Kabul-based sector processors and traders, I started looking for land to buy on which we all could build our factories in 2004. With the approval of the First Vice-President and further yerification by the Minister of Commerce, I was granted permission for a plot of vacant land ( 65 jeribs) located in Juma Muhammadi industrial park in Kabul. However, when it came time for AISA to issue a title to the land, documents were put on file and forgotten for almost two years with no explanation. We are not asking for free land from AISA. Each of us operating in Kabul is ready to contribute to the cost of the land whenever it is needed. However, for more than two years the land has remained vacant and we are ready to pay US $\$ 20,000$ per one jerib in order to establish our factories."

From the point of view of AISA, the necessary documentation regarding this land transaction has not been provided, accounting for this case not being resolved.

\section{Unpredictable and inconsistent taxation environment}

In early 2005, a Presidential decree exempted dried fruit and nuts exporters from taxes in order to promote exports. This exempts the industry from the business tax and export taxes. Prior to this Decree, the dried fruit exporters paid 2.5 percent to customs as an export tax and two percent of the total product value as a mandatory contribution collected by customs in favour of the Afghanistan Red Crescent, totalling 4.5 percent.

However, following the Decree, despite being tax exempt, the traders have been required to pay 16 percent of the total value of exported products as an export tax which, according to government officials, goes to the Afghanistan Red Crescent. The enterprises in the sector have received no satisfactory explanation and/or justification from the Minister of Finance, AISA or the Chamber of Commerce.

\section{Multiple export controls}

There are three different export controls between Kabul and the Pakistan border: Kabul, Jalabad and Torkhan. Each of these controls obliges the exporter to go through the same procedures as in Kabul and each requires a stamp. This entails additional time and expense, when one control of exports would be sufficient. 


\section{Absence of an agreement with the Pakistani authorities on transit of Afghan goods}

During the course of transit of Afghan products through Pakistani territory to India via road, Afghan traders come across numerous problems and difficulties within Pakistan. As Afghan trucks are not allowed to cross the border into Pakistan, traders have to load and unload their products on and off Pakistani trucks - first at the Pakistani and then at the Indian border. This process means that the goods have to be loaded and unloaded five times, starting from Afghanistan's official and unofficial customs controls via Pakistan to India, before the product reaches the end point, which negatively affects the quality of the products.

\section{Lack of support from the Raisin and Dried Fruit Export Promotion Institute}

Dried fruit and nuts enterprises contribute in kind to the financing of the Raisin and Dried Fruit Export Promotion Institute, designed to be independent of the Government, although Government appointees hold key positions. Yet, processors and traders have not benefited from the existence of the Institute, despite its mandate to provide support to and respond to the needs of the private dried fruit and nuts sector. There is limited research on this topic.

\section{Absence of insurance services}

In the current insecurity, the absence of insurance services in Afghanistan is particularly problematic. Exporters and transporters require insurance to cover products as well as vehicles.

\section{Absence of quality standards and certification}

In the absence of official quality standard certification by the Government of Afghanistan, which would verify the quality of their product, the Afghan traders are not able to reach the end consumer without a middleman who benefits from the higher premiums when reaching the end consumer. In India, due to the absence of the quality standard licence, the Afghan traders sell the products to the wholesalers, who obtain the certificate/licence from India's Ministry of Health.

\section{CONCLUSIONS AND RECOMMENDATIONS}

The driedfruit and nuts sector has demonstrated the potential to expand production of high quality and unique products and expand the export market. From the viewpoint of the fruit and nut exporters, the implementation of a limited number of recommendations would not only provide a better business environment in which to continue to expand production and exports, but also build confidence in the future of Afghanistan.

\section{Establish greater capacity at industrial parks and clarify procedures required to gain access: The establishment of greater capacity at dedicated industrial sites with access to power (energy) would allow enterprises to install new equipment applying more modern technologies, and would ensure the necessary minimum hygienic standards.}

\section{Introduce uniform tax mechanisms:}

Clarifying taxes on exports and making them consistent with the Presidential decree on tax exemption for the dried fruit and nuts sector would make the business environment more predictable.

\section{Simplify procedures and make them more} transparent: $A$ reduction in the number of export controls would reduce the cost of exporting. Making the payments required more transparent would create more confidence in the system.

4. Develop the technical capacity of the staff: Expanding opportunities for skills training would allow the enterprises to introduce new technologies.

\section{Negotiate and implement effective transit} trade agreements between Governments of Afghanistan and Pakistan: This would facilitate the transit of Afghan products through Pakistan into India.

\section{Foster the development of a business} association, independent from Government, which would serve the needs of the enterprises. 


\section{DISCUSSION QUESTIONS}

1. What are the main constraints to access to land (e.g. cost, lack of title etc.)? What are the procedures to obtain a clear (enough) title? How do domestic firms experience constraints compared to foreign investors?

2. To what extent has a lack of infrastructure (roads, power, water) been a fundamental constraint?

3. What are the most challenging issues when navigating through administrative procedures? In what areas is the application of regulations and administrative procedures inconsistent and unpredictable?

\section{How have transit issues affected business} development?

5. What support do enterprises require for: technology transfer, skills development and developing the voice of the industry? What institutions could provide this support? What should be the roles and responsibilities of the public and private sectors?

6. What financial services are most needed by Afghan enterprises? How has the lack of access to insurance limited business expansion and increased costs?

This case study was prepared based on a series of interviews with Mr Haji Hassan, the Head of the Kabul Fruit and Nuts Consortia and Director of Angaza Limited.
'Official dried fruit and nuts exports increased 23 percent between 1999 and 2003 to US\$ $41.7 \mathrm{~m}$, driven mainly by growth in almonds and pistachios. Source: OTF Group (2005) Dried Fruit and Nuts Cluster Situation Analysis

${ }^{2}$ OTF Group (2006) Strategy and Action Plan for Afghanistan's Dried Fruit and Nuts Cluster

${ }^{3}$ Source ICARDA: The Rich Potential of Horticulture. International Center for Agriculture Research in the Dry Areas. Accessible on http://www.icarda.org/Afghanistan/Rich.htm ${ }^{4}$ OTF Group (2006) Strategy and Action Plan for Afghanistan's Dried Fruit and Nuts Cluster ${ }^{5}$ Presented at RALF Symposium accessible on http: //www.icarda.org/RALFweb/SSLPWF/RalfPresentations/ 2006/2nd\%20RALF\%20Workshop/5.ppt\#2

${ }^{6}$ OTF Group (2006) Strategy and Action Plan for Afghanistan's Dried Fruit and Nuts Cluster

${ }^{7}$ The five members currently operational are: Angaza Ltd, Sabet Saqib Trading Co. Ltd, Mojtaba Sajjad Refat Co. Ltd, Biratharan Nasri Ltd and Yasin Nasir Ltd. Two are non-operational: Haji Nader Ltd and Yasin Nasir Ltd. The Kabul Dried Fruit and Nuts Consortia was established with the support of the OTF Group. See www.kabuliwala.com 



\title{
EXPANDING THE OUTREACH OF FINANCIAL SERVICES: THE EXPERIENCE OF FINANCIAL INSTITUTIONS
}

\author{
Case study prepared for the Enabling Environment Conference
}

\section{CONTEXT AND BACKGROUND}

In 2002, the formal financial sector was inefficient and dominated by state-owned commercial banks and certain specialised banks. Most of these banks were bankrupt and too weak to provide efficient financial services. Moreover, the legal framework for the financial sector was essentially non-existent or inappropriate. Da Afghanistan Bank (DAB), the central bank of Afghanistan, had a structure which was moribund and staff which were too unskilled to undertake efficient monitoring and supervision of the financial sector.

There was an urgent need for a strong central bank as well as a legal framework with prudential regulations. Against this backdrop, restructuring and modernisation of the DAB began in mid-2003. In September of the same year, the President issued a decree to pass a new central bank law that would provide a strong framework for a two-tier banking system: state commercial banking activities and private commercial banking activities. It also provided the DAB with autonomous regulatory power to implement monetary and banking supervision policy.

The DAB is in the process of enacting the following three laws to initiate commercial banks to expand their lending programme to the private sector: (a) Secured transaction law; (b) Mortgage law; and (c) Negotiable instruments laws. These laws are particularly aimed at modernising the financial sector as well as improving the enabling environment for the private sector. Other programmes for reform of the private and financial sector are also underway and include:

- The establishment of a facilitative legal framework for private sector development, with 10 priority laws to be approved, four of which were signed by the President in January 2007.

- The strengthening of the supervisory framework for financial institutions with the aims of improving deposit protection and confidence in the financial system, and enhancing the private sector's access to finance. This includes reforms of the banking sector, the bulk of which is scheduled to be implemented by the end of 2008 . Regulations for the microfinance sector were introduced at the end of 2006 .

- The broadening and deepening of financial service delivery by building capacity in financial institutions as well as adopting and implementing national accounting and auditing standards. Most of these measures have yet to be implemented, with a target of end of 2008 .

Overall, the major reforms of the financial sector are scheduled to be completed by the end of 2008 . 
In the meantime, however, the outreach of financial services in Afghanistan remains very limited, and small and medium businesses have almost no access to bank credit and only limited access to banking services. In the most recent Doing Business (2007) rankings for Getting Credit, a measure of credit information sharing and legal rights of borrowers and lenders, Afghanistan ranked 174 th out of 175 countries.

There has been significant growth of private commercial banks: Fifteen banks have been licensed, while 14 of them are operating in Afghanistan. The banks are mostly concentrated in Kabul and provide services primarily to international donors, large businesses, foreign NGOs and foreign government agencies. There are also a small but ever increasing number of nonbank financial institutions, including one credit union and 13 microfinance institutions that provide limited services and small amounts of credit. Furthermore, a leasing finance company is also operating in Kabul, but with limited capital to employ in the business. Although the extent of financial services is expanding, these institutions are nascent and able to provide only a fraction of what is needed.

As a result, Afghan businesses are almost entirely reliant on internal funds from friends, relatives and money lenders. Informal fund transfer systems (hawala) used to make payments and transfer funds are also dominant. Although informal financial sector credit may be playing an important role in manufacturing and commercial activities, it is not adequate for long-term private sector development because such funds are often costly and short-term. There is therefore a pressing need for bank and non-bank financial institutions to provide viable alternatives to the informal sector. As the economy expands, the inability of firms to obtain reliable external financing at competitive costs could be a serious constraint to growth.

In summary, while some considerable advances have been made with respect to basic legislation, some central banking reform, the introduction of a new currency, and the beginnings of a microfinance sector-much work still remains to be done.

These case studies examine the experience of the following five different groups of financial market participants operating in Afghanistan. The examination of each institution will address the factors that have facilitated expansion and the constraints it has faced in further expanding financial services.

- Reputable private investors

- Small and Medium Entrepreneurs

\section{- BRAC, a Microfinance Institution}

- Kabul Bank, a fast growing commercial bank

- Bank Millie, a state-owned bank

This paper also analyses the constraints and opportunities that are common to one, several or all of these financial market participants, and concludes with recommendations from the perspectives of these institutions.

\section{THE CASE STUDIES}

\section{Reputable private investors: "Doing business out of my own pocket"}

Safi Brothers and Kabul Trade Center are the leading business conglomerates in Afghanistan. However, they remain outside the formal banking system. These businessmen are reluctant to go to the banks as they perceive the process of obtaining loans to be cumbersome and interest rates for longterm loans as being quite high. One of these businessmen is interested in constructing a cement manufacturing plant and expressed interest in seeking one or more bank loans from an international institution. However, often these businessmen do not see the importance of due diligence required from the financial institutions.

\section{Case Study 1: Kabul City Centre (Safi Land Mark)}

Safi Bothers Import and Export Company, with its main office in Dubai, is the owner of the Safi Land Mark, the largest shopping complex and hotel in Kabul with UN security clearance. The construction cost of the Safi Land Mark was about US\$ 35 million and was entirely financed by Safi Brothers; no bank loans were taken out. Safi Brothers exports dry fruit and imports construction materials and is building a "twin tower" in Herat province. Safi Brothers recently established a Gypsum factory in Kandahar with a total investment of US\$ 20 million, also self-financed without any bank loan.

\section{Case Study 2: Kabul Trade Centre}

Basir Omarzai owns the Kabul Trade Center, a shopping and office complex in Kabul. The cost of construction is estimated to have been about US\$ 20 million. Mr Omarzai met the entire cost from his own resources and was not keen to seek any bank loan. He is a businessman based in Dubai and has a paper manufacturing company there. 


\section{Small and Medium Entrepreneurs (SMEs): "Limited access to finance"}

\section{Case Study 3: Sabaoon Aryana Construction Company, Kabul}

Small businesses are undergoing hardship since they have almost no access to finance. Sabaoon Aryana Construction Company could have expanded its growth by many times if it had had US $\$ 250,000$ from the bank or leasing company to buy an asphalt machine.

Wahed Ahmad is the owner of Sabaoon Construction Company, which was established in 2004. He invested US\$ 300,000 in the construction business. Initially he started with building construction, but later moved to road construction. In 2005 , the company's annual turnover from road construction was US\$210,000. However, in 2006 , the annual turnover tripled to US\$ 600,000 . The construction company created permanent employment for 24 people. Sabaoon lost one large contract of US\$ 1.28 million from the United Nations Office for Project Services (UNOPS) because it did not have an asphalt machine. UNOPS told Mr Ahmad that although they had been very happy with his work, the road contract could not be given to Sabaoon since it did not have an asphalt machine. Currently, he buys asphalt from a supplier, but UNOPS is not happy with the quality. He was told by UNOPS that if Sabaoon procured an asphalt machine in 2007 , the company could get road contracts amounting to US\$ 4 to 5 million.

Mr. Ahmad needs US\$ 250,000 to buy this machine. The profit from the UNOPS contracts would enable him to pay for this machine in two to three years. He uses Standard Chartered Bank to cash the checks received from the contracts. The commercial banks are fully aware of his regular cash flow transactions, but are not willing to provide investment or working capital loans. Sabaoon Aryana said the following: "What is the purpose of having so many banks in Kabul, if they do not lend money to the deserving investors?"

\section{Case Study 4: Ahmad Printing Press, Kabul}

Ahmad Printing Press, a medium-sized printing company, is also very unhappy with the commercial banks because of their reluctance to help the small businesses and the high interest rates that they charge.

Ahmad Printing Press invested about US\$ 450,000 from its own capital. The owner, Ahmad Hossain Farhad, has about US\$ 400,000 as working capital to do a big order. He always has working capital shortages to bid for large supply contracts for books. He needs about US\$ 700,000 as working capital to implement a large contract. When $\mathrm{Mr}$ Farhad needs working capital, he usually borrows money from friends at a higher interest rate ( 25 to 30 percent) to execute large supply orders. Ahmad Printing Press has a bank account at the Standard Chartered Bank, which is needed to cash the checks that are received as payment from donor contracts. Although the bank has good knowledge of Ahmad Printing Press' cash flows, it is not keen to extend any working capital loans to it. Mr Farhad commented, "Although I am doing my business transaction with a reputable bank, [...] I cannot receive any working capital loan for my business." If Ahmad Printing Press had enough working capital, it could expand its printing activities by three to four times. Mr Farhad has good management and marketing skills; however, due to the shortage of funds, he cannot further expand his business and create more employment.

\section{Microfinance Institutions (MFI): "Finding niche market where the current banking system does not work"}

\section{Case Study 5: Bangladesh Rural Advancement Committee (BRAC), Small Enterprise Project}

BRAC is the largest MFI in Afghanistan. It started the Small Enterprise Program (SEP) in April 2005 , targeting small businesses mainly in the Kabul area.

The main objective of the programme is to help generate income and employment in rural and semiurban areas through enterprise development. The type of enterprises it is extending loans to comprise bakeries, grocery stores, carpet weaving shops, tailoring shops, various types of workshops, goldsmiths, beauty parlours, pharmacies, home appliance delivery stores and shoe-making factories. The typical loan size varies from US\$ 800 to US\$10,000. Loan tenure is one year as for the microfinance, but the payment is on a monthly rather than weekly basis in microfinance. Savings from the borrower is mandatory, and is collected at the time of monthly payments. Unlike microfinance, the SEP requires collateral.

Currently SEP has been implemented in 10 provinces and 10 districts. There are 41 Area Offices, but these offices are the same offices used for the Microfinance programme. A Senior Regional Manager is heading the SEP operations, supported by 10 District Managers and 56 Programme Organisers. There are a total of 1,200 borrowers, of which 979 have current outstanding loans. The total amount disbursed so far was US\$ 1.4 million and the current outstanding is US\$ 869,100 . 


\section{Case Study 6: Kabul Carpet Store \\ "Desire to be a client of the BRAC Afghanistan Bank"}

BRAC SEP is helping small businesses grow, and they are happy with their credit relationship with BRAC. However, they think that BRAC should do more since the size of the fund is not enough to help business expansion. The owner of Kabul Carpet store needs about US\$ 40,000 for his business growth because he imports carpets from Turkey and Iran. The loan amount he received from BRAC SEP programme only amounted to 10 percent of his requirement. However, he wants to continue the credit relationship with BRAC SEP because he believes that this relationship will one day help him to be a client of BRAC Afghanistan Bank.

Ghulam Abbas is the owner of Kabul Carpet Store at Que Marcus. He has been a borrower of BRAC SEP since February 2006. He borrowed US\$ 4,000 and has been paying in installments of US\$ 392 with a monthly savings of US\$ 10 . Ghulam employs eight people in the shop and pays US\$ 720 in wages, US\$ 1,300 in rent and US\$ 80 in electricity per month. He imports carpets from Iran and Turkey and wholesales them in the local market. Each import consignment costs about US\$ 95,000 to US $\$ 100,000$. Total stock of carpets in his shop amounts to about US\$200,000 or more. He says that his monthly sale varies between USS 25,000 and US\$ 30,000 and his net profit is about 10 to 15 percent of sales value. Ghulam is also a good tax payer. He pays a total annual tax of US\$ 500 and operates through a trade licence from the Municipality which he renews each year.

Given the scale of Ghulam's carpet business, one wonders why he would borrow US $\$ 4,000$ from BRAC SEP. His answer to this was revealing: "I cannot get loans from the banks, although I do an honest business with recorded transactions. So I wanted to be a BRAC client and prove my credit record and worthiness." He also said, "I heard BRAC is opening a bank in Kabul, I want to establish a credit relationship with BRAC SEP to eventually be a client of BRAC bank and borrow about US\$ 40,000 to help consolidate and expand my business."

\section{Case Study 7: Brotheren Ittehfaq Hardware} Store "Effective use of SEP Loan as working capital"

Bariwalai Nakshbandi, the owner of Brotheren Ittehfaq Hardware Store, is helping other small informal hardware businesses which have no access to any form of loans by providing trade credit to them. Although he borrowed a loan of US\$ 6,000 from SEP, he needed at least US\$20,000 to expand his own business and the businesses of the small traders.

Bariwalai is a reputable businessman in the market and has 10 shops selling various types of goods. He received a loan of US\$ 6,000 from BRAC SEP in April 2006. His monthly instalment is US\$ 588 and he contributes a savings of US\$ 12.5 . He owns the shop, which has a market rent of US\$ 3,000 . He employs two people and has a monthly wage bill of US\$ 200 and an electricity bill of US\$ 20 . His monthly sales are about US\$ 18,000 to US\$ 20,000 with a monthly profit of US\$ 1,200 to US\$ 1,500 . Total stock is about US $\$ 100,000$. Bariwalai has a trade licence and pays an annual tax amounting to US\$ 1,600 for all his shops.

Bariwalai has said that the SEP loan is very useful to him, since it perfectly meets his working capital needs. Due to this loan he has been able to increase his stock and provide credit to the small traders. He commented,

"They never fail to pay and I have already provided goods worth US\$ 2,400 on trade credit. I have developed a long-standing credit relationship and trust with the traders. The small traders are very regular to make payments and this trade credit is also profitable business for me."

He has said that BRAC SEP could make him an agent to disburse funds to the small traders and he would be ready to retail the loans on behalf of BRAC with a small commission and undertake all the credit risk. Bariwalai has also never failed to pay his instalment and wants to maintain a good credit relationship with BRAC. In the future, he would like to borrow US\$ 20,000 from BRAC SEP and would like to increase the range of products and the trade credit, and expand his business.

\section{Kabul Bank: "Constraints to expand the loan portfolio"}

\section{Case Study 8: Kabul Bank}

Established in June 2004 as the first private Afghan commercial bank, the Kabul Bank has emerged as the leading commercial bank in Afghanistan in the last two and a half years. Its initial capital of USS 20 million in 2004 has increased to US\$ 38 million due to infusion of new capital and reinvested profit. The deposit from March 2006 to March 2007 (SY1385) has been increased by about 180 percent, reaching the current deposit of US\$ 348 million. The bank is expecting to steadily improve its deposit and its management believes that there is 
ample opportunity to mobilise significant deposits, despite the number of new entrants in the market. The current lending of the bank is US\$ 260 million, with a lending to deposit ratio of 75 percent. The bank sees opportunities to increase this ratio further, but is constrained by the DAB limit of 75 percent ratio. The lending growth from March 2006 to March 2007 was about 167 percent, where most of the loans were extended to traders in the importexport business and about 10 percent of the loans were given to the industry sector including flour mills, steel forging, oil storage tank, tea processing and cigarette packaging. The loan portfolio has been quite sound; only about 1.86 percent of the total loan portfolio constitutes non-performing loans. In 2006, the average interest rate for loans was about eight percent, and its net profit was US\$ 2.3 million.

The management of the bank wants to further expand its loan portfolio; however, there are several factors holding it back from doing so. First, the absence of a Credit Information Bureau (CIB), coupled with the absence of audited balanced sheets makes it very difficult and costly to assess the credit risk of borrowers. This causes banks to require borrowers to provide extraordinary amounts of collateral and consequently to increase the cost of loans. Second, high cost of collateral registration leads borrowers to be hesitant to borrow money from banks. It takes three percent of the value of the contract (loan amount) to execute the collateral registration and another three percent to release the property from registration, i.e. a total of six percent. However, property transfer as collateral in the name of the bank takes about six percent of the property value, and thereby another 6 percent to transfer it back to the owner. Therefore, a total of 12 percent is needed for transfer and re-transfer to the owner a very high cost for the borrower. Third, because of weak human resource capacity in the financial sector, it is very difficult to hire qualified banking experts.

Management also expressed that capacity building of both the commercial bank staff and the staff of DAB would be essential, and could be done by establishing a banking training institute. Furthermore, the enactment of a Secured Transaction Law, Mortgage Laws and the Negotiable Instruments Law would help improve the lending situation. Once this legislation is in place, the banks could widen their proposal evaluation to include more customers for extension of loans.

\section{Bank Millie: "Struggling with lack of qualified staff"}

\section{Case Study 9: Bank Millie}

The Bank Millie was one of the three licensed stateowned commercial banks (SCBs) which were relicensed in 2003. It is the largest SCB, followed by Bank Pashtany and the Export Promotion Bank. Although Millie has much higher capital than any other commercial bank, the quality of the lending portfolio is very weak with about 53 percent of the loan portfolio being non-performing. Nonperformance of the SCBs initiated restructuring of these banks. The Cabinet has decided to have two SCBs: the Bank Millie remaining as an independent bank; and the Export Promotion Bank merging with Pashtany Bank.

Bank Millie was the first bank to be created in Afghanistan and was established with a 72 percent share of the private sector and 28 percent of the Government in 1933. It was operating as the central bank of Afghanistan until 1939, when Da Afghanistan Bank was established and took over the responsibility. Based on a Presidential decree in 1976, the bank became a government entity. The Ministry of Finance currently holds the majority of shares ( 96.6 percent). Bank Millie has 21 branches, out of which nine branches are operating in different parts of Kabul city, and 10 branches are operating in the provinces. Recently the bank restarted lending and so far has approximately 3,600 small and medium borrowers. It has a capital of US\$ 140 million including real estate assets. Total loans made are US\$ 19.6 million.

Bank Millie's management has voiced that efforts to restructure the bank have been constrained by several factors, particularly the lack of skilled labor with strong financial experience and knowledge at all levels of banking operations. The restructuring of a bank inevitably entails replacement of unqualified staff by capable new staff. However, Bank Millie is finding this to be very difficult for various reasons. First, the specific salary ceiling for each position is too low to attract qualified staff from the region or even within Afghanistan. Second, the stakeholders require that Bank Millie hire only Afghans in key positions in order to build local capacity in the banking sector. Given that Afghanistan has few experienced bank professionals, the key positions are usually filled by less competent employees who can incur additional costs without improving operational efficiency in the bank. Third, Bank Millie is short of professional banking experts from outside who could carry out the restructuring process. Currently only one adviser from BearingPoint is supporting the bank operation. Although the Government promised to 
send one more expert, this is still not enough to undertake a successful restructuring process. Finally, Bank Millie is overstaffed with unqualified employees. The bank now has 545 employees, although 67 of these were given a golden handshake. Out of 280 employees recently tested for basic banking competence, only 125 passed. There is little understanding of the components of profit and loss, cash/funds flows, financial intermediation, computer and automation technology, accounting, loan administration, and risk assessment and management. Although most of the staff have long tenures in the banks, this has not translated into genuine banking experience owing to more than two decades of economic and banking inactivity due to war and internal strife. Hardly a single employee has been exposed to modern accounting and organisational systems or technology.

\section{ANALYSIS}

The banks in Afghanistan are mostly risk averse and not willing to extend loans to a new borrower, even to the reputable investors without secured collaterals. According to the World Bank's recent investment climate survey (2006), only three out of 335 firms in five major cities in Afghanistan (Kabul, Kandahar, Mazar-e-Sharif, Jalalabad and Herat) reported having bank credit for new investment. On average, nearly 94 percent of new investment by firms was funded by either internal funds or money from family and friends. Even some of the large investors in Kabul did not access bank financing as they found it very difficult to obtain such financing. It will be a challenge for the financial institutions to bring these types of investors into the banking network. Inclusion of them in banking services would certainly strengthen the economic growth of the country.

Access to finance is extremely limited for almost all SMEs in Afghanistan. This is severely constraining the overall growth of small businesses in the country and reducing the prospect of employment generation and expansion of individual small business. Although there is strong demand for credit from SMEs, the financial institutions are not responding to it. Limited access to finance, particularly for working capital, is a severe problem for SMEs. Discussions with AISA registered entrepreneurs have found that due to the shortage of working capital, some SMEs pay higher prices for raw materials which they buy in the local market with deferred payment conditions. The prices they pay are 20 to 25 percent higher than what they would pay if they were importing these materials either from Pakistan or India.
Since private commercial banks (PCBs) have been comfortable lending extensively for trading activities with secured cash collaterals, they are reluctant to venture widening their lending base to loans for industries. Lending for industries, in particular SMEs, was virtually absent in the case of PCBs. Financial systems or commercial banking does not see the small businesses as a potential market source for sustainable investment and commercial banking, thus losing the potential earnings from these credit relationships. On the contrary, Microfinance Institutions (MFIs) have taken advantage of this situation to expand their business to SMEs with great success in the absence of competition from commercial banks.

The World Bank's investment climate survey (2006) stated that 51 percent of firms considered access to finance a major problem for investment and business operations in Afghanistan. An ongoing World Bank survey of 50 enterprises, registered under the Afghanistan Investment Support Agency (AISA), shows that institutional financing in terms of working capital or investment capital could have a positive impact on business competitiveness, resulting in business expansion, increased employment and improved profitability.

More recently, the banking sector has grown significantly. Fourteen banks in operation have successfully been able to mobilise funds in terms of deposits from the informal sector of the economy, which previously avoided banking services. Although mobilisation of deposits has been growing, there has been little improvement on the lending side. Overall, lending to the manufacturing or service sector, except for the increase in trade financing, has been less significant due to the absence of CIB, the higher cost of registration and the weak capacity of banking human resources.

Commercial bankers have stated that the legal framework is not strong enough and that the court system is too weak to enforce contracts. The enactment of three new financial laws initiated by DAB would help improve this situation. However, the enforcement issue will remain and this will require setting up special commercial courts, recruiting and training of judges and also facilitating infrastructural facilities.

SCBs have been plagued by problems such as weak corporate governance and management structures, unskilled labour, outdated technological capacity, and serious liquidity and solvency problems. The first financial assessment of the banks conducted in January 2003 concluded that all the banks were in dire financial condition. Restructuring of three licensed SCBs is underway, and the Cabinet has recently approved a strategy paper on the 
restructuring of Bank Millie to meet the IMF's benchmark for the financial sector. A similar restructuring paper for the Pashtany Bank will be placed in the Cabinet in June 2007 to meet the benchmark. Although the restructuring effort of these banks is in progress, the extent and intensity of the process needs to be evaluated properly to examine its impact on improving the operational and financial performance of these banks.

\section{RECOMMENDATIONS}

\section{Improving access to financial services}

Lack of access to adequate financing on reasonable terms is partly caused by the risk averseness of the conservative banking systems in Afghanistan which have neither the necessary credit information on small borrowers to price risks accurately, nor the instruments to transfer such risks. In this context, the goal of improving access to finance will over the longer-term be met by building efficient financial markets and institutions and the necessary infrastructure underpinning these markets. However, in the period of transition to an efficient banking system, targeted approaches to help jumpstart financing are needed. Such approaches would include innovative risk-sharing methods, such as credit guarantee instruments designed to share banks' risks in lending; providing housing loans to low-income groups; and developing leasing markets which could meet the financial needs of small businesses as an alternative to traditional formal banking finance.

\section{Setting up a banking training institution}

The capacity building of the commercial banks has become important in order to provide efficient and transparent banking services. Establishment of a Banking Training Institute (BTI) will improve the skills of the employees of commercial banks, financial institutions and the central bank. While some individual banks are developing their own programmes, these are not adequate to meet the national need. The BTI can directly contribute to: (i) upgrading the skills and knowledge of credit officers, managers and administrators; (ii) developing banking systems with qualified professionals; and (iii) conducting research and promoting discussions on the financial sector policy issues to help national development.

\section{Establishing a Credit Information Bureau}

Establishment of a Credit Information Bureau (CIB) in Afghanistan could help the banking and financial institutions to maintain high quality loan portfolios of the customers. Commercial banks and financial institutions strongly support the establishment of a CIB for gathering, processing and storing information on the payment behaviour of businesses and consumers to help with risk assessments of the borrowers. The CIB needs to be linked to the central bank, since DAB has natural advantages to collect such information from the commercial and other financial institutions.

\section{QUESTIONS FOR DISCUSSION}

1. Even some of the large investors in Kabul did not access bank financing as they found it very difficult to obtain. What are the main reasons for this?

2. Why does commercial banking not see the small businesses as a potential market source for sustainable investment and commercial banking, while some MFIs, i.e. BRAC SEP, see them as excellent business opportunities?

3. What are the success factors for BRAC SEP to be able to expand SME loans?

4. In the case of Bank Millie, what would be more important, "building local capacity in the banking sector" or "revitalising the bank by allowing the bank to hire qualified international banking experts" or both?

5. How serious is the lack of capacity in banking human resources, and what are efficient ways to develop the capacity?

6. How could a CIB help financial institutions assess the credit risk of borrowers, and how urgent is it to establish a CIB in Afghanistan?

7. Why is the cost of collateral registration so high and what are the ways to bring down the cost for efficient financial transactions?

This case study was prepared based on a series of interviews with stakeholders in the financial services sector operating in Afghanistan. 

THE ENABLING ENVIRONMENT CONFERENCE

Effective Private Sector Contribution to Development in Afghanistan

\section{SUMMARY OF ROUND TABLE CONSULTATIONS WITH THE PRIVATE SECTOR (BUSINESS AND CIVIL SOCIETY)}

Summary Report prepared for the Enabling Environment Conference

\section{CONSULTATIONS HELD WITH DOMESTIC SMALL AND MEDIUM ENTERPRISES ACROSS AFGHANISTAN}

\section{In support of the Enabling Environment} Conference, the Afghanistan Investment Support Agency (AISA) organised a series of roundtable consultations with domestic small and medium enterprises (SMEs). Three meetings took place this year in Kabul (14 and 27 February and a larger meeting on $28 \mathrm{March}$ ). The remaining round table consultations took place outside Kabul: in Jalalabad (18 April), in Herat (22 April), and in Mazar-iSharif (26 April). More than 90 SMEs were consulted across the four cities.

This report illustrates the outcomes of the round table consultations, which were designed to consult the private business sector with regard to the issues it faces, as well as to elicit recommendations and proposed actions to enable private initiative in Afghanistan.

\begin{abstract}
Analysis of the Issues
At the consultations with the domestic SMEs (carpet, marble, dried-fruit and nuts, construction and service delivery, transportation and manufacturing sectors), the following impediments were identified across the four cities:
\end{abstract}

- Access to land. In Jalalabad, Mazar-e-Sharif and Kabul, access to land was underlined as a priority for the development of the private sector in Afghanistan. Processing and storing locally made goods require factories, equipment and warehouses; in the absence of land, such facilities cannot be created. As a result, most factories are currently located either in close proximity to, or within, residential areas. The current practice of selling land through auctions does not allow the domestic SMEs to access much needed land, as they are not able to compete with bigger players.

\footnotetext{
"Experience illustrates that often land is sold to individuals, theoretically, for business purposes. However, in reality after the procurement of land it is rented out to foreigners/expatriates in order to make money."
} 
- Access to finance. Access to finance is viewed as equally important. Due to high interest rates and loans being short-term (one year), it is not viable for domestic SMEs to borrow from the private and/or state-owned banks. In addition to high interest rates, the burdensome administrative procedures (e.g. obtaining necessary papers to process the loan) entail going through different ministries and municipal administration and also requires paying government officials in order to get the paper work done-Domestics SMEs describe themselves as in desperate need of credit.

\section{"Government should differentiate between the} producers and those who access finance just to import those goods which can be produced locally from outside. Specifically, the government should protect the local producers by at least reducing the interest rates from $12 \%$ on the loans. "

- Lack of access to advanced technologies: machinery/equipment and knowledge. In the absence of land, and therefore properly equipped factories, production and processing is done using outdated manual techniques. This negatively affects the quality of the products. As a consequence, locally processed and packed dried fruit and nuts do not meet international quality standards and the expansion of exports is limited.

Across the four cities, participants flagged the need for capacity development of domestic SMEs. At present, state institutions do not provide the much needed technical training courses on the utilisation of modem machinery or on business skills (management, accounting, etc).

- High taxes and nuisance taxation. The current taxation system was described as 'unclear' and 'unorganised' and little is done by the relevant government authorities to improve the situation. It was indicated that it is close to impossible to obtain the copy of the Laws on taxation from the Ministry of Finance, which are important to have before dealing with the government officials at the Customs Control and other tax collection points.

The current taxation system does not protect nascent industries against imported finished products. Not only do domestic industries pay an 8 percent tax on production, they must pay a tax of 25 percent on net income at the end of each fiscal year.

Inconsistent export duties were identified as a key impediment to the development of the local industries. In the past, the export tax was at 2 percent of the total product value. Currently, 16 percent of the value of the export is collected by Customs as a 'voluntary' contribution for the Afghanistan Red Crescent.
- Absence of transit polícies. At present, Afghan trucks are not allowed to cross the border into neighbouring countries due to security, in particular to counter illicit drug trafficking. Goods which are exported out of the country are not allowed to be sealed in containers; as a result, the goods are damaged by the time they reach the consumer. For example, in the case of dried fruit and nuts exporters, during the course of transit of their products through Pakistani territory to India via road, the traders have to load and unload their products five times from Kabul to India.

Transferring goods using air services usually takes three months, mainly the time required to prepare the necessary documents. Furthermore, high fees are charged to use 'Ariana' air-shipment services. In addition, in the absence of an agreement between Ariana and foreign airlines, shipment via air is not possible beyond Ariana destinations. As a result, in order to avoid time consuming and costly procedures, the companies prefer to use the Pakistan land route to access world markets.

- Pervasive Corruption. Administrative corruption was identified across the four cities as one of the major impediments to the development of the SMEs in Afghanistan. They encounter this problem whenever dealing with the government officials to complete administrative work.

In order to complete necessary loan documents, in some cases enterprises have to pay bribes to bank officials as well as to the Kabul municipality, to ensure that the required loan documentation is issued as collateral for the loan.

According to domestic SMEs, the manipulation of administrative procedures provides many opportunities for corruption. For instance, there are many checkpoints on the roads, the reason for which (for all appearances) is illegal revenue collection.

- Absence of government policies protecting domestic private sector. Across the four cities, the need to introduce government policies protecting the domestic private sector against imported finished goods was emphasised, notably by the marble and carpet sectors.

- Absence of quality standards. Across the cities, domestic SMEs emphasised the importance of quality standard procedures which are at present absent in Afghanistan. For instance, in the absence of official quality standards certification by the Government, Afghan dried fruit and nuts traders sell their products at a lower price to wholesalers, who obtain the certificate/licenses from India's Ministry of Health. 
- Inconsistency in implementation of the laws. SMEs experience differences in the application of registration and licensing procedures between provinces and Kabul. As was highlighted by one of the participants: "We have one government but 20 ways of implementing the one Law."

Although there is an established registration procedure handled through the AISA regional office, the licence obtained is often not valid in the neighbouring provinces. As a result, companies and organisations are requested to register with the provincial and district authorities where they actually set up businesses.

- Burdensome administrative procedures. Even though AISA issues licenses to the private sector within a short time, it takes almost three to four months to get sector-specific clearance required for operation from the relevant ministries. It was indicated at the round table consultations in Kabul and in Jalalabad that giving bribes cuts the time it takes to issue a licence to a minimum. Export procedures are also time consuming.

\section{"It takes from 12 to 15 days to prepare the necessary documents and get necessary signatures from the government authorities in order to export stone. Who amongst the foreign buyers and traders are ready to wait for so long?"}

- Lack of security for the private sector to operate. Across the four cities, security was highlighted as one of the major impediments to development of the domestic private sector, as well as to attracting much needed foreign investment.

\section{"We are not talking about overall security but security of private businesses. Sometimes we have to pay informal taxes to local commanders and our work is under threat by criminal gangs. Thereby, security of domestic as well as international traders should be ensured."}

- Infrastructure. Consistent access to power and high cost of power were highlighted as problems in Mazar-e-Sharif, Jalalabad and Kabul. In the absence of power, generators are used, for which fuel is costly. In the existing industrial park in Herat, where 60 factories operate, the high cost of power, as well as the absence of water and waste management systems, were flagged as areas for immediate improvement in the industrial park.

- Absence of insurance services. Domestic SMEs across the four cities emphasised the importance of having insurance services in Afghanistan, to cover production facilities, vehicles and staff.

\section{Recommendations}

1. Provide the domestic private sector with access to land: (a) construct more industrial parks; (b) eliminate the current practice of selling land through auctions; and (c) provide long-term loans for land.

\section{Provide access to power (energy): (a)} introduce subsidies; (b) develop local potential for producing power; and $(\mathrm{c})$ privatise the power sector.

3. Provide access to finance: (a) reduce the high interest rates on loans ( 12 percent), at least by the state-owned banks; (b) establish an 'industrial development bank' which would provide low interest loans to private sector; and (c) encourage use of AISA certificate/licence as guarantee of the existence and operation of the business.

4. Eradicate corruption: (a) increase wages of government officials; and (b) introduce strong penalties for those who are involved in corruption.

\section{Simplify sector-specific licensing} procedures: establish a committee which would include representatives of all line ministries relevant to the private sector, which would be responsible for sector registration of all private sector companies and for issuing licences, ideally within AISA.

\section{Protect domestic infant industries: (a)} increase tariffs on, or ban, the import of goods that compete directly with locally made products; (b) provide subsidies for domestic production by introducing five year tax holidays to infant industries; and (c) remove duties on the import of raw materials.

7. Introduce transit policies: (a) explore the use of traditional import and export routes (e.g. importing from China through Badakhshan province rather than through Karachi); and (b) establish a government institution responsible for sealing containers and vehicles, whose certification would be recognised not only within Afghanistan but also in neighbouring countries.

\section{Improve security for the private sector: (a)} permit domestic private investors / businesses to possess fire arms for self defence; and (b) encourage greater international emphasis on improving the capability of the Afghan National Army and, more importantly, the Afghan National Police.

9. Simplify the income tax, customs and banking laws and their implementation. 


\section{CONSULTATION HELD WITH INDIGENOUS CIVIL SOCIETY ORGANISATIONS}

In support of Enabling Environment Conference, the Foundation for Culture and Civil Society (FCCS) in collaboration with Afghan Civil Society Forum organised a round table consultation with indigenous civil society organisations on the 4 th April 2007 in Kabul. This section outlines the issues discussed.

\section{Analysis of the Issues}

- Absence of consultation mechanism prior to approval of the Non-Governmental Organisations and Social Organisations Laws. The notion of "social organisation" (SO) and NGO is a relatively new phenomenon in Afghanistan. The first indigenous SOs were established in 1989. However, there was a lack of consultation with indigenous SOs and NGOs prior to sending the relevant Laws to the Wolesi Jirga for hearing and approval. The Law on Social Organisations was enacted in 2003 and the NGO Law in 2005),

The current SO Law is considered to be not applicable in the present context of Afghanistan. In post-conflict setting where funding comes primarily from international sources, in accordance with the current law, SOs are not allowed to seek and raise funds from foreign sources. The lawmakers are considered to have insufficient knowledge about the mission and purpose of the existing NGOs and SOs and about the challenges they encounter whilst dealing with the government officials. However, despite the existing gaps in the Laws, the main problem lies in their implementation.

- Lack or complete absence of coordination between international and indigenous NGOs and SOs. There are too many umbrella organisations established in Afghanistan and almost all of them are externally led. The international community has not contributed significantly towards empowerment of indigenous SOs and NGOs.

"In the absence of a clear coordination mechanism in the provinces we have areas where 5 or 6 international and indigenous $\mathrm{NGO}$ s and $\mathrm{SO}$ s operate with similar programme profile. In the neighbouring province the need is much greater but none is operating there."

- Absence of dialogue between the donors and the recipients. At present, the development process in Afghanistan is donor driven. Donors fail to listen to the indigenous grass root organisations when developing their projects/programmes, and pursue their own priorities and agenda.
"In one of the villages people were saying that their primary need was construction of an irrigation channel, so they would be able to have sufficient water for their crops. However, the international NGO came and constructed a school. The villagers were saying that there was no need for school at present as for years they were sending their children to the nearby village to school."

- Mis-perception of indigenous SOs and NGOs by ordinary people and government officials. Government officials believe that NGOs are forprofit organisations, established to pursue a certain agenda This negatively reflects on the reputation and image of SOs and NGOs in the country.

"Government thinks that the NGOs and SOs are undertaking construction projects in order to fill their pockets. Government does not understand the difference in the construction approach of the NGOs. In our understanding construction is not only hardware that NGOs provide, which private construction companies do not, but also work carried out with the communities, as well as establishing maintenance systems. Government should understand that the approach of the NGOs is suitable and focused for construction of community level development."

- Taxation of the infrastructure activities undertaken by indigenous and international NGOs/SOs. It is not clear in the new proposed amendments to the law whether tax is to be levied on the import of the construction materials or on the value of the infrastructure projects.

- Burdensome registration and reporting requirements. The government is not clear about the information to complete a registration application. There are successive new requests for documents. The registration timeframe varies: some organisations can register and obtain a licence within five to six days (if $\$ 300$ is paid) and for some it is an 11 month procedure. However, according to the law governing NGOs, the application should be processed within six months.

"There are a lot of requirements which are not stipulated in the law. When you try to explain the registration procedures in accordance with the law, the government officials are getting upset and further complicate the registration process."

"There is no clear information provided by the government at the outset regarding what information is required to complete application. The current reality is that when you complete one document and submit it, the next day there will be another document, and another one the next day. The government should provide us with complete 
information regarding what is required to complete the application once, at the initial stage."

Multiple reporting requirements on the status of an NGOs' activities are time consuming.

\section{"Almost all government ministries including} provincial governments require submission of a report. Even the Ministry of Interior and

Intelligence is asking for one in which the detailed information about staff, salary of the staff and the budget of organisation is provided."

- Lack of access to funding for indigenous SOs. According to the law governing SOs, they are not allowed to mobilise funds from international sources. This article hinders development of indigenous SOs, in particular given the fact that most funds required for operation of the indigenous organisations come from international sources.

- Lack of clear understanding by the government of the roles and responsibilities of SOs and NGOs. There is a lack of understanding not only within government, but also within indigenous SOs/NGOs of their roles and responsibilities.

"Government should understand that indigenous SOs and NGOs can be a great asset for Government during implementation of a broad spectrum of development projects, in particular in areas where Government 's presence is limited."

- Lack of coordination within relevant line ministries. Registration and licensing at the national level do not guarantee that there will be no problems at the provincial level.

"Although each operating NGO is registered with relevant line ministries at the national level, the lack of coordination between national and provincial offices creates problems for the operations of both SOs and NGOs. For example, in order to initiate an agriculture project, we had to go through the provincial Department of Agriculture, which requested us to give them money in addition to allocating one of their officers to work with us in the project"

- Lack of support from the government. There is a lack of support for the indigenous SOs/NGOs from the Government. Government officials perceive SOs/NGOs as their "opponents;" current relations between the two have been characterised as uncooperative and at times hostile.

"It is close to impossible to get support from the government, even when it comes to sharing the necessary documentation related to our organisations. For instance, if you go to the
Ministry of Justice, it takes ages to buy copies of the law governing NGOS and SOs."

- Strong State control of NGO and SO activities. The Government gets involved even in the development of an organisation's statutes. When the statutes are submitted as required under the law, they are revised by government officials.

"The government officials make you submit items which are not relevant to our organisation's statues. For instance, property owned, number of employees and their salaries and wages - even the number of chairs and desks in our office premises. "

"Government officials think that if they issue licences to indigenous NGOs and SOs they have some sort of authority over us. Yet, it is almost impossible to get government officials to come to the conferences and meetings organised by the local SOs and NGOs. One official even indicated that it would be below him to visit any local NGOs or SOs premises and if the latter wants to have him at the meeting they should hold it at the mosque."

\section{Recommendations}

1. Push the government to consider amendments to the respective laws proposed by indigenous SOs and NGOs. The ten amendments to the law governing SOs have been proposed for the hearing in the National Assembly. ACBAR has proposed amendments to the NGOs Law.

2. Consult with SOs and NGOs prior to the enactment of laws. Ensure consultation with indigenous SOs and NGOs prior to passage of the SO/NGOs Laws.

3. Introduce uniform registration procedures both for NGOs and SOs.

4. Establish a mechanism that will ensure the proper implementation of the laws.

5. Establish a uniform reporting mechanism with a focal point ideally in the Ministry of Economy. Establish a focal point through which the line ministries will access the indigenous and international NGOs for necessary information instead of directly (ideally Ministry of Economy).

6. Raise the awareness of government officials about the SO and NGO laws.

7. Provide/ensure security in the programme areas and the safety of SO/NGO personnel. 


\section{CONSULTATION HELD WITH INTERNATIONAL NGOS}

In support of Enabling Environment Conference, the Aga Khan Foundation, Afghanistan in collaboration with the Agency Coordinating Body for Afghan Relief (ACBAR) organised a roundtable consultation with international non-governmental organisations (NGOs) on the $5^{\text {th }}$ of May 2007 in Kabul. This section outlines the issues discussed.

\section{Analysis of the Issues}

- Security. Security of international NGOs was identified as a major constraint for the full operation of international NGOs. Owing to the unstable security situation, most international NGOs are not active in the eastern and southern provinces of Afghanistan.

- Donors focus on conflict areas i.e. East and South. At present, the interest of the donors has shifted to the south and east where the PRTs are located. It is becoming difficult to find resources for the projects in north and west Afghanistan.

- Resource-scarce environment. Currently, international NGOs are mainly concerned about their own existence; in the changing funding environment, they are pushed to write proposals for tenders and to act as sub-contractors for the Government or other funding bodies.

"Donors' perspectives are short-sighted and their focus unbalanced: i.e. on the private sector ignoring those basic needs of the rural population that are still not satisfied."

- Lack of coordination within international NGO community/absence of a single body to coordinate coherent and consistent policy and advocacy. There is a lack of consistency within international NGOs, which complicates relationships with govemment officials. Most of the NGOs are operating on their own.

- Government's negative perception of international NGOs erodes the trust between communities and NGOs.

'Public statements saying that international NGOs misuse most of the development money erode the trust between communities and NGOS.

- Lack of qualified local personnel. NGOs allocate resources for the development of local capacity, only to lose them, once trained, to other projects.

- Widespread corruption. Corruption is widespread and obvious at the provincial level.
- Shrinking space for innovation and pilot projects. Donor-driven development leaves little space for innovation and initiation of pilot projects.

- Burdensome reporting procedures. While international NGOs do not face major problems related to registration, some reporting requirements are considered irrelevant as well as burdensome.

"In Herat, the provincial department of the ministry demands numerous reports from international and national NGOs, even though a letter was obtained by ACBAR from the Ministry of Economy in Kabul and distributed to NGOs operating in Herat, in which it is indicated that no reports would be required from the NGOs operating in Herat, since the necessary information is submitted to the Ministry of Economy in Kabul by the organisations 'headquarters. However, despite this the ministry department at provincial level does not follow these instructions."

- Inconsistent implementation of the laws. The Procurement Law is vague and not relevant to the Afghan context (a post-conflict situation where capacity constraints are considerable).

- Inconsistency in disbursement of funds for government financed projects. NGOs are facing difficulties when it comes to the implementation of government funded projects. In some cases, it takes almost a year for funds to get disbursed. (Funds are channelled by the donors to the ministries.)

- Inconsistent and opaque legal framework. Inconsistency in laws, and at times contradictions between the laws and the guidelines to implement them, are due to the fact that external technical assistance to draft laws is not coordinated.

- Absence of a mechanism for dissemination of information. The current mechanism for channelling information is inadequate (e.g. information on state advertised tenders).

\section{Recommendations}

I. Implement consistent and transparent laws governing operations of indigenous and international SOs/NGOs.

2. Establish a focal point for reporting, ideally, the NGO Department of the Ministry of Economy

3. Develop clear information on roles and responsibilities of private initiatives and government.

4. Establish a policy and advocacy body for international NGOs. 
IV.

\section{CONSULTATION HELD WITH THE AFGHAN DIASPORA IN CANADA}

In support of Enabling Environment Conference, the Aga Khan Foundation Canada and the Afghan Embassy in Canada organised a roundtable consultation with representatives of the Afghan Diaspora on the $29^{\text {th }}$ of March 2007 in Toronto, Canada. This section outlines the issues discussed.

\section{Analysis of the Issues}

The diaspora is optimistic about opportunities to contribute and has a strong desire and to do so. However, there is an acknowledgement that the Afghan diaspora needs to be considerably more engaged, and that many factors continue to deter the diaspora from engaging in greater numbers.

Key messages that emerged can be divided into (i) those that affect all prospective investors in Afghanistan, and; (ii) those issues found to be more specific to the experience of the Afghan diaspora.

\section{Issues and challenges common to all prospective investors}

- A sense of uncertainty about the future stability of the country. The continued support of the international community sends a critical message of confidence to all prospective investors and is vitally important to maintaining a sense of optimism for future development.

- Security of investments. Many participants cited challenges relating to the legal, regulatory and administrative framework for trade, investment and licensing of businesses as an ongoing impediment. The issue of land titles and property rights is especially important for returning Afghans.

- Ongoing impediments to business and economic development posed by the lack of economic infrastructure in the country, particularly the lack of access to reliable electrical power.

- The shortage of human resources available in the country is not only a constraint to business operations, but is viewed as also making Afghan enterprises less competitive due to the high cost of skilled labour, relative to HR costs in the region.

- Lack of access to finance, insurance and other financial services was noted as a major constraint to the establishment and expansion of diaspora investments in the country.

\section{Issues raised specific to the Afghan diaspora}

- While there are tremendous opportunities for a wide range of diaspora involvement, there is a perception that the overall success of their individual contribution is heavily reliant on the existence of strong relationships and connections within Afghanistan. Members of the diaspora who have maintained strong ties to Afghanistan are perceived to have a clear advantage to those with few existing connections.

- There is a reluctance to leave their newly established lives in Canada, i.e. unwilling or unable to divest from home, profession, mortgages.

- There is a concern that the Diaspora's return would take opportunities away from those who have remained in Afghanistan throughout the years of conflict.

- Many returning Afghans have found the process of re-assimilation into their home country extremely challenging. Members of the diaspora who have enjoyed success in western countries often face complex and difficult issues upon returning to Afghanistan.

- The diaspora feels a strong moral commitment to make a contribution, but many lack the means or resources to navigate the complexities of investing in their country to do so individually.

\section{Recommendations}

Recommendations offered echo findings that emerged in the background papers and case studies, such as (i) increasing access to financial services, (ii) clarifying the legal and regulatory systems governing business activity, (iii) and encouraging investment in infrastructure and social services needed to underpin economic development and make Afghan businesses competitive. In addition, the following recommendations were made:

1. Establish business-council networks for information sharing, and encourage and support efforts of individual investors.

2. Create a safety net of subsidised insurance for prospective investors.

3. Develop local suppliers to ensure access and technology transfer continues beyond current international donor involvement. 
4. The human resource needs should be met by investing in a wide range of professional and adult education whilst simultaneously supporting the rebuilding of Afghanistan's education system.

Participants stressed the importance of providing opportunities for young diaspora members, newly graduated from Canadian institutions, to return for short and long-term placements within and outside of government institutions. The importance of providing scholarships to promising Afghan youth for academic and professional training outside of Afghanistan was also strongly emphasised.

\section{v. CONSULTATION HELD WITH THE AFGHAN DIASPORA IN GERMANY}

In support of Enabling Environment Conference, the AKDN and the Afghan Embassy in Germany organised a roundtable consultation with representatives of the Afghan Diaspora on the $14^{\text {th }}$ of May 2007 in Hamburg, Germany. This section outlines the issues discussed.

\section{Analysis of the Issues}

A range of issues were raised, many of which confirm messages from other consultative meetings, research and interviews.

- Security is an overarching concern for the German Afghan Diaspora; fear for life and property dissuades members of the diaspora from investing.

- There is a general sense that the Government has not been very supportive of investors: (i) unpredictability and inconsistency of messages across various ministries, particularly with regard to the payment of taxes and customs duties, (ii) widespread corruption, and (iii) extremely cumbersome bureaucracy, including with regard to recovering pre-war assets.

It took one of the participants over a year of intense work with the government machinery up to the deputy minister-level to get the paper work done to be able to reclaim his pre-war property. Bribes were asked for throughout the process.

The Government and Siemens agreed on Siemens importing and selling 100,000 bulbs on a non-profit basis. However, when the cargo arrived, the customs authorities insisted on assessing full duties.

One businessman is producing small windcraft and solar energy installations on a non-profut basis in a village in Wardak. For production, he needs to import solar panels. Customs has argued that he was not able to prove that he would not resell the panels on the Kabul market and have therefore demanded $12 \%$ customs, rather than $3 \%$ customs duty on the import of inputs for production.

- The cost of production in Afghanistan remains high in comparison to neighbouring countries. The main factors here include: (i) lack of access to cheap, reliable energy and (ii) high labour costs, particularly in comparison to Pakistan.

With the end of the conflict five years ago, many Afghan carpet weavers relocated back from Peshawar into Afghanistan. However, there is no carpet washing facility in Afghanistan and installing one would involve a major investment. This is not possible because of lack of access to land, water and electricity needed (as well as security for employees), In addition, high labour costs in Afghanistan further damages the competitiveness of the sector. Most carpet weaving businesses have left Afghanistan again and have relocated to, as during the war years, Peshawar.

- Markets in Afghanistan are often dominated by few powerful individuals. It is therefore difficult for small and medium sized businesses to enter the market, particularly as there are limited sources of capital for small investors relative to larger and more 'influential' investors.

- The rules and regulations of international transport create serious problems for the transportation businesses and substantially increase costs of exporting or importing over land.

A transportation company pointed out that the lack of good roads was only a secondary problem for cross border transit: goods transported over land to Afghanistan have to be on and off-loaded several times at borders.

- The lack of standards, quality controls and the related capacity within government was a crosscutting theme.

Entrepreneurs involved in the solar energy equipment business have the necessary technical know-how to advise customers, However, within the Department for Renewable Energy of the Ministry of Energy, there is no expertise with this technology (for quality control purposes and to conduct basic analyses) even though the technology is being deployed through the NSP. As a result, some unscrupulous suppliers are engaging in illegal activity.

- Lack of qualified government personnel across the board was brought up several times as a major impediment. 
- Technical training: there is a complete absence of appropriate training institutions with regard to new technologies (such as renewable energy). It is very difficult for private sector to counterbalance this gap, as people trained internally, at the cost of the business, leave shortly after completing their training. There is a dearth of managers; Afghan businesspeople have even resorted to employing Pakistani managers because they cannot find qualified Afghans.

- There is too much emphasis put on the development of Kabul and other large centres, which cannot cope with the enormous pressures linked to their rapid growth. The results are slums, increasing levels of crime, inhumane living conditions for many people, particularly children. More emphasis should be put on supporting decentralised development that enables people to make a living in small towns and villages as well.

- Lack of institutionalised links between the diaspora and Afghan businesses and civil society. Generally, it was obvious that there is a great interest not only to invest and conduct business in Afghanistan, but also to help on a nonprofit, philanthropic basis. However, Afghans in Germany do not know how to offer their help. There is a need for a better coordination and institutionalisation on both sides, as well as some proactive support from the side of government to unleash the huge potential that exists.

Hamburg is the biggest carpet trading centre in the world with over 400 carpet traders based in Hamburg, 40 percent of whom are Afghans. Yet, the Hamburg based Afghan carpet trading industry has so far not benefited the Afghan based carpet weaving industry. They would be keen to help but do not have a reliable counterpart with whom to link up in Afghanistan. This role could be played by a chamber of carpel weavers and traders

\section{Recommendations}

1. Establish a scientific body/standards control regulator within the Ministry of Energy.

2. Provide for more technical training and capacity building, particularly for Ministry staff.

3. Ensure greater consistency between licensing, registration, agreement and customs procedures and their implementation.

4. Take the focus away from Kabul and to diversify development and investment in provincial centres.

5. Ensure that there are sources of capital for small investors.

6. Promote conditions for production, not just trade.

7. Establish an issues or problem resolution mechanism for small businesses.

8. Improve competitiveness through for example export incentives (as provided for in Pakistan); and bringing down the cost of energy and security.

9. Facilitate non-profit activities, rather than subjecting them fo additional taxation.

10. Improve the security situation.

11. Create a reliable point of contact within government for interested investors, and for the diaspora willing to contribute to Afghanistan's development through donations or expertise. AISA's mandate is too limited to meet the needs of investors.

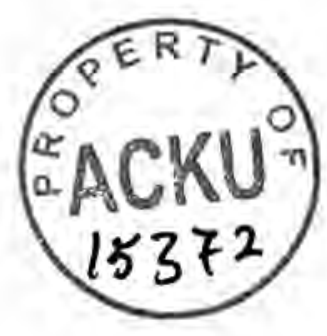


